NASA Contractor Report $16827 \%$

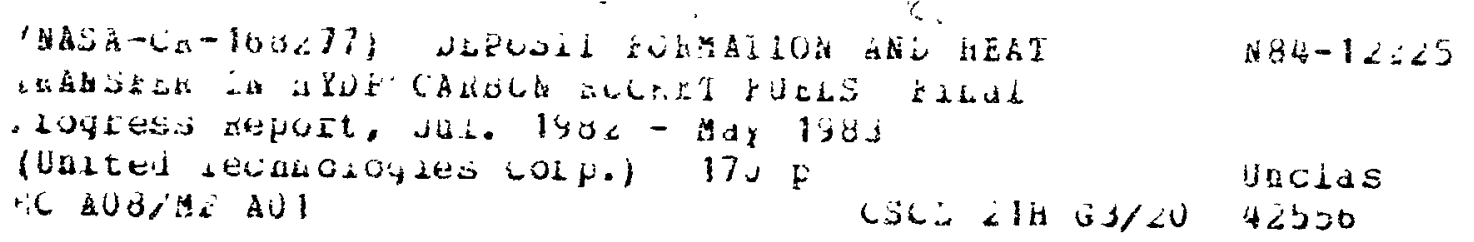

\title{
Deposit Formation and Hect Transfer in Hydrocarbon Rocket Fuels
}

Anthony J. Giovanetti

Louis J. Spadaccini

Eugene J. Szetela

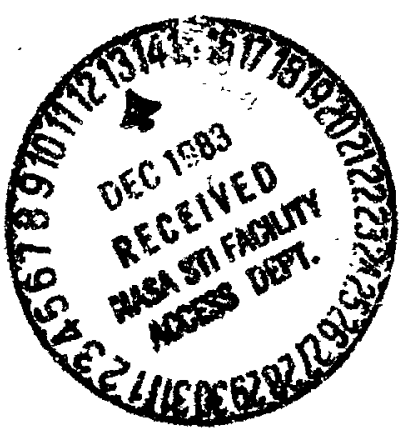

UNITTD TECHNOLOGIES RESEARCH CENTER East hartford, CT 06108

October 1983

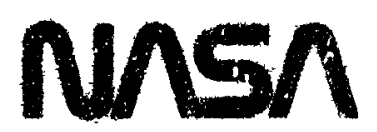

National Aeronautics and Space Aơministration

Lewl. Research Centor

Cleveland, Ohis 44135 


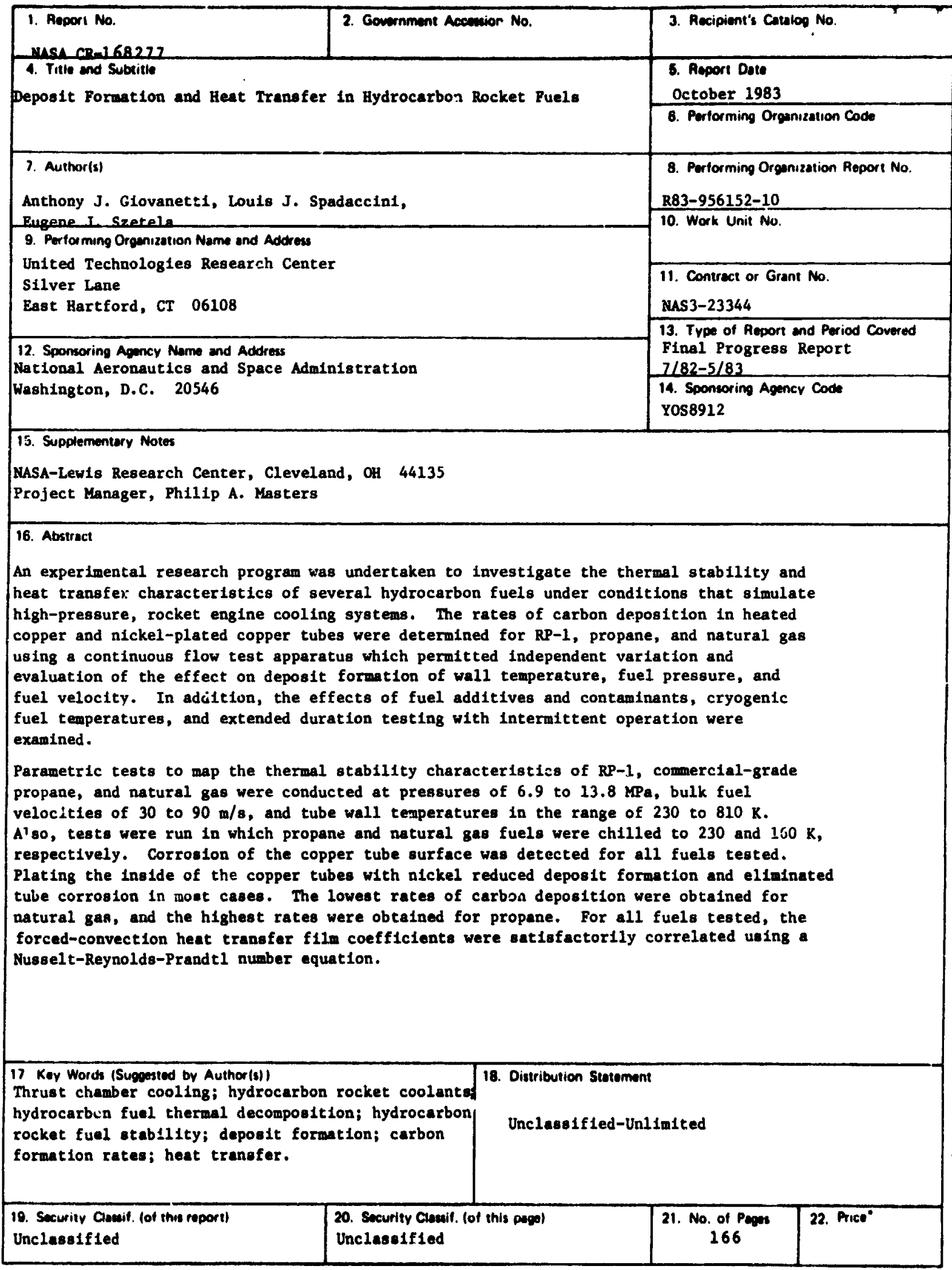

'For sale by the National Technical Inlormation Service. Springlield, Virginia 22161 
Deposit Formation and Heat Transfer in Hydrocarbon Rocket Fuels

TABLE OF CONTENTS

Page

FOREWORD . . . . . . . . . . . . . . . . . . . . . . . . . i

SUMMARY . . . . . . . . . . . . . . . . . . . . . . . . .1

INTRODUCTION . . . . . . . . . . . . . . . . . . . . . . . . 3

BACKCROUND . . . . . . . . . . . . . . . . . . . . . 5

Mechanisms for Deposit Formation . . . . . . . . . . . . . . 5

Chemistry of Deposit Forming Processes . . . . . . . . . . . . . 5

Empirical Correlations . . . . . . . . . . . . . . . . 8

Catalytic Effect of Metals . . . . . . . . . . . . . . 9

Background Summary . . . . . . . . . . . . . . . . . . . 9

EXPERIMENTAL APPARATUS AND TEST PROCEDURES . . . . . . . . . . . . . 11

Fuels Characterization and Pretreatment . . . . . . . . . . . . 11

Test Facility and Test Procedures . . . . . . . . . . . . . 13

Data Analys is . . . . . . . . . . . . . . . . . . . 19

EXPERIMENTAL RESULTS AND DISCUSSION . . • . . . . . . . . . . . . 24

RP-1 Tests . . . . . . . . . . . . . . . . . . . 24

Propane Tests . . . . . . . . . . . . . . . . . . . 27

Natural Gas Tests . . . . . . . . . . . . . . . . . . 32

Deposit Morphology . . . . . . . . . . . . . . . . . 35

Heat Transfer Correlation Analyses . . . . . . . . . . . . . 38

Hydrostat ic Burst Tests . . . . . . . . . . . . . . . . 39

CONCLUDING REMARKS . . . . . . . . . . . . . . . . . . . . . 41

REFERENCES . . . . . . . . . . . . . . . . . . . . . . . . 43

LIST OF SYMBOLS • . . . . . . . . . . • . . . . . . . . . . . 46

TABLES

FIGURES

APPENDIX A - TABULATED TEST DATA . . . . . . . . . . . . . . . A-1 
This research was condu=ted under Contract NAS3-23344 from NASA-Lewis Research Center, Philip A. Masters, Project Manager. Additional support for heat transfer correlation analyses was provided by United Technologies Research Center as part of a Corporate-sponsored IR\&D program. The authors acknowledge research engineer John TeVelde and laboratory technicians Bruce S. True and David Terza for their assistance in this program. 
Deposit Formation and Heat Transfer in Hydrocarbon Rocket Fuels

\author{
A. J. Giovanetti \\ L. J. Spac recini \\ E. J. Szetela
}

SUMMARY

An experimental research program was undertaken to investigate the thermal stability and heat transfer characteristics of several hydrocarbon fuels under conditions that simulate high-pressure, rocket engine corling systems. Tira rates of carbon deposition in heated copper and nickel-plated copper tubes were determined for RP-1, propane, and natural gas using a continuous flow test apparatus which permitted independent variation and evaluation of the effect on deposit formation of wall temperature, fuel pressure, and fuel velocity. In addition, the effects of fuel additives and contaminants, cryogenic fuel temperatures, and extended duration testing with intermittent operation were examined.

Parametric tests to map the thermal stability characteristics of RP-1, commercial-grade propane, and natural gas were conducted at pressures of 6.9 to $13.8 \mathrm{MPa}$, bulk fuel velocities of 30 to $90 \mathrm{~m} / \mathrm{s}$, and tube wall temperatures in the range of 230 to $810 \mathrm{~K}$. Tests were performed in which RP-1 base fuel was either doped with an additive designed to inhibit copper migration, or contaminated with two representative sulfur compounds. Also, tests were run in which propane and natural gas fuels were chilled to 230 and $160 \mathrm{~K}$, respectively.

Corrosion of the copper tube surface was detected for all fuels tested, possibly due to reactions with the trace sulfur impurities present in the fuel. Plating the inside of the copper tubes with nickel reduced deposit formation and eliminated tube corrosion in most cases. Doping RP-1 fuel with a commercially-produced metal deactivator resulted in a significant reduction in the levels of deposit formed. Also, for short test durations ( $30 \mathrm{~min}$ ), the rates of deposit formation decreased as test time increased. Chilling the propane fuel prior to entry into the heated tube oignificantly reduced deposit 
formation rates. Cryogenic cooling of natural gas (97 percent methane) did not aignificantly reduce deposit formation. At a given wall temperature and fuel velocity, carbon deposition rates for propane in copper tubes were highest and ranged from 300 to $580 \mu \mathrm{g} / \mathrm{cm}^{2}-\mathrm{hr}$ at wall temperatures between 400 and $580 \mathrm{k}$. The lowest rates of carbon deposition were obtained for natural gas in copper tubes and did not exceed $80 \mu \mathrm{g} / \mathrm{cm}^{2}-\mathrm{hr}$ at wall temperatures between 500 and $650 \mathrm{~K}$. Carbon deposition rates of 200 to $320 \mathrm{\mu g} / \mathrm{cm}^{2}-\mathrm{hr}$ were typical for RP-1 in copper tubes at wall temperatures between 560 and $750 \mathrm{~K}$.

For all fuels tested, multiple linear regression correlation analyses were performed to correlate experimentally-measured fuel-side heat transfer film coefficients with Nusselt-Reynolds-Prandt 1 number expressions for a Nusselt number range of 100 to 10,000. In addition, total deposit thermal resistances which ranged from 0.001 to $1.0 \mathrm{k}-\mathrm{cm}^{2} / W$ were computed at the end of each test. Together, these two pieces of information can be used to predict the heat transfer characteristics of a rocket engine cooling system in the presence of deposit formation. 


\section{INTRODUCTION}

In an effort to increase the performance of hydrocarbon/liquid oxygen rocket engines for space booster or orbit transportation systems, (i.e., to reduce weight and increase specific impulse) combustion pressures as high as practical are desirable. However, increased combustion pressure leads to a nearly proportionate increase in wall heat flux in the thrust chamber, and therefore, greater stress is placed on the design of the regenerative cooling system. Regenerative sooling with hydrocarbon fuels is feasible up to a point where the coolant wall temperature reaches a limit defined by a thermal decomposition or "coking" temperature. Deposit formation on the coolant wall surface, which usually occurs when the thermal decomposition temperature is reached, causes an increased thermal resistance, leading to a progressively increasing wall temperature and, ultimately, failure.

In the previous phase of this program (Ref. 1), an experimental effort was initiated to study deposit formation in hydrocarbon fuels under flow conditions that exist in high-pressure, rocket engine cooling systems. A fuel coking test apparatus was designed and developed and was used to evaluate the carbon deposition rates in heated copper tubes for two hydrocarbon rocket fuels, RP-1 and commercial-grade propane. Also, tests were conducted using $\mathrm{JP}-7$ and chemically-pure propane as being representative of more refined cuts of the baseline fuels. The results indicated that substantial deposit formation occurred in ten minute tests with RP-1 fuel at wall temperatures between 600 and $800 \mathrm{~K}$, with peak deposit formation occurring at wall temperatures near $700 \mathrm{~K}$. Relatively high carbon deposition rates of between 200 and $600 \mu \mathrm{g} / \mathrm{cm}^{2}-\mathrm{hr}$ were observed for RP-1, and the rate of deposit formation increased slightly with pressure over the range 13.8 to $34.5 \mathrm{MPa}$. In preliminary tests, plating the inside wall of the tubes with nickel was found to significantly reduce carbon deposition rates for $\mathrm{RP}-1$ fuel. No improvements were obtained when deoxygenated JP 7 fuel was substituted for RP-1.

The carbon deposition rates for the propane fuels were generally higher than those obtained for either of the kerosene fuels at any given wall temperature. Deposits were found with propane at a wall temperature as low as $420 \mathrm{~K}$. However, the migration and interdiffusion of copper and carbon in the form of dendritic formations which appeared to grow out of the copper surface improved heat transfer from the tube to the fuel and suppressed any significant thermal resistance buildup. Severe wall temperature instability was experienced when the heat flux was raised to increase the wali temperature above $420 \mathrm{~K}$, allowing the bulk temperature of the prupane to pass through a value corresponding to the maximum point of inflection in the specific heat 
v8. temperature curve. There appeared to be little difference between commercial-grade and chemically-pure propane with regard to type and quantity of deposit for wall temperatures between 400 and $600 \mathrm{~K}$.

The objective of this investigation was to extend the available data base for deposit formation in hydrocarbon fuels under conditions that exist in high-pressure rocket engine cooling systems. Experiments were conducted to evaluate the rates of carbon deposition in electrically-heated tubes for RP- 1 , commercial propane, and natural gas for a range of fuel pressures, flow velocities, and tube wall temperatures. In addition, the effects on fuel thermal stability of variations in tube material, extended duration testing with intermittent operation, fuel additives and contaminants, and cryogenic fuel temperatures were examined. The method of approach to accomplish these tasks consisted of ( 1 ) characterizing each test fuel with respect to its chemical composition and physical properties, (2) modifying and fabricating components for an existing heated-tube test facility, (3) thermally stressing each test fuel in accordance with a prescribed matrix of operating conditions, and (4) characterizing the deposit thermal resistance and levels of carbon deposition observed in the experiments.

The organization of this report is as follows: First, a background section is presented which discusses possible mechanisms for deposit formation and the empirical correlations used to relate deposit formation rate with fuel composition. The experimental apparatus and procedures used in this program are then presented, followed by presentation and discussion of the experimental results. The last section of this report summarizes tne important conclusions drawn from the program. A complete listing of all the test data acquired, including calculated parameters, is presented in the Appendix. 


\section{Mechanisms for Deposit Formation}

The rate of formation of deposits on heated walls in contact with flowing hydrocarbon fuels has been found by a number of investigators (Ref. 2) to vary with temperature in a unique manner as shown in Fig. 1. The Region $A$ is characterized by the presence of oxidation products in the fuel stream and oxygen in the deposits. The Region B is characterized by the pyrolysis of hydrocarbon molecules and the scisson of hydrogen. The reaction mechanism in the region between $A$ and $B$, which is characterized by a decreasing deposit formation rate, is not well understood, and any effort to explain the behavior of fuel in that region would prove to be conjecture. Most of the available deposit formation data obtained from kerosene-type fuels flowing in tubes falls into either Region $A$ or the negative-slope region between $A$ and $B$. Furthermore, reactions can be accelerated if the passage surfaces are made of reactive or catalytic metals.

In the previous phase of this program (Ref, 1), deposit thermal resistance were shown to be strong functions of wall temperature in Region $A$. Also, deposit formation rate and thermal resistance decreased with increasing velocity. These trends indicate that the deposit forming mechanisms tend to Le limited by the chemical kinetics of the deposition reaction rather than by diffusion. The higher shear resulting from increased velocity may have served only to promote washing away of deposit from the tube wall.

\section{Chemistry of Deposit-Forming Frocesses}

The detailed chemical reactions that result in fuel deposits are very complex and not well understsod at present. It is widely agreed, however, that they usually begin with oxidation of the fuel, which is promoted by dissolved air. The fuel/oxygen reaction, which involves free radical chains, is termed autoxidation. Common impurities such ss compounds of sulfur, nitrogen, and metals enter and accelerate the reactions.

The following chain reaction mechanism is usually cited to describe hydrocarbon autoxidation (Ref. 3):

$$
\begin{array}{ll}
\text { Initiation } & 2 \mathrm{R}-\mathrm{H}+\mathrm{O}_{2} \stackrel{\mathrm{M}}{ } \text { Propagation }\left\{\begin{array}{l}
\mathrm{R} \cdot+\mathrm{H}_{2} \mathrm{O}_{2} \\
\mathrm{RO}_{2} \cdot+\mathrm{O}_{2} \rightarrow \mathrm{RO}_{2} \cdot
\end{array}\right.
\end{array}
$$


Termination $\left\{\begin{array}{l}\mathrm{RO}_{2} \cdot+\mathrm{RO}_{2} \cdot \text { ketone }+ \text { al cohol }+\mathrm{O}_{2} \\ \mathrm{RO}_{2} \cdot+\mathrm{R} \cdot+\mathrm{ROOR} \\ \mathrm{R} \cdot+\mathrm{R} \cdot+\mathrm{R}-\mathrm{R}\end{array}\right.$

Reaction (a) forms an alkyl free radical ( $R \cdot$ ), in most cases with the aid of a surface. The propagation steps (b) and (c) carry the chain to a stable product, a hydroperoxide. Reaction (b) is relatively fast and Reaction (c) is normally rate controlling. At low oxygen concentrations (1 to $20 \mathrm{ppm}$ ), however, Reaction (b) may be rate controlling. Termination reaction rates also depend on oxygen concentration, with Reaction (d) predominating at high oxygen concentrations and Reaction ( $f$ ) at low concentrations.

The rates of the reactions in autoxidation are tependent upon temperature, hydrocarbon structure, and oxygen concentration. Catalysts and frea radical initiators can also materially alter rates, particularly that for step (a).

If sufficient oxygen is present, the hydroperoxide concentration will reach a limiting concentration. Hydroperoxide decomposition ensues and additional free radical reactions occur. Alcohols and ketones are the major products in the initial stages of this process, but the more extensive oxidation which follows yields acids, hydroxyketones, and esters. If the oxygen supply is limited but the temperature is raised, hydroperoxide will decompose. The major products are alcohols, ketones, and small hydrocarbons.

The importance of autoxidation reactions may be their ability to generate a spectrum of free radical intermediates wich can accelerate other reactions such as oxidative polymerization (Ref. 4). Vranos (Ref. 5) has postulated that it is the simulteneous formation of olefins and free radicals which ultimately leads to the formation of polymeric deposits, and he has constructed a scheme for describing how polymer formation proceeds in a n-alkane/oxygen system.

\section{Effect of Hydrocarbon Type}

Taylor (Ref. 6) has studied the effect of hydrocarbon type on fuel thermal stability and, as shown in the table below, has normalized his results relative to deposit formation in $n$-dodecane. 
it the range of $\mathrm{C}_{10}$ to $\mathrm{C}_{16}$, the $\mathrm{n}$-alkanes produced fewer deposits at a given temperature. Hydrocarbon chain branching increased the rate of deposit formation. Pure aromatics produced more deposits than $n$-alkanes, but actually seemed to inhibit deposit formation when blended with $n$-alkanes. Naphthenes behaved much as did aromatics in these studies, and olefins were quite deleterious to fuel atability. The most reactive species were diolefins with non-conjugated terminal double bonds.

\section{Effect of Impurities and Dissolved Oxygen}

Nitrogen and sulfur compounds and certain metals play a major role in the oxidation process by catalyzing the formation and decomposition of hydroperoxides for the free radical autoxidative polymerization. The following discussion of the effects of sulfur and nitrogen compounds and dissolved oxygen was taken from the CRC Literature Survey on the Thermal Oxidation stability of Jet Fuel (Ref. 3).

The only major study on the role of sulfur in thermal oxidation stability vas made by Taylor (Ref. 7). In this study, pure sulfur compounds were added at the 1000 ppm $s$ level to a sulfurfree jet fuel. Experiments were conducted in the Esso kinetic unit at semperatures between 366 to $709 \mathrm{~K}$. Of 12 sulfur compounds examined, two--diphenyl sulfide and dibenzothiophene-produced sight effects. Disulfides, thiols, and other sulfides exhibited significant increases, in sone cases up to twentyfold. This effect increased as the temperature was raised. Deposit formation appeared to increase proportional to the square root of the sulfur concentration. 
Much less is known about the effect of nitrogen conpounde on thermal oxidation etability. Indule, 2-ethylpyridine and 2,5 dimethylpyrrole incresed teposit formation rates four- to ten-foid in the kinetic unit when added at the $1000 \mathrm{ppm}$ nitrogen level (Ref. 8). This effect, which was tested in the 379 to $422 \mathrm{~K}$ range, was more pronounced at higher temperatures. Other tests with the pyrrole at lower concentrations demonstrated that this compound increased deposits even at the 10 ppm $N$ level.

As discussed above, dissolved molecular oxygen participates in complex free-radical chain reactions which have been shown ultimately to result in the formation of sediments, gum, and deposits. This suggrsts that fuel stability can be enhanced by suppressing these autoxidative deposit forming reactions via removal of dissolved oxygen.

The effect of deoxygenation was investigated (Ref. 4) with a spectrum of jet fuels whose quality ranged from very good to poor. The fuels were evaluated on both an air-saturated and deoxygenated basis $\left(<1 \mathrm{ppm} 0_{2}\right)$ at $7.0 \mathrm{MPa}$. The ranking of these fuels on an air-saturated basis agreed well with previous evaluations. Total deposits were markedly reduced by the removal of molecular oxygen with all fuels except the poorest quality fuel. It was concluded that although deoxy.genation has the potential for arked reduction in deposit formation rate, deoxygenation by itself does not guarantee such a reduction, and the corposition of the fuel in a deoxygenated system is equally important for reduced denosit formation rates.

\section{Empirical Correlations}

Because of the complexity of the reposit Formation pioblem, empirical correlations offer the best possibility of formulating generalized relation- hips between deposit rate and the environment in which a deposit forms. An example $c$ f a correlating equation relating JPTOT breakooint temperature (i.e., the temperature at which deposit level is considered agnificant based on a visual comparative tent) to the quantity of certain fuel constituents (Ref. 9) is shown below:

$$
T=255+259(S)^{-0.024}(N)^{-0.008 .15}(\mathrm{Na})^{-0.0149}(\mathrm{OL})^{-0.082}(\mathrm{Ar})^{-0.067}
$$

The percentages of tha materials are denoted by the following symbols: S - Sulfur, N - Nitrogen, Na - Nephthelenes, OL - Olefins, and Ar - Aromatics; and $\mathrm{T}$ is the breakpoint temperalure in degrees Fahrenheit. 
The utility of such equations is limited to the fuels tested and by the range of applicability of the empirically-determined conatants. Not unexpectedly, recent data (Ref, 10) with pyridene, ethylpyridene, indole, pyrrole, and quinoline indicates that the particular type of nitrogen compound has a greater effect on breakpoint temperature than the total nitrogen concentration in the fuel. Other date (Ref. 11) obtained in a JFTOT indicate that benzene (aromatic) yielded less deposit than Jet A while l-hexene (olefin) yielded more deposit than Jet $A$.

\section{Catalytic Effect of Metal:}

It has been widely st own in tie literature that both soluble and insoluble metals can catalyze reections involved in autoxidation. For example, a concentration of only $0.01 \mathrm{ppm}$ of elemental copper in jat fuel can significantly decrease its thermal stability and result in excessive deposit formation. Low allowable metal contaminate concentration thresholds have also been reported for iron, zinc, lead, and vanadium (Ref. 12).

Studies of the catelytic effects produced by various tube wall materials have indicated that copper and copper-alloy surfaces cause high deposit formation rates while aluminum, titanium, and nickel surfaces result in low rates of formation. Deposit formation on stainless steel is generally llw, particularly for type 316; however, higher deposit rates have been reported for eype 304 .

Baker (Ref. 13) has suggested that nickel can also be very resctive, particularly with light hydrocarbons, and can promote a gredter degree of fuel pyrolysis and deposit formation than copper. Copper alloys are also conaidered to be very reactive. Gold may be the only metal that can be considered unreactive and continuous, pore-free coating might protect copper. Although pure methare is not likely to form deposits, impurities commonly found in natural gas such an olefins (e.g., cthylene, propylene) and sulfur ore likely to be very reactive.

\section{Jackground Sumary}

Experiments conducted with kerosene-typu fuels have shown deposit formation on metal surfaces, such es stainless steel in the temperature range of 400 to $600 \mathrm{~K}$, depende upon the formation of oxidation products. Oxygen is often present in the deposits. If oxygen is removed from the fuel, deposit 
formation is reduced. Some metal surfaces accelerate these reactions; copper has been found to be very reactive. The presence of copper may even overshadow the effect of oxygen. Certain sulfur and nitrogen compounds in the fuel result in increased leposits on some metal surfaces. A high concentration of certain hydrocarbons, particularly olefins, also result in increased deposits.

The chemistry involved in deposit formation at temperatures above $800 \mathrm{~K}$, where the effects of oxygen are no longer important, includes cracking of the hydrocarbon and the production of carbon. The carbon may migrate into the metal surface and even remove some of the metal from the surface. Some metals are quite reactive and $c$ an be considered to be catalytic at elevated temperatures, e.g., nickel. The effect of copper at temp'zratures above $800 \mathrm{~K}$ has not ; et been adequately documented.

Although the chomistry of fuel deposit formation continues to he studied, in the near term, empirical correlations of data offer the best possibility of formulating generalized relationships between deposit rate and the environment in which a deposit occurs. Where deposit formation measurements include thermal resistance, these correlations can be extended to include the heat transfer effects of deposit formation. 


\section{EXPERIMENTAL APPARATUS AND TEST PROCEDURES}

Experiments were conducted to evaluate the rates of carbon deposition for RP-1, commercial-grade propane, and natural gas under flow conditions that exist in high-pressure rocket engine cooling systems. The fuel characteristics, test facility, and data analysis procedures are discussed in the following sections.

\section{Fuels Characterization and Pretreatment}

The base fuels which were tested during this program were RP-I rocket fuel (MIL-P-25576), commercial-grade propane, and natural gas (a simulant for methane). Both the propane and natural gas fuels were acquired from local comnercial suppliers, and RP-1 was supplied by the Government. In addition, two samples of stock RP-1 fuel were pretreated with additives to study the effects of altering fuel composition on thermal stability and carbon deposi$t$. In rate. These modified fuels were produced by (1) doping with a commercially-produced adjitive designed to inhibit copper migration into the fuel, and (2) contaminating with two selected organic sulfur compounds to raise the sulfur concentration in RP-1 to the specification limit (i.e., 0.05 wt\%). These modifications were made immediately prior to a test run and no special storage or handling facilities were required for the fuel.

The chemical compositions of the test fuels were obtained by utilizing a combination of available Government-furnished information and independent analytical laboratory facilities; that is, a certificate of analysis for the RP-1 fuel used in this program was supplied by the Government (Ref. 14), and the propane and natural gas fuels were analyzed at an independent laboratory (Refs. 15 and 16). Selected results of the RP-1, propane, and natural gas fuel analyses are summarized in Tables I to III, respectively. Thermophysical and transport properties of each fuel as functions of temperature and pressure were obtairied from several sources (Refs. 1, 17 to 20). Tables IV to VI summarize the variation of viscosity, specific heat, thermal conductivity, density, and s,acific enthalpy as a function of pressure and temperature for $R P-1$, propane, and methane, respectively.

Fuel Treatment with Metal Deactivator

The tendency of the copper tube mater al to migrate into the fuel was inhibited by treatment of the test fuel with DuPont Metal Deactivator (DMD),

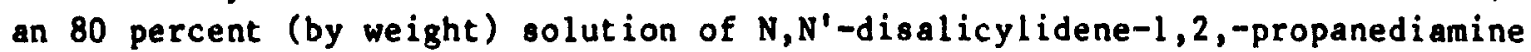
in xylene (Ref. 21). When added to the fuel in proper concentrations, DMD acts to combine with dissolved copper to form a stable chelate of copper. 
Because DMD was developed to increase long term storage stability and to reduce gum formation in liquid hydrocarbon fuels at moderate temperatures, it was unknown whether it would have a positive effect in reducing carbon deposition and improving fuel thermal stability at the elevated temperatures characteristic of the heated-tube tests. DMD is a liquid at room temperature. When 1 ated above a temperature of $422 \mathrm{~K}$, DMD begirs to break down. At $556 \mathrm{~K}$, the material boils and decomposes rapidly to lower boiling point compounds, including phenol.

DuPont recommends that the concentration of DMD be approximately five times the concentration of the copper dissolved in the fuel, and not exceed 0.005 percent by weight for optimum benefit. The concentration of copper in the RP-1 fuel is normally less than $0.01 \mathrm{ppm}$ by weight (Ref. 1). However, because it was believed that additional copper would dissolve into the fuel when passed through the copper test tube, it was decided to add the maximum: recommended amount of DMD. A concentrated stock solution of RP-1 and DMD was accurately prepared and, prior to test, it was added to a preweighed quantity of RP- 1 to produce an effective concentration of 0.005 percent DMD in RP- 1 . In order to ensure thorough mixing of the RP-1 and DMD, the contents of the drum were recirculated using a fuel transfer pump until approximately ten times the volume had passed through the pump.

Fuel Treatment with Sulfur Compounds

The maximum concentration of sulfur permitted in RP-1 in accordance with the applicable military specification is 0.05 percent by weight; however, the RP-1 fuel used in this test program was analyzed and found to contain only 0.007 percent sulfur by weight (see Table I). Therefore, a batch of the asdelivered fuel was treated with enough thianaphthene, $\mathrm{C}_{6} \mathrm{H}_{4} \mathrm{C}_{2} \mathrm{SH}_{2}$, and benzyl disulfide $\left(\mathrm{C}_{6} \mathrm{H}_{5} \mathrm{CH}_{2}\right)_{2} \mathrm{~S}_{2}$, to raise its sulfur concentration to the specification limit, i.e., from 0.007 to 0.05 percent by weight. The selection of trianaphthene and benzyl disulfide compounds as the sulfur-containing species was based on typical analyses of the crude oil performed by the refiner. These analyses indicate that nearly two-thirds of the sulfur is bound in the form of thiophenes and one-third is bound in the form of disulfides (Ref. 22). Also, the solubility of each of these compounds in RP-l had been previously verified in the laboratory.

The same experimental techniques followed for doping RP-l fuel with metal deactivator were followed in the sulfur treatment test; that is, a concentrated stock solution of thisnaphthene and benzyl disulfide dissolved in RP-1 was prepared and mixed with a preweighed quantity of RP-1 just prior to test. The net effect was to raise the sulfur concentration of the test fuel to 0.05 percent by weight. 
In order to verify proper treatment of the stock RP-1 fuel with sulfur, a sample was dram and its composition analyzed (Ref. 23). The result of this analyais are shown in Table VII. The certified analysis confirmed that the appropriate amount of sulfur had been added to the stock fuel to bring it to the specification maximum of 0.05 percent by weight.

Test Facility and Test Procedures

\section{Experimental Apparatus}

The test program was conducted in an existing self-contained combustion test facility which consists of a concrete test cell and a separate control room housing operating personnel and the data acquisition system. The facility and test apparatus employed in this experiment are capable of continuous operation over a range of conditions including fuel flow velocities up to $100 \mathrm{~m} / \mathrm{s}$, fuel pressures up to $13.8 \mathrm{MPa}$, and tube wall temperatures up to $866 \mathrm{~K}$. An electrical power supply capable of delivering 4000 amp at $40 \mathrm{kVA}$ $a-c$ was used to provide power for heating the test tubes while flowing fuel. The experimental facility is capable of handling both gaseous and liquid fuels.

The test apparatus, shown schematically in Fig. 2, consists of the following major components: (1) a fuel supply tank, (2) a zeolite-type molecular sieve used to remove water, carbon dioxide, and sulfur from the natural gas, (3) a fuel delivery system consisting of four pistun-type accumulators having a total volume of $0.35 \mathrm{~m}^{3}$ and used to drive fuel through the test section, (4) a cryogenic heat exchanger to cool the propane and natural gas in selected tests to teinperatures of $230 \mathrm{~K}$ and $160 \mathrm{~K}$, respective$1 y$, (5) a resistance-heated test tube connected to a $40 \mathrm{kVA}$ high-amperage power supply, (6) an in-line nylon-membrane filter $(0.45 \mu \mathrm{m})$ for collecting any solid particles which might form in the bulk flow or break off from the tube wall during a test, (7) a fuel cooler, (8) an electrically-driven metering valve to control the fuel flow through the test section, (9) turbine and venturi flowmeters, (10) a fuel dump tank, and (11) an air-driven ejector and exhaust stack used when testing with natural gas. A photograph of the facility is presented as Fig. 3.

The heat exchanger, provided to cool the propane and methane, is part of the cryogenic fuel delivery system depicted schematically in Fig. 4. The basic components of this system include: (1) three nested, double spiral, heat exchanger coils fabricated from $0.95-\mathrm{cm}$ OD stainless steel tubing, each approximately 36-m long; (2) a 76-l vented dewar flask filled with liquid nitrogen; (3) a liquid nitrogen level sensor and level control unit; (4) a flexible, stainless steel liquid nitrogen transfer line attached to a porous, sintered-bronze phase separator; (5) a cryogenic solenoid valve; and (6) a low 
pressure, insulated liquid nitrogen supply vessel to replenish the liquid nitrogen that is vaporized in the dewar.

The stainless steel heat exchanger coils were immersed in the vented dewar flask of liquid nitrogen. Natural gas or propane entered the coils at approximately $290 \mathrm{~K}$ and $13.8 \mathrm{MPa}$. All three coils, connected in parallel, were required to cool the natural gas to the temperature of $160 \mathrm{~K}$, whereas, a single coil was sufficient to lower the temperature of the propane to $230 \mathrm{~K}$. An electronic control unit and liquid-level sensor element were used to actuate a solenoid valve in the transfer line to enable automatic transfer of liquid nitrogen from the supply vessel to the dewar, as required. The phase separator, attached to the discharge end of the transfer line, minimized flashing of liquid nitrogen into vapor during filling of the dewar. A photograph of the heat exchanger, liquid nitrogen supply vessel, and zeolite molecular sieve is provided as Fig. 5.

Since it was not possible to reclaim the natural gas used in this program, a special mixer/diffuser was fabricated to dilute the natural gas below its flammability limit. The gas/air exhaust system consisted of a compressed-air-driven ejector installed approximately $6 \mathrm{~m}$ above ground. The ejector primary nozzle and mixing sections were designed to yield an entrainment ratio of 3.3 (using the data in Ref. 24) and to dilute the natural gas with air, resulting in natural gas mass fraction at the exhaust of approximately 0.008 ; a value well below both the flammability limit and the level affecting pulmonary function.

\section{Heated Test Tube Fabrication and Characterization}

The heateo test tube assembly and a cross-sectional view of the tube configuration art shown schematically in Fig. 6 . The test tube comprised a duplex arrangement formed by an inner $0.196-\mathrm{cm}$ ID $\times 0.348-\mathrm{cm}$ OD, 99.99 percent pure copper tube and an outer $0.348-\mathrm{cm}$ ID $\times 0.475-\mathrm{cm}$ OD Incone, 600 tube. The Inconel sheath provided the necessary high-temperature tensile strength while the inner copper tube provided the desired test material and surfa o condition for studying fuel deposit formation in rocket engine cooling systems. The test tubes were of igned to withsiand continuous operation at maximum outer wall temperatures up to $866 \mathrm{~K}$ and fuel pressures up to $13.8 \mathrm{MPa}$. While the structural had was carried by the outer Inconel sheath, the major electrical power fraction (approximately 95 percent) was carried by the higher conductivity cowper tube. Therefore, the induced radial temperature gradient was smal: .

The diplex tubes were fabricated by inserting the copper tubing into oversize Inconel tubing and drawing the assembly through die, thereby reducing the tube diameters and creating a mechanical bond. Prior to fabrication, tie wanufacturer cleaned both the Inconel and copper tube components 
using a opecial cleaning procedure designed to ensure against the existence of any ignificant electrical or thermal resiatance at the interface of the two metals, which could stem from contamination or oxidation. The cleaning procedure adopted for the copper tubing consisted of immersing the tubing in a solution of 10 percent sulphuric acid and 90 percent water for a period of 10 to $15 \mathrm{~min}$, followed by a thorough water rinse to semove all traces of acid residue. Th. Inconel tubing was degreased by immersing in acetone for a period of 5 to $10 \mathrm{~min}$.

After fabrication, the integrity of the Inconel/copper bond in the test tubes was ascertained by testing a sample length. These tests consisted of metallographic examinations made with a scanning-electron microscope and elemental analysis at the tube interface made utilizing a scanning-electron microprobe. Microscopic examination of the interface showed that the mechanical bond was satisfactory. The microprobe analys is comprised searches for carbon, oxygen, sulfur, an.l chlorine. These analyses indicated that the interface region was clean and free of constituents which would affect the tube heat transfer characteristics.

The test tube interior surface finish was characterized using a Bendix type AD, Model 17 profilometer. A tracing speed of $0.25 \mathrm{~cm} / \mathrm{s}$ was used. The measured interior surface roughness height (i.e., the average deviation from the mean surface) of the tube was from 0.25 to $0.30 \mathrm{\mu m}$, slightly smoother than the 0.63 to $0.84 \mu \mathrm{m}$ finish tube tested in the previous program (Ref. 1).

In an effort to passivate the normally reactive copper surface, several test tubes were plated with nickel by a vendor who used an electroless process. Phosphorous is a major constituent in the electroless plating solution and was found present in the nickel plate (Ref. 1). After the plating process, selected tube specimens were split longitudinally to verify that there was complete coverage of the copper with nickel. In addition, in order to determine the thickness of nickel deposited on the copper surface, a longitudinal specimen of plated tubing was polished and examined microscopically. The average thickness of the nickel plating was $6 \mu \mathrm{m}$.

Test tube assemblies depicted in Fig. 6 were cut from $1.9-m$ lengths of duplex tubing and brazed to copper bus rings, which in turn were bolted to copper ring adapters. In order to avoid excessive heating of the test tube, a $95 / 5$ percent cadmium/silver solder having a solidus of $611 \mathrm{~K}$ and a liquidus of $667 \mathrm{~K}$ was used in this operation. Ten chromel-alumel thermocouples were spot welded to the Inconel sheath at $2.54-\mathrm{cm}$ intervals, starting at $1.27 \mathrm{~cm}$ from the electrical bus ring. The surfac'e of the Inconel tube was coated with Sauereisen cement at the thermocoupie junctions, to electrically insulate the thermocouple lead wires from the tube, and the wire was wrapped once around 
the tube and coated with additional Sauereisen cement to ensure good thermal contact and thereby minimize heat conduction from the junction.

The test section mounting arrangement is also shown in the photograph in Fig. 7. The test tube assembly was mounted on teflon-lined cradles designed to accommodate the bus rings and to permit thermal expansion by providing a smooth sliding surface. The teflon also acted as an electrical insulator to prevent grounding of the test tube. In addition, nonconductive flexible hose was installed at the entrance and exit of the test tube assembly to allow thermal expansion and to electrically isolate the tube from the other components of the test apparatus. The test tube assembly was connected to the power supply using a rigid connector and flexible water-cooled cable. The flexible cable permitted thermal expansion of the test section. Adjustable wall anchors and adjustable transformer connections were used to assist in aligning the test section prior to a run.

\section{Instrumentation and Data Acquisition System}

The locations of the principal instrumentation elements are shown in the schematic of the test apparatus in Fig. 2. All test data were recorded using a calculating data-logger microprocessor (Ref. 25). When set at standard resolution, the data system is capable of a scan rate of up to 35 channels per second. The data system converts the output signals from thermocouples, pressure transducers, current transducers, voltage transducers, and flow meters to precisely scaled $d-c$ voltages for measurement, but displays the data in engineering units as specified by the operator through built-in linear scaling functions. A cathode-ray tube displays key operating variables, thereby providing a continuous visual check of up to 13 channels. If a measured test parameter exceeds a specified setpoint, an alarm message is displayed, and a contact may be closed to terminate the experiment. The raw data are logged on paper tape either by demand logging or by programmed interval logging. In addition, \& magnetic tape drive coupled to the data system is used to store test data for subsequent processing on a high-speed digital computer.

During the RP-1 and propane tests, the primary fiel flow measurement was made using a turbine-type flow meter located downstream of the test section. In addition, redundant fuel flow measurement was made downstream of the test section with a venturi and a differential pressure transducer. Generally, the turbine meter and venturi flow rate measurements agreed within four percent. The natural gas flow rates were established by utilizing an appropriately sized critical-flow venturi that was installed in the same location downstream of the test section. The pressure drop between the venturi inlet and throat was monitored continuously to verify critical flow conditions at the throat. 
Other pertinent data parameters monitored and recorded during each test included: the outer wall temperature of the test tube at ten axial locations, the temperature of the fuel entering and exiting the test tube, the fuel pressure at the test tube inlet, the d:op in fuel pressure across the test tube, the voltage applied to the test tube, and the current through the test tube. Since piercing the heated test section to measure bulk temperatures is not considered to be good practice (because of possible fuel leakage, insertion of preferential sites for deposition, and electrical discontinuities), only inlet and exit fuel temperature measurements were made. However, theoretical predictions of the axial variation of fuel temperature suggest that the distribution is nearly linear. Fuel pressure measurements were made using strain-gauge-type pressure transducers and all temperature measurements were made using chromel-alumel thermocouples. The a-c current was measured using a commercially-produced inductive pickup and current transmitter.

\section{Test Matrix and Test Operation}

The test matrix, shown in Table VIII, comprised twenty-four te;ts for RP-1, commercial-grade propane, and natural gas fuels that were conducted at the nominal conditions consisting of a fuel delivery pressure of $13.8 \mathrm{MPa}, a$ fuel delivery temperature of $290 \mathrm{~K}$, maximum initial inner wall temperatures of 589,700 , and $811 \mathrm{~K}$, and for a test duration of $10 \mathrm{~min}$. Also, a calibration test for RP-1 and three additional tests (one for each fuel) were conducted during the course of the program. The RP-1 and propane test.s were performed to extend the data base that was acquired under the previous phase of this program (Ref. 1). The experimental program began with a sequence of calibrations using RP-l fuel to establish operating procedures and to verify proper performance of the data acquisition system.

Referring to Table VIII, the initial series of tests (Runs 1 to 4 ) used RP-1 fuel. Run 1 provided data for a copper tube in which the nominal fuel inlet velocity was $6 ! \mathrm{m} / \mathrm{s}$; Run 2 explored the effect of nickel plating on deposit formation for RP-1 at a nominal fuel velocity of $30 \mathrm{~m} / \mathrm{s}$; and Runs 3 and 4 made use of copper test tubes to evaluate the effects of (1) doping ise fuel with metal-deactivating agent, and (2) increasing the sulfur content of the fuel to the RP-1 specification limit of 0.05 percent by weight, respectively.

The second series of tests (Runs 5 to 12) used commercial-grade propane fuel. Runs 5 to 8 were conducted for ambient temperature propane, while Runs 9 to 12 explored the effects of cooling the fuel to a nominal delivery temperature of $233 \mathrm{~K}$. With the exception of Runs 5 and 11 , all tests used nickel-plated copper tubes. In Run 5, the effect of a nominal fuel inlet velocity of $61 \mathrm{~m} / \mathrm{s}$ on carbon deposition in a copper tube was explored. In Run 7, fuel pressure was reduced to a nominal value of $6.9 \mathrm{MPa}$. In Run 8 , which 
was performed using ambient temperature propane in nickel-coated tube, the tube was operated intermittently; that is the power and fuel flow were cycled on and off eight times. Each power on cycle was approximately three minutes in duration. Between power-on cycles, fuel flow was maintained long enough to cool the tube wall to about $310 \mathrm{~K}$. Once the tube wall had been sufficiently cooled, the power was reset to the previous level and the cycle was repeated. The total time for which the tube was heated was $24 \mathrm{~min}$.

The third series of tests (Runs 13 to 24 ) were conducted using natural gas as a simulant for methane. Runs 13 to 20 were conducted using ambient temperature natural gas, and Runs 21 to 24 were conducted using cryogenic natural gas. Both copper and nickel-plated copper tubes were used. Runs 17 and 18 were performed at nominal fuel inlet velocities of 61 and $91 \mathrm{~m} / \mathrm{s}$, respectively and at a fuel pressure of $6.9 \mathrm{MPa}$. As in the case of Run 8 with propane, Run 20 was designed to explore the effect of intermittent operation on carbon deposition. Total run time at high temperature was $24.5 \mathrm{~min}$, comprising eight cycles with power on and eight cycles with power off. Runs 21 to 24 were conducted using cryogenic natural gas cooled to a nominal inlet temperature of $160 \mathrm{~K}$ at $13.8 \mathrm{MPa}$ de!ivery pressure. An additional test coded as Run 220 is listed at the bottom of Table VIII. This run was a first attempt at Run 22 , but was repeated because there were large fluctuations in the fuel inlet temperature.

Prior to running a test, the interior surface of each test tube assembly was degreased and cleansed. The cleaning procedure adopted consisted of the following steps:

1. Swab several times with pipe cleaners dipped in acetone, and rinse with distilled water.

2. Swab several times with pipe cleaners dipped in an aqueous solution comprised of $3 \mathrm{~g}$ ciiric acid dissolved in $50 \mathrm{ml}$ of hot distilled water and $10 \mathrm{ml}$ of 3 percent by volume hydrogen peroxide.

3. Rinse with distilled water and dry with nitrogen.

To ensure that no contaminants were present on the test surface, scanning-electron-microprobe analyses were conducted to verify that the cleaning procedure adopted was successful in removing the trace quantities of contaminant species found cn the uncleaned copper surface (e.g., chlorine, sulfur, and phosphorous).

Routine preteot facility preparation consisted of installing a clean test tube and particle filter, charging the accumulators with an appropriate quantity of fuel, activating the data acquisition system and closed-circuit 
television monitor, and checking all transilucer calibrations and thermocouple junctions. After pressurizing the accumulators with nitrogen, the entire system was inspected for leaks by flowing fuel momentarily. Provided there were no leaks, the test was initiated by opening the electrically-powered fue: shutoff valve and adjusting the downstream metering valve until the desired flow rate was obtained. The electric powerstats were then activated and set to a relatively low power level (e.8., wall temperatures in the range of 350 to $450 \mathrm{~K}$ ). This was done to verify proper operation of all the thermocouples. The electric powerstats were then rapidly advanced to heat the tube to the desired wall temperature (transient time was about $15 \mathrm{sec}$ for RP-1 and methane and 1 min for propane), and data logging was commenced. At high electrical power settings, wall temperature was very sensitive to potrerstat setting, and it was difficult to set the maximum initial wall temperature accurately; hence the slight deviation from nominal values (Table VIII). Data were usually recorded every $30 \mathrm{sec}$. The test was continued for the specified duration or until the maximum wall temperature exceeded $866 \mathrm{~K}$. After the test was completed, power was turned off and fuel flow was maintained for a brief period (approximately $15 \mathrm{sec}$ ) to cool the test tube to about 310 to $340 \mathrm{~K}$. The test tube and particulate filter were then removed from the facility and set aside for post-test analysis.

A slightly nodified run procedure was adopted for the tests utilizing cryogenic fuels. The fuel flow and the liquid nitrogen flow to the cryogenic heat exchanger were started simultaneously. Typically, a ten minute system cooldown period was allowed to achieve a steady-atate temperature prior to starting the test. During the system cooldown period, a low level of electrical power was supplied to the test section, to maintain the fuel discharge temperature above cryogenic levelg and thereby simplify the apparatus downstream of the test section. Once the desired fuel inlet temperature was attained, the normal run procedure was begun. The start-up procedure was especially critical in the case of natural gas. Here, a trace amount of carbon dioxide remaining in the fuel after it passed through the zeolite filter would cryatallize and block the heat exchanger coils if a low fuel flow rate was not maintained at all times.

\section{Data Analysis}

Test data were recorded on magnetic tape and subsequently transferred to a high-speed digital computer for further processing. A data reduction program was developed for calculating additional parameters of interest, such as Reynolds number, fuel-side heat transfer coefficients, friction factors, and deposit thermal resistances. 
The local inner wall temperatures of the test tube (i.e., temperatures at interface between deposit layer and tube wall) were computed from the measured outer wall temperatures using results from a numerical heat transfer simulation known as TCAL. In this analysis, a finite difference representation of the heat conduction equation (a time-dependent version of Laplace's equation) is solved by a relaxation technique. The temperature at the interface between the fuel and the deposit layer which forms inside the tube equals the initial inner wall temperature, provided the convective heat transfer coefficient remains constant (i.e., constant heat flux and flow rate). The local value of the forced-convection heat transfer coefficient was determined based on the assumption of a linear bulk fuel temperature profile. A more rigorous analysis (Ref. 1) has verified that this assumption is a reasonable one for $\mathrm{RP}-1$ at the conditions of interest.

Two measures of the effect of carbon formation on heat transfer were employed in the data reduction analysis. The deposit thermal resistance $(t / k)$, defined as the ratio of deposit thickness to deposit thermal conductivity was computed from

$$
t / k=\left(\frac{1}{v}-\frac{1}{v_{0}}\right)
$$

where $U$ is the instantaneous overall inside wall heat transfer coefficient. It is defined as

$$
U=\frac{Q / A}{T_{w_{i}}-T_{f}}
$$

where $Q / A$ is the instantaneous heat $f l u x, T_{w_{i}}$ is the calculated local inside wall temperature, and $T_{f}$ is the local bulk fuel temperature. Notice that as defined, $U$ incorporates the resistance due to deposit formation. However, at time zero when the tube is clean, $U$ reduces to the heat transfer film coefficient $v_{0}$.

In addition, the thermal resistance buildup rate $\left(\dot{R}_{c}\right)$ is given by 


$$
\dot{R}_{c}=\frac{\Delta T_{v_{0}}}{(Q / A) \Delta t}
$$

where $\Delta T_{w_{0}}$ is the observed rise in outer wall temperature and $\Delta t$ is the elapsed time for which the tube was heated. The latter definition assumes 1 inearity over the time period $\Delta t$. It is a simple matter to prove that $t / k$ equals $k_{c} \cdot \Delta t$, provided the heat $f l u x$ and bulk fuel temperature profiles do not change with time.

Analyses were performed to correlate the experimentally-derived heat transfer film coefficients $\left(U_{0}\right)$ for each fuel with a Nusselt-ReynoldsPrandt I number expression (Ref. 26) given by

$$
\frac{N u}{\operatorname{Pr}^{c}[1+2 /(x / D)]}=A \operatorname{Re}^{b}\left(\frac{\rho}{\rho_{w}}\right)^{d}\left(\frac{\mu}{\mu_{w}}\right)^{e}\left(\frac{k}{k_{w}}\right)^{f}\left(\frac{C_{p}}{C_{p}}\right)^{g}\left(\frac{P}{P_{c r i l}}\right)^{h}
$$

where $\mathrm{Nu}$ is the Nusselt number, Re is the Reynolds number, $\mathrm{Pr}$ is the Prandt 1 number, $\rho, \mu, k, C_{p}$, and $P$ are local values of the fuel density, absolute viscosity, thermal conductivity, specific heat, and pressure, respectively. $C_{p}$ is the average value of specific heat computed from the inside wall temperature and the fuel bulk temperature, and $x / D$ is the axial distance to diameter ratio. The subscript $w$ denotes evaluation of the fuel property at the wall temperature. All other fuel properties are evaliated at the bulk temperature. In this analysis, it was assumed that $c=0.4$.

The unknown coefficient $A$ and exponents $b, d, e, f, g$, and $h$ were determined using a multiple linear regression and correlation analysis computer program. The above equation is of the form

$$
Y=a B^{b} D^{d} E^{e} F^{E} G^{B} H^{h} .
$$

Taking the natural logarithm of each side of the latter equation and denoting the natural logarithm of quantity by $(*)$ gives a linear equation of the form

$$
Y^{\star}=A^{\star}+b B^{\star}+d D^{\star}+C E^{\star}+f F^{*}+g G^{\star}+h H^{\star}
$$


The rog". -ion analysis operates to make the sisard deviation

$$
\sigma=\left(\frac{\left[\left(Y^{*} \exp -Y_{\left.c a_{-}\right)^{2}}\right)^{n-m}\right.}{i}\right.
$$

a minimum, where $n$ is the gotal number of isia foints, $m$ is the cotal number of regression coeffirients (e.g., seven), stis the subscripts exp and calc Indicate that the value of $Y^{*}$ is derived fecra experiment or calculated from the correlation equation. The standard deviation is an absoluce measure of disperdion of the dat about the fitted curye.

At the same time, the regression analysis maximizes the correlation coefficient

$$
R=\left(\frac{\sum_{n}\left(Y_{\exp }^{*}-\bar{Y}_{\text {exp }}^{*}\right)^{2}-\sum_{n}\left(Y_{\exp }^{*}-Y_{\text {ealc }}^{\star}\right)^{2}}{\sum_{n}\left(Y_{\exp }^{*}-\bar{Y}_{\exp }^{*}\right)^{2}}\right)^{1 / 2}
$$

where an overbar denotes a mean value. The correlation coefficient is a relative measure of the closeness of fit of the correlating equat ion to the experimental data, and its square (the coefficient of determination) may be interpreted as the percentage of the tutal variation in the dependent variable that is ssociated with variation in the independent variables. The correla$t$ ion coefficient takes on values between 0 and 1 , with perfect correlation occurring for $R=1$.

In additior, to solving for the unknown coefficient and exponents for the assumed correlating equation, the regression and correlation analysis computer progran incorporated a tatiatical agnificance teat (Student's test, 95 percent confidence) wich sutomatically deleted the least ignificant independent variables from the original correlaing equation and recomputed new values of the coefficient and exponents for the remaining terms.

\section{Depoeit Characterization}

The quantity of carbon on the test tube surface was decermined by burning off the deposit in oxygen with analyois of the evolved $\mathrm{CO}$ and $\mathrm{CO}_{2}$. $\mathrm{As}_{\text {s }}$ shown in Fig. 8, four equally-spaced sections (each approximately $3.81-\mathrm{cm}$ long) were cut from each teat tube and used for the burnoff lesta. The four tube sections represent approximately 60 percent of the lotal surface area of the 
tube; the remainder of the tube was cut into longitudinul sections which were examined microscopically. A epecial fixture and jewelers naw were used to section the tubes. Prior to the burnoff procedure, the test tube sections were dried in a vacuum oven at $390 \mathrm{~K}$ for 24 to 48 hours to evaporate any residual liquid fuel. To acquire the deposit formation rate date, a metered flow of oxygen was fassed at a constant. rate through the inside of a heated section of the test tube (see Fig. 9). The product gases from the burnoff were passed through an Infrered Industries, Inc. Modsl 1 R-702 nondispersive infrared (NDIR) analyzer which measured the concentralions of $\mathrm{CO}$ and $\mathrm{CO}_{2}$ in the test tube effluent. The analyzer was calibrated before each series of burnof? ests using nitrogen for setting the instrument zero level and a $\mathrm{N}_{2} / \mathrm{CO}_{2}$ ur $\mathrm{N}_{2} / \mathrm{CO}$ gas mixture of certified concentration for establishing the appropriate scale factor. Output frcin the analyzer was recorded continuously to give a time trace of the percentage of $\mathrm{CO}_{2}$ and $\mathrm{Cn}$ evolved during burnoff of the deposit. Integration of the data over th total hurnoff lime yielded the total volumes of $\mathrm{CO}_{2}$ and $\mathrm{CO}$ evolved, from which a carbon weight and deposition rate were calculated. The catalyst bed shown in Fig. 9 was used o convert any $\mathrm{CO}$ evolved to $\mathrm{CO}_{2}$, thereby simplitying the calculation. The carbon deposition rate is defined as the mass of carbon deduced from the burnoff analysis divided by the product of the inside lateral surface area of the tube section and the total test time, and is expressed in units of $u_{g} i_{\text {all }}{ }^{2}-h_{i}$. In this program, carbon depcsition rates are reported as both tube local and tube average quantities. The local rate is computed for a single $3.81-\mathrm{cm}$ long tube section wheress the average rate is the arithmetic mean value from four of these sections.

The accuracy of the burnoff procedure :as verified periodi ally by oxidizing a known mass of iolid carbon in the apparatus, measuring the concertrations of $\mathrm{CO}_{2}$ and $\mathrm{CO}$ in the effluent gases, and computing the mass of carbon. Typically, the computed ond measured values of carbon mass agreed to within 6 percent. Also, burnoff teats were conducted for clean, unuasd copper and nickel tube specimens to compensate for any tare carbon mass present. All deposit messes and deposit formation rates reported in this program inciude a sare ad justment.

In selected cases, the longitudinal tube sections shown in Fig. b, were scanned optically and the deposit wes characterized qualitalively in terms of its type and uniformity. A Scenning-Electron Microscope (SEM) was used to elucidate the morphology of the deposit; limited elemental analyois of the deposit was performed using a Scanning-Electron Microprobe (SEMP). This procedure invulved a qualitative scan of alements present in the deposit (e.g., carbon, copper, sulfur, oxygen, and nitrogen) within a deiectability linit of approximately 200 ppan. X-ray emissinn inngery of the selected element (indicated by elusters of wite dots on a black background) was matched to atandard photomicrographs of the anmple deposits. In addition, a computer algorith was used to process the $X$-ray map data and to quantify the elemental composition of the deposit on a mass fraction basis. 
In this section, the data for the heated-tube tests conducted for RP-1, commercial-grade propane, and natural gas are presented. In addition, a summary of the results of the deposit characterizations, including the burnoff data and deposit morphology, is provided. The extent of corrosion within a test tube due to the carbon deposition process is quantified through results of hydrostatic burst tests on selected tube specimens. A complete listing of all the on-line test data acquired, including calculated parameters, is presented in the Appendix. A summary of the tube burnoff data for the three fuels is found in Tables IX to XI.

$$
\text { RP-1 Test } 8
$$

\section{Calibration Tests}

In order to chardcterize the test tube input power requirements for RP-1 fuel, a series of calibration tests was conducted. The fuel inlet velocity was fixed and the electrical power supplied to the tube was varied incrementally to produce peak inside wall temperatures between 400 and $800 \mathrm{~K}$. These tests were conducted at a nominai fuel inlet pressure of $13.8 \mathrm{MPa}$. Operating conditions were held constant only momertarily so that data could be recorded at each power setting in the absence of significant deposit formation. The inner wall temperature distributions and corresponding power levels for fuel in :et velocities of 21,44 , and $65 \mathrm{~m} / \mathrm{s}$ are shown in Fig. 10 . Inlet Reynolds number at these velocities are $14-, 21-$, and $43 \times 10^{3}$, respectively. As reported in Ref. 1, at high inlet Reynolds numbers, the wall temperature profiles indicate no apparent entrance effects associated with a developing thermal boundary layer. At the lower power levels for the range of velocity explored, wall temperature is nearly uniform along the tube. At higher power levels, wall temperature decreases slightly from the tube entrance to the tube exit. This characteristic profile stems from the variation of bulk fuel properties with temperature and was explained in detail in Ref. 1.

Effect of Fuel Velocity on Carbon Deposition and Thermal Resistance

As discussed in Ref. 1 , the rate of carbon deposition is affected by changes in fuel velocity. In Fig. 11, which is based on data acquired in the previous phase of this program, the rate of carbon deposition for RP-1 in copper tubes is plotted as a function of the initial inner wall temperature for several fuel inlet velocities. The data are based on tube-averaged quantities; that is, an average temperature and an average carbon deposition rate have been computed for each tube. The figure shows that along a curve of constant fuel velocity, there is a maximum value of the rate of carbon deposition. As fuel velocity increases, the maximum rates of carbon deposition 
shift to higher wall temperatures. Also, the rates of carbon deposition decrease as fuel velocity increases. In order to further explore these trends, two tests were conducted to extend the existing data base for copper and nickel-plated tubes. Fuel inlet velocity was set at $58 \mathrm{~m} / \mathrm{s}$ for the copper tube and $30 \mathrm{~m} / \mathrm{s}$ for the nicke1-plated tube. Both tests were run at $13.8 \mathrm{MPa}$ fuel inlet pressure. Composite plots summarizing the burnoff data from Ref. 1 and from this program and describing the effects of fuel velocity on carbon deposition for copper and nickel-plated tubes are shown in Figs, 12 and 13, respectively.

In Fig. 12, the rate of carbon deposition is plotted as a function of fuel inlet velocity and grouped into two bands enclosing initial inner wall temperature data less than $640 \mathrm{~K}$ and greater than or equal to $640 \mathrm{~K}$, as suggested by the trends in Fig. 11. For wall temperatures less than $640 \mathrm{~K}$, the rate of carbon deposition decreases as fuel velocity increases from 7 to $30 \mathrm{~m} / \mathrm{s}$. However, when wall temperature is greater than or equal to $640 \mathrm{~K}$, the rate of carbon deposition exhibits a reverse trend and increases with increasing fuel velocity in the range of 7 tc $58 \mathrm{~m} / \mathrm{s}$. Also, at low fuel velocities $(e .8 ., 7$ to $15 \mathrm{~m} / \mathrm{s})$ the rates of carbon deposition for wall temperatures less than $640 \mathrm{~K}$ exceed those rates for wall temperatures greater than $640 \mathrm{~K}$.

The opposing trends observed for the effect of fuel velocity on carbon deposition for the two wall temperature ranges shown may be explained as follows. At low wall temperatures (e.g., less than $640 \mathrm{~K}$ ) the rate of deposit formation may be limited by the kinetics of the carbon deposition processes, so that the additional fuel supplied to the hot surface (corresponding to an increase in fuel velocity) is not reacted. The slight decrease in the rate of carbon deposition associated with an increase in fuel velocity at these t.emperatures may be due to increased flaking of deposit from the tube surface. However, at high wall temperatures (e.g., greater than or equal to $640 \mathrm{k}$ ), the carbon deposition kinetics are accelerated so that in the limit, the rate at which deposit forms is governed only by the rate at which fuel is supplied to the hot tube surface. Thus, at the higher temperature the increase in fuel mass flow rate associated with an increase in fuel velocity promotes further deposit formation.

The higher rates of carbon deposition shown for wall temperatures less than $640 \mathrm{~K}$ at fuel velocities between 7 and $15 \mathrm{~m} / \mathrm{s}$ may be due to the observa$t$ ion that the rate of carbon deposition reaches a maximum at an intermediate value of wall temperature and decreases thereafter for further increases in wall temperature (cf., Fig. 11). Previously, this value was determined experimental'y to be between 550 and $600 \mathrm{~K}$ at a fluid velocity of $7 \mathrm{~m} / \mathrm{s}$ (Ref. 1). Carbon ueposition rates decreased rapidly when wall temperature exceeded these values. 
In the case of nickel-plated tubes, Fig. 13 summarizes the results of the rate of carbon deposition as anction of initial inner wall temperature for fuel inlet velocities of 6,18 , and $30 \mathrm{~m} / \mathrm{s}$. Open symbols correspond to data derived from a particular section of a tube; whereas solid symbols correspond to data based on tube-averaged quantities. The plot shows that the carbon deposition rates for velocities 6 and $18 \mathrm{~m} / \mathrm{s}$ (Ref. 1) fall in a band significantly below that data correspouding to $30 \mathrm{~m} / \mathrm{s}$ (Run 2). in the range of wall temperatures tested, an increase in fuel velocity is accompanied by a significant increase in the rate of carbon deposition. This increase in the rate of carbon deposition cannot be attributed solely to the increased fuel flow at higher velocity. Also, a comparison of Figs, 13 and 11 shows that for fuel velocities betreen 6 and $13 \mathrm{~m} / \mathrm{s}$, the rates of carbon deposition for nickel tubes are approximately one-fifth of those for copper.

The effect of fuel velocity on the thermal resistance buildup rate ( $R$ ) defined earlier was explored for copper tubes. Previously, it was determined that, for fuel velocities between 7 and $30 \mathrm{~m} / \mathrm{s}$, the thermal resistance buildup rate reached a maximum at an initial wall temperature in the range 650 to $700 \mathrm{~K}$ and decreased thereafter for further increases in wall temperature (Ref. 1). In addition, the thermal resistance buildup rates decreased as fuel velocity increased. In order to summarize this trend for the data compiled in Ref. 1 and in this program, a plot of maximum thermal resistance buildup rate as a function of fuel inlet velocity is shown in Fig. 14. These rates were calculated for tube locations where thermocouple measurements exhibited an overall rise for the full test duration. In Fig. 14, the thermal resistance buildup rate is shown to decrease by a factor of five with an increase in fuel velocity from 8 to $58 \mathrm{~m} / \mathrm{s}$; a trend that cannot be explained by a reduction in the level of deposit produced (cf., Fig. 12). Therefore, the reduction in the thermal resistance buildup rate is attributed to enhancement of the local heat transfer coefficient due to increased velocity and/or roughening of the tube wall during the carbon deposition process. Also, it is postulated that as the mass of deposit increases, its porosity decreases, and its thermal conductivity increases from a value representative of the fuel to a value typical of amorphous carbon. Consequently, the higher deposit loadings observed for an increase in fuel velovity could improve heat tranefer and reduce the thermal resistance buildup rate.

Effect of Fuel Composition on Carton Deposition

Two heated-tube tests were conducted to explore the effects of (a) doping RP-1 base fuel with a metal deactivator designed to inhibit copper migration and (b) contaminating the fuel with compounds to increase the total sulfur concentration to the specification maximum of 0.05 percent by weight. A composite plot comparing the data for the fuel composition modification tests with those obtained for RP-1 base fuel is shown in Fig. 15. Here the rate 
of carbon deposition is plotted as a function of initial inner wall temperdture and a curve is drawn through the data for the RP-1 base fue:.

Based on the tube-averaged data, there is a significant reduction in the rate of carbon deposition when RP-1 is doped with metal deactivator. At an initial wall temperature of about $670 \mathrm{~K}$, this reduction is approximately a factor of two. With regard to the data obtained for the sulfur-doped fuel, the tube-averaged data suggests no significant increase in the rate of carbon deposition when compared to RP-1 base fuel. However, as will be discussed later, significant loss of deposit caused by flaking from the tube surface because of corrosion of the copper was characteristic for most of this tube. In general, the deposit appeared thicker than that obtained for RP-1 base fuel and the peak deposit rate of $970 \mu \mathrm{g} / \mathrm{cm}^{2}-\mathrm{hr}$ at a wall temperature of $725 \mathrm{k}$ (a threefold increase relative to the base fuel) may be more representative of the tube-averaged level that would be obtained had flaking not occurred. The results of the sulfur-doped fuel test indicate that high concentrations of fuel-bound sulfur (e.g., 0.05 wt \% s) accelerate deposit formation and tube corrosion. However, further work utilizing fuels with naturally-occurring high sulfur concentrations is necessary before a definitive conclusion can be reached.

\section{Propane Tests}

\section{Effect of Fuel Velocity on Carbon Deposition}

The effects of fuel velocity on carbon deposition in copper tubes for propane fuel, were explored by comparing the results of Ref. 1 with those of a test in which the fuel inlet velocity was set at $49 \mathrm{~m} / \mathrm{s}$. Nominal f'jel inlet pressure and temperature were maintained at $13.8 \mathrm{MPa}$ and $290 \mathrm{~K}$, respectively. A plot summarizing the burnoff data from Ref. 1 and that from this program is shown in Fig. 16 where the rate of carbon deposition is plotted as a function of fuel inlet velocity and the data are grouped in three bands enclosing initial inner wall temperature data less than $400 \mathrm{k}$, between 400 and $560 \mathrm{~K}$, and greater than $560 \mathrm{k}$. The data points shown on the figure are for tubeaveraged deposition rates. The temperature ban?s were selected on the basis of a natural grouping of the data. Along a band of initial inner wall temperatures, the rate of carbon deposition decreases with increases in fuel inlet velocity in the range of 6 to $50 \mathrm{~m} / \mathrm{s}$. In addition, for most fuel velocities, an increase in initial wall temperature produces an increase in the rate of carbon deposition.

The trends exhibited by these curves in Fig. 16 are consistent with the hypothesis that the rate of deposit formation is limited by the kinetics of the carbon deposition reaction. An increase in wall temperature accelerates the reactio kinetics, but an increase in fuel velocity, which corresponds to 
an increase in fuel supplied to the hot tube wall, does not promote additional deposit formation. As in the case for RP-1 fuel, the decrease in the rate of carbon deposition associated with an increase in fuel velocity along a band of wall temperatures may be due to increased washing of the deposit from the tube surface at higher velocities. However, as will be discussed later and in contrast to the results for RP-1, deposit coverage of the tube surface appeared to be uniform and local flaking of deposit was not visible.

\section{Effect of Tube Surface Material on Carbon Deposition}

Teats were conducted using nickel-plated tubes and ambient temperature propane $(290 \mathrm{~K})$ to explore the effects of iube surface material on carbon deposition. As shown in Fig. 17 (a SEMP photograph which is taken from Ref. 1), extensive degradation of the tube wall, manifested in the form of dendrite structures, was characteristic for propane flowing through a copper tube. The SEMP analysis showed the dendrite to contain a high concentration of copper, suggesting that tube material was forced up and away from the surface. Some carbon was evident at the base of the tree-like deposit structure. A very low concentration of sulfur was also detected, but no oxygen was observed. The objective of the nickel tube experiments was to determine if this phenomenon could be mitigated. Nominal fuel inlet velocity was $30 \mathrm{~m} / \mathrm{s}$ for each test at nominal inlet pressures of 13.8 and $6.9 \mathrm{MPa}$.

The carbon deposition data for copper tubes, reported in Ref. 1 , and the data for nickel tubes tested in this phase of the program are summarized in Fig. 18, with all data corresponding to ten minute tast durations. In the figure, the rate of carbon deposition is plotted as a function of initial inner wall temperature. Lines are drawn through the two groups of tube data to indicate the trends. The plot shows that at relatively low wall temperatures (e.8., $400 \mathrm{~K}$ ) the rates of carbon deposition for copper and nickel tubes are similar. However, as wall temperature increases, the rate of carbon deposition for copper tubes increases while that for nickel tubes remains nearly constant. At $580 \mathrm{~K}$, the highest common value of wall temperature tested, the rate of carbon deposition on copper tubes exceeds that of nickel by a factor of four. In addition, as noted in Fig. 18, the tube surface degradation that is characteristic for copper tubes does not occur for nickel tubes in the range of conditions explored. Also, there appears to be no significant effect of fuel pressure on carbon deposition for the nickel-tube tests.

The differing trends exhibited by the rates of deposition for copper as compared with nickel tubes may be related to the tube surface degradation process. As reported in Ref. 1 and as will be discussed later, the size of the dendrite structures which form on the copper surface appear to be a function of tube wall temperature. Microscopic examination of several tube sections revealed that at higher wall temperatures, dendrite size is visibly 
larger than that found at lower temperatures. Therefore, at higher wall tempe-atures more copper metal is pushed out from the tube and the surface area exposed to fuel is increased. Consequently, additional carbon deposit is formed around the base of a dendrite, and scanning-electron-microprobe anaiyses done in Ref. 1 support this conclusion. $\mathrm{Tl}_{\mathrm{i}}$ is mechanism is not present in nickel tubes as witnessed by the absence of visible dendrites. Also, at low wall temperatures, (e.g., $T_{\text {wa } 11}<400 \mathrm{~K}$ ) dendrite formation (i.e., corrosive attack) on copper is not as prevalent, and the rates of carbon deposition for copper and nickel tubes are similar as the data of Fig. 18 indicate.

Effect of Intermittent Operation and Test Time on Carbon Deposition

A test in which a nickel tube was heated intermittently for eight $3-m i n$ cycles was performed to determine the effects of intermittent operation and test duration on carbon deposition. The motivation for intermittent lesting derives from a desire to simulate a number of operating cycles for a reuseable rocket engine application. A summary of the carbon deposition rates acquired for several tests are shown in Fig. 19.

In Fig. 19, the rate of carbon deposition is plotted as a function of test time (i.e., the total time for which heat was applied) for nickel tubes. Note that the longer test corresponds to intermittent operation. Nominal inlet pressure, velocity, and temperature of the propane fuel were $13.8 \mathrm{MPa}$, $30 \mathrm{~m} / \mathrm{s}$, and $290 \mathrm{~K}$, respectively. All data plotted correspond to tests having the same range of initial inner wall temperatures (i.e., 490 to $590 \mathrm{~K}$ ). Based on the data in Fig. 19, the rate of carbon deposition decreases as test time (no. of cycles) increases. This result is consistent with that obtained for continuous tests with copper tubes (Ref. 1). An explanation for decreasing deposit formation rate with increasing test time may be that the depozit breaks away from the tube surface as test time increases (this effect would be intensified by intermittent operation), or due to a suppression of the deposit formation rate owing to passivation of the tube surface resulting from the buildup of deposit over the longer operating pericd.

Effect of Fuel Chilling on Carbon Deposition

A series of tests was performed to study the effects on carbon deposition in copper and nickel tubes of prechilling the propane to $233 \mathrm{~K}$. The motivation for fuel prechilling was an attempt to reduce fuel temperatures and thereby avoid wall temperature instabilities that limited the data of Ref. 1 . Nominal fuel inlet pressure was either 6.9 or $13.8 \mathrm{MPa}$; fuel inlet velocity was $30 \mathrm{~m} / \mathrm{s}$; and fuel inlet temperature was $233 \mathrm{~K}$. The carbon deposition rates 
determined from these tests and from those of Ref. 1 are plotted in Fig. 20, wherein the results obtained for ambient temperature and for chilled propane are compared. The ambient temperature curves for copper and nickel tubes that were previously presented in Fig. 18 are represented in Fig. 20, as are the individual data points and corresponding curves for the data representing the chilled fuel tests.

As indicated in Fig. 20, chilling the fuel results in a substantial reduction in the rate of carbon deposition for wall temperatures in the range 400 to $600 \mathrm{~K}$ for both copper and nickel tubes. Chilling the propane to $233 \mathrm{~K}$ reduces deposit formation by a factor of three for nickel tubes and by over two orders of magnitude for copper tubes. Because of the narrow range of wall temperature which resulted during the single copper tube test, it is not clear whether or not the rate of carbon deposition increases with increasing wall temperature as shown earlier for the ambient temperature fuel. Furthermore, although the rates of carbon deposition for chilled propane on copper tubes are lower than those for chilled propane on nickel tubes, the differences may not be significant due to the inherent scatter in the data at these low deposic rates. However, as will be discussed later, a similar phenomenon occurred for natural gas. As before, there is no apparent effect of fuel inlet pressure on deposit formation for the range of conditions tested.

The reduction in the rates of carbon deposition observed for chilled commercial-grade propane may be due to freezing and removal of trace sulfur impurities present in the fuel. As shown in Table II, chemical analysis of the propane showed a total sulfur concentration of $25 \mathrm{ppm}$. This sulfur is usually in the form of corrosive compounds such as methyl mercaptan $\left(\mathrm{CH}_{3} \mathrm{SH}\right)$, hydrogen sulfide $\left(\mathrm{H}_{2} \mathrm{~S}\right)$, and carbonyl sulfide (COS) (Ref. 27). Adsorption of these compounds onto the tube wall could be a mechanism for carbon deposit formation. Because of nucleate boiling, the inside wall temperature of the cryogenic heat exchanger was close to the liquid nitrogen boiling point of $77 \mathrm{~K}$ at $0.1 \mathrm{MPa}$. The melting points of $\mathrm{CH}_{3} \mathrm{SH}, \mathrm{H}_{2} \mathrm{~S}$, and $\mathrm{COS}$, are 150,189 , and $135 \mathrm{~K}$, respectively (Ref. 28). Therefore, it is likely that some fraction of these impurities was frozen and retained inside the cryogenic heat exchanger. Consequently, the chilled propane fuel entering the heated test tube probably contained lower concentrations of sulfur impurities, which should have resulted in a reduced amount of adsorption onto the tube wall and a lower rate of carbon deposition. It is unlikely that the slight reduction in the fuel bulk temperatures for the chilled propane tests had a significant effect on the carbon deposition processes.

As in the case of ambient temperature propane, tube wall corrosion in the form of dendrites was evident on the coppor tube for the chilled propane test. However, contrary to the previous results, after one of the chilled propane tests for a nickel tube (Run $12, \mathrm{~T}_{\text {wall }}=785 \mathrm{~K}$ ), copper dendrites were 
visible pushing through the nickel plating. The dendrites appeared to start at a location one-third of the way in from the tube entrance, and they extended to the tube exit. Tubes tested at lower wall temperatures (Runs 9 and 10) did not show any deterioration of the nickel plating or the pre-ence of copper dendrites.

The deterioration of the nickel plating and appearance of copper dendrites on the tube used for Run 12 may be a consequence of mechanical rather than chemical phenomena. It is unlikely that the nickel plating on that tube was defective due to the manufacturing process since all tubes were plated simultaneously in the same plating bath. It is more likely that the nickel plating may have fractured as a result of the extreme temperatures and severe gradients that the tube sustained. Initially, cold propane fuel was flowed through the tube, and thereafter electrical power was applied. Because of the different coefficients of thermal expansion between copper and nickel (i.e., a 25 percent difference), the nickel coating may not have expanded as rapidly as the copper during the tube heating process, and it may have cracked. Once the protective nickel coating was broken, propane may have come in contact with the copper and formed dendrites. As will be discussed, cracking of the nickel coating was also observed for tubes subjected to cryogenic natural gas. A more detailed discussion of the appearance and behavior of nickel tubes subjected to high wall temperature conditions will be presented later.

\section{Thermal Resistance}

For those thermocouples exhibiting a temperature rise over the test period, the thermal resistance buildup rate $\left(k_{c}\right)$ and thermal resistance $(t / k)$ were computed. The results are summarized in Figs. 21 and 22 for $k_{c}$ and $t / k$ as functions of reciprocal initial inner wall temperature. Nominal fuel inlet velocity was $30 \mathrm{~m} / \mathrm{s}$ and fuel pressures were 6.9 and $13.8 \mathrm{MPa}$ for all data shown. The data (acquired in this program) are for a 10-min run duration and include copper and nickel tubes, ambient temperature fuel $(290 \mathrm{~K})$, and chilled fuel $(230 \mathrm{~K})$ tests. Although there is scatter in the data, the smooth curves drawn in both figures are based on trends exhibited hy kerosene-type fuels in Refs. 1 and 20. The peak thermal resistance buildup rates for propane are of the same order of magnitude as those determined for RP-1 at comparable test conditions. 


\section{Wall Temperature Distributions and Thermal Resistance}

Figures 23 and 24 summarize typical inner wall temperature and bulk fuel temperature distributions as a function of tube axial position for natural gas in copper and nickel tubes, respectively. Each figure presents results from two tests; the upper plot corresponds to ambient temperature fuel and the lower plot to cryogenic fuel. Temperature distributions measured at the start of a test and after $10 \mathrm{~min}$ are shown.

As is evident in Fig. 24, the wall temperatures for natural gas in nickel tubes increase monotonically from the tube entrance to the tube exit. This was characteristic of all tests using nickel tubes. However, as shown in Fig. 23, the wall temperature distributions for copper tubes exhibited points of inflection characterized by steep positive and negative gradients. At the same time, occasional wall temperature instabilities were common for the copper tubes during early stages of the tests. The exact reasons for these phenomena are not known. Possible explanations include large variations in the energy transport properties of the fuel as the bulk temperature nears the critical temperature $(191 \mathrm{~K})$, and/or superficial effects owing to deterioration of the inner tube wall due to corrosion by the sulfur impurities in the fuel.

The thermal resistance buildup rate and thermal resistance were computed, and the results are summarized in Figs. 25 and 26 for 10-min tests. Data from copper tube, nickel tube, ambient temperature $(290 \mathrm{~K})$, and cryogenic $(160 \mathrm{~K})$ fuel tests are shown. Both the thermal resistance buildup rate and thermal resistance reach their maximum values at a wall temperature of approximately $430 \mathrm{~K}\left(1 / \mathrm{Tw} \mathrm{w}_{\mathrm{I}}=2.3 \times 10^{-3}(\mathrm{~K})^{-1}\right)$. There appears to be no effect of either tube material or bulk fuel temperature on thermal resistance or thermal resistance buildup rates. Peak thermal resistance buildup rates (as well as thermal resistances) for natural gas are about an order of magnitude higher than those found for RP-I (cF., Fig. 14). As will be shown in the next section, carbon deposition rates for natural gas are well below those for RP-1. This apparent anomaly between the thermal resistance buildup and carbon deposition rates for the two fuels may be explained through differences in the surface condition of the deposit (e.g., roughness) and/or thermal conductivity. 
Effect of Tube Surface Material on Carbon Deposition

Figures 27 and 28 summarize the rate of carbon deposition data for natural gas on copper and nickel tubes, respectively. In each figure, the rate of carbon deposition is plotted as a function of initial inner wall temperature on an absolute basis $\left(\mu \mathrm{g} / \mathrm{cm}^{2}-\mathrm{hr}\right)$ and on a normalized basis $\left(\mathrm{ppm} / \mathrm{cm}^{2}-\mathrm{hr}\right.$ ) where the mass of Jeposit has been divided by the total mass of fuel which flowed through the tube during the test period. Data for both ambient temperature and cryogenic natural gas are displayed. Arrows are shown on the plots to designate which data points correspond to a given fuel temperature.

On Figs. 27a and 28a, trend of decreasing rates of carbon deposition with increasing wall temperature is evident for copper and nickel tubes. Contrary to the previous results for RP-1 and propane, on average, the carbon deposition rates for nickel tubes exceed those for copper tubes. As discussed earlier using information cited from Ref. 13, deposit formation on nickel resulting from pyrolysis of light hydrocarbon gases is often greater than that on copper. Also, research done for methane (Ref. 29) showed the rate of deposit formation on nickel to be several times greater than that on copper. The highest rates of carbon deposition occur at wall temperatures in the range of 300 to $500 \mathrm{~K}$, and correspond to those tests ising cryogenic fuel. Becallse of the possibility that this trend due to the difference in fuel flow rates (density) between ambient temperature (gaseous) and eryogenic (compressed liquid) fuels (a factor of four), the rates of carbon deposition were normalized relative to the total mass of fuel passed through the test tube. These plots are summarized as Figs. $27 \mathrm{~b}$ and $28 \mathrm{~b}$. A trend of decreasing rates of carbon deposition with increasing wall temperature may still exist, but the relative magnitude of this decrease is obviously not nearly as great as it first appears when comparisons are made on an absolute basis. Of course, differences due to surface material are unaffected by normalizing the data.

Similar to observations with propane, most natural gas tests using copper tubes show deterioration of the surface manifested in the form of copper dendrites. However, the size and number of these dendrites appear to be significantly less than observed for a typical propane test. For tests using ambient cemperature natural gas, the nearly uniform formation of dendrites at all axial locations between the tube entrance and tube exit is typical. However, for cryogenic fuel tests, dendrites form only at those sections closest to the tube exit (i.e., near the maximum wall temperature). Dendrite formation is greatest on tube sections with initial inner wall temperatures between 500 and $700 \mathrm{~K}$. The only copper tube not to show any evidence of copper dendrites was that of Run 16 , which $7 l s o$ has zero deposit. This test 
was for a relatively high maximum initial wall temperature (i.e., $824 \mathrm{~K}$ ). This observation is consistent with the hypothesis that carbon deposition in natural gas may be due to adsorption of mercaptane (corrosive hydrocarbonsulfur impurities) in the fuel on the tube wall. As wall temperature increases, the rate at which the adsorption mechanism proceeds decreases, thereby decreasing deposit formation and tube corrosion. Also, deposit formation owing to pyrolysis reactions (i.e., crasking of the hydrocarbon fuel molecule) which normally occur at high temperature for fuel molecules having more than a single carbon atom are nonexistent for methane. Thus, it may be possible to minimize deposit formation in natural gas by operation at high wall temperatures.

All nickel tube tests using cryogenic natural gas showed evidence of breakdown of the nickel plate and formation of copper dendrites at axial locations near the tube exit. Initial inner wall temperatures for these tube sections were between 700 and $800 \mathrm{~K}$. However, no deterioration of the nickel plating occurred at these wall temperatures for ambient temperature natural gas. As explained earlier for chilled propane, fracturing of the nickel plating may be a consequence of the different cnefficients of thermal expansion between nickel and copper and the rapid change in wall temperature during test start-up as electrical power is applied to the tube.

As reported in Table IIl, the sample of natural gas used in this program contained $4 \mathrm{ppm}$ total sulfur. Typically, an odorant called tertiary-butyl mercaptan $\left[\left(\mathrm{CH}_{3}\right)_{3} \mathrm{CSH}\right]$ is added to natural gas at the refinery to give a total sulfur concentration of between 4 and $5 \mathrm{ppm}$ (Ref. 30). Therefore, it is logical to assume that all of the sulfur contained in natural gas is in the form of $\left[\left(\mathrm{CH}_{3}\right)_{3} \mathrm{CSH}\right]$. The melting point of $\left[\left(\mathrm{CH}_{3}\right)_{3} \mathrm{CSH}\right]$ is $274 \mathrm{~K}$ (Ref. 28).

As will be discussed later, a scanning-electron-microprobe analysis of a typical natural gas deposit in a copjer tube showed sulfur present. The concentration of sulfur in the deposit, the degradation of the copper tube, and the increase in the rate of deposit formation with a decrease in tube wall temperature may be explained through the adsorption mechanism described earlier. A decrease in the rate of carbon deposition with an increase in wall temperature could be due to a decrease in the rate of adsorption of mercaptan on the tube wall. Also, at wall temperatures above $700 \mathrm{~K}$ and wall temperatures below $500 \mathrm{~K}$, dendrite formation was visibly less than that occurring between 500 and $700 \mathrm{~K}$. When the inside tube wall is below the melting point of the mercaptan, tube corrosion is reduced because in solid state, the mercaptan is unable to react with the copper wall. At very high wall temperatures a corrosive agent such as mercaptan cannot condeise onto the tube surface. Consequently, corrosion is reduced. 
Effect of Fuel Velocity on Carbon Deposition

In order to explore the effects of fuel velocity on carbon depoeition for na:ural gas, copper tube tests were performed at two additional fuel inlet vislocities $(65$ and $98 \mathrm{~m} / \mathrm{s})$ above the baseline value $(30 \mathrm{~m} / \mathrm{s})$. Nominal inlet pressure and temperature were $6.9 \mathrm{MPa}$ and $290 \mathrm{~K}$, respectively. A plot summarizing the rates of deposition and describing the effects of fuel velocity on carbon deposition is shown in Fig. 29. In the figure, carbon deposition rates corresponding to the three fuel velocities are shown for initial inner wall temperatures between 550 and $625 \mathrm{~K}$. Although there is scatter, the data indicate the rate of carbon deposition is nearly constant with fuel velocity. Based on these experiments, it is reasonable to conclude that there is no effect of fuel velocity on carbon deposition suggesting deposit formation may be limited by the kinetics of the deposition processes for natural gas.

\section{Effect of Intermittent Operation and Test Time on Carbon Deposition}

Similar to what was done for propane, a longer duration test was performed in which a nickel tube was heated intermittently for eight $3-m i n$ cycles to determine the effects of intermittent operation and test duration on carbon deposition. A sumary of the carbon deposition rates acquired for two test durations is shown in Fig. 30. Nominal fuel inlet pressure, velocity, and temperature of the natural gas were $13.8 \mathrm{MPa}, 30 \mathrm{~m} / \mathrm{s}$, and $290 \mathrm{~K}$, respectively. The data plotted correspond to initial inner wall temperatures between 550 and $620 \mathrm{~K}$. As the line drawn through the data points suggests, there appears to be no effect of intermittent operation or teat time on the carbon deposition rates for the range of conditions shown. Recall earlier for propane, there was a trend of decreasing carbon deposition rales with increasing teat time. However, since carbon deposition rates for natural gas are low (i.e., less than $100 \mu \mathrm{g} / \mathrm{cm}^{2}-\mathrm{hr}$ ) and because of dala scatler, differences associated with test time may not be discernible.

\section{Deposit Morphology}

\section{Deposit Appearance}

Longitudinal sections of copper test cubes were photographed at low magnification $(8 x)$ to document the macrostructure of deposits formed from RP- 1 , comercial-grade propane, and natural gas. These photographs are presented in Fig. 31. The sections correspond to a point on the tube approximately $1.9 \mathrm{~cm}$ downetream of the entrance (i.e., Section 2, Fig. 8). A section of a clean, unused copper tube is also shown in the figure and serves as a reference for comparison. The test conditions corresponding to asch tube section are listed in Table VIII for the indicated run number. 
A. shown in the photograph for the RP-1 bese fuel, there is a nonuniform coverage of the tube surface by a black deposit, and there is evidence of flaking of the deposit layer. These flakes of deposit were collected on a nylon-membrane filter downstream of the test section and subsequently examined under a low-power microscope. There was evidence in the deposit collected that copper had been stripped from the tube wall, presumably as a consequence of the flaking action. Because of the obvious difficulties associated with recovering or accurately weighing such small particles, no attempt was made to quantify the amount of deposit or copper collected on the filter. In addition, the tube surface appears to have been roughened by this flaking action.

The effect of doping RP-1 with metal deactivator (0.005\% by weight) is shown in Fig. 31. Although the tube is discolored, th amount of deposit on the tube is visibly less than that shown for the base fuel. As before, deposit flaking and erosion of the copper wall are evident. Recall that on average, carbon deposition rates obtained for this test were lower than those obtained for RP-1.

The deposits formed from RP-1 doped with sulfur additives $(0.05 \%$ sulfur by weight), shown in Fig. 31 are noticeably thicker in appearance than those obtained for the KP-l base fuel. In addition, a greater degree of flaking of deposit accompanied by roughening of the tube surface is apparent. Copper dendrites breaking through the deposit were evident on tube mids an and exit sections (i.e., Sections 6 and 10, not shown). The characterist of these dendrites will be discussed further in the next section.

The appearance of propane deposits on copper is significantly different from that of RP-1. As show in Fig. 31, the tube is covered with aniform layer of black deposit and at the same time, copper dendrites are visible. Examination of the entire tube showed the size and number of dendrites to increase from the tube entrance to exit (i.e., so wall cemperature increases). The dendrites could be easily removed by acraping, leaving a depression in the tube. The roughening of the tube surface associated with formation of denóites is a possible explanation for the significant drop in fuel pressure with axial location for heated-tube tests exhibiting dendrites. The natural gas deposite are imilar in appearance to thone obtained with propane; that is, the tube surface shown in Fig. 31 is covered with a nearly uniform layer of loose deposit and copper dendrites were visible on sections near the tube exit. However, the dendrites appeared smaller and were not as numerous as those seen for propane. Although a layer of black deposit is clearly visible on this tube, the burnoff tests indicated negligible carbon deposit levels across the tube. Low-magnification color photographs taken of deposits on nickel tubes were not helpful because of the difficulty in discriminating black deposits on the dark-colored nickel surface. 
Some additional coments relative to the appearance of deposits on tube surfaces are in order. Although sections of the nickel tute that was tested with RP-1 (Run 2) appeared clean under low-power magnification, high levels of carbon were detected by the burnoff analyses. In contrast to this, a black layer of carbonaceous deposit always formed with propane (ambient and chilled) in copper tubes for a: wall temperatures investigated. Thus, there was often no correlation between the appcarance of the deposit on the tube and the amount of carbon present (cf., Fig. 20). For propane (ambient and chilled) in nickel cubes at wall temperatures below $450 \mathrm{~K}$, the surface of the trbe always appeared clean (as though $i$. were unused); however, $X$-ray scans aliu the burnoff analyses delected significant levels of carbon. For wall lemperatures above $450 \mathrm{~K}$, the nickel surface was covered with a layer of black deposit, and this deposit contained a relatively high concentration of oxygen 'as deteiled by $X$-ray mappiis!.).

For natural gas in copper tubes, the tube surface was covered with a black deposit layer at wall temperatures between 230 and $700 \mathrm{~K}$. The color of this layer changed to gray at wall temperatures above $700 \mathrm{~K}$. In addition, carbon deposit vels were negligible at wall temperatures above $600 \mathrm{~K}$. For natural gas in sckel tubes, high levels of carbon deposit were found at wall temperatures below $700 \mathrm{~K}$ (Eube appeared clean); whereas carbon deposit levels above $700 \mathrm{~K}$ were negligible (tube had a layer of black deposit). The apparently non-carbonaceous deposits which form on nickel tubes at wall temperature above $700 \mathrm{~K}$ may be oxide layers produced from impurities (i.e., introduced in the electroless plating process).

Deposit Composition

Quantitative scanning-electron-microprobe analyses were done for representative deposits formed in copper tubes to determine the approximate relative elemental concentratione of carbon, copper, sulfur, oxygen, ald nitrogen present in the deposit. Copper was a major constituent for all deposit amples analyzed. In general, those deposits exhibiling aignificant copper dendrite formation (i.e., Runs 4 and 5) showed the highest levels of copper. Also, the concentrations of oxygen and nitrogen were aignificant in all casis, and taey generally exceeded those of carbon and sulfur. Presumably, the oxygen and nitrogen ill the deponit originated from trace concentrations present in the fuel.

Scanniag-electron-microscope photographs of deposit formed from RP-1 doped with sulfur were taken to document the degree of tube deterioration and to relate it to that reported for propane in Ref. 1. Photographa of different aspects of the deposit are shown in Fig. 32. Four typically different regions are shown and are labelled $A, B, C$, and $D$. In conjunction with the scanning- 
electron-microscope photographs, a scanning-electron microprobe incorporating an $X$-ray energy dispersive spectrometer was used to produce a qualitative scan of the elements having atomic numbers greater than 11. Carbon (atomic number 6) escapes detection by this technique. As expected, Region A which corresponds to the copper tube wall was found to contain only copper. Region $B$ which appears to be a layer of deposit immediateiy adjacent to the lube wall was rich in copper and sulfur and contained traces of silicon and aluminum. Region $C$, which is adjacent to Region $B$, was similar in composition to Region $B$. Because Regions $B$ and $C$ appear black, it is reasonable to assume they contain carbon; however, the concentrations of sulfur suggest compounds such as copper sulfide (e.g., $\mathrm{Su}_{2} \mathrm{~S}$ or CuS). Finally, Region $\mathrm{D}$ (i.e., dendrites) was found to contain only copper. As shown in Fig. 32a, these dendrites have broken through layers of deposit. Another view of a dendrite forming and piercing the layers of deposit is shown as Fig. 32b. This phenomenon is similar to that observed for propane. However, fewer dendrites formed in the $\mathrm{RP}-1$ and sulfur test in comparison to the number found after a typical propane test.

\section{Heat Transfer Correlation Analyses}

The forced-convection heat transfer data acquired in this program and in the previous phase (Ref. 1) were correlated using the expression defintd earlier in Eq. (4), and best-fit empirical relations were determined for clean tubes. Nusselt number was correlated as a function of Reynolds number, Prandt 1 number, and fuel properties and expressions were developed for each of the test fuels (RP-1, chemically-pure propane, commercial-grade propane, and natural gas) within the range of experimental conditions. In addition, the forced-convection data from several of these fuels were commingled, and a gercralized expression was developed for liquid hydrocarbons. The results of the heat transfer correlation analyses are summarized in Table XII.

As shown in Table XII, an attempt was made to simplify the correlating equations by eliminating some of the fuel properties terms. For RP-1 and propane (chemically pure and commercial grades), the simple Dittus-Boelter form of the equation was found to be satisfactory for correlating the data; that is, there was no significant reduction in the correlation coefficient when the fuel properties ratios were deleted. Therefore, the major effects on the heat transfer coefficient are accounted for by the Reynolds and Prandt 1 number terms, and this dependence is illustrated graphically in Fig. 33. Because of the wide variations in the thermophysical properties of natural gas over the test temperature range, which extended well below and well above the critical temperature $(191 \mathrm{~K})$, it was not possible to obtain a satisfactory correlation without retaining the fuel properties terms. This is illustrated 
in Table XII by the failure to obtain a suitably accurate Dittus-Boelter type correlation of the natural gas data. However, as shown in the table, it is possible to simplify the overall natural gas correlation by eliminating the term $\left(P / P_{C r i t}\right)^{h}$ using a statistical significance test (Student's $t$ ) that is included as part of the regression analyais computer program.

A correlating expression for each fuel was selected from Table XII and used to calculate a value of Nusselt number at each data point. The calculated Nusselt numbers are compared to the experimentally-derived values in Figs. 34 to 37 , with the imposed bandwidth of \pm 30 percent illustrating the extent of the departure. For each fuel, the valid ranges of Reynolds and Prandt l numbers for which the correlation was developed are shown. As shown in these figures, the agreement between the experimentally-derived and calculated Nusselt numbers is satisfactory; that is, the bandwidth of \pm 30 percent encloses 94 percent of the data for RP-1, 97 percent for chemicallypure propane, 78 percent for commercia!-grade propane, and 97 percent for natural gas. The commingled correlation for RP-1 and propane, shown in Fig. 38, encloses 82 percent of the data within a bandwidth of \pm 30 percent. In addition, there is very good agreement between the correlation for RP-1 plotted in Fig. 34 and a RP-1 expression generated at Rocketdyne (Ref. 31).

\section{Hydrostatic Burst Tests}

The extent of corrosion damage incurred by a test tube owing to the carbon deposition process is of interest. Considerable surface degradation resulted from heated copper-tube tests conducted with RP-1 fuel having a high sulfur content and with commercial-grade propane. This surface degradation manifested itself in the form of fibrous dendritic or tree-like structures which appeared to grow out of the copper surface. In order to assess whether the mechanical strength of the copper tube was significantly reduced as a consequence of this phenomenon, hydrostatic burst tests were conducted on two $3.81-\mathrm{cm}-10 \mathrm{ng}$ tube specimens. A specimen from a clean copper tube, not subjected to test conditions, served as a control. The test specimen was evaluated after burnoff analysis and corresponded to a typical propane test (Run 5, Section 7). Copper dendrite structures were clearly visible along the entire length of the longitudinal sections upstream and downstream of the test specimen.

For each specimen, the outer Inconel sheath was removed from the inner copper tube using a specially developed technique to ensure that the copper tube would not be damaged during the removal process. The procedure involved machining the diameter of the outer Inconel tube on a lathe and threading the 
specimen through a die to engrave apiral pattern in the sheath. Using a pair of needle-nosed pliers, the Inconel sheath, now sufficiently weakened by the turning and threading operations, was easily stripped away from the copper core tube.

The theoretical burst pressure at room temperature for the thick-wall copper tubes used in this investigation was estimated to be of $115 \mathrm{MPa}$. Because a pressure source of only $69 \mathrm{MPa}$ was available, the tests were conducted at elevated temperature to reduce the ultimate tensile strength of the copper and consequently the burst pressure. Therefore, each tube was heated in an oven and pressurized with oil supplied from a positive-displacement pump. Results of these experiments which were conducted at $820 \mathrm{~K}$ showed the control tube and the tube subjected to the deposit test to burst at 36.0 MPa and 33.2 MPa, respectively. The theoretical burst pressure of the control tube was approximately $40 \mathrm{MPa}$. Based on the accuracy of the instrumentation used and the anticipated variation in tube samples, it was concluded that no significant reduction in mechanical strength resulted from the corrosive effects observed in the heated-tube deposit test. 


\section{CONCLUDING REMARKS}

Thermal stability and deposit heat transfer characteristics were investigated for RP-1, commercial-grade propane, and natural gas in heated copper and nickel-plated copper tubes. In addition, the effects of fuel additives and contaminants, cryogenic fuel temperatures, and extended duration testing with intermittent operation were examined. The continuous flow test apparatus used in the experiments permitted independent variation and evaluation of the effects of wall temperature, fuel pressure, and fuel velocity on deposit formation.

Corrosion of the copper tube surface was detected for all fuels tested, possibly due to reactions with the trace sulfur impurities present in the fuel. Plating the inside of the copper tubes with nickel reduced deposit formation and eliminated tube corrosion in most cases. However, cracking of the nickel plating did occur when subjected to cryogenic natural gas at $160 \mathrm{~K}$. For natural gas in copper tubes, operation above wall temperatures of $700 \mathrm{k}$ produced a significant reduction in deposit formation on ansolute basis and a complete elimination of tube corrosion.

Doping RP-1 fuel with a commercially-produced metal deactivator resulted in a significant reduction in the levels of deposit formed. However contaminating the RP-1 fuel with organic sulfur compounds in order to increase its sulfur concentration to the specification maximum resulted in significantly greater deposit formation and tube corrosion.

For short test durations ( $<30 \mathrm{~min}$ ), the rates of deposit formation were found to decrease as test :ime increased.

Chilling the propane fuel prior to entry into the heated tube significantly reduced deposit formation rates. However, cryogenic cooling of natural gas (97 percent methane) did not significantiy reduce deposit formation.

The effect of fuel velocity on deposit formation was varied. For RP-1 and propane in copper tubes at wall temperatures below $650 \mathrm{~K}$, increases in fuel velocity resulted in decreases in the rate of carbon deposition. However, counter trends were observed for RP- 1 in copper tubes at wall temperatures above $650 \mathrm{~K}$ and $\mathrm{RP}-1$ in nickel tubes. No effect of fuel velocity on the rates of carbon deposition was detectef for natural gas.

For all fuels investigated, tormation of deposit did not always coincide with a rise in wall temperature. Total deposit thermal resistances ranged from 0.001 to $1.0 \mathrm{k}-\mathrm{cm}^{2} / \mathrm{W}$. For $R P-1$, peak thermal resistance buildup rates were found to decrease rapidly as fuel velocity increased. 
For RP-1, propane, and natural gas, multiple linear regression correlation analyses were performed to correlate experimentally-measured fuelside heat transfer film coefficients with Nusselt-Reynolds-Prandt 1 number expressions for Nusselt numbers between 100 and 10,000. The agreement between the experimentally-derived and calculated Nusselt number was good and, in most cases, better than 90 percent of all data fell within a bandwidth of \pm 30 percent.

A plot summarizing the variation of the rates of carbon deposition in copper and nickel tubes for RP-1, commercial-grade propane, and natural gas as a function of wall temperature is shown in Fig. 39. In most cases, the three fuels are compared at a common test condition corresponding to a fuel inlet pressure, temperature, and velocity of $13.8 \mathrm{MPa}, 290 \mathrm{~K}$, and $30 \mathrm{~m} / \mathrm{s}$, respectively. The data for RP-1 in nickel tubes were obtained at velocities of 6 and $18 \mathrm{~m} / \mathrm{s}$. Carbon deposition rates for propane in copper tubes were highest and ranged from 300 to $580 \mu \mathrm{g} / \mathrm{cm}^{2}-\mathrm{hr}$ at wall temperatures between 400 and 580 $K$. The lowest $r$ t.r 28 of carbon deposition were obtained for natural gas in copper tubes, anc they did not exceed $80 \mu \mathrm{g} / \mathrm{cm}^{2}-\mathrm{hr}$ at wall temperatures between 500 and $650 \mathrm{~K}$. Carbon deposition rates of 200 to $320 \mu \mathrm{g} / \mathrm{cm}^{2}-\mathrm{hr}$ wtre typical for RP-1 in copper tubes at wall temperatures between 560 and $750 \mathrm{~K}$. For natural gas, the unexpected trend of increasing carbon deposition rates (approaching those of $\mathrm{RP}-1$ ) with decreasing wall temperature was explained as being possibly due to wall adsorption of mercaptans present in the fuel in trace concentrations. It is postulated that at higher fuel temperatures, this mechanism did not exist.

Based on the results of this program, the following conclusions can be made:

1. Natural gas is an attractive rocket fuel with regard to thermal stability.

2. Metallic coatings on the insides of the copper cooling tubes are an effective way to reduce deposit formation and tube corrosion.

3. Cryogenic cooling of the fuel may be a means to remove some of the impurities which are detrimental to thermal stability.

This key benefit derived from this program is the quantitative assessment of the carbon deposition and the associated thermal resistance rate as a function of wall temperature for several fuels. Measureable deposits occur for all the candidate hydrocarbon fuels over the temperature range tested and the data generated serve as basis for the specification of cooling system design criteria. 


\section{REFERENCES}

1. Roback, R., E. J. Szetela, and L. J. Spadaccini: Deposit Formation in Hydrocarbon Rocket Fuels. NASA CR-165405, August 1981. Also Journal of Engineering for Power, Trans. ASME, Vol. 105, pp. 59-65, January 1983.

2. Szetela, E. J.: Deposits from Heated Gas Turbine Fuels. ASME Paper No. 76-GT-9, 1976.

3. ANON: CRC Literature Survey on the Thermal Oxidation Stability of Jet Fuel. CRC Report No. 590, Coordinating Research Council, Inc., At lanta, GA. April 1979.

4. Taylor, W. F.: Deposit Formation from Deoxygenated Hydrocarbons, Part I - General Features. Ind. and Eng. Chem., Prod. Res. and Devel., Vol. 13, No. 2, pp. 133-138, 1974.

5. Szetela, E. J., and A. Vranos: Deposits from Heated Fuel-An Information Study. United Technologies Research Laboratories Report R75-214388-1, December 1975.

6. Taylor, W. F.: Kinetics of Deposit Formation from Hydrocarbons. Ind. and Eng. Chem., Prod. Res. and Devel., Vol. B, No. 375, 1969.

7. Taylor, W. F. and T. J. Wallace: Kinetics of Deposit Formation from Hydrocarbons - Effects of Trace Sulfur Compounds. Ind. and Eng. Chem., Prod. Res. and Devel., Vol. 7, No. 198, 1968.

8. Taylor, W. F.: Mechanisms of Deposit Formation in Wing Tanks. SAE Transactions, Vol. 76 , No. $2811,1968$.

9. Lohmann, R. P., E. J. Szetela, and A. Vranos: Analytical Evaluation of the Impact of Broad Specification Fuels on High Bypass Turbofan Engine Combustors. NASA CR-159454, December 1978.

10. Antoine, A.: Effect of Some Nitrogen Compounds on Thermal Stability of Jet A. NASA TM-82903, June 1982.

11. Wong, E. L. and D. A. Bittker: Effect of Hydrocarbon Fuel Type on Fuel Thermal Stability. NASA TM-82916, June 1982.

12. Meehan, R., W. Carson, and R. Morgan: Determine the Effects of Various Metals on the Thermal Stability of Jet Fuel. Pratt \& Whitney Aircraft Materials Development Laboratory Work Request, No. 13230, July 1968. 
REFERENCES (Cont'd)

13. Baker, R. T. K. and P. S. Harris: The Formation of Filamentous Carbon. Chemistry and Physics of Carbon, Vol, 14. P. L. Walker and P. A. Thrower Ed. Marcel Dekker, Inc., New York 1978.

14. McIntosh, L. V.: Fuels Test Report for RP-1 (MIL-P-25576), No. 81-P-48, Aerospace Fuels Laboratory, Mukiteo, WA. December 17, 1981.

15. Winfrey, J. C.: Certificate of Analysis No. 104727, Sample of Liquid Propane, Southern Petroleum Laboratories, Inc., Houston, TX. February 25, 1983.

16. Winfrey, J. C.: Certificate of Analysis No. 105674, Sample of Natural Gas, Southern Petroleum Laboratories, Inc., Houston, TX. March 30, 1983.

17. ANON: Technical Data Book - Petroleum Refining Chapters 7-14, Second Edition. American Petroleum Institute, Division of Refining, Port City Press, Inc., Baltimore, MD. 1971.

18. Goodwin, R. D. and W. M. Haynes: Thermophysical Properties of Propane from 85 to $700 \mathrm{~K}$ at Pressures to $70 \mathrm{MPa}$. Thermophysical Properties Division, National Bureau of Standards, Boulder, CD. NBS Monograph 170.

19. Hendriks, R. C. and A. K. Baron: GASP - A Computer Code for Calculating the Thermodynamic and Transport Properties for Ten Fluids: Parahydrogen, Helium, Neon, Methane, Nitrogen, Carbon Monoxide, Oxygen, Fluorine, Argon, and Carbon Dioxide. NASA TN D-7808, February 1975.

20. TeVelde, J., L. J. Spadaccini, E. J. Szetela, and M. R. Glickstein: Thermal Stability of Alternative Aircraft Fuels, AIAA Paper No. 83-143, June 1983.

21. ANON: DuPont Metal Deactivator. Product Brochure A-7984, Petroleum Chemicals Division, E.I. DuPont de Nemours \& Co., Inc., Wilmington, DE.

22. Strigler, Bert. (Technical Services Manager, Conoco): private communication to the author.

23. Winfrey, J. C.: Certificate of Analysis No. 103758, Sample of RP-1 Kerosene Fuel, Souchern Petroleum Laboratories, Inc., Houston, TX. February 4, 1983. 


\section{REFERENCES (Cont'd)}

24. Peschke, W.: Advanced Ejector Thrust Augmentation Study - Mass Entrainment of Axisymetric and Rectangular Free Jets. Bell Aerospace, Technical Report AFFDL-TR-73-55, April 1973.

25. Bloom, K.: Autodata Ten/10 Calculating Datalogger Operation and Installation Manual, Acurex Corporation, Mountain View, CA. April 1980.

26. Masters, P. A. and C. A. Aukerman: Deposit Formation in Hydrocarbon Rocket Fuels with an Evaluation of a Propane Heat Transfer Correlation. NASA TM-82911, June 1982.

27. Gabe1, Robert (Sales Representative, Matheson): private communication to the author.

28. Handbook of Chemistry and Physics, 63rd Edicion, 1982-83, CRC Press, Inc., Boca Raton, FL, 1982.

29. Nishiyama, Y. and Y. Tamai: Wall Effects During Thermal Reactions. Chemtech Journal, November 1980.

30. Braker, W. and A. L. Mossman: Matheson Gas Data Book, Sixth Edition, Matheson, Lyndhurst, NJ, 1980.

31. Hines, W. S.: Turbulent Forced Convection Heat Transfer to Liquids at Very High Heat Fluxes and Flowrates. Rocketdyne Research Report 61-41, 1961 . 
A

$\mathrm{C}_{\mathrm{p}}$

D

E

EB

f

h

I

k

L

in

Nu

$\mathbf{p}$

Pr

Q/A

$\mathbf{R}$

$\mathbf{R}_{\mathrm{c}}$

$\operatorname{Re}_{D}$

$\mathbf{T}$

$t$

$\Delta \mathrm{t}$ experimentally-determined constant

specific heat at constant pressure

inside tube diameter

electrical power

energy balance

friction factor

specific enthalpy

current

thermal conductivity

tube length

maso flow rate

Nusselt number, $U_{0} D / k$

pressure

Prandt 1 number, $C_{p} \mu / k$

heat flux

correlation coefficient

thermal resistance buildup rate

Reynolds number based on tube diameter, $\rho v D / \mu$

temperature

thickness

elapsed time 


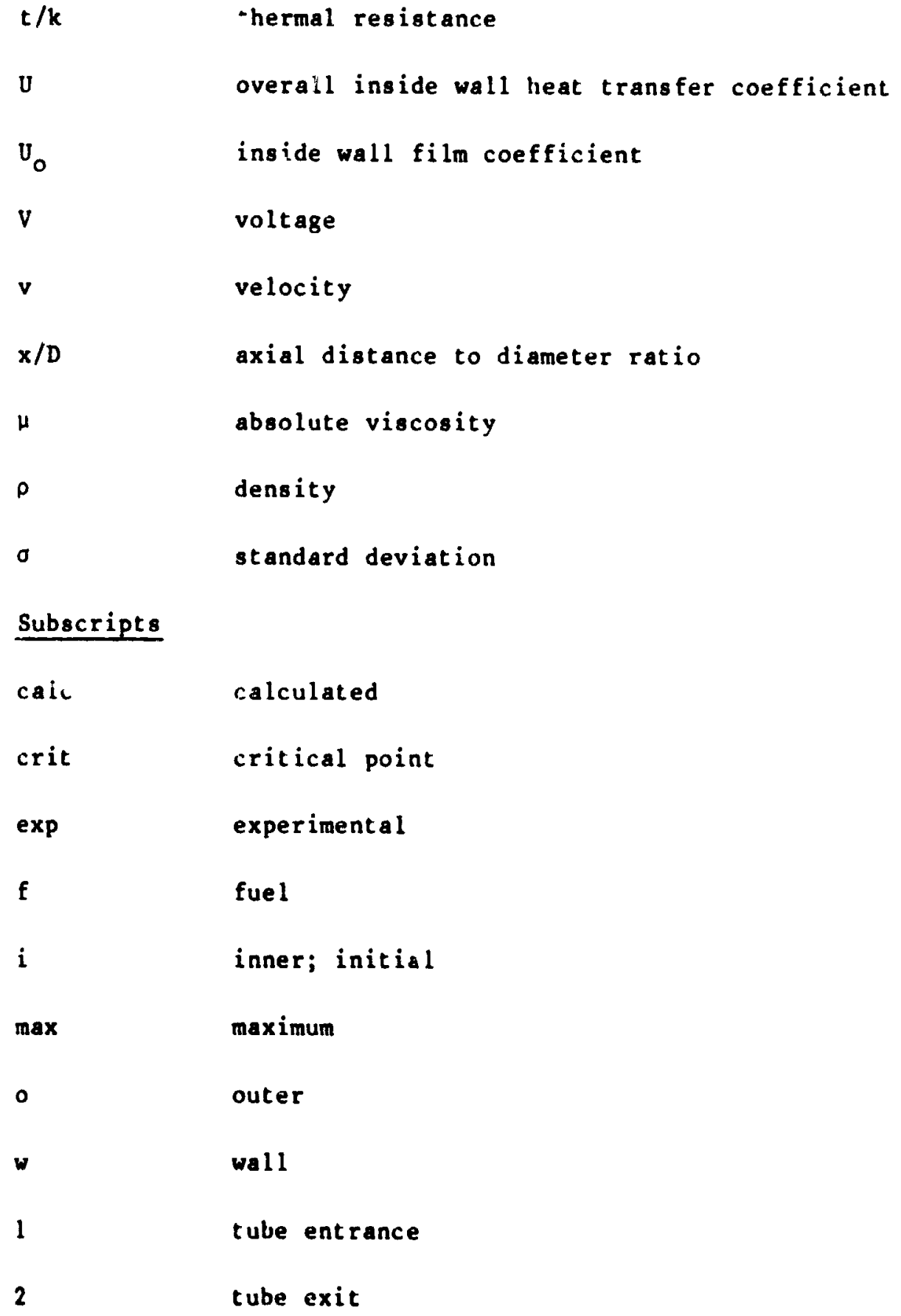

$t / k$

U

$v_{0}$

v

$\mathbf{v}$

$x / D$

$\mu$

$\rho$

o

Subscripts

caic

crit

$\exp$

f

i

$\max$

$\circ$

w

1

2 


\section{TABLE I}

CERTIFIED CHEMICAL ANALYSIS OF RP-1 SPECIFICATION FUEL

Distillation (K)

Initial boiling point $\quad 461$

$10 \%$ evaporated 471

$50 \%$ evaporated $\quad 487$

907 evaporated $\quad 512$

Final boiling point 532

Residue, vol\% 1.3

Loss, volz 0.7

Gravity, "API $\quad 43.6$

Existent Gum, mg/100ml $\quad 2.0$

Total sulfur, wt\% 0.007

Mercaptan sulfur, wt\% $\quad 0.0002$

Aromatics, volz 1.26

Olefins, vol\% 0.3 
TABLE II

CERTIPIED CHEMIOAL ANALYSIS OP COMGRCIAL-GRAD PROPANE
Propane, mol\%
94.00
Ethane, mol\%
Iso-Butane, mol\%
4.27
Propylene, mol\%
0.78
n-Butane, molz
0.61
Methane, mo1\%
0.26
Nitrogen, mol\%
0.07
Sul fur, ppro
0.01
Organic Chloride, ppm
25
Ethylene, mol\% in ethane
$<1$
0.01 
TABLE III

CERTIFIED CHEMICAL ANALYSIS OF MATURAL GAS

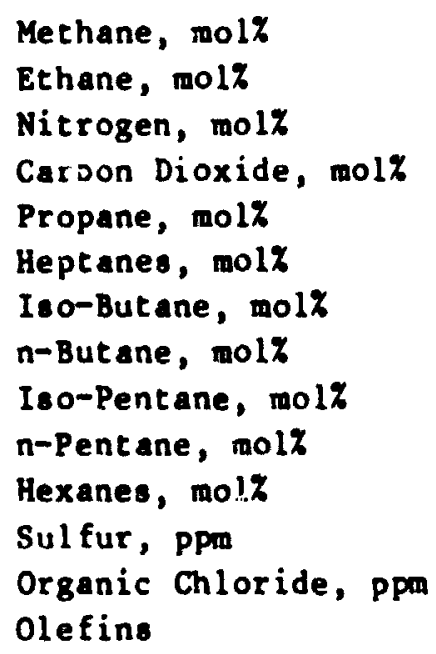

96.508

1.542

0.826

0.571

0.254

0.096

0.063

0.062

0.028

0.025

0.025

4

$<1$

No' Detected 
TABLE IV

THERMODYNAMIC AND TRANSPORT PRDPERTIES OF RP-1

\begin{tabular}{|c|c|c|c|c|}
\hline $\mathbf{T}$ & $C_{p}$ & $\rho$ & $\mu$ & $k$ \\
\hline (K) & $\left(k J / k_{g} \cdot k\right)$ & $\left(\mathrm{kg} / \mathrm{m}^{3}\right)$ & $\begin{array}{c}\left(\mathrm{kg} / \mathrm{m}^{\circ} \mathrm{s}\right) \\
\times 10^{4}\end{array}$ & $(W / m \cdot K)$ \\
\hline 256 & 1.64 & $84^{\circ} ;$ & 51.85 & 0.133 \\
\hline 283 & 1.77 & 824 & 24.51 & 0.126 \\
\hline 300 & 2.00 & 801 & 15.63 & 0.0885 \\
\hline 325 & 2.10 & 782 & 10.87 & 0.0911 \\
\hline 350 & 2.20 & 763 & 7.52 & 0.0942 \\
\hline 375 & 2.36 & 744 & 5.42 & 0.0967 \\
\hline 400 & 2.41 & 724 & 4.26 & 0.0974 \\
\hline 425 & 2.52 & 704 & 2.51 & 0.0982 \\
\hline 450 & 2.63 & 682 & 2.98 & 0.0971 \\
\hline 475 & 2.73 & 660 & 2.56 & 0.0958 \\
\hline 500 & 2.84 & 637 & 2.23 & 0.0942 \\
\hline 525 & 2.95 & 612 & 1.90 & 0.0922 \\
\hline 550 & 3.06 & 583 & 1.74 & 0.0898 \\
\hline 575 & $3.1^{7}$ & 552 & 1.54 & 0.0871 \\
\hline 600 & 3.28 & is & 1.36 & 0.0837 \\
\hline 625 & 3.40 & 472 & 1.21 & 0.0798 \\
\hline 650 & 3.50 & 405 & 1.04 & 0.0730 \\
\hline
\end{tabular}

$P_{\text {crit }}=2.20 \mathrm{MPa}$

$T_{\text {crit }}=666 \mathrm{~K}$ 


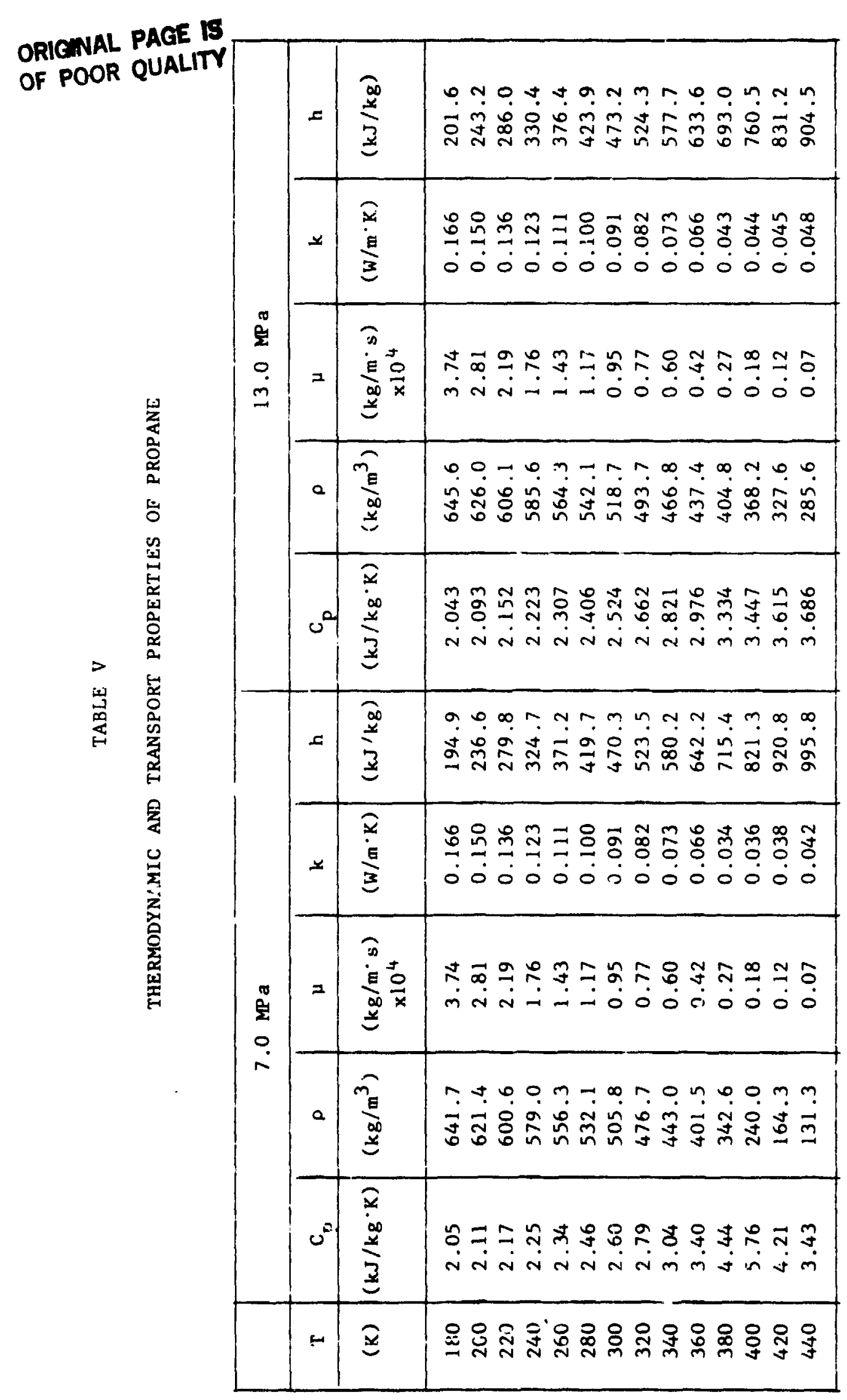

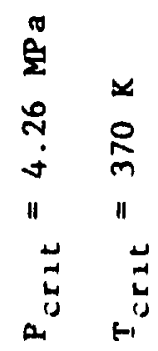




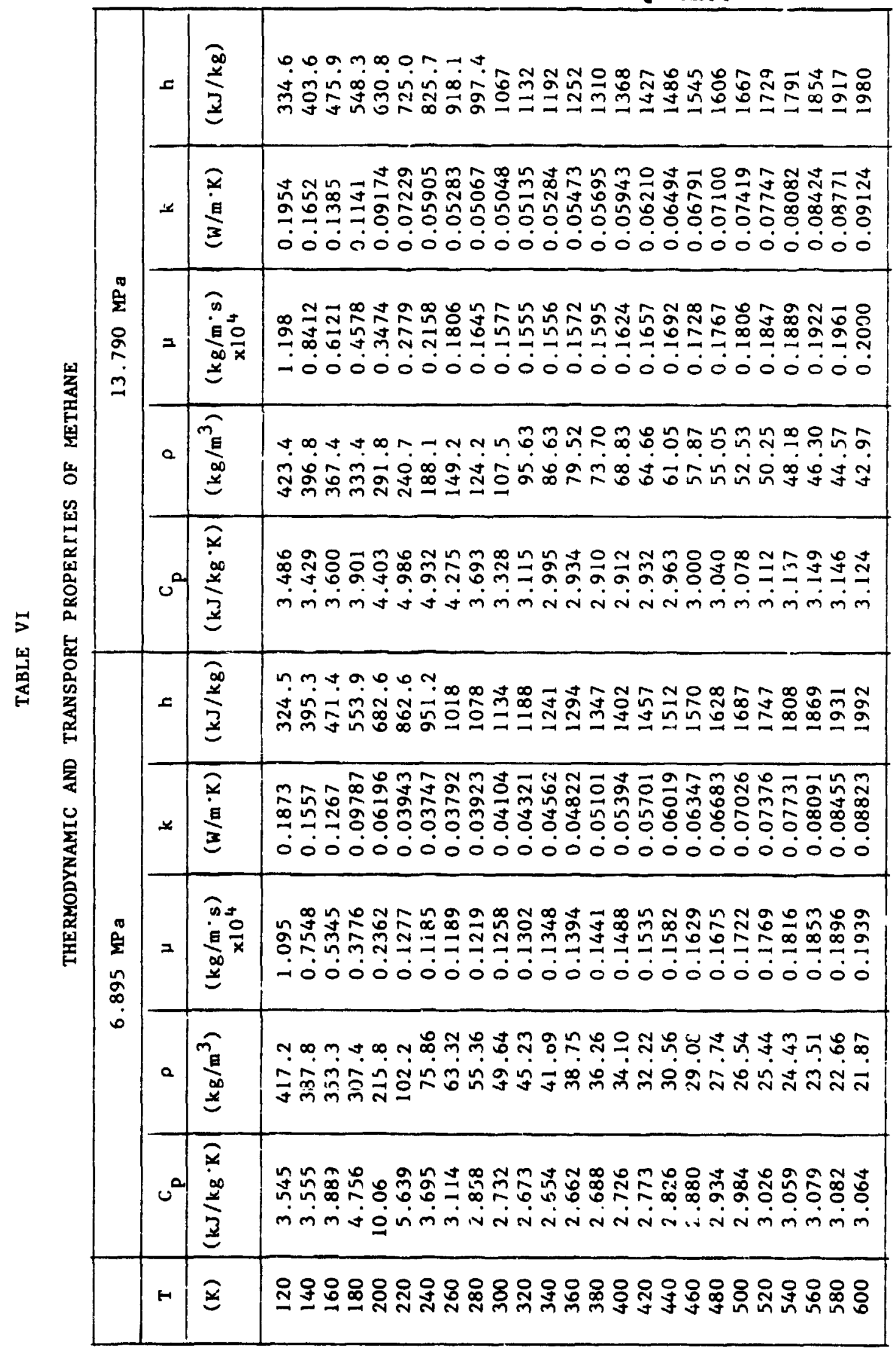


TABLE VII

CERTIFIED CHEMICAL ANALYSIS OF SULFUR-DOPED RP-1

\author{
Carbon, wt\% \\ Hydrogen, wt\% \\ Oxygen, wt\% \\ Sulfur, wt\% \\ Nitrogen, wt\% \\ Naptha and Paraffins, vol\% \\ Aromatics, vol\%
}

86.34

13.26

$<0.5$

0.050

0.043

$>99.0$

1.20 
TABLE VIII

SUMMARY OF TEST CONDITIONS

\begin{tabular}{|c|c|c|c|c|c|c|c|}
\hline Run & Fue1 & $\begin{array}{l}\text { Tube }(!) \\
\text { Mat'1 }\end{array}$ & $\begin{array}{c}\text { Duration } \\
\text { (min) }\end{array}$ & $\begin{array}{l}\text { Fue }{ }^{(2)} \\
\text { Inlet } \\
\text { Temp. } \\
(\mathrm{K}) \\
\end{array}$ & $\begin{array}{l}\text { Fuel }{ }^{(2)} \\
\text { Inlet } \\
\text { Velocity } \\
(\mathrm{m} / \mathrm{s}) \\
\end{array}$ & $\begin{array}{l}\text { Fuel }{ }^{(2)} \\
\text { Inlet } \\
\text { Pressure } \\
\text { (MPa) } \\
\end{array}$ & $\begin{array}{l}\text { Max. Init. } \\
\text { Inner Wall } \\
\text { Temp. (K) }\end{array}$ \\
\hline 1 & $\overline{R P-1}$ & $\mathrm{Cu}$ & 10.1 & 279 & 58 & 13.7 & 682 \\
\hline 2 & $t$ & $\mathrm{Ni}$ & 10.4 & 289 & 30 & 13.2 & 701 \\
\hline 3 & $\mathrm{RP}-1 \& \mathrm{DMD}^{(3)}$ & $\mathrm{Cu}$ & 10.2 & 291 & 30 & 13.6 & 693 \\
\hline 4 & $R P-1 \& s^{(4)}$ & $\mathrm{Cu}$ & 9.9 & 287 & 29 & 13.2 & 821 \\
\hline 5 & Propane & $\mathrm{Cu}$ & 10.0 & 284 & 49 & 13.2 & 629 \\
\hline 6 & 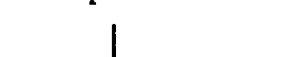 & $\mathrm{Ni}$ & 9.0 & 281 & 34 & 13.9 & 589 \\
\hline ; & & $\mathrm{Ni}$ & 10.5 & 287 & 30 & 7.44 & 691 \\
\hline 8 & & $\mathrm{Ni}$ & $24.0^{(5)}$ & 289 & 32 & 13.6 & 590 \\
\hline 9 & & $\mathrm{Ni}$ & 10.0 & 234 & 32 & 14.5 & 670 \\
\hline 10 & & $\mathbf{N i}$ & 10.2 & 231 & 31 & 7.22 & 694 \\
\hline 11 & & $\mathrm{Cu}$ & 9.6 & 236 & 30 & 7.16 & 683 \\
\hline 12 & 1 & $\mathrm{Cu}$ & 10.1 & 229 & 30 & 7.40 & 785 \\
\hline 13 & Nat. Gas & $\mathrm{Ni}$ & 10.3 & 292 & 31 & 13.2 & 596 \\
\hline 14 & & $\mathrm{Ni}$ & 10.2 & 292 & 32 & 13.6 & 692 \\
\hline 15 & & $\mathrm{Cu}$ & 10.4 & 291 & 31 & 13.1 & 753 \\
\hline 16 & & $\mathrm{Cu}$ & 9.8 & 289 & 31 & 13.0 & 813 \\
\hline 17 & & $\mathrm{Cu}$ & 10.3 & 292 & 65 & 7.30 & 700 \\
\hline 18 & & $\mathrm{Cu}$ & 10.3 & 291 & 98 & 7.48 & 723 \\
\hline 19 & & $\mathrm{Ni}$ & 10.3 & 296 & 32 & 14.2 & 804 \\
\hline 20 & & $\mathrm{Ni}$ & $24.5^{(5)}$ & 293 & 32 & 14.3 & 698 \\
\hline 21 & & $\mathrm{Ni}$ & 10.0 & 168 & 34 & 13.3 & 694 \\
\hline 22 & & $\mathrm{Ni}$ & 8.2 & 173 & 35 & 13.0 & 843 \\
\hline 23 & & $\mathrm{Cu}$ & 10.0 & 156 & 32 & 13.4 & 683 \\
\hline 24 & 1 & $\mathrm{Cu}$ & 10.0 & 157 & 33 & 13.7 & 862 \\
\hline $\begin{array}{c}\text { Calib. } \\
220\end{array}$ & $\begin{array}{l}\text { RP-1 } \\
\text { Nat, Gas }\end{array}$ & $\begin{array}{l}\mathrm{Cu} \\
\mathrm{Ni}\end{array}$ & $\frac{-}{10.4}$ & $\begin{array}{c}\text { varied } \\
133\end{array}$ & $\begin{array}{c}\text { varied } \\
29\end{array}$ & $\begin{array}{l}13.8 \\
14.2\end{array}$ & $\begin{array}{c}\text { varied } \\
793\end{array}$ \\
\hline $\begin{array}{l}\text { (1) } \mathrm{Cu} \\
\text { (2) At } \\
\text { (3) RP. } \\
\text { (4) RP. } \\
\text { (5) Int }\end{array}$ & $\begin{array}{l}\text { = Copper; } \mathrm{Ni} \\
\text { midpoint of ru } \\
-1 \text { and DuPont } \\
-1 \text { and sul ir } \\
\text { termittent oper }\end{array}$ & $\begin{array}{l}\text { - Nickel- } \\
\text { un } \\
\text { Metal De: } \\
\text { additive } \\
\text { ration }\end{array}$ & $\begin{array}{l}\text {-plated cop } \\
\text { activator } \\
\text { s }\end{array}$ & & & & \\
\hline
\end{tabular}




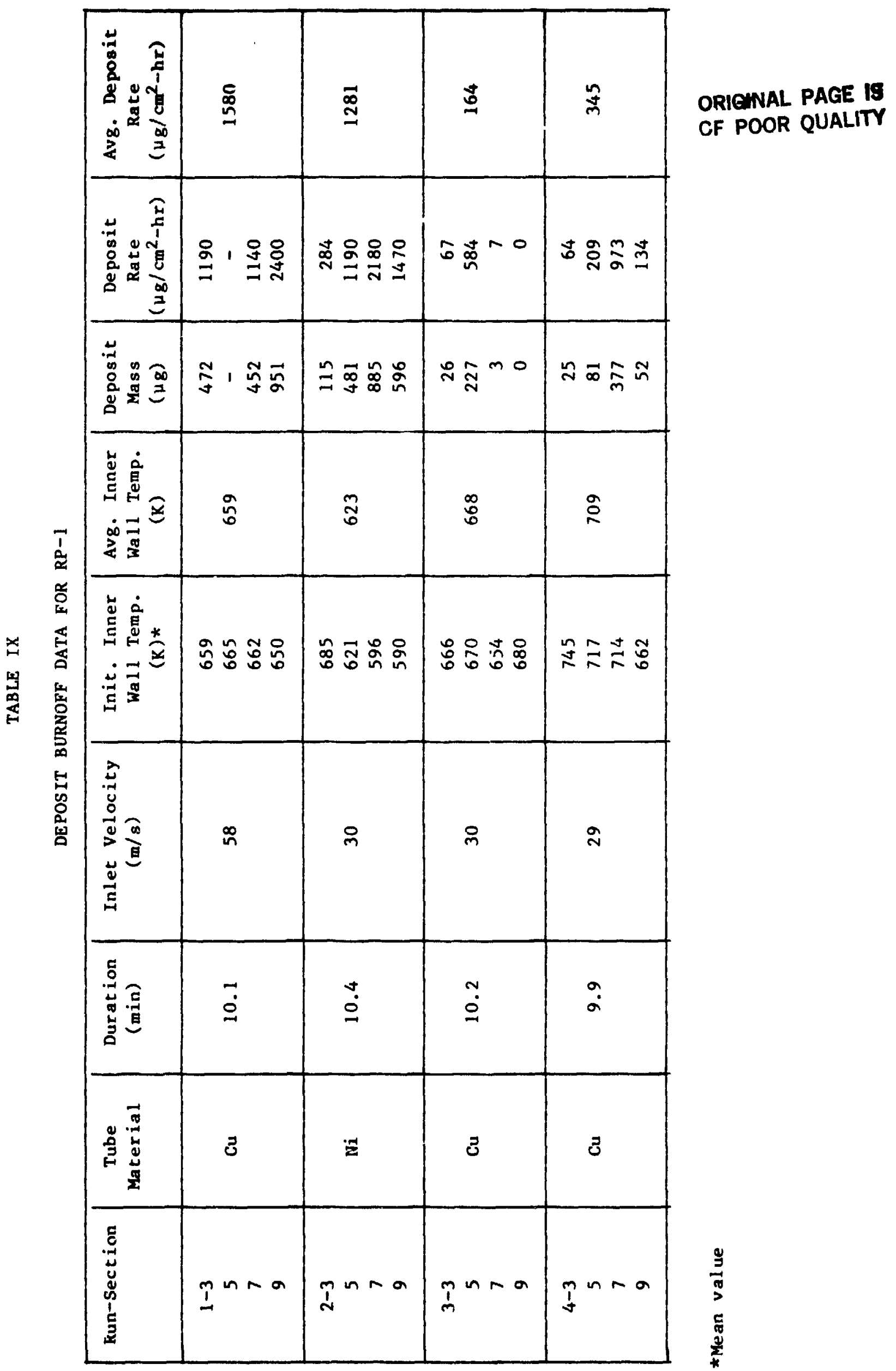




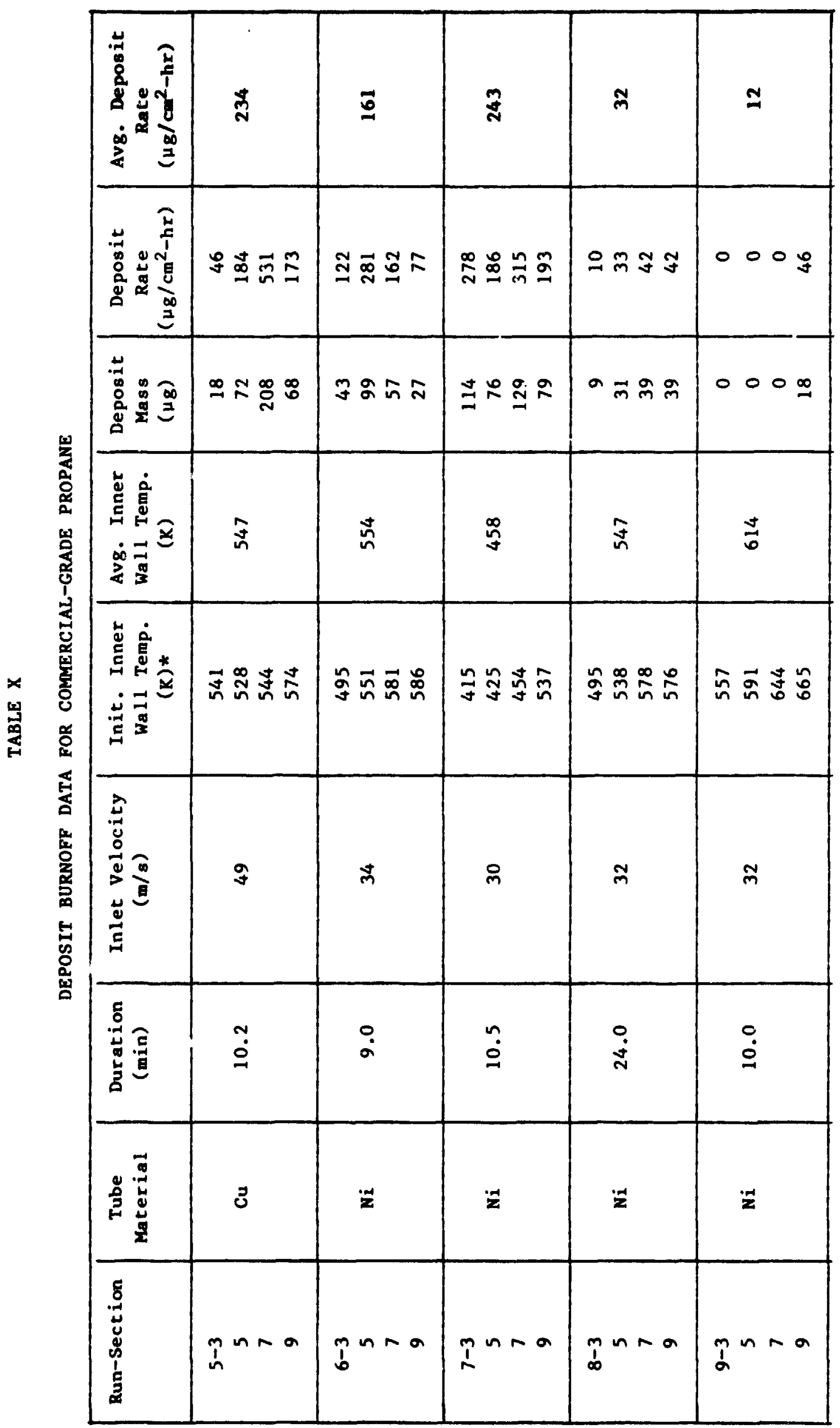




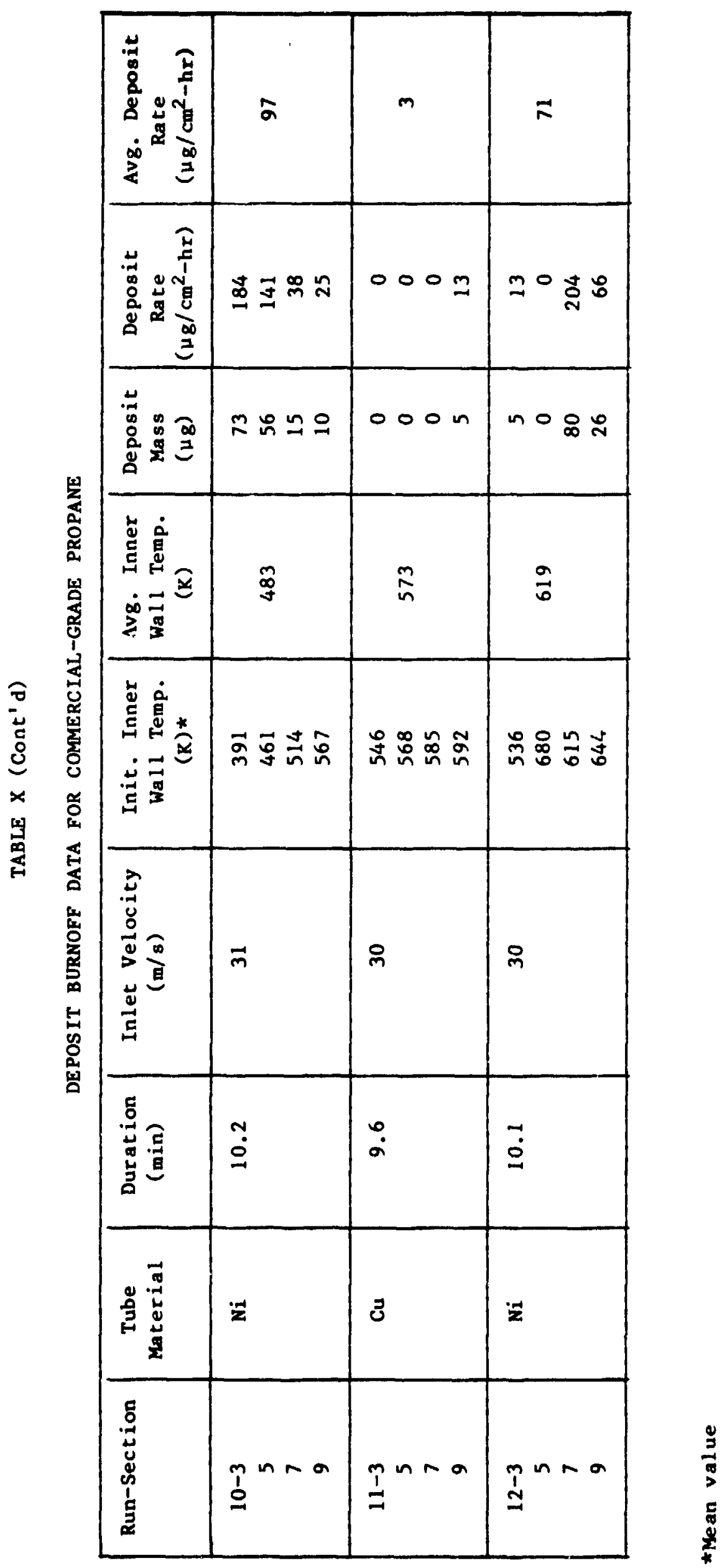




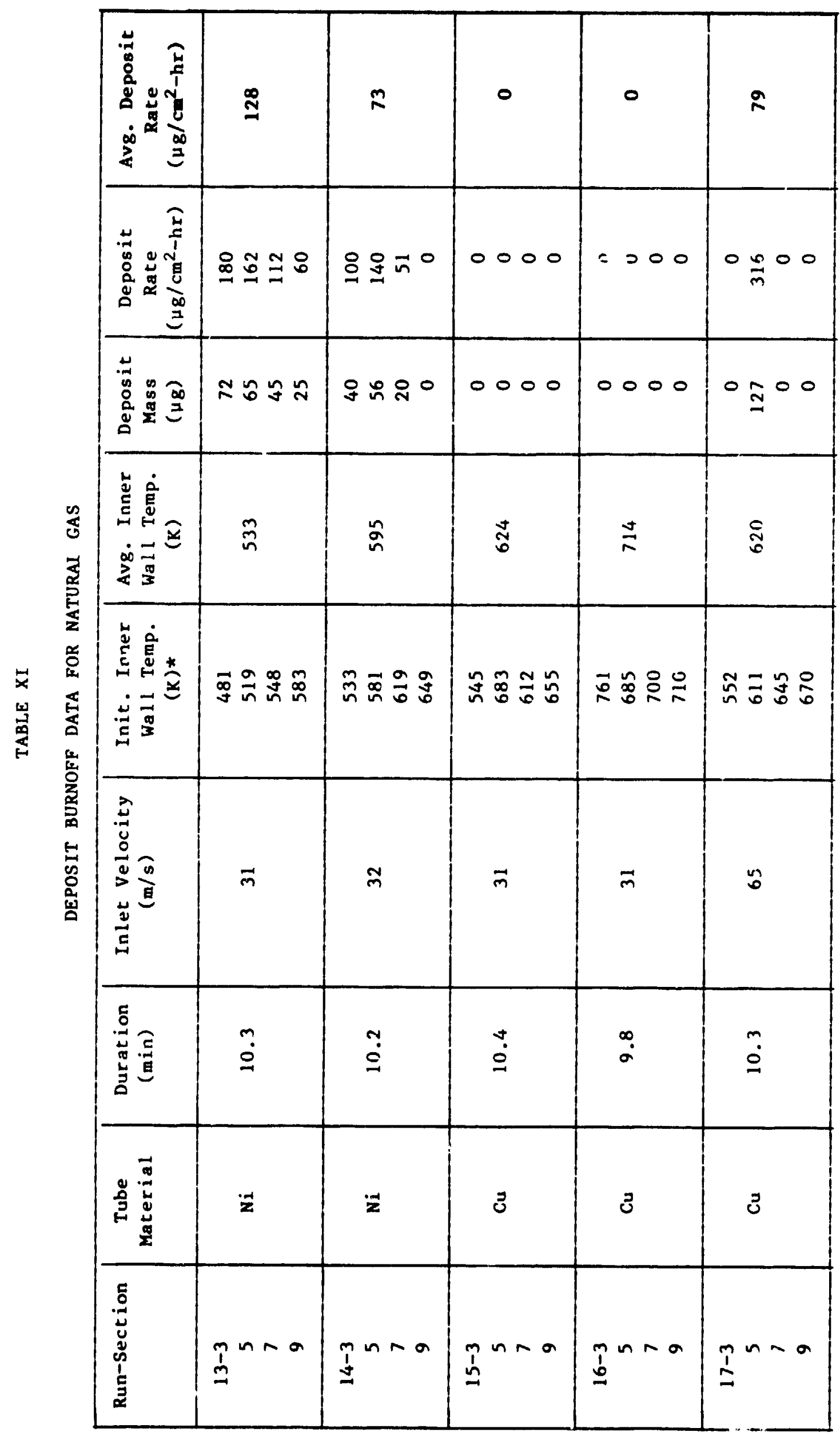




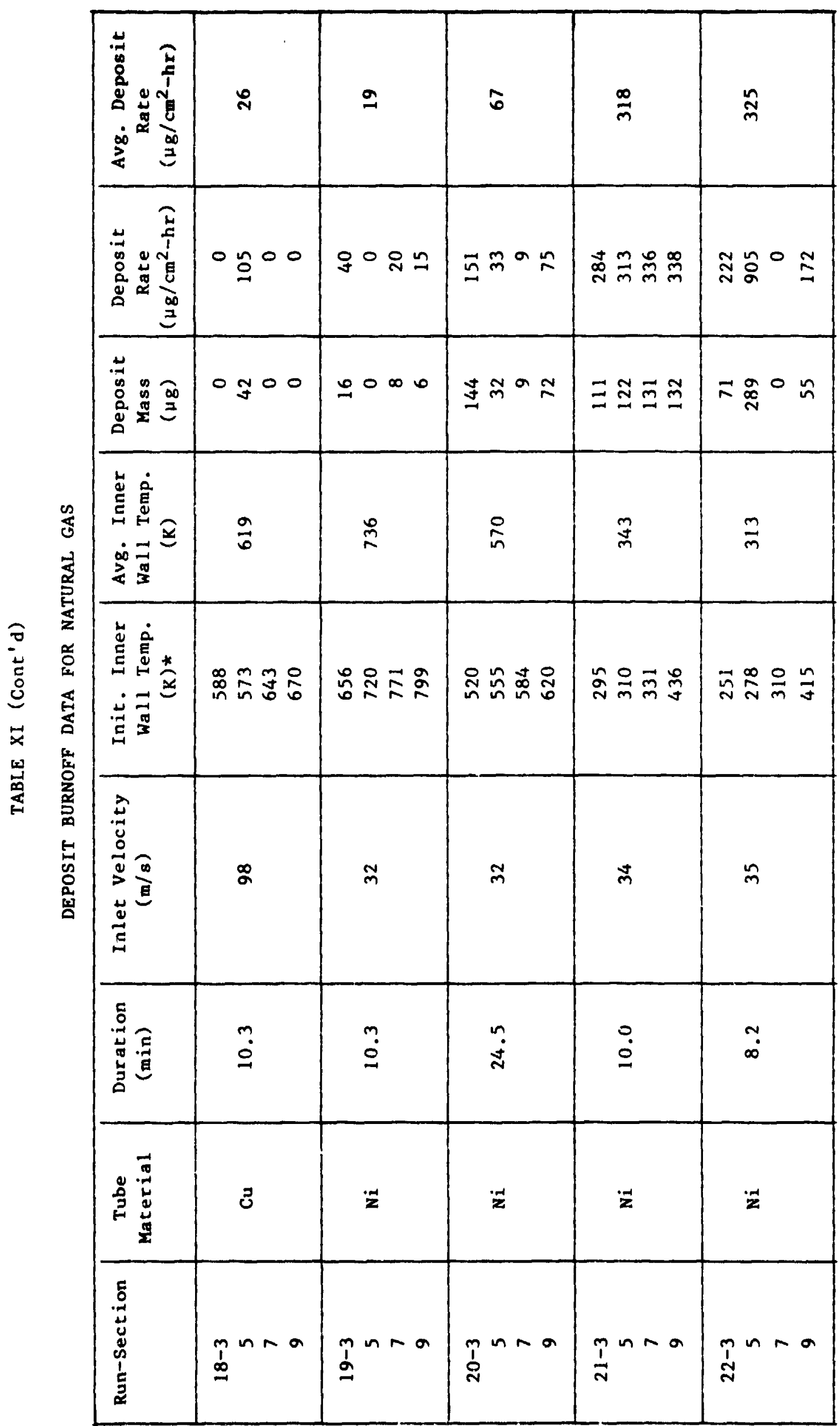




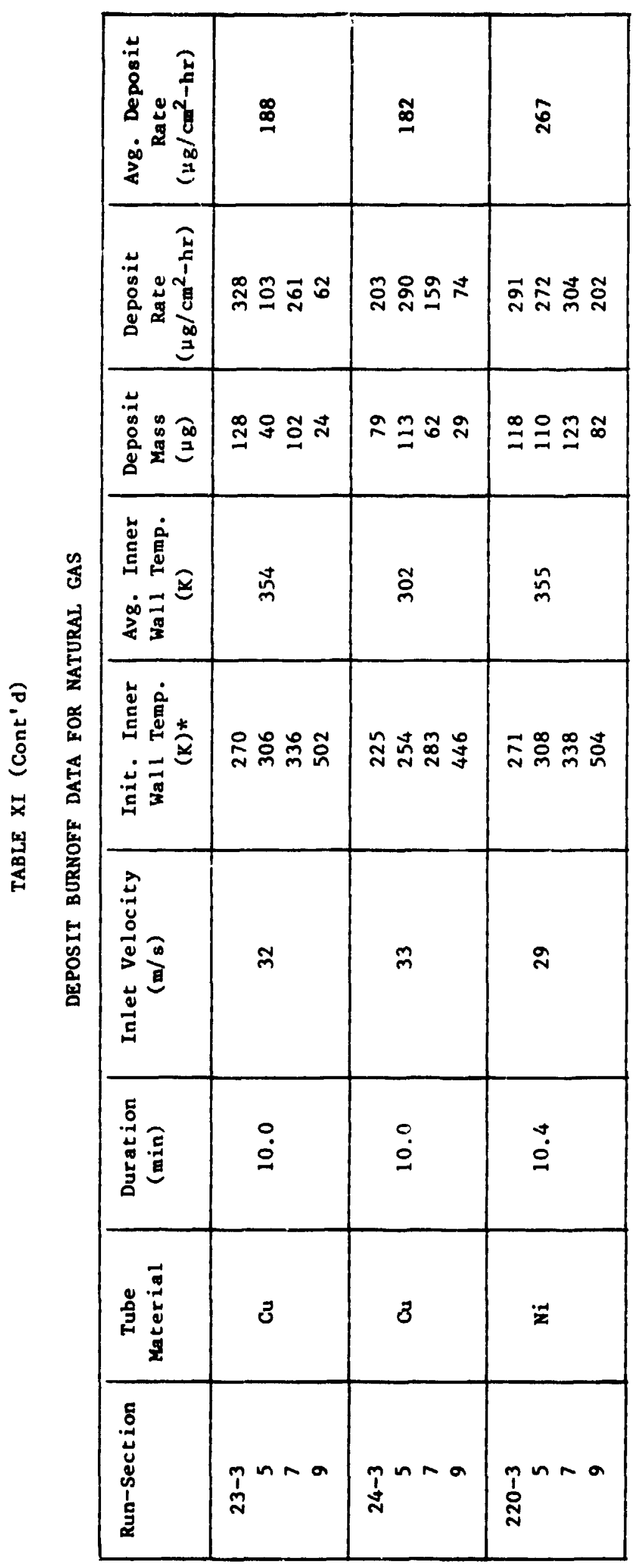




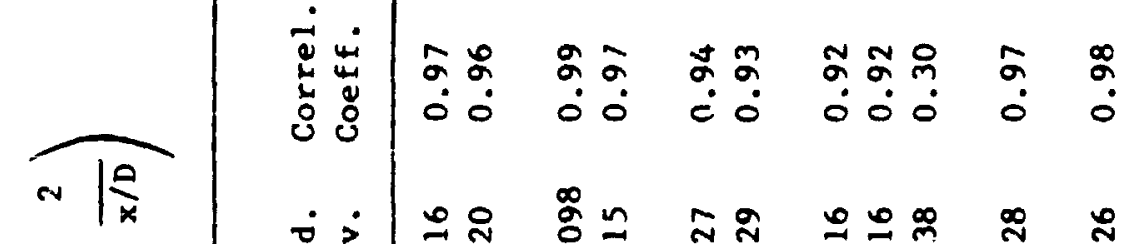

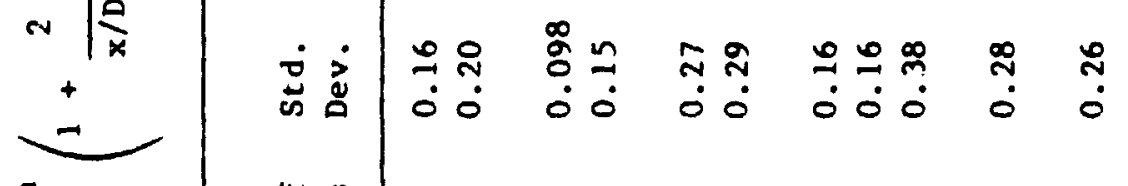

工

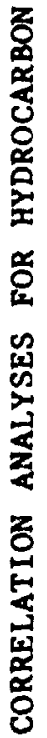

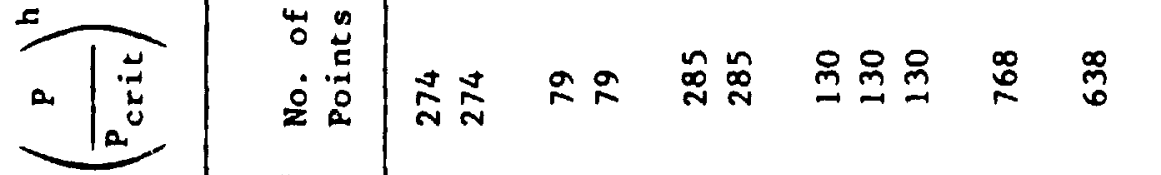

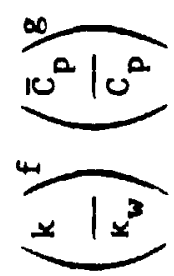

$=12^{3}$

$\underbrace{212}_{0}$

$21 a^{3}$

ए

u

焉

ฉัฒ

$\leftarrow$

"

是

z

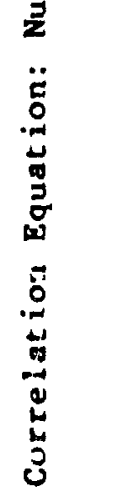

\begin{tabular}{|c|c|c|c|c|c|c|c|}
\hline \multirow{7}{*}{ 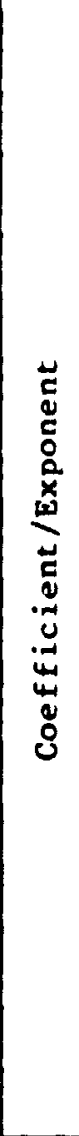 } & $\infty$ & $\dot{0}_{0}^{*}$ & 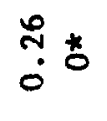 & $\ddot{\sim}^{*}$ & $\ddot{\sim} \dot{\sim}$. & กี & $\stackrel{*}{0}$ \\
\hline & $w$ & $\stackrel{0}{*}_{i}^{*}$ & $\tilde{i}^{n}{ }^{*}$ & $\begin{array}{l}\infty \\
\stackrel{\infty}{ \pm} \\
\dot{i}\end{array}$ & $\ddot{0} \stackrel{m}{0} \tilde{0}^{*}$ & $\begin{array}{l}0 \\
0 \\
0 \\
0\end{array}$ & ثี \\
\hline & 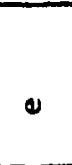 & $\delta_{0}^{\delta}$ & $\dot{\sim}^{*}$ & $\begin{array}{l}\infty \\
\delta_{0}^{\infty} \\
0\end{array}$ & ? & $\frac{a}{8}$ & $\hbar$ \\
\hline & 0 & $\ddot{m} \dot{m}^{*}$ & $\stackrel{0}{i}$ & $\stackrel{*}{*}{ }_{i}^{*}$ & $\stackrel{\sim}{\sim}$ & $\begin{array}{l}\dot{n} \\
0 \\
\dot{0}\end{array}$ & tै \\
\hline & $u$ & $\stackrel{*}{*} \stackrel{*}{*}$ & $\begin{array}{l}* \\
\forall \\
0\end{array}$ & $\stackrel{*}{*} \stackrel{*}{*}:$ & $\begin{array}{ll}* & * \\
0 & * \\
0 & 0\end{array}$ & $\stackrel{*}{:}$ & $\stackrel{*}{*}$ \\
\hline & مـ & $\begin{array}{l}\sigma \\
\sigma \\
0\end{array}$ & $\begin{array}{l}\tilde{\infty} \\
\dot{0} \\
\dot{0}\end{array}$ & $\begin{array}{l}0 \\
\infty \\
\dot{0} \\
0\end{array}$ & $\because \stackrel{0}{-} \stackrel{\sim}{-}$ & $\vec{\infty}$ & $\stackrel{0}{0}$ \\
\hline & $<$ & 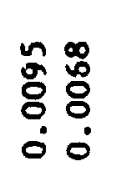 & $\begin{array}{l}=0 \\
0 \\
0 \\
0\end{array}$ & 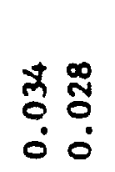 & 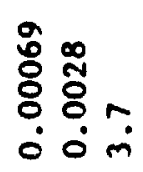 & $\begin{array}{l}\frac{a}{0} \\
0\end{array}$ & $\begin{array}{l} \pm \\
0\end{array}$ \\
\hline & $\vec{g}$ & $\bar{d}$ & 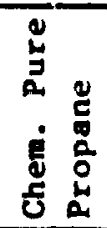 & 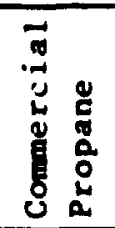 & 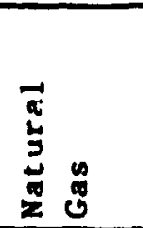 & $\begin{array}{l}\Xi \\
\stackrel{2}{0} \\
\dot{0}\end{array}$ & 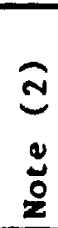 \\
\hline
\end{tabular}

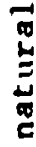

ฮั

ֻे

รั๊

$\stackrel{9}{5}$

ํํำ

ขั

\&

:

ํㅜํ

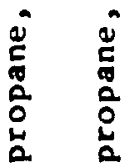

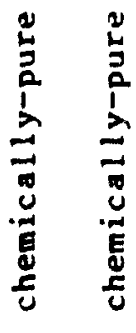

ì

눈

등

$\stackrel{ \pm}{\Phi}$

岕

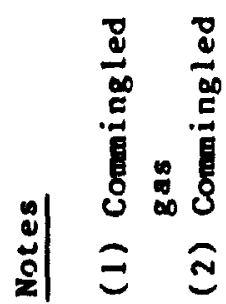


OPHCWAL PAGE IS
OF POON QUALITY

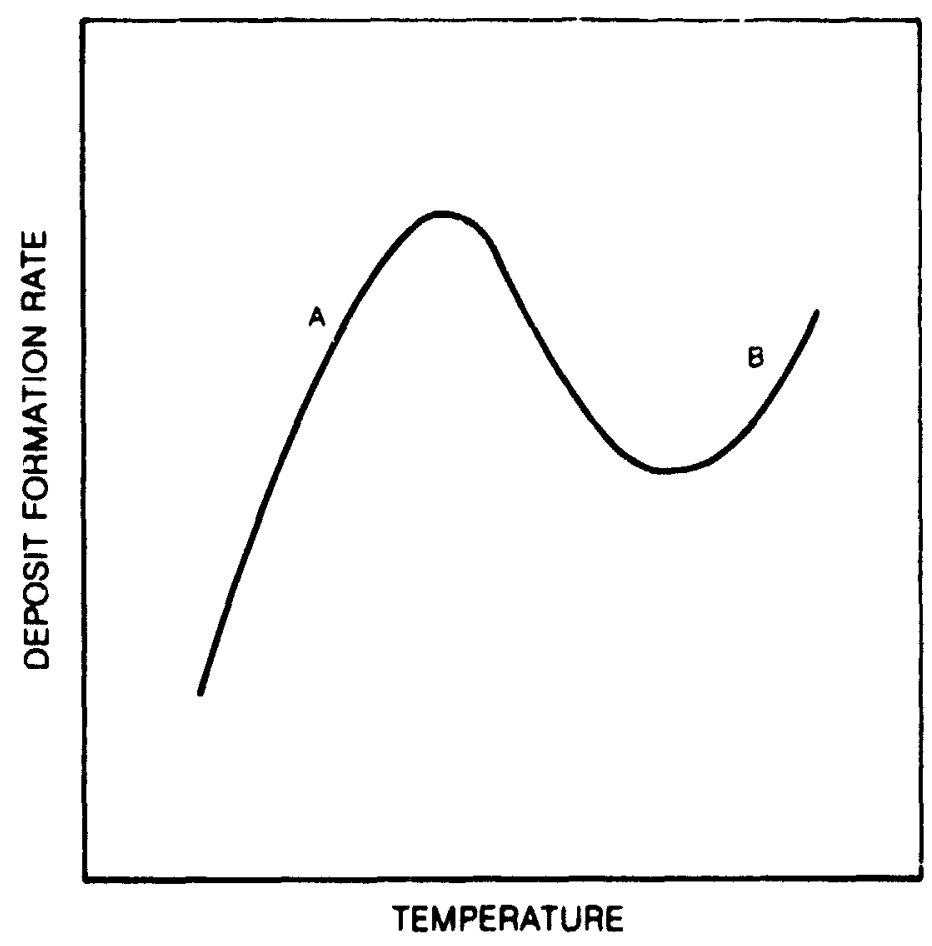

Figure 1. Carbon Doposition for Hydrocarbon Fuols in Contact with a Hot Surtace

$03-8-23-6$ 


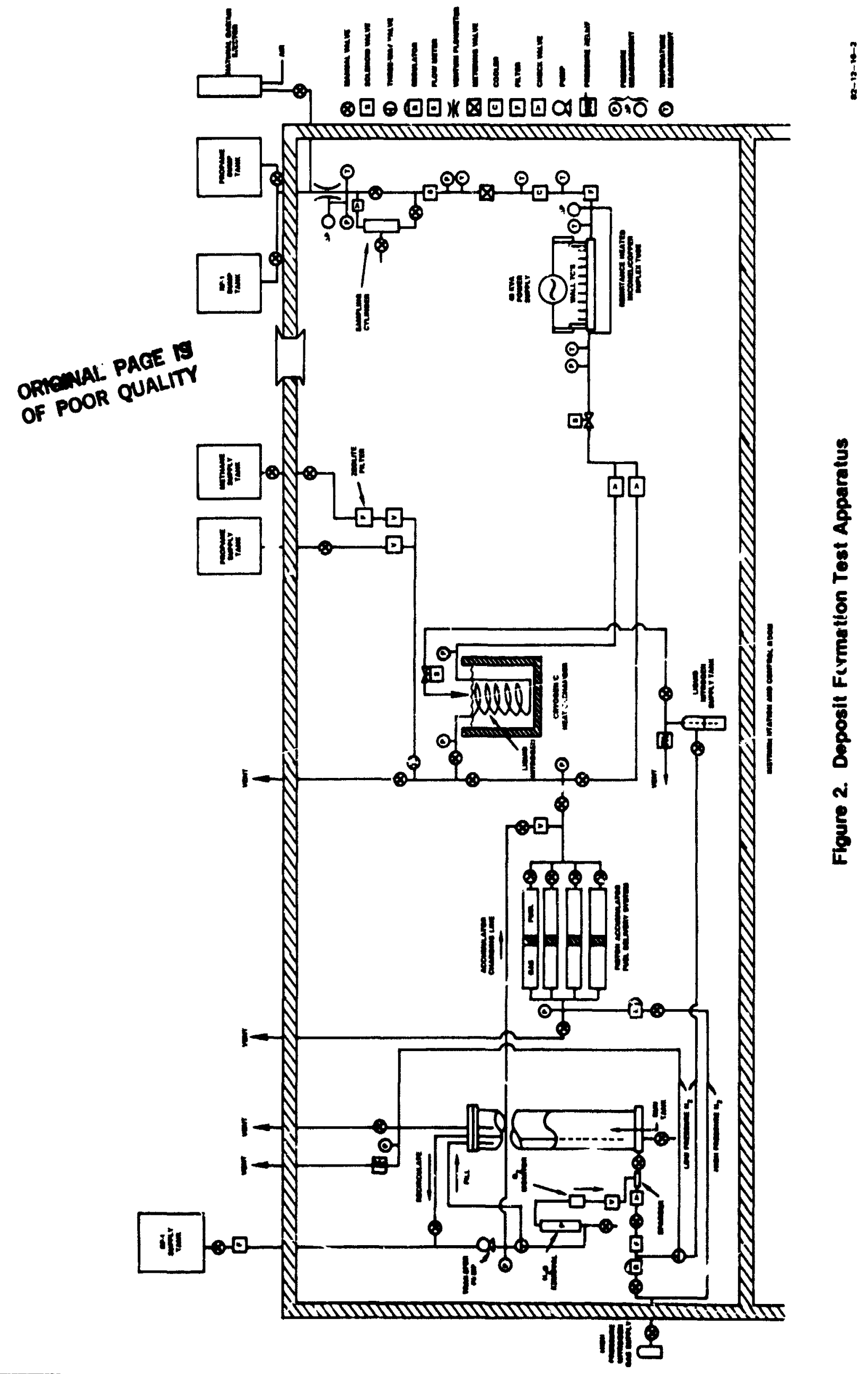




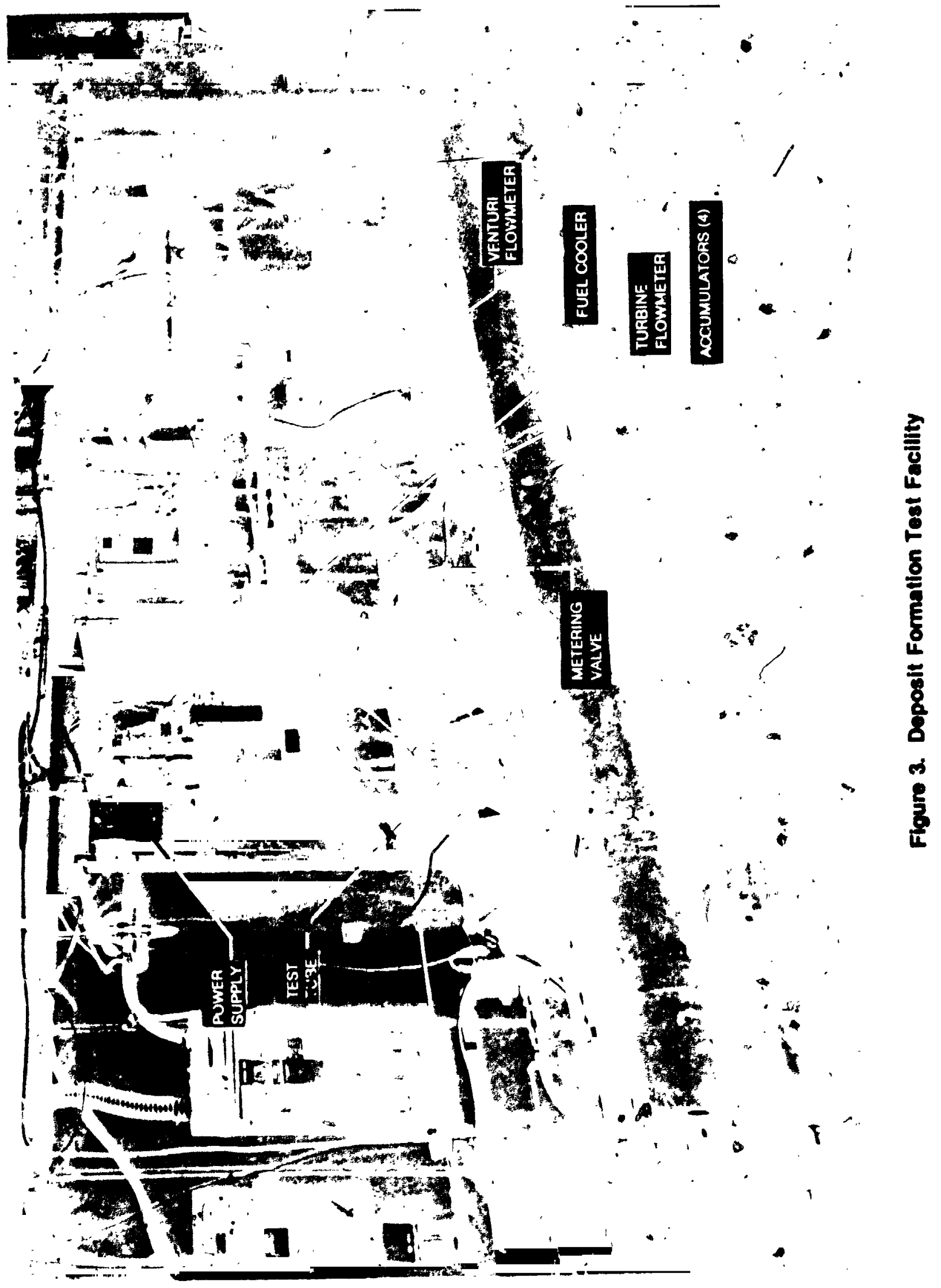




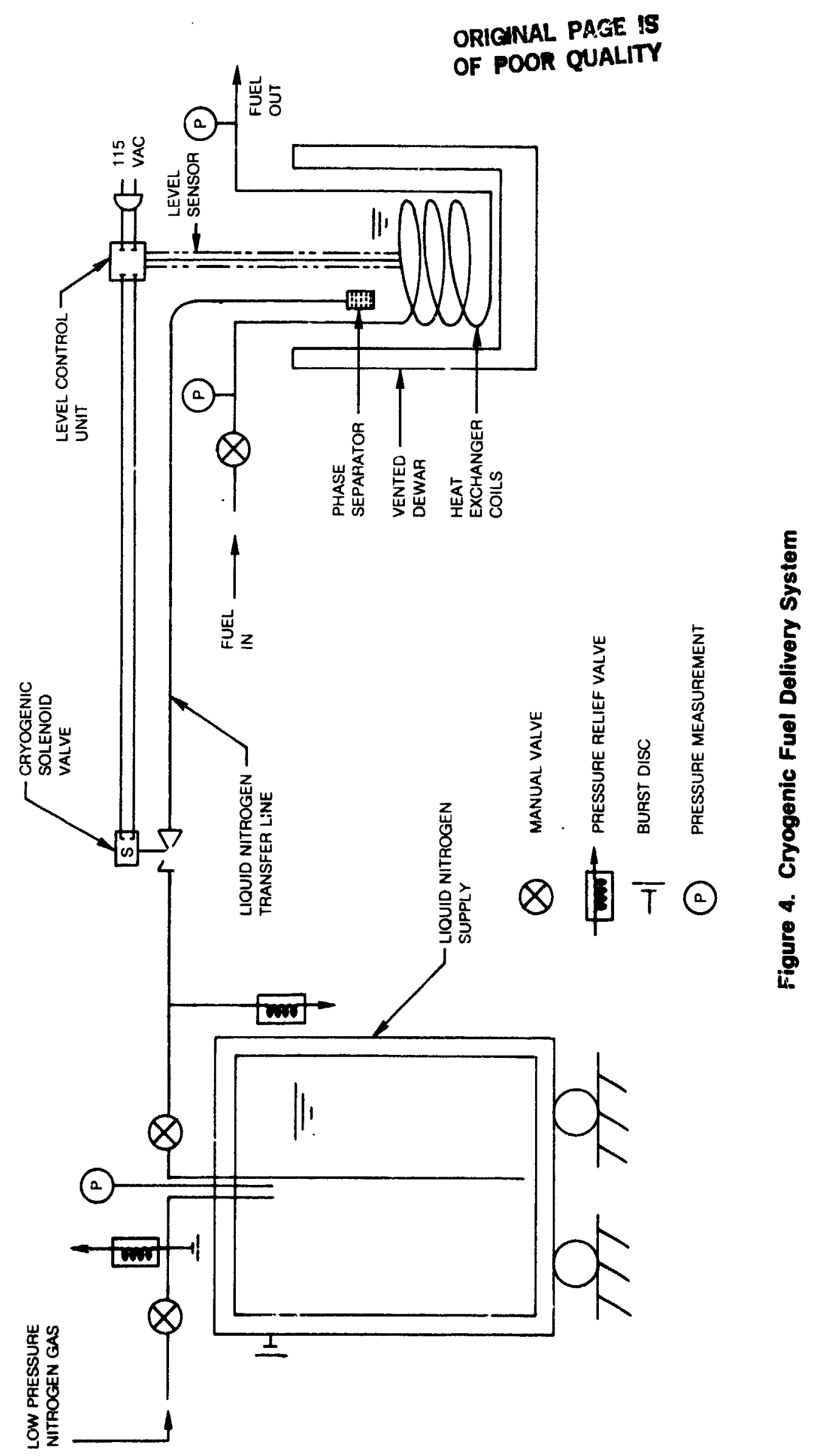

$82-10-57-4$ 


\section{ORICNAL PAGE IS \\ OF POOR QUALITY}

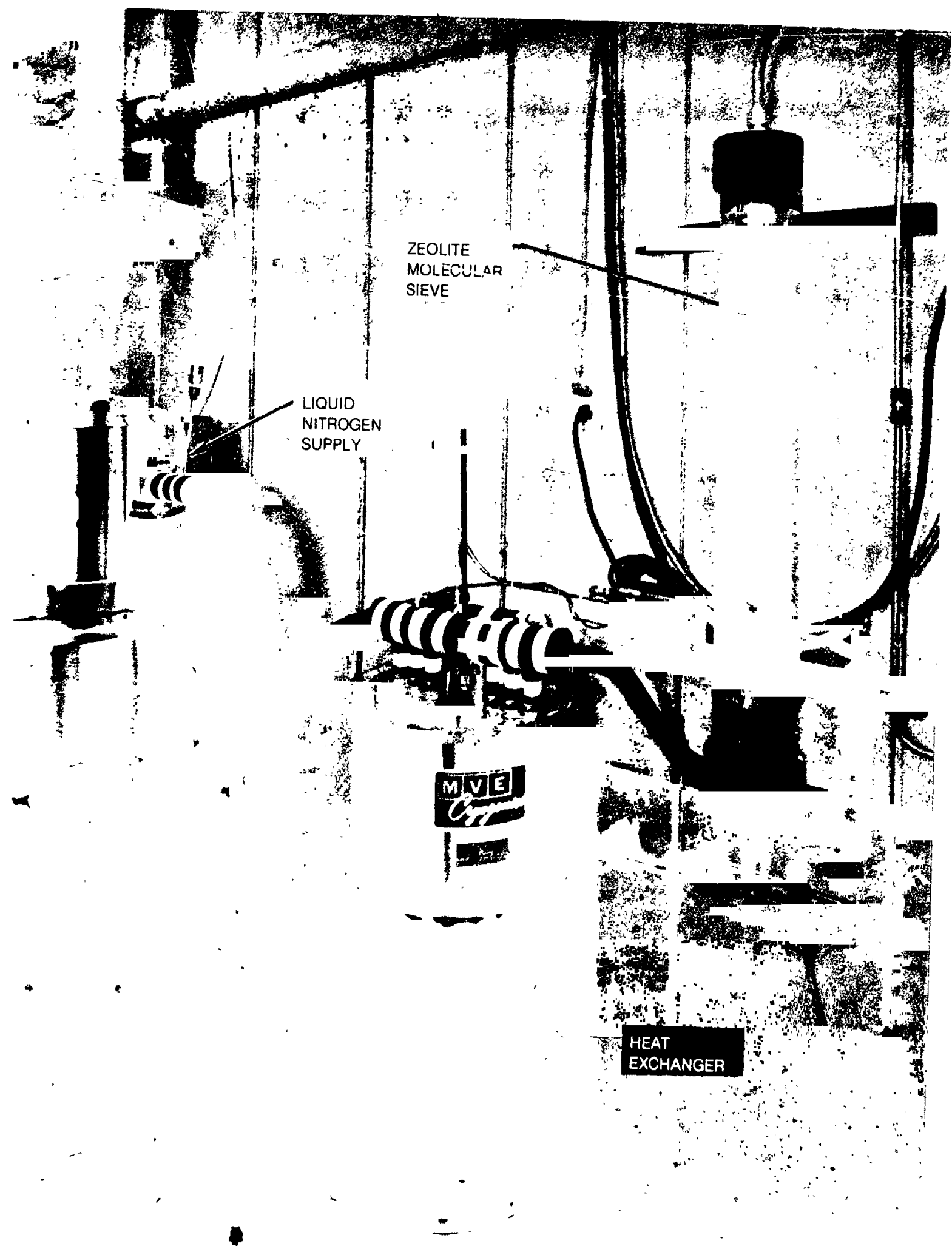

Figure 5. Cryoge.ic Heat Exchanyer 


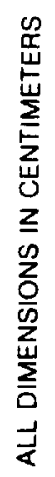

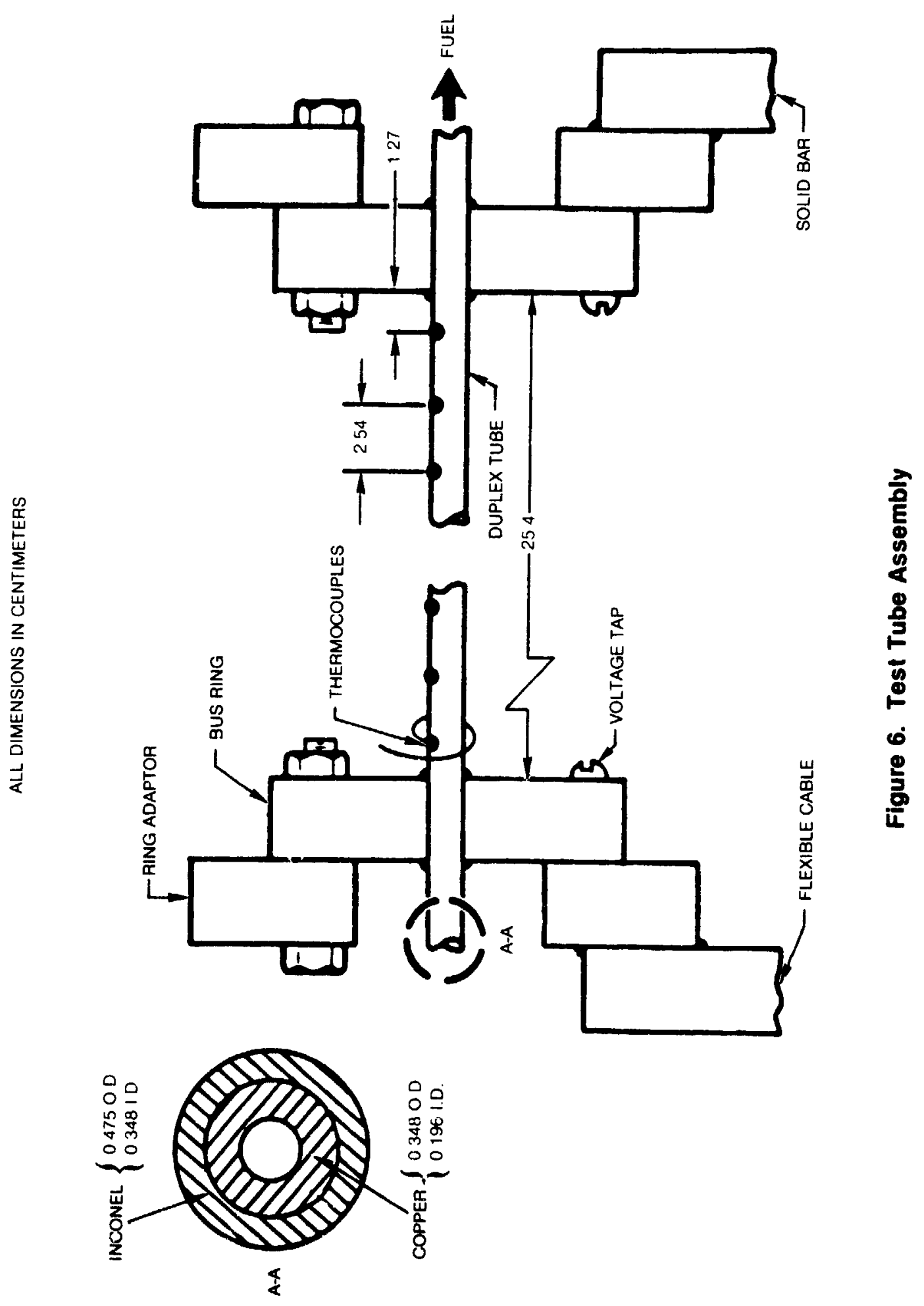

$82-10-57-1$

OMIONAL PAGE IS

OF POOR QUALITY 


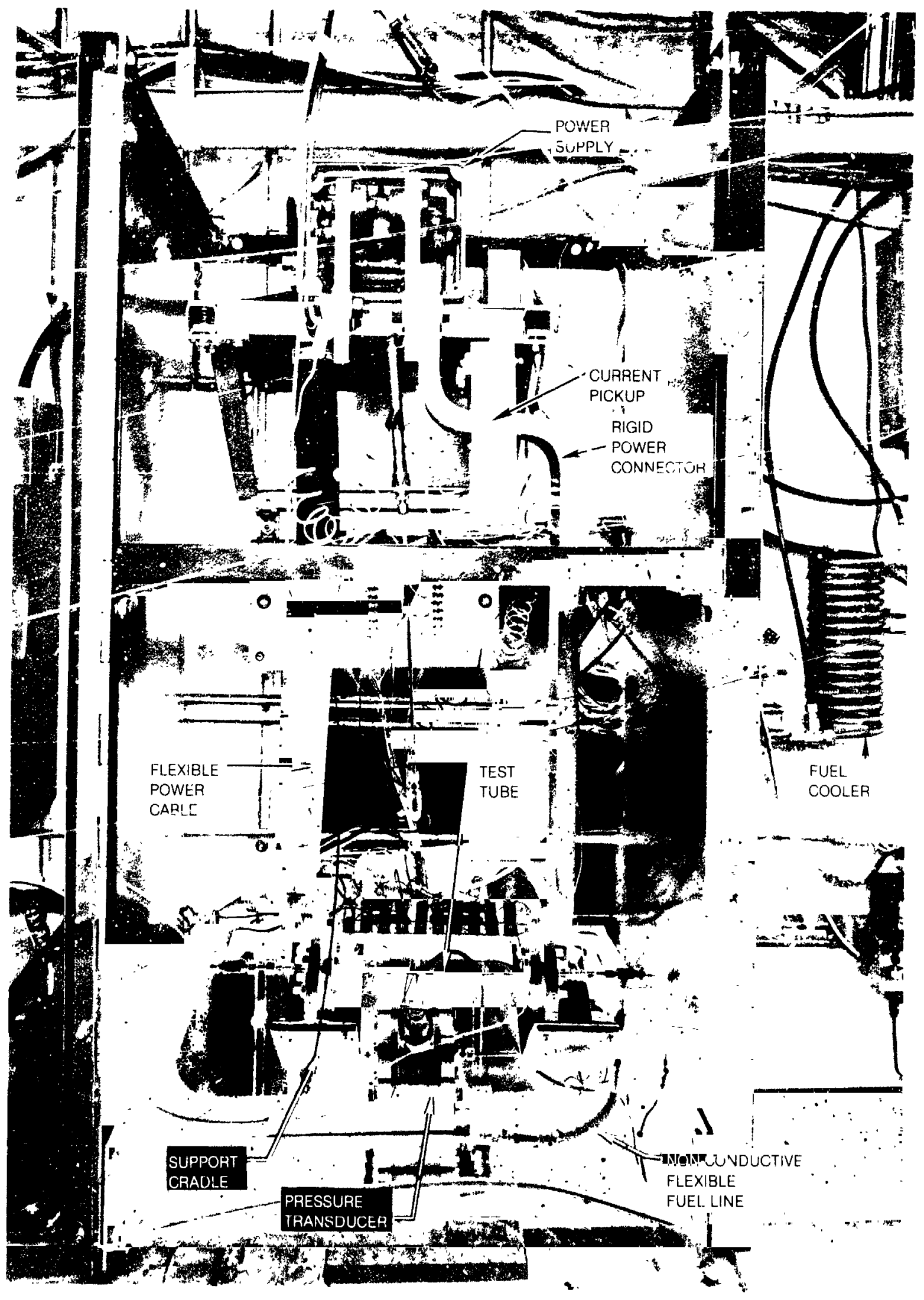

Figure 7. Test Section Mounting Arrangement 

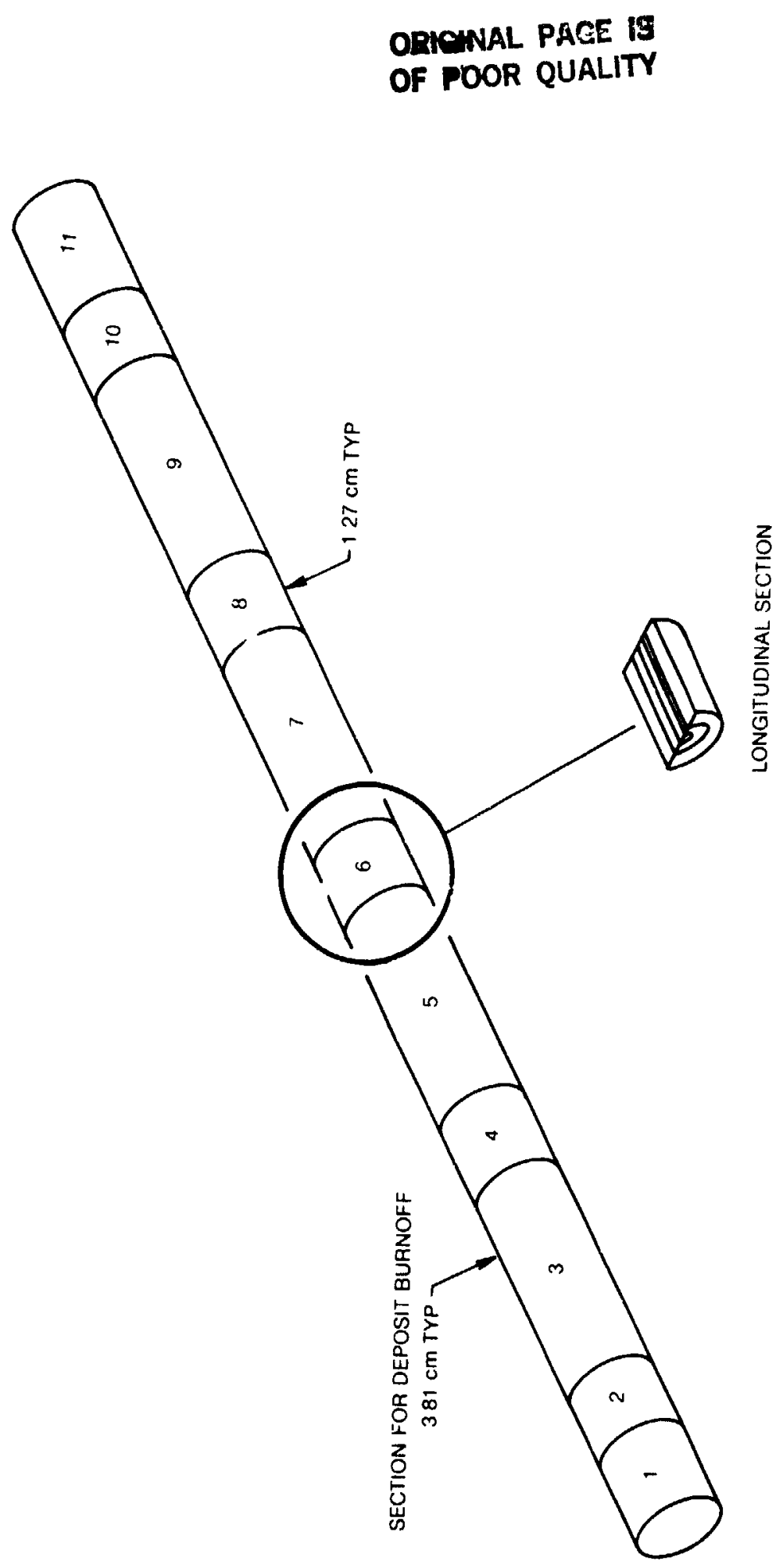

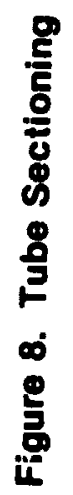




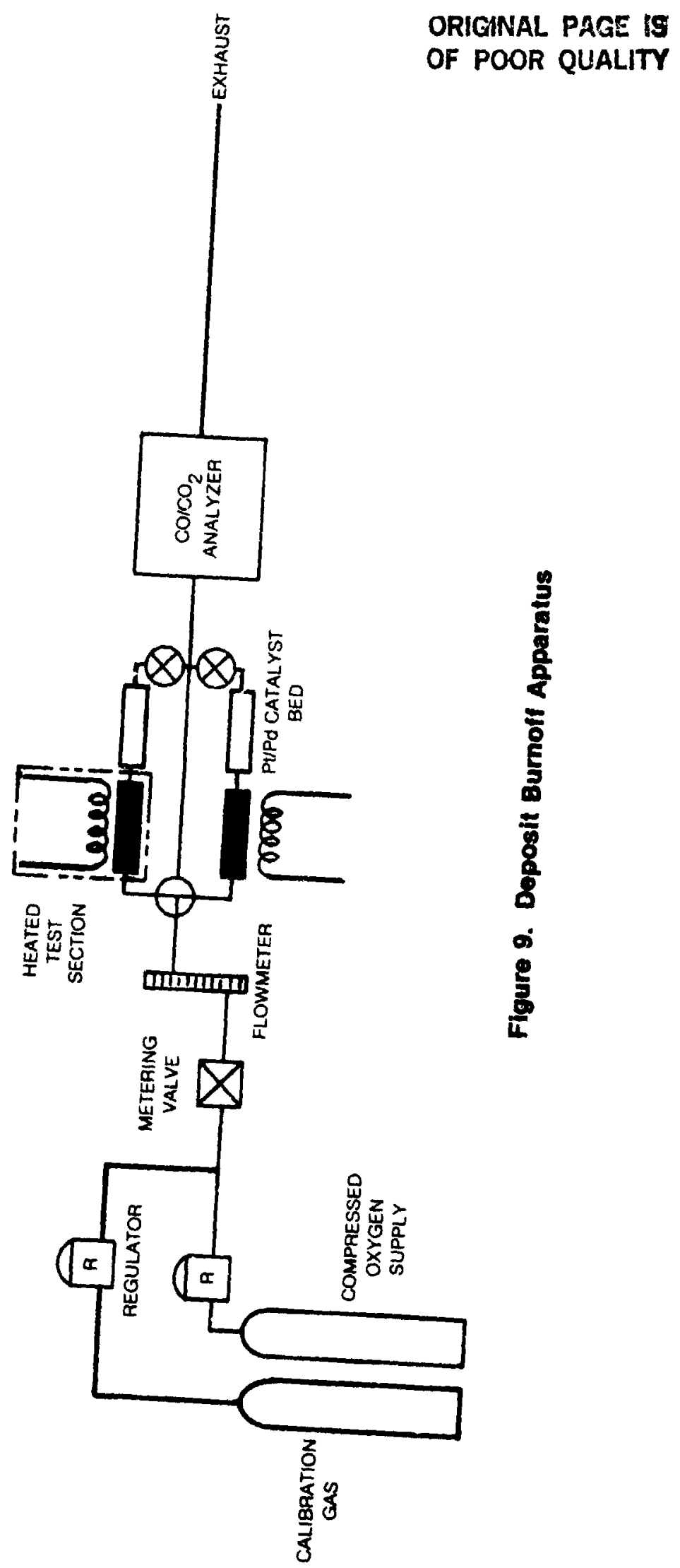


ORIGHAL PAGE

OF POOR QUALITY

RP-1

COPPER TUBE

$P=13.8 \mathrm{MPa}$

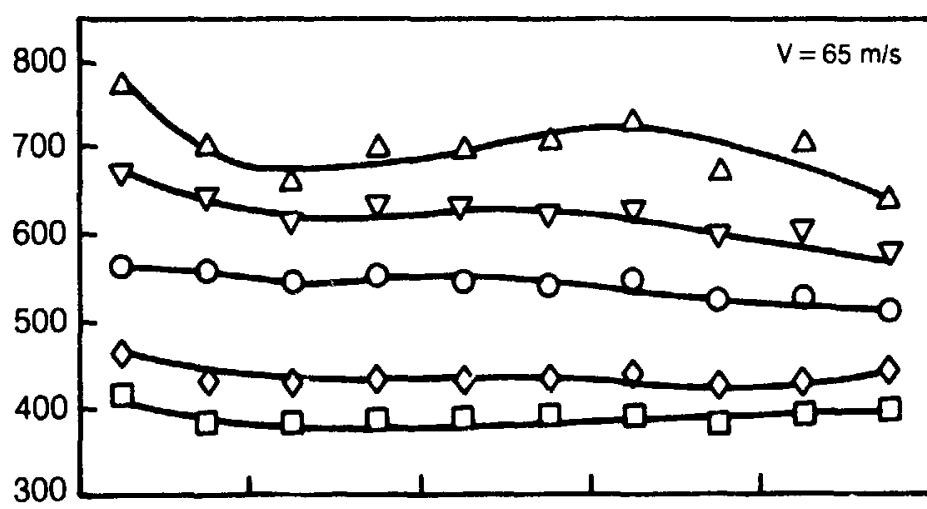

POWER (kW)

D 6.9

$0 \quad 104$

O 19.1

$\nabla \quad 26.7$

$\Delta \quad 353$

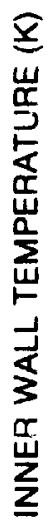

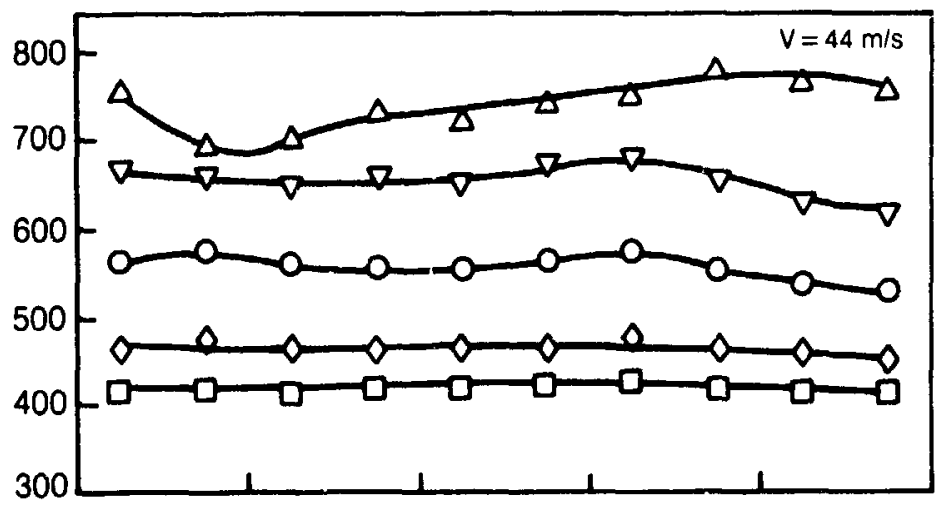

ㅁ 6.1

- 8.2

O 133

$\nabla \quad 201$

$\Delta \quad 28.6$

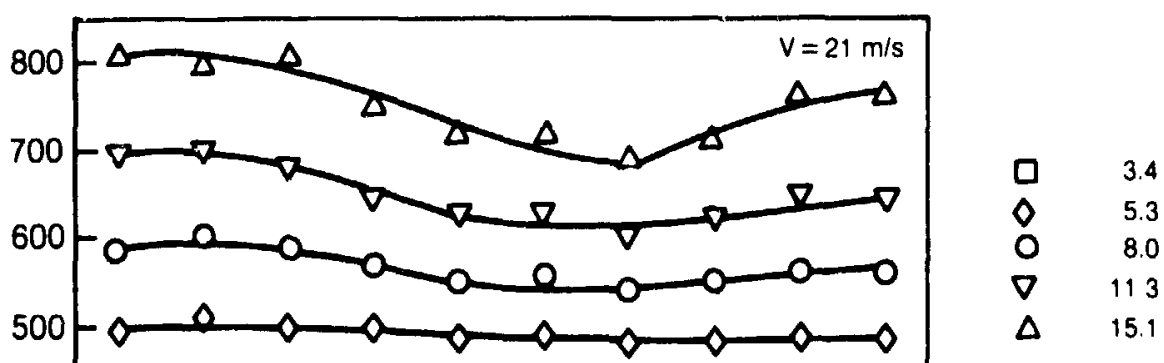

Flgure 10. Variation of Axial Wall Temperature with Power 
ORIGINAL PAGE IS

OF POOK QUALITY

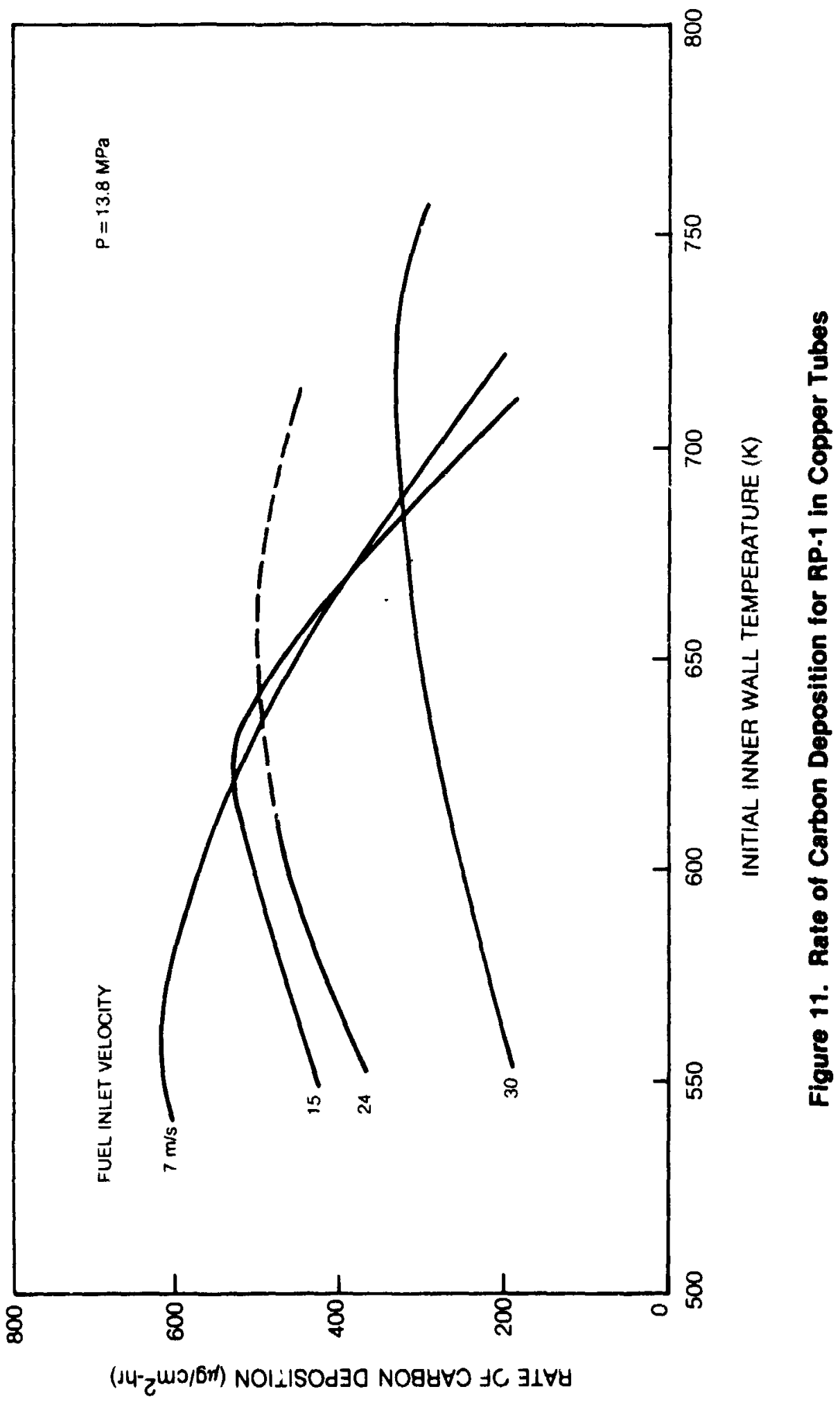


ORIGNAL PAGE ES

OF POOR QUALITY

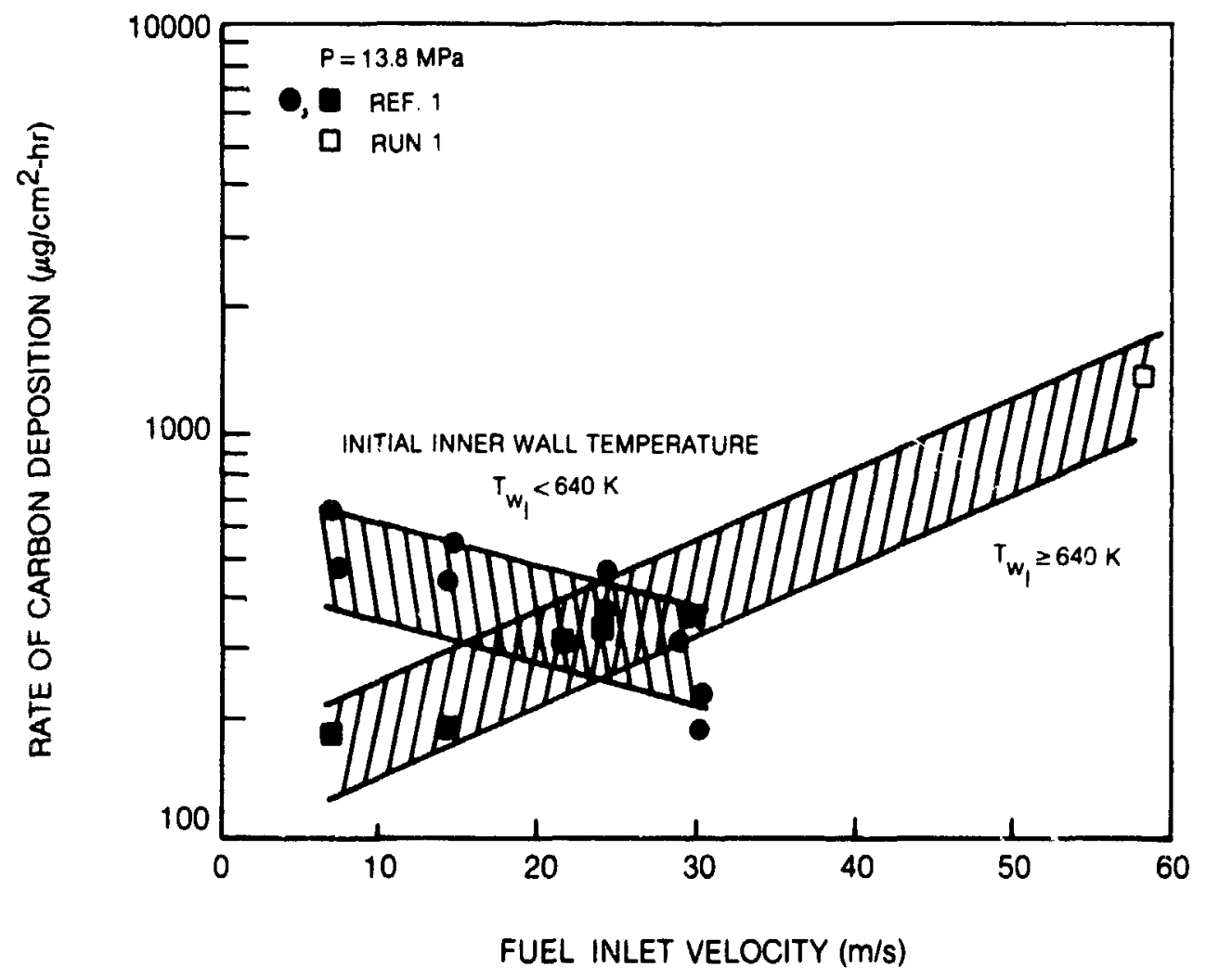

Figure 12. Elfect of Fuel Velocity on Carbon Deposition for RP.1 in Copper Tubes 


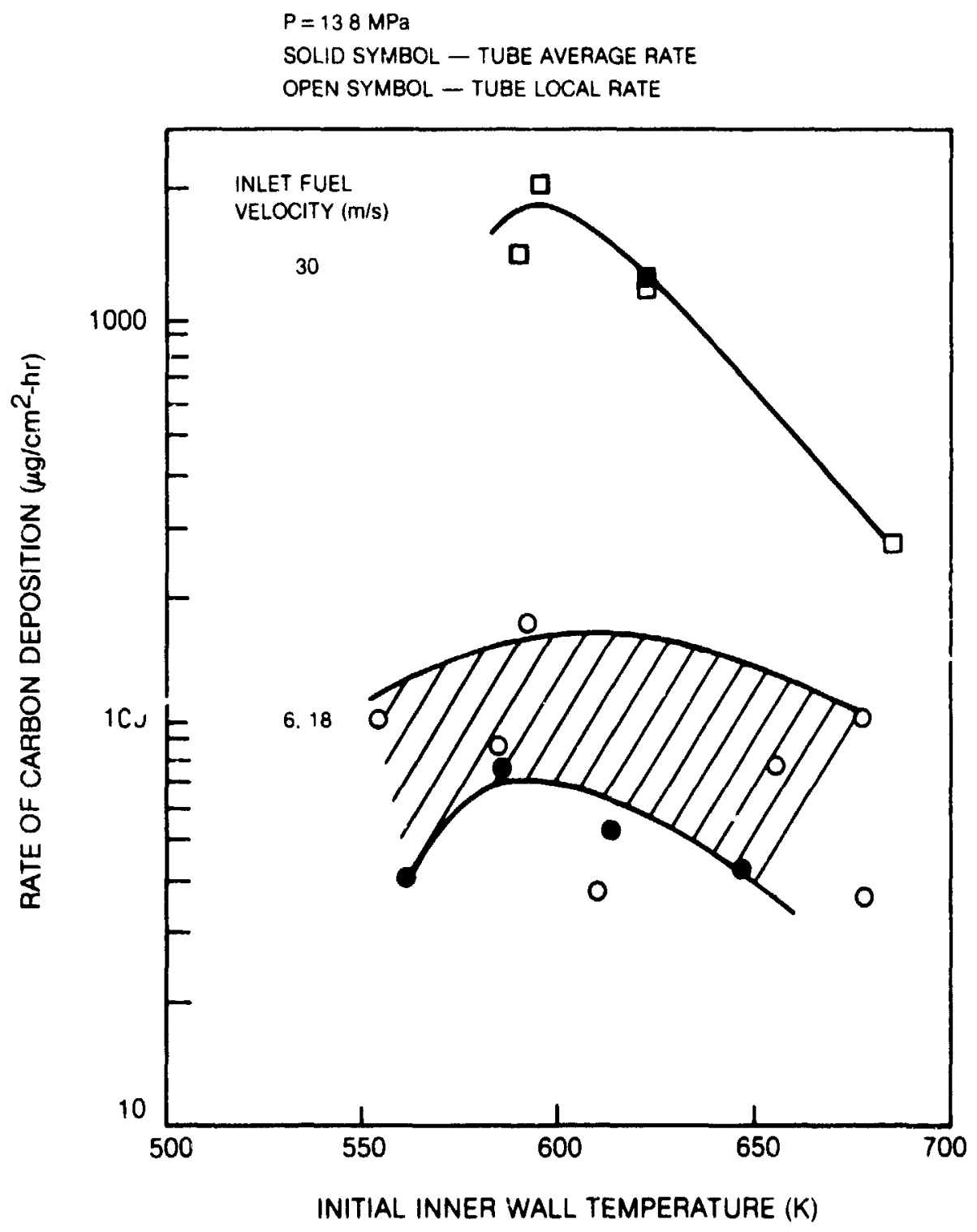

Figure 13. Effect of Fuel Volocity on Carbon Deposition for RP.I in Nickel Tubes 


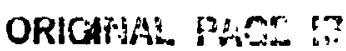

OF PCOR QUALITY

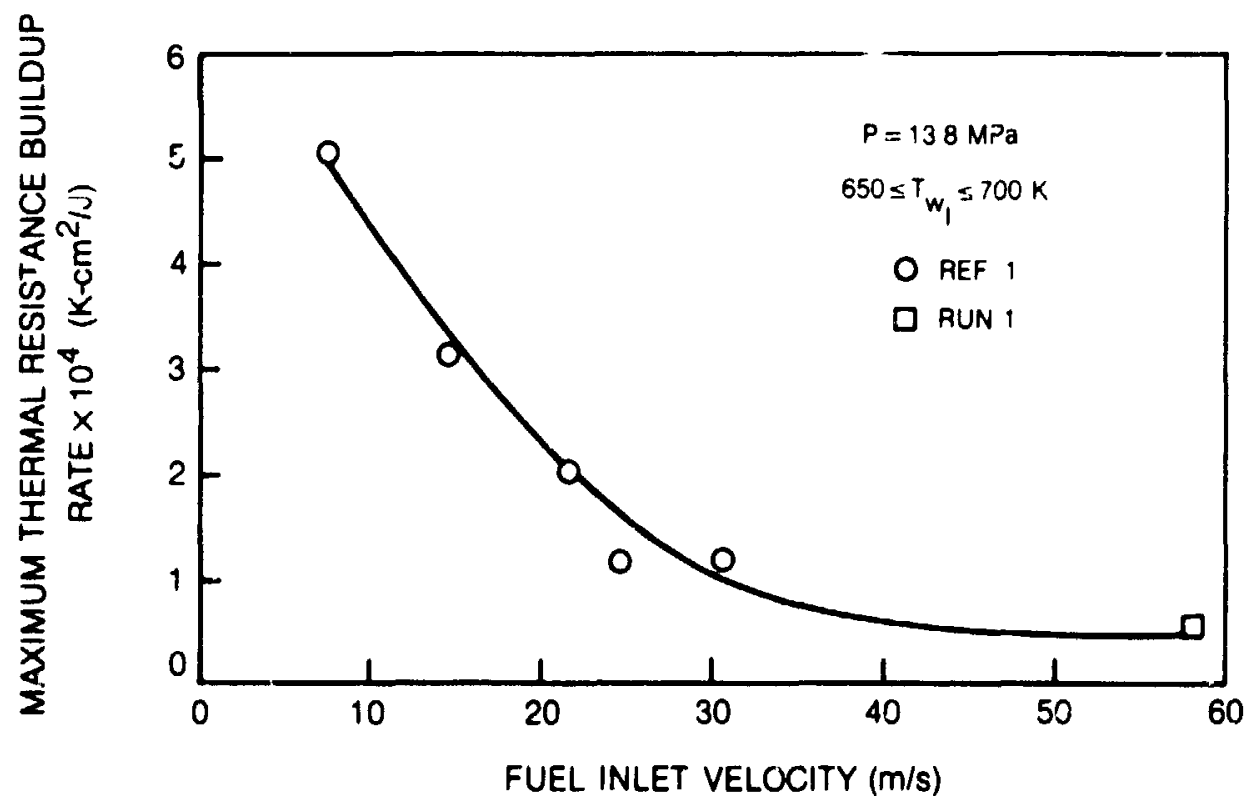

Figure 14. Effect of Fual Velocity on Thermal Resistance Bulldup Rate for RP.1 in Copper Tubes 


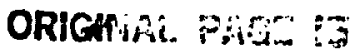

OF POOR QUALLITY
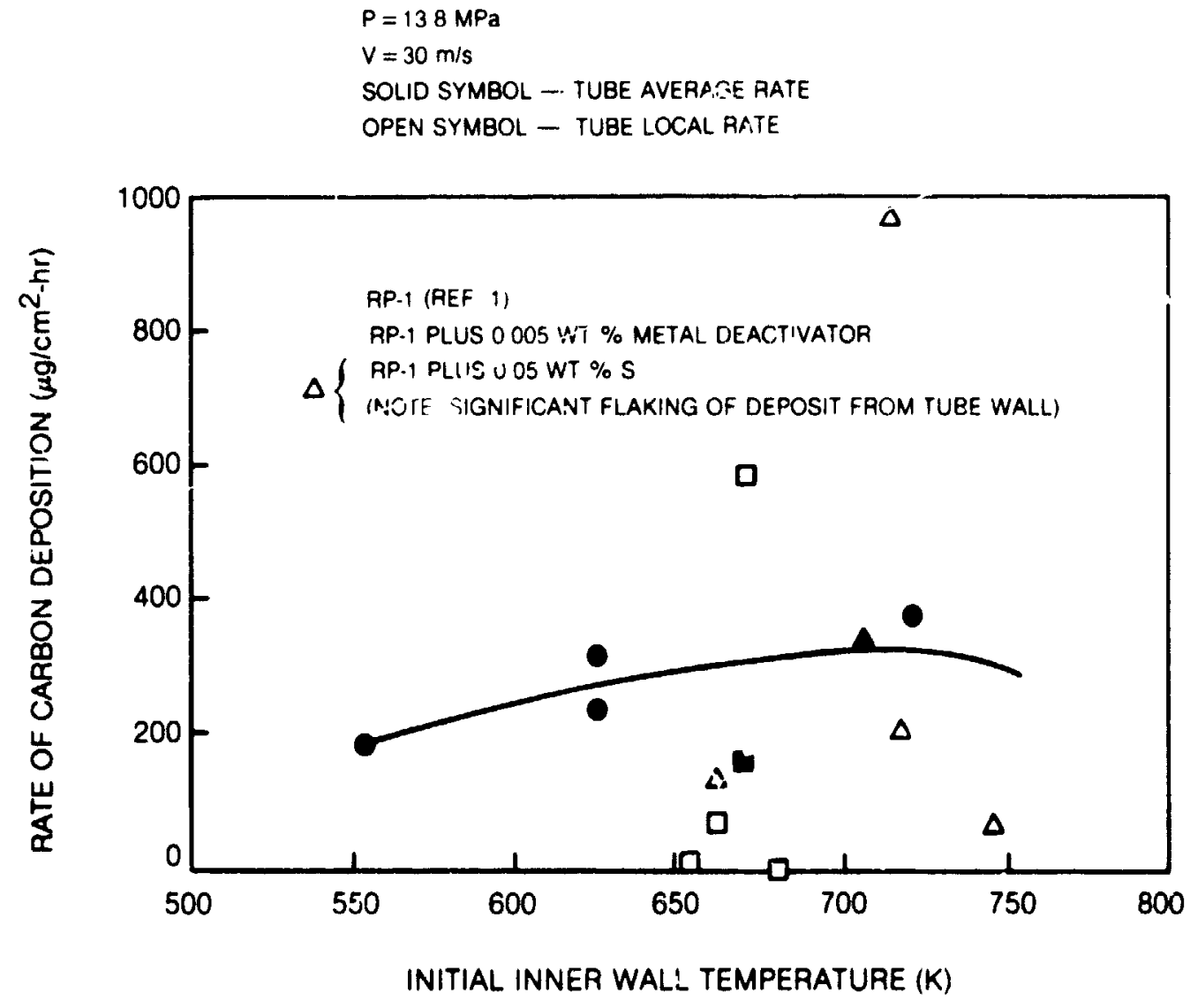

Figure 15. Effost of Fuel Composition on Carbon Deposition for RP.1 Fual In Copper Tubes 
OKIGINAL FG:

OF PONR QUALITY

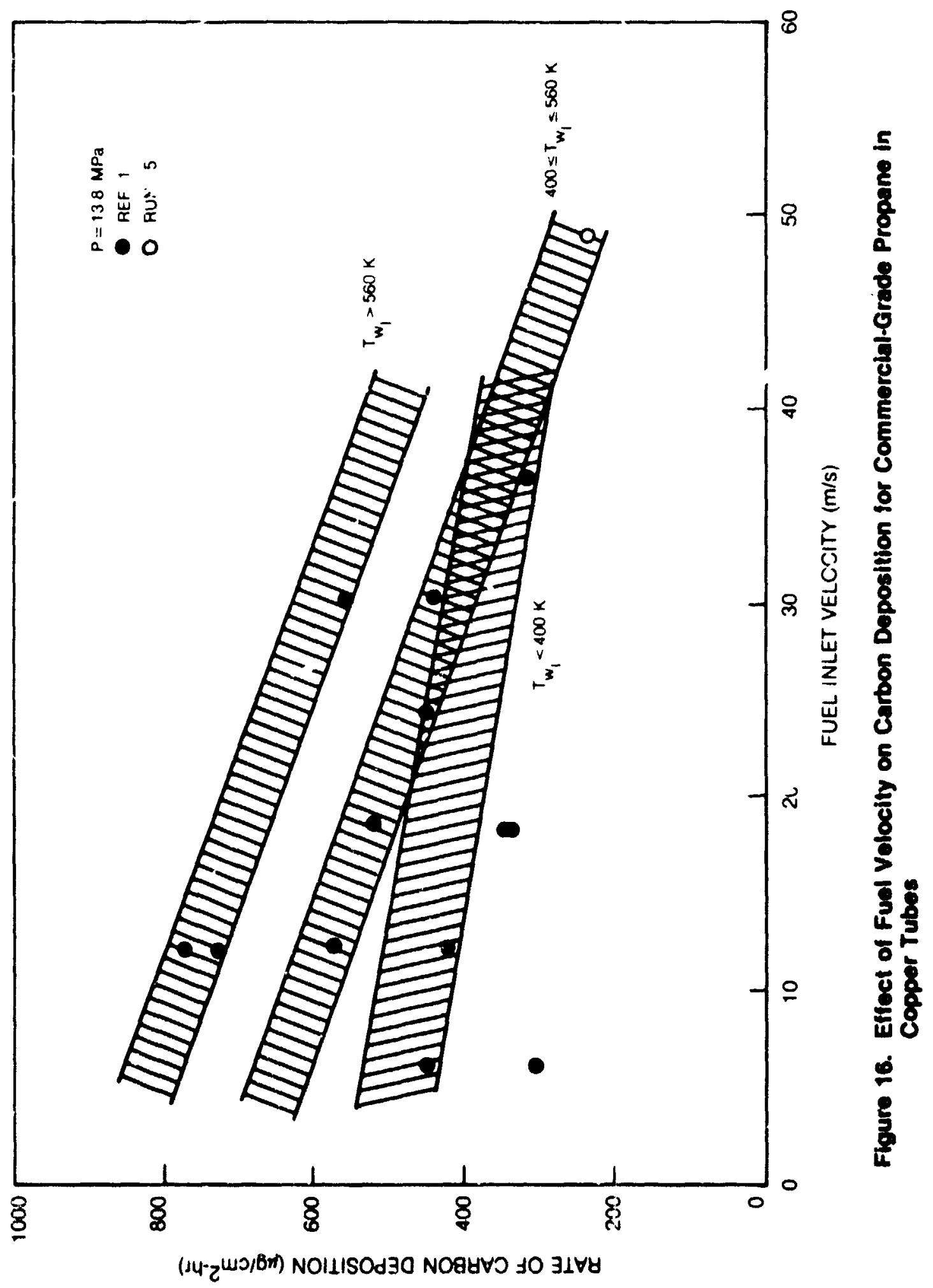

e3-5-73-15 
ORABI:

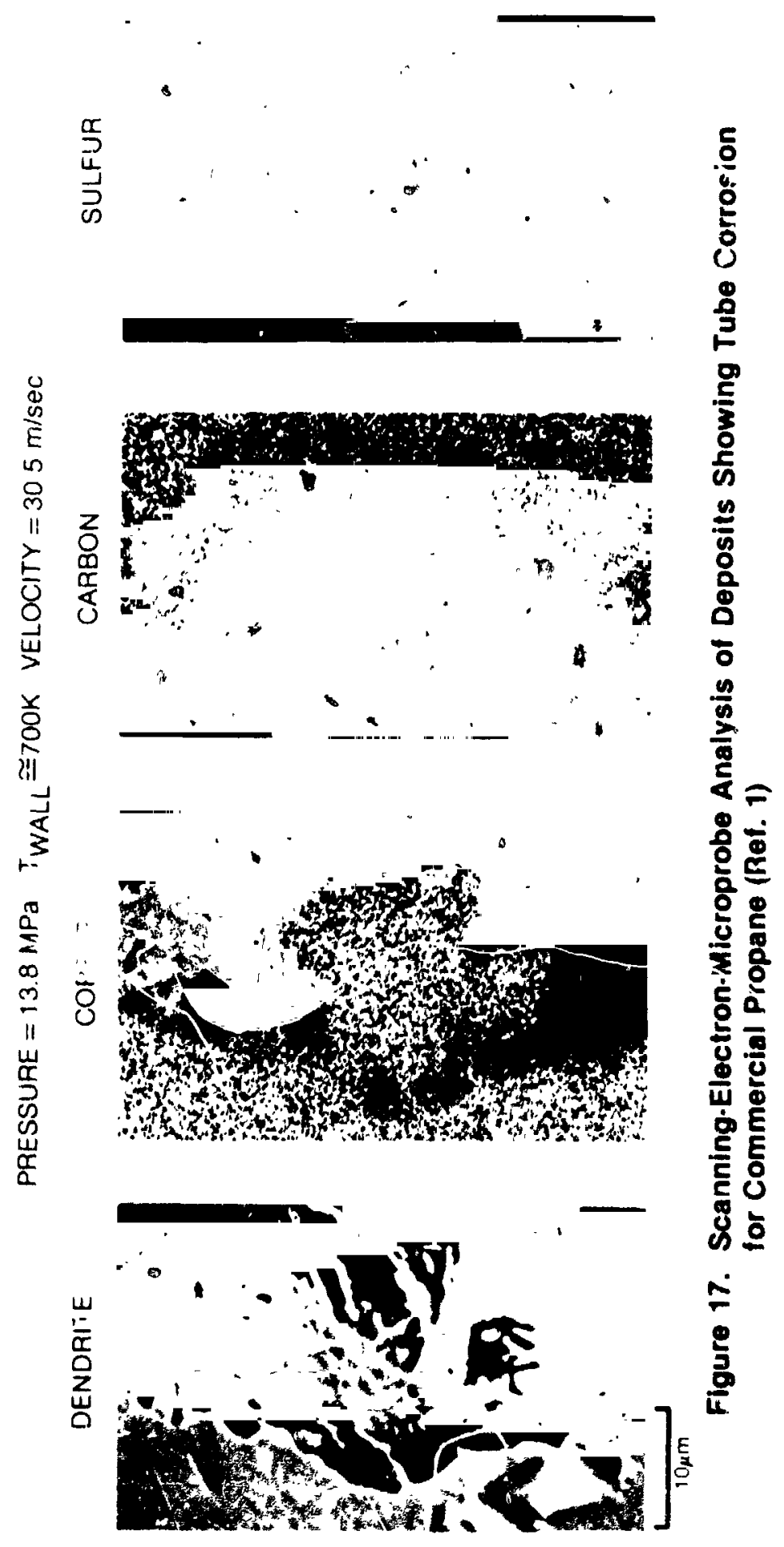




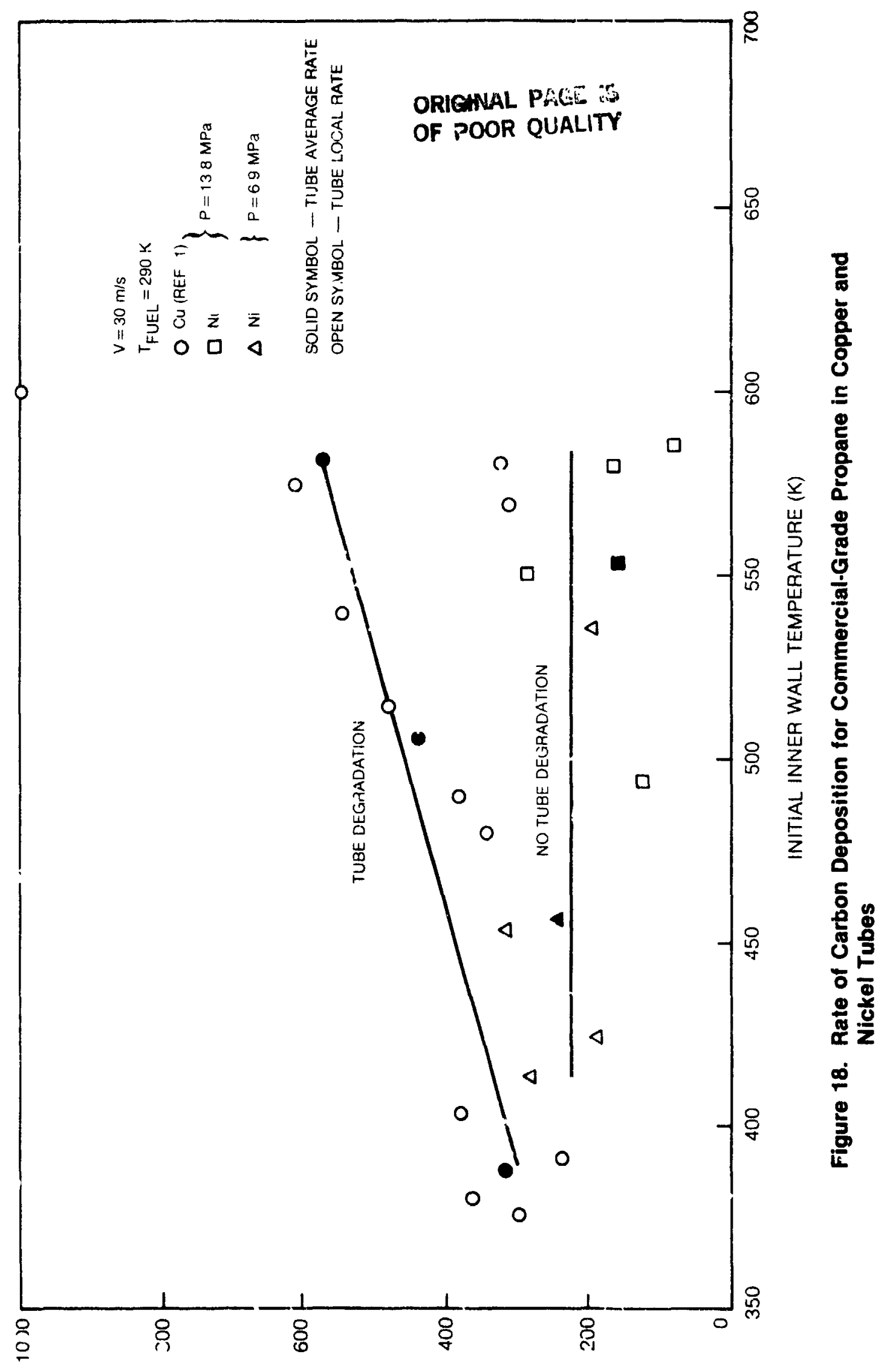

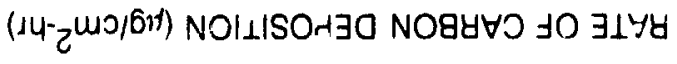




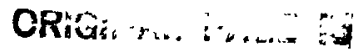

OF. POOR QUALITY

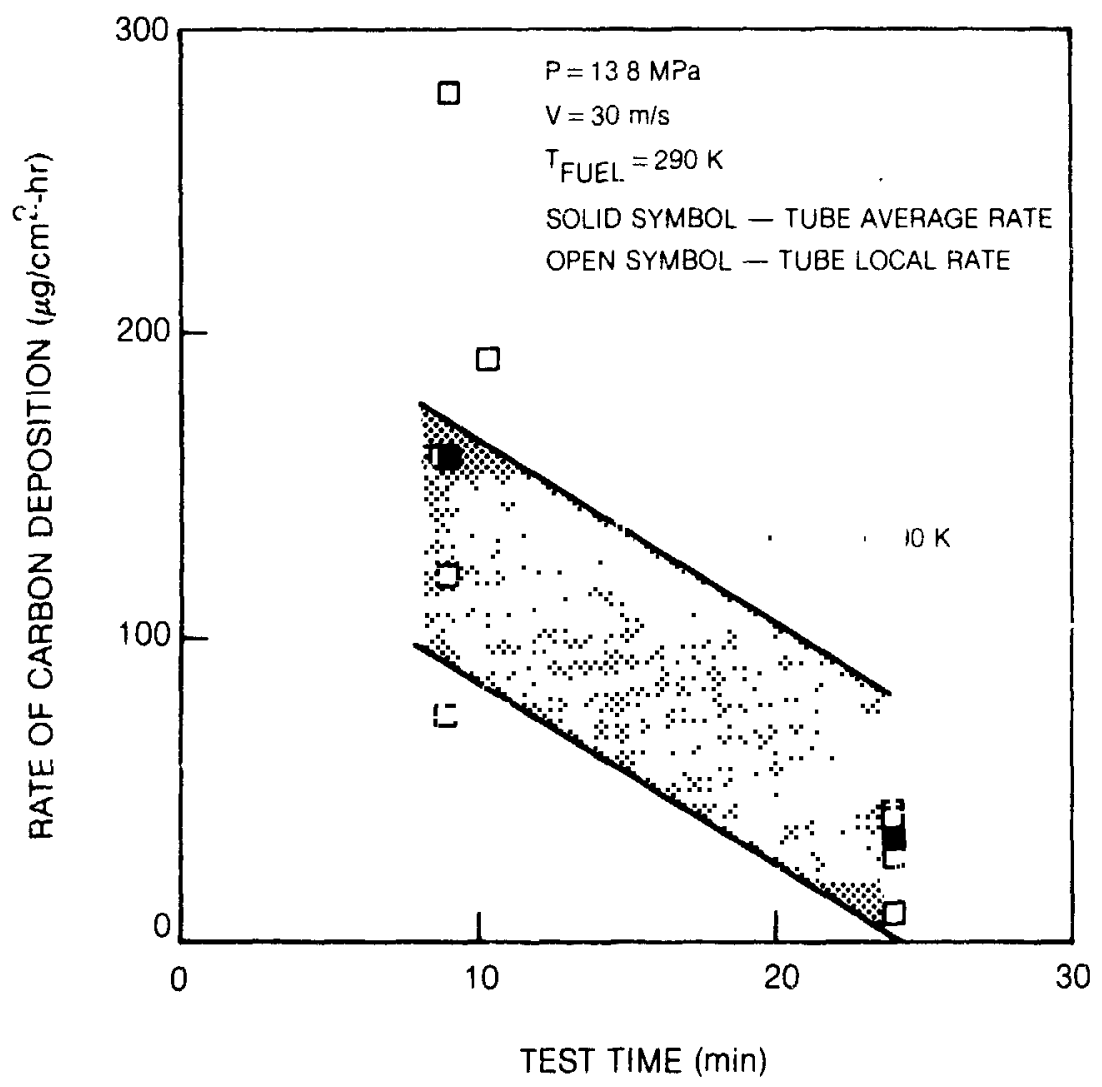

Figure 19. Effect of Intermittent Operation and Test Time on Carbon Depositicn for Commercial-Grade Propane in Nickel Tubes 


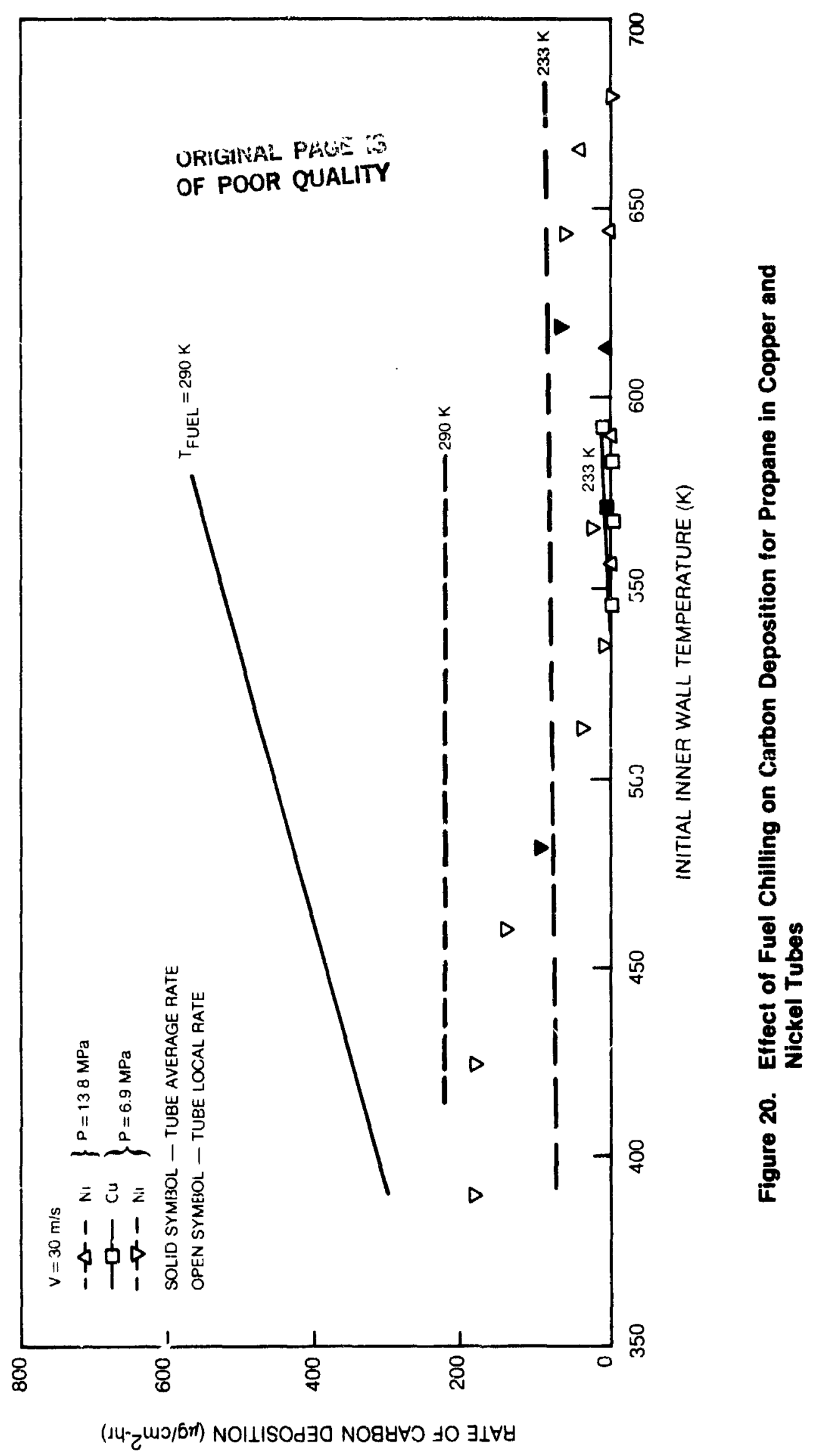

$83-5-73-18$ 
ORIGNAL PAGE IS

OF POOR QUALITY

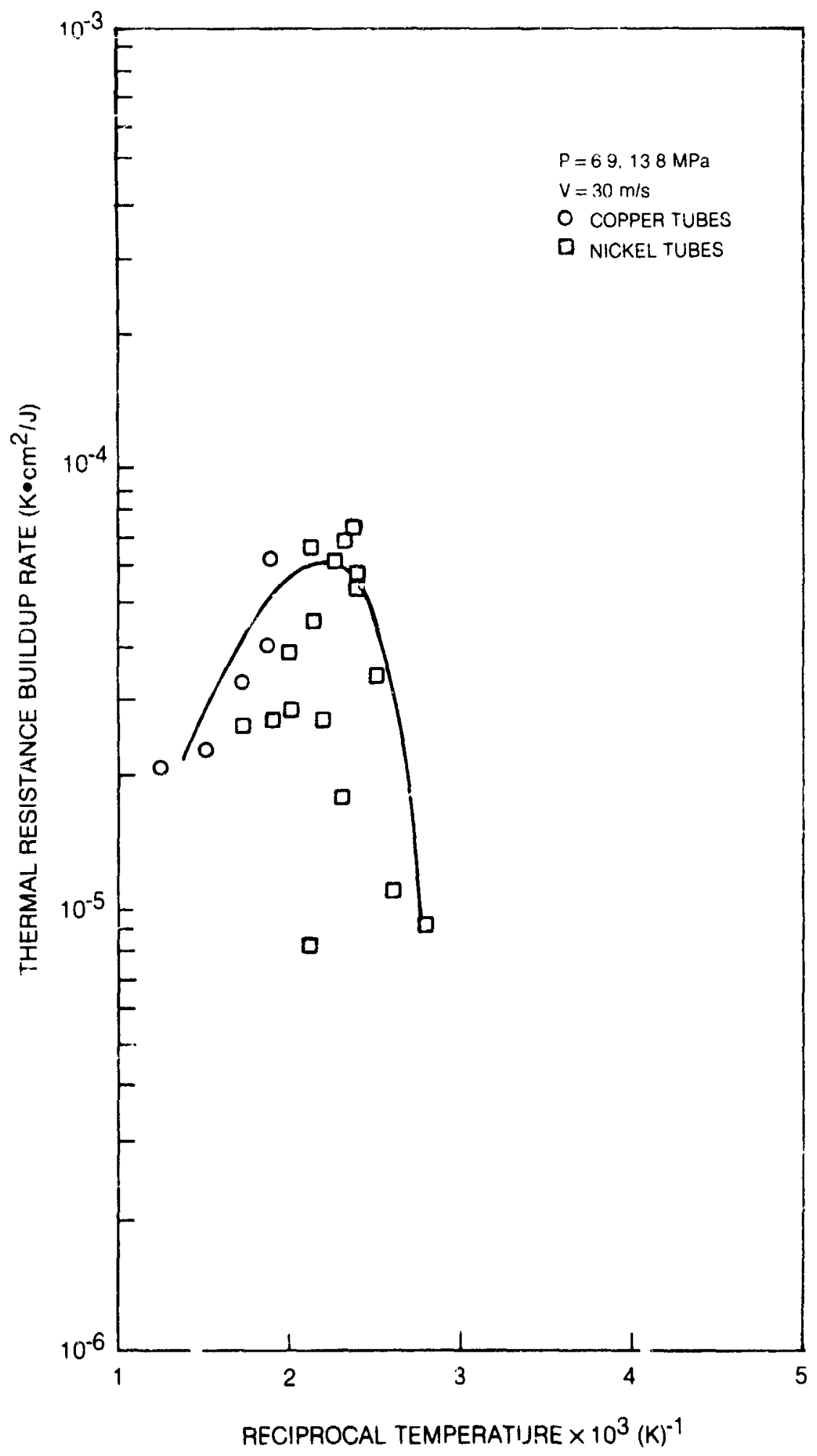

Figure 21. Deposit Thermal Resistance Buildup Rate for Commerclal-Grade Propane 
ORIGHIAL PR:SE TE

OF POOR QUALITY

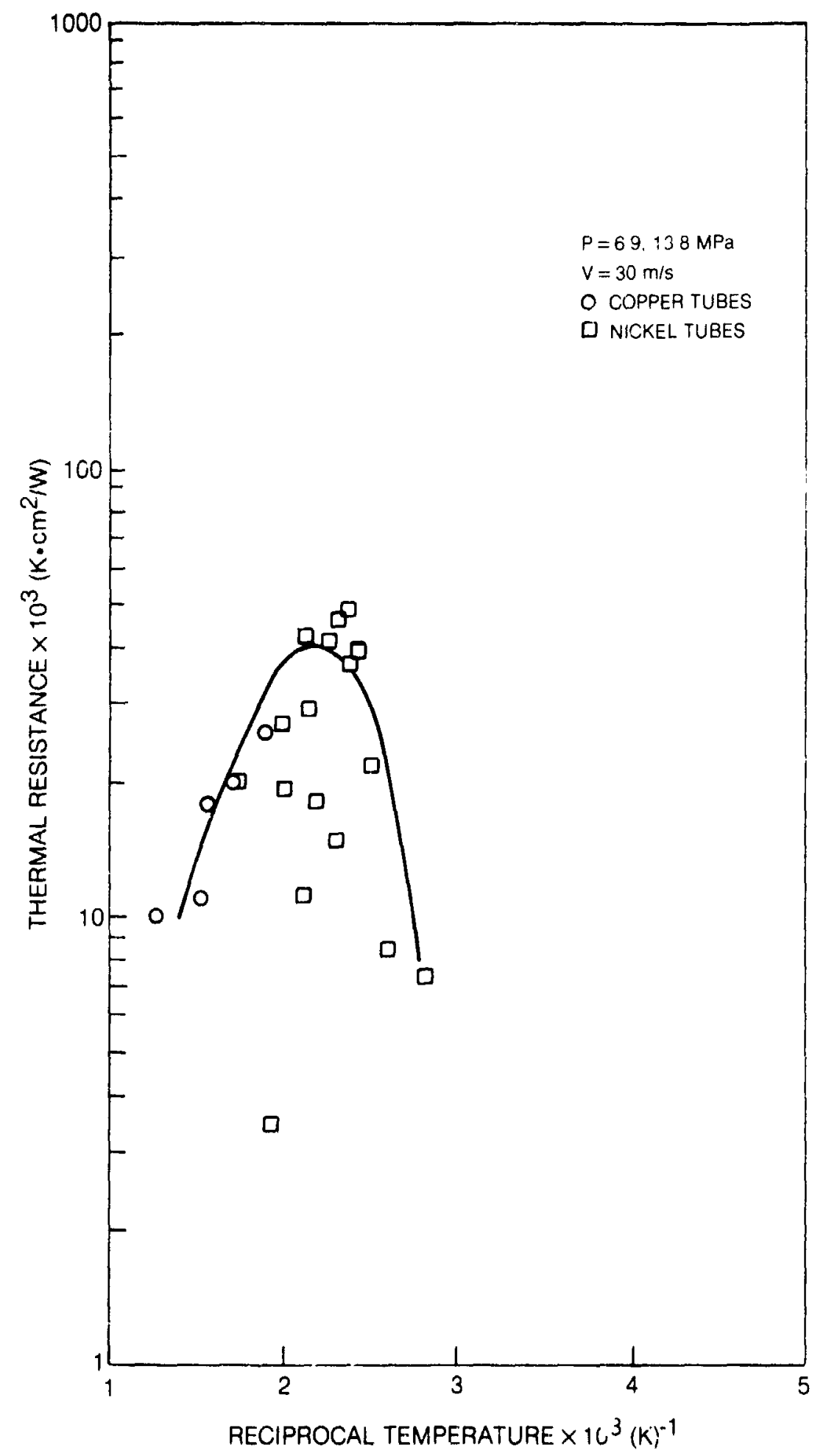

Figure 22. Deposit Thermal Resistance for Commercial.Grade Propane 


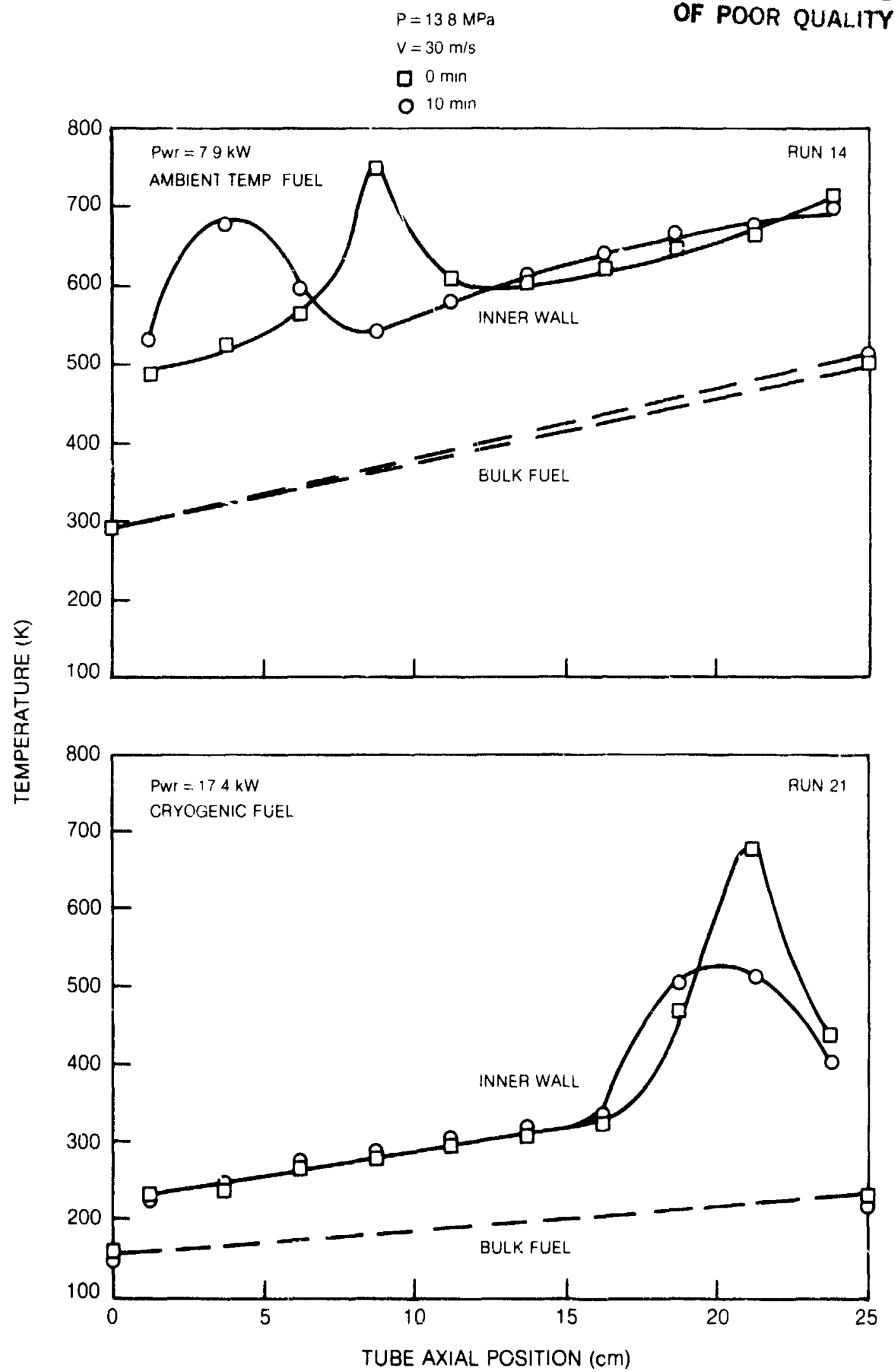

Figure 23. Wall and Bulk Fuel Temperaturs Proflles for Ambient Temperature and Cryogenic Natural Gas in Copper Tubss 


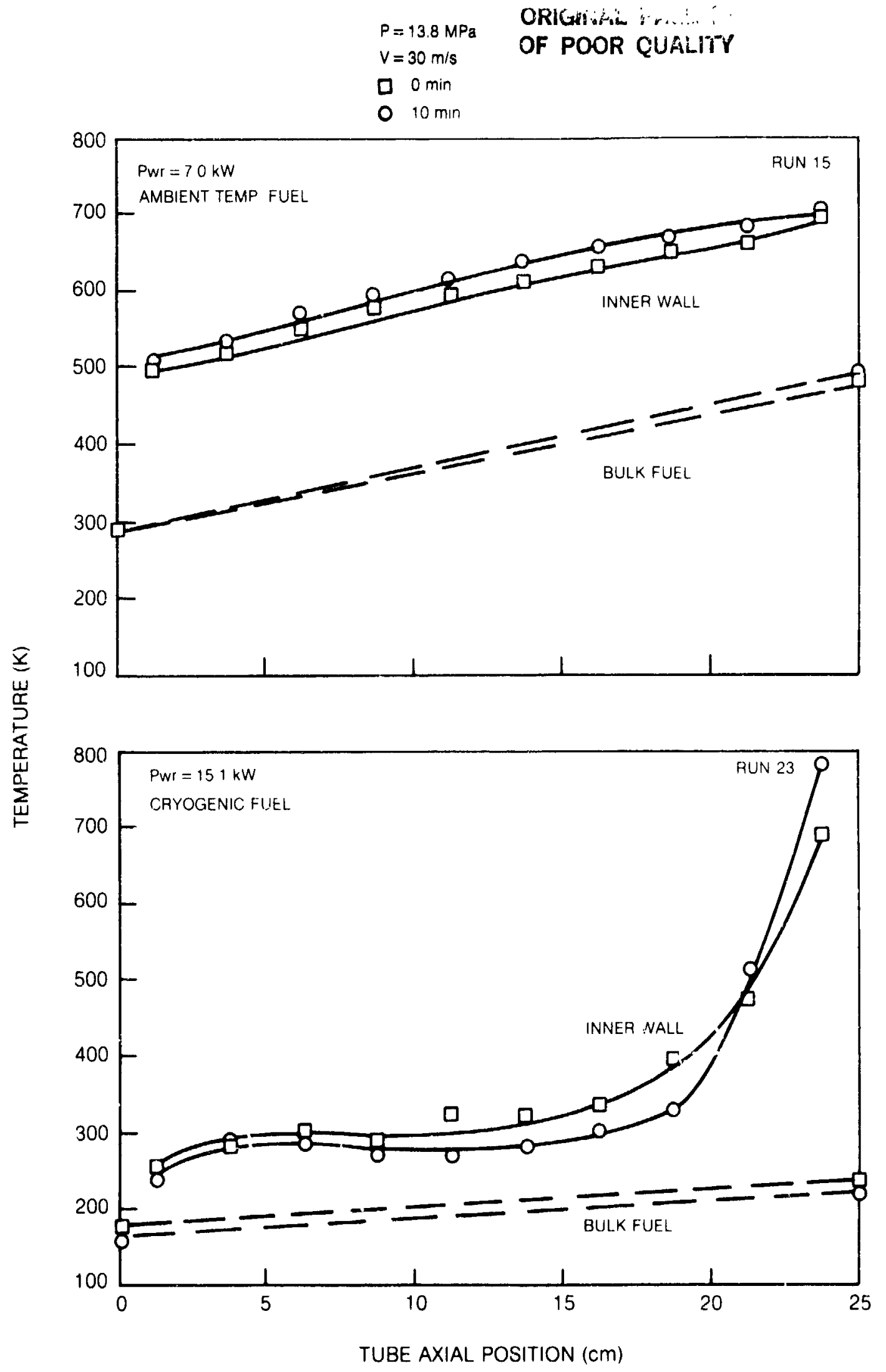

Figure 24. Wall and Bulk Fivel Temperature Profiles for Ambient Temporature and Cryogenic Natural Gas in Nickel Tulues

$P=13.8 \mathrm{MPa}$

$V=30 \mathrm{~m} / \mathrm{s}$

a $0 \mathrm{~min}$

O $10 \mathrm{~m} / \mathrm{n}$ 
ORIGHAR OSOE:

OF POOR QUALITY

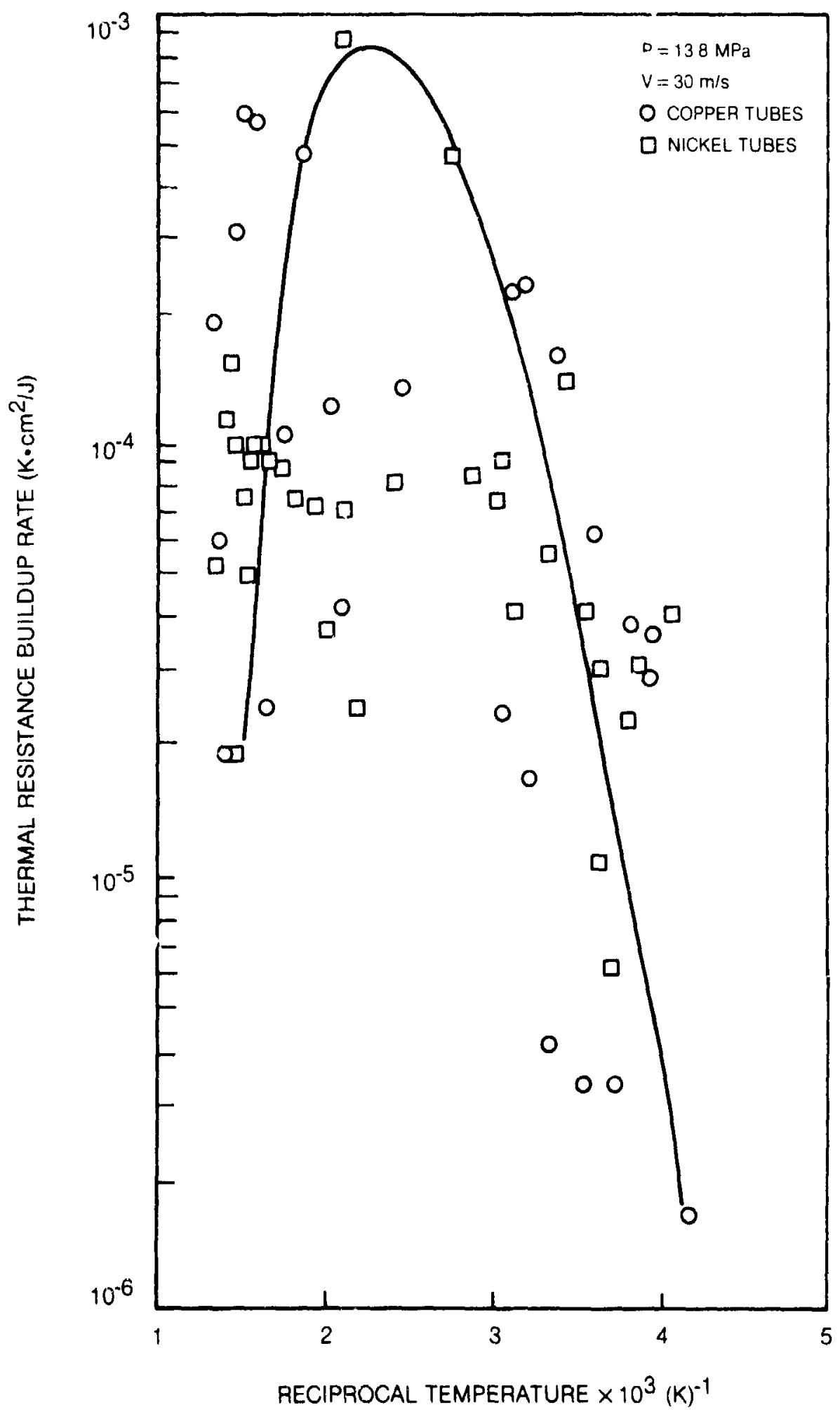

Figure 25. Deposit Thermal Resistance Buildup Rate for Natural Gas 
ORIGINFL $\because \therefore: 1$

OF POOR QUALITY

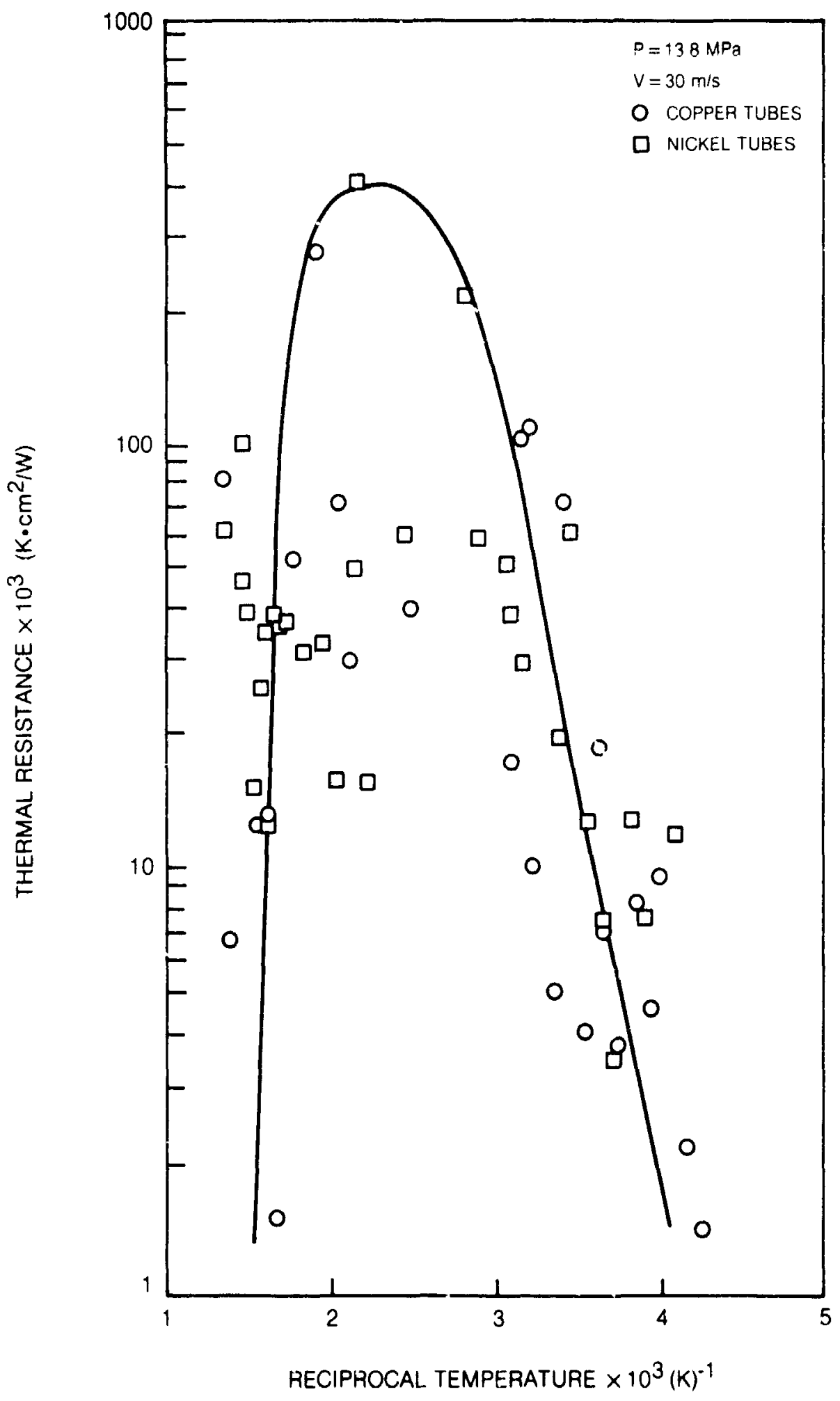

Figure 26. Deposit Thermal Resistancs for Natural Gas 


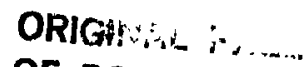

OF POOR QUALIT

(a)

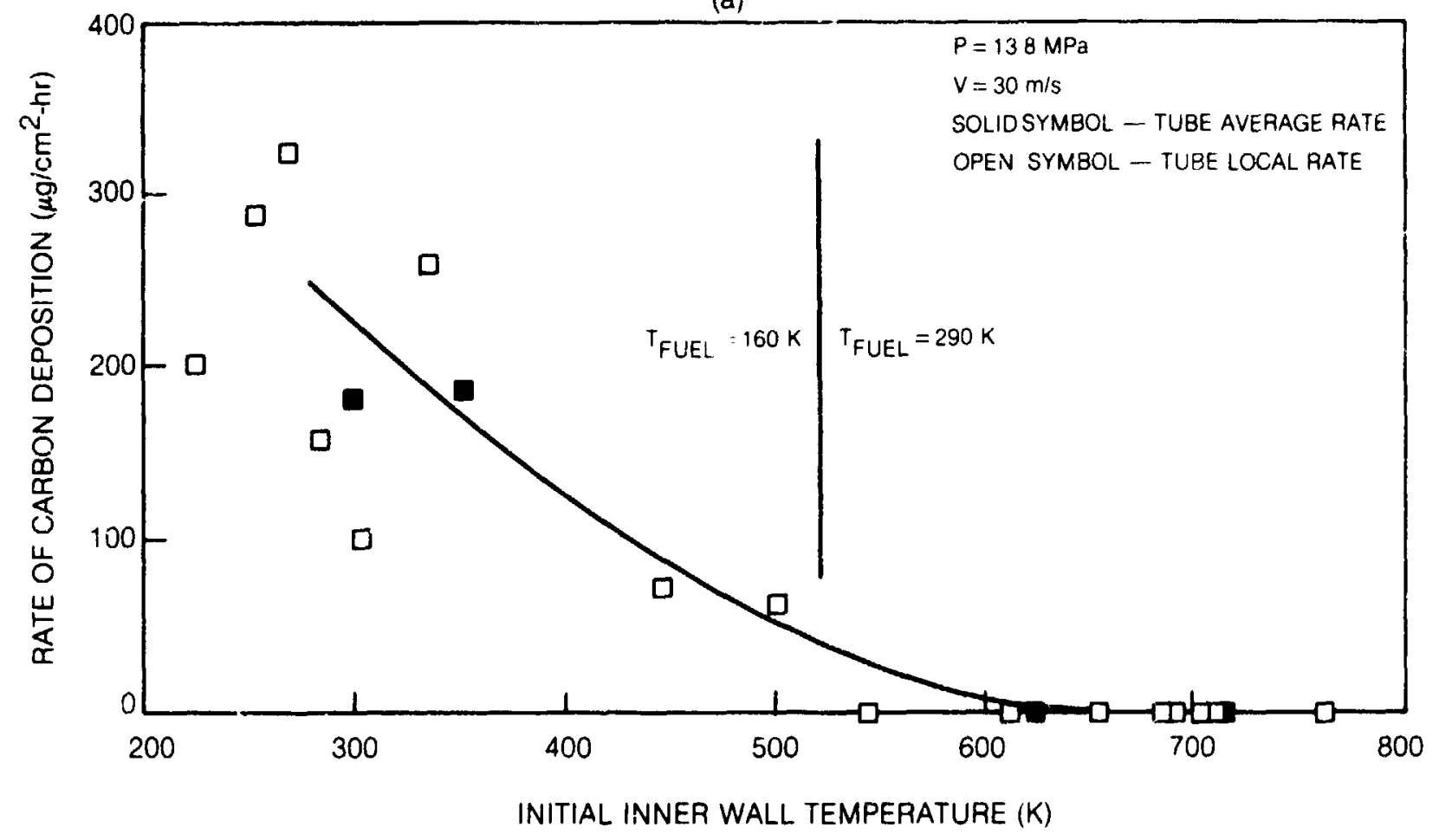

(b)

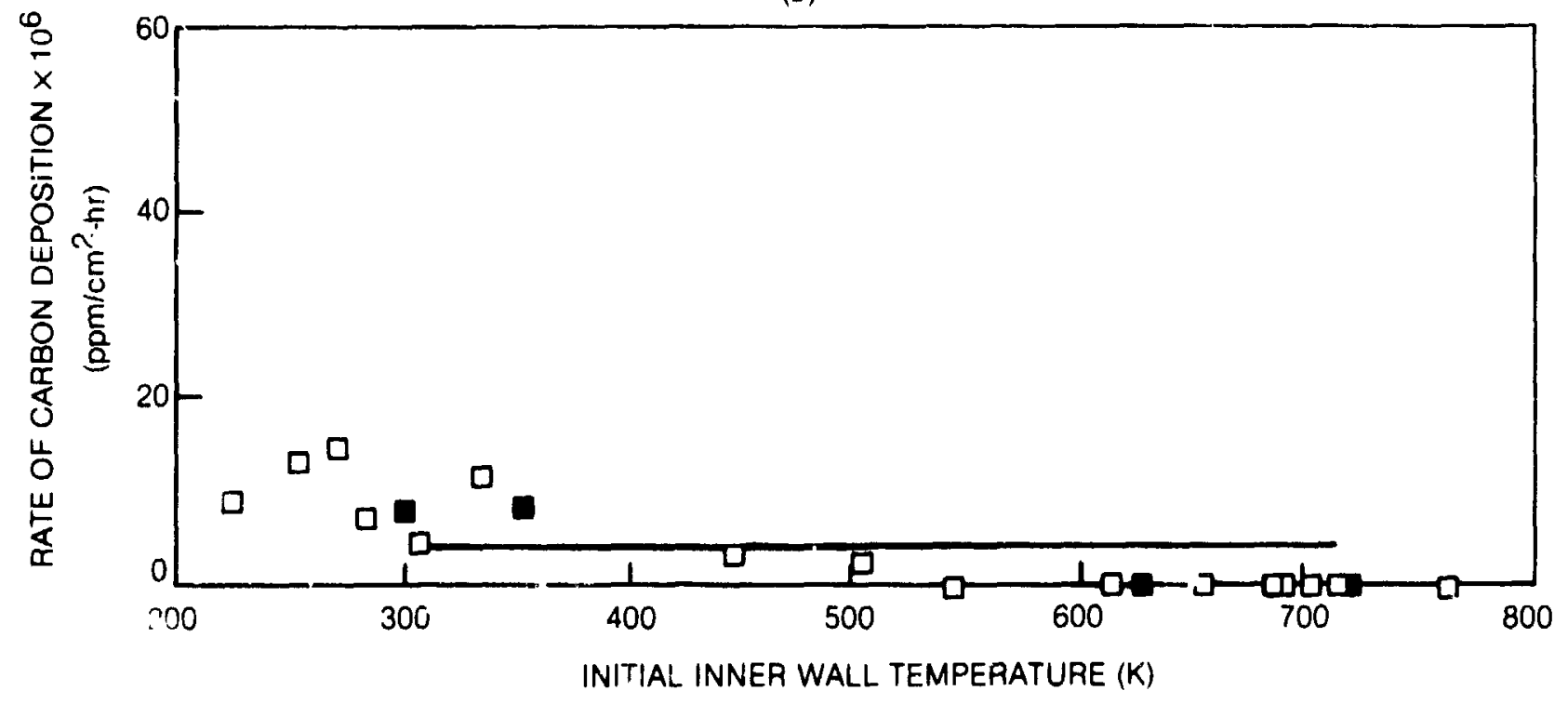

Figure 27. Absolute and Normalized Rates of Carbon Deposition for Natural Gas in Copper Tubes 
(a)

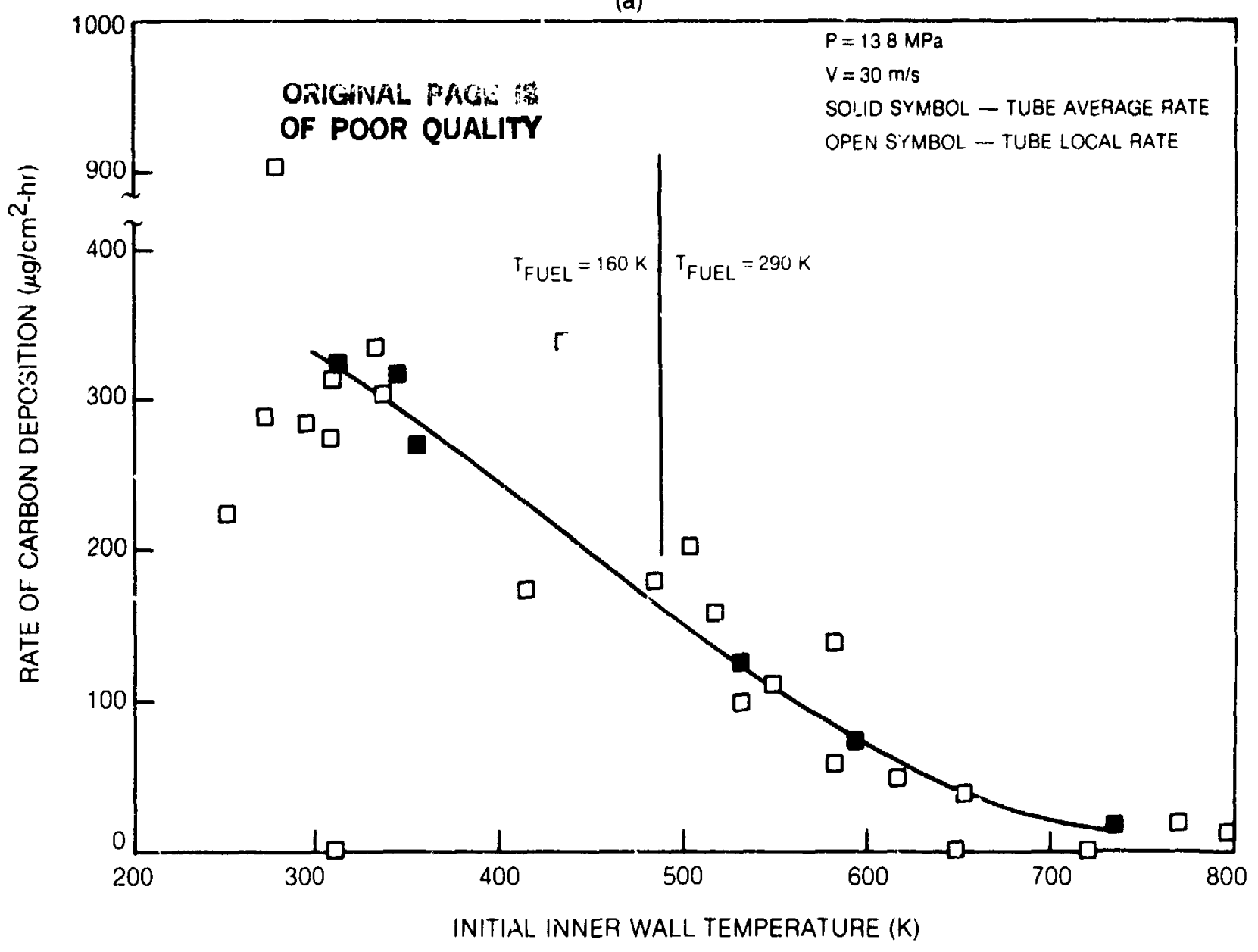

(b)

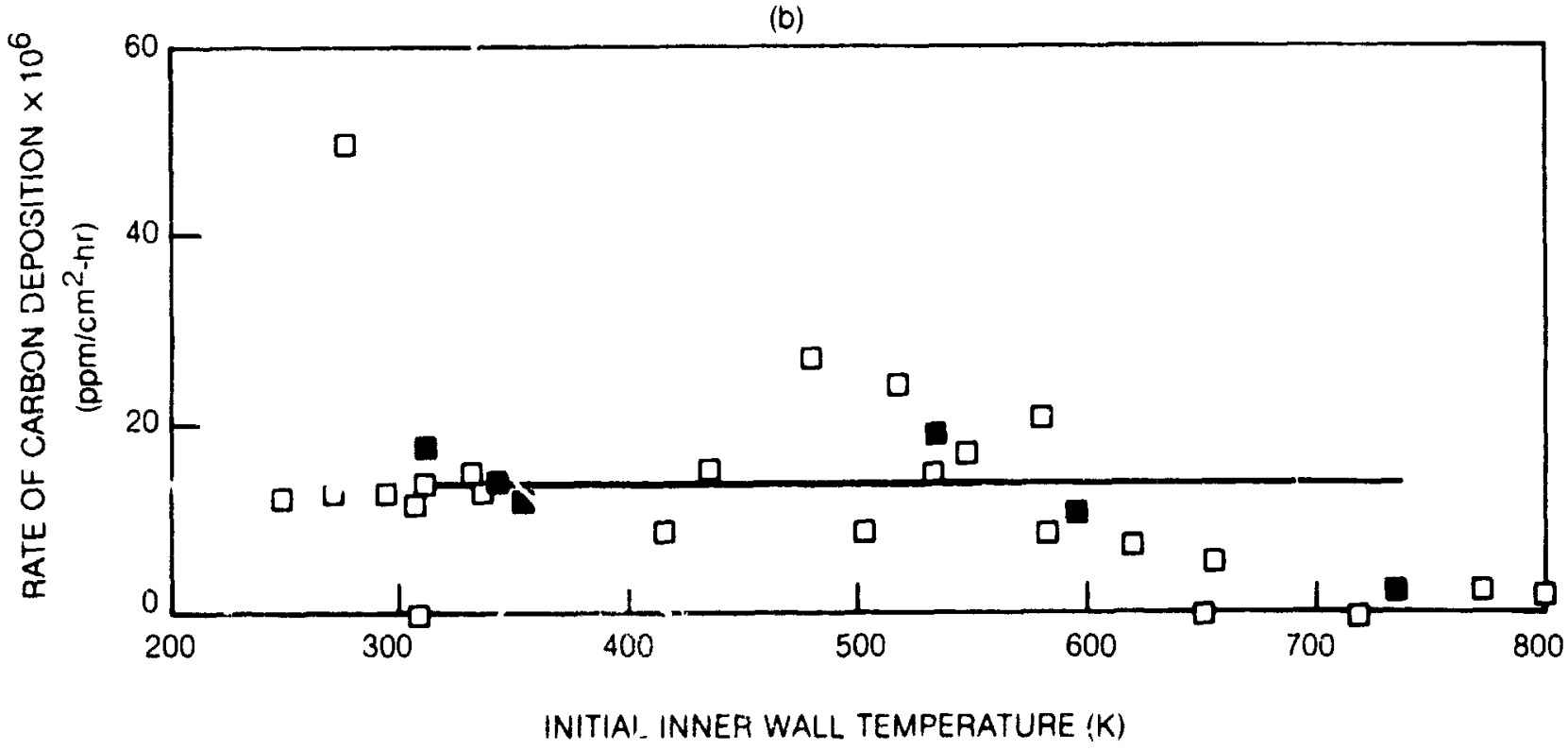

Figure 28. Absolute and Normslized Rates o' Carbon Deposition for Natural Gas in Nickel Tubes 
ORIGINAL Fris:

OF POOR QUALITY

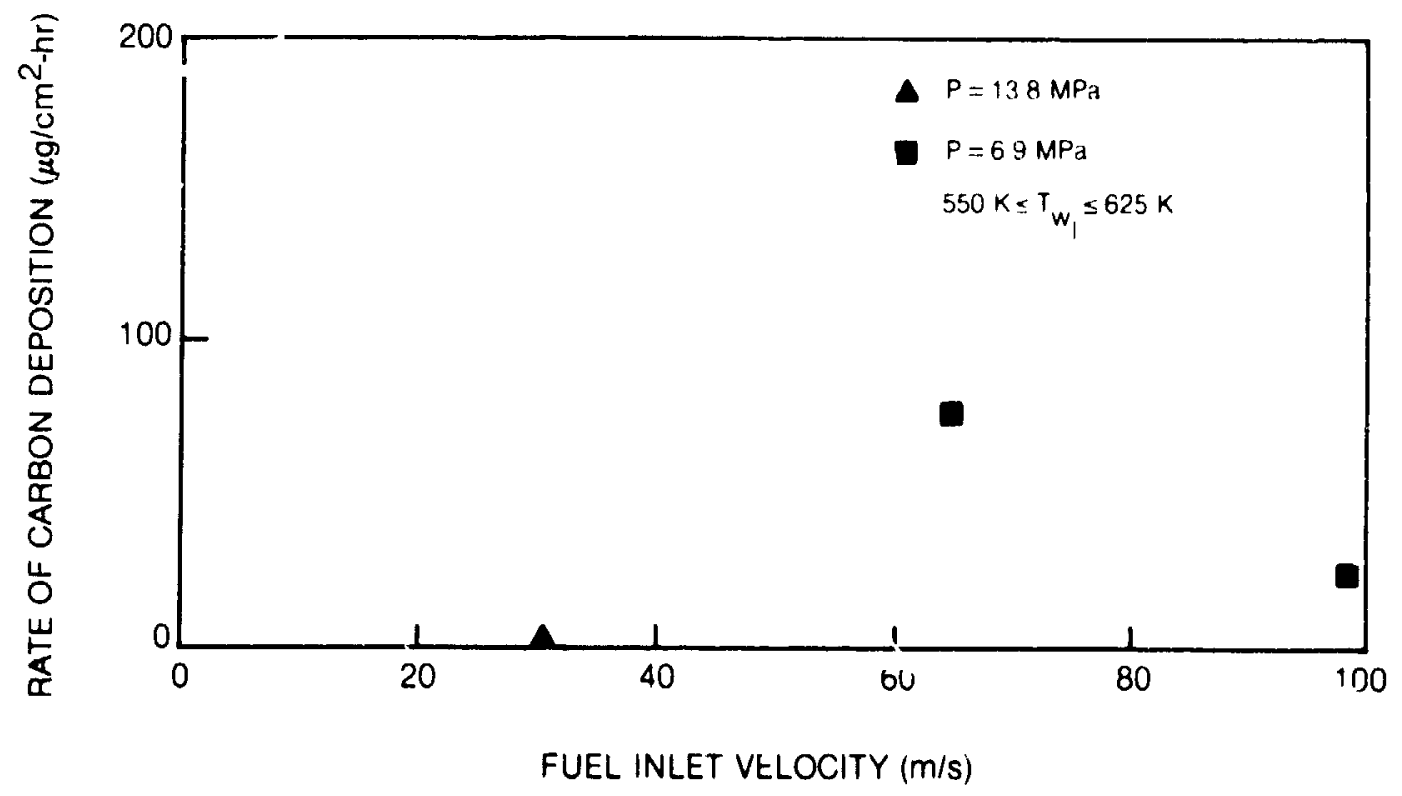

Figure 29. Effect of Fuel Velocity on Carbon Deposition for Natural Gas in Copper Tubes 


\section{OR!CANAL PAG: IS \\ OF POOR QUALIT}

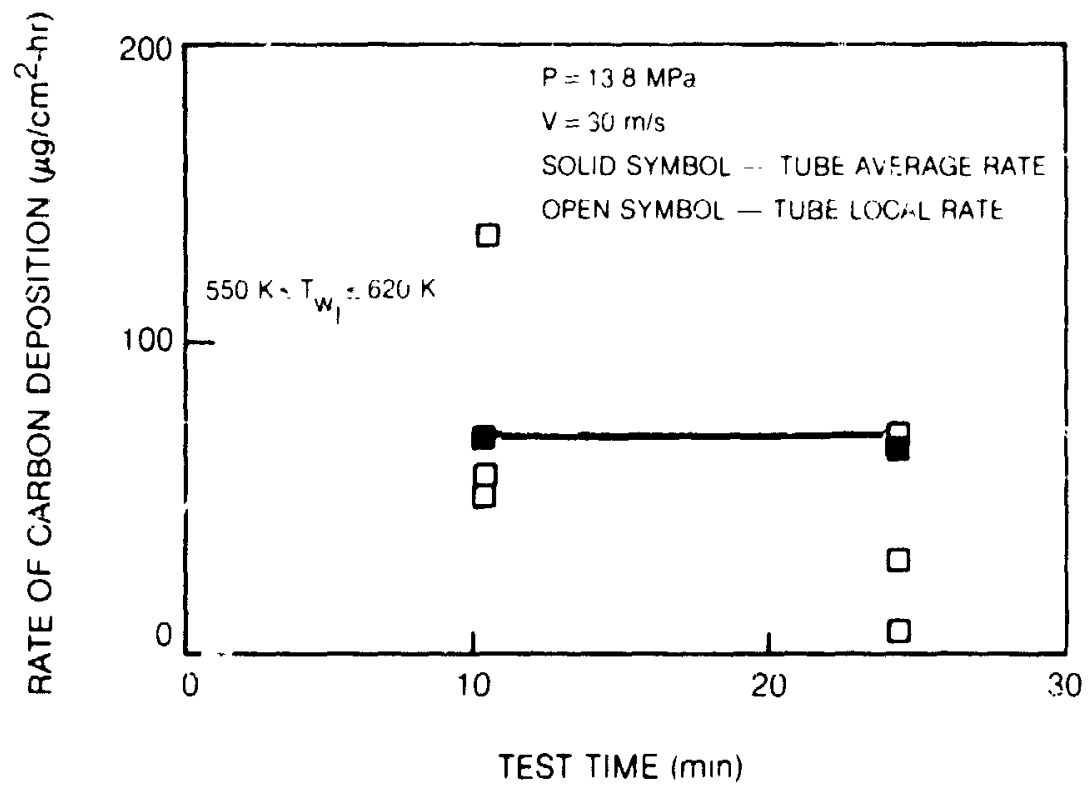

Figure 30. Eftect of Intermiltent Operation and Test Time on Carbon Deposition for Natural Gas in Nickel Tubes 
ORIGINAL FAC:

OF POOR QUALITY
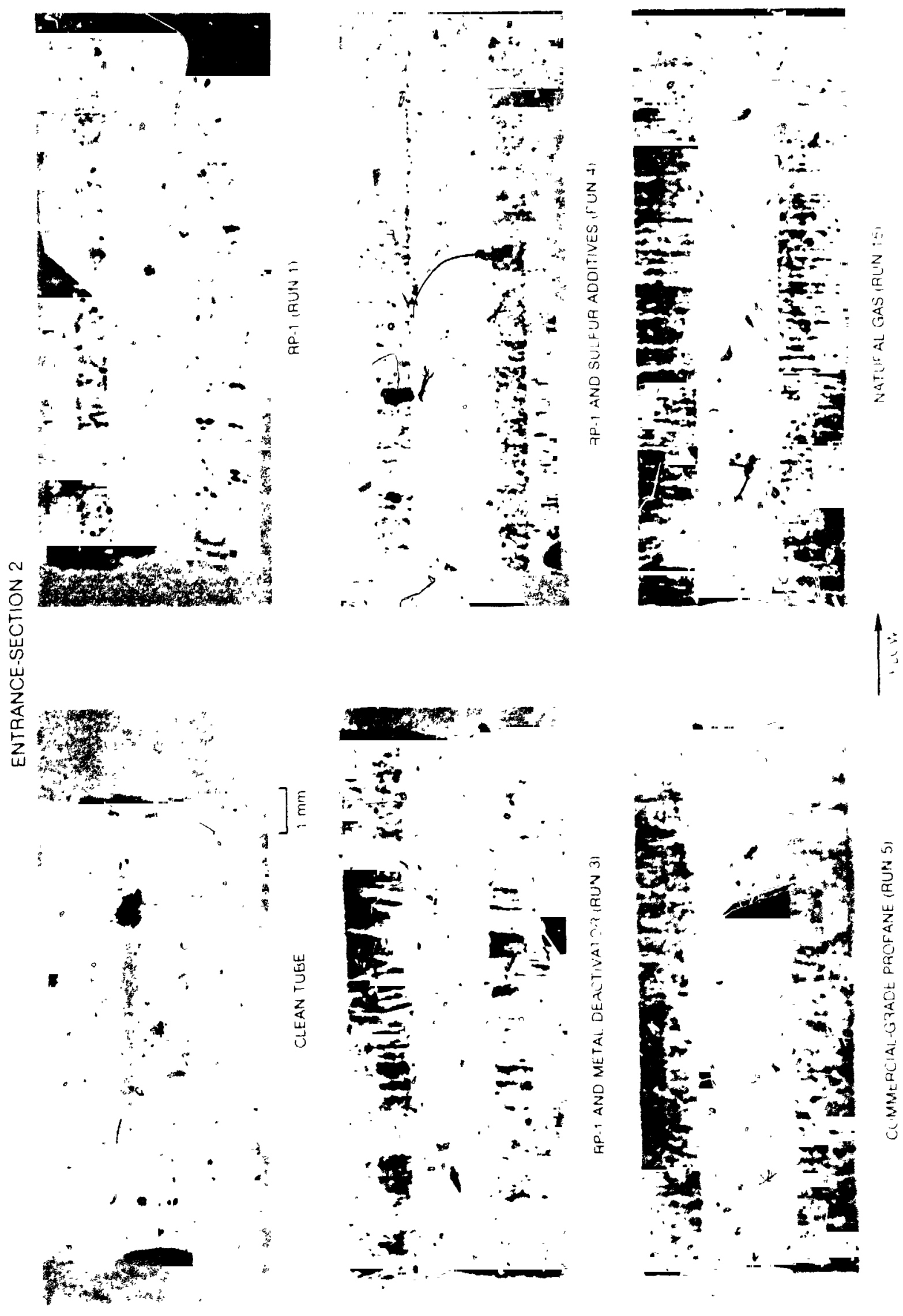

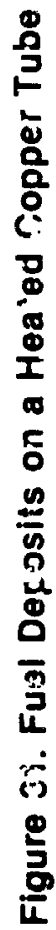

$83-8 \cdot .54-1$ 


\section{ORIGINAL PAGE IS \\ OF POOR QUALITY}

(a)

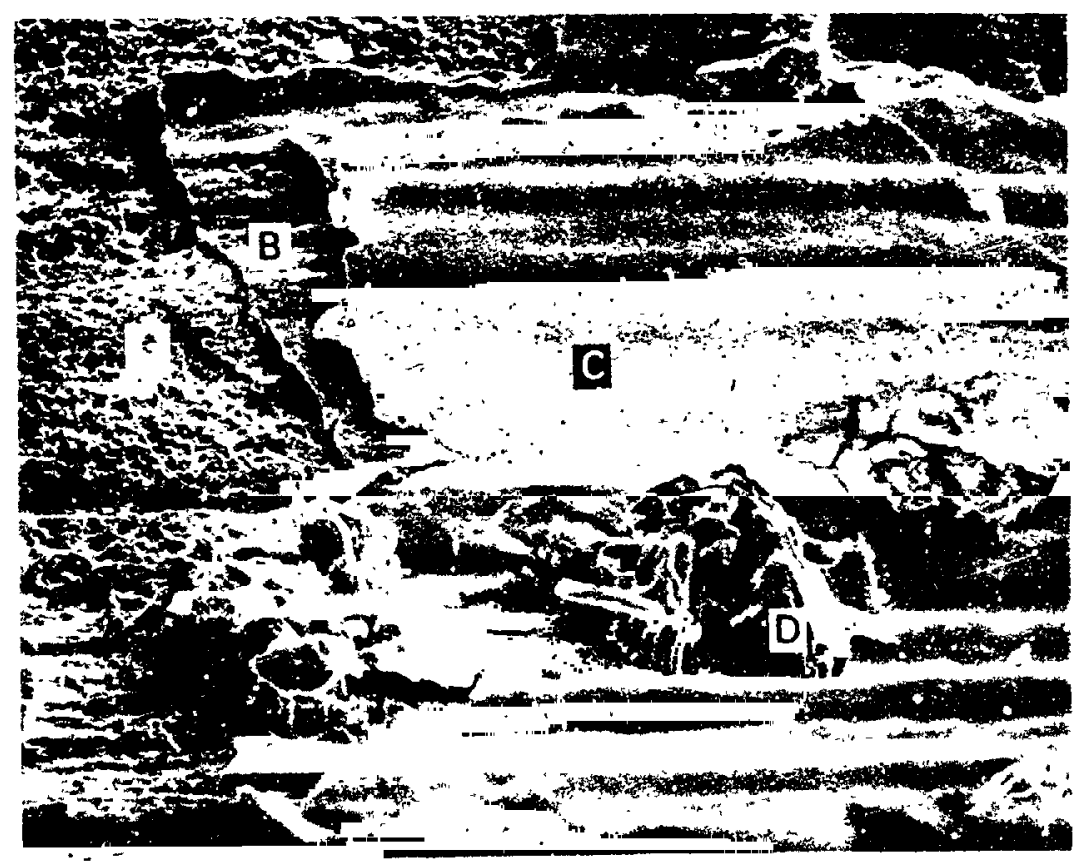

(b)

$01 \mathrm{~mm}$
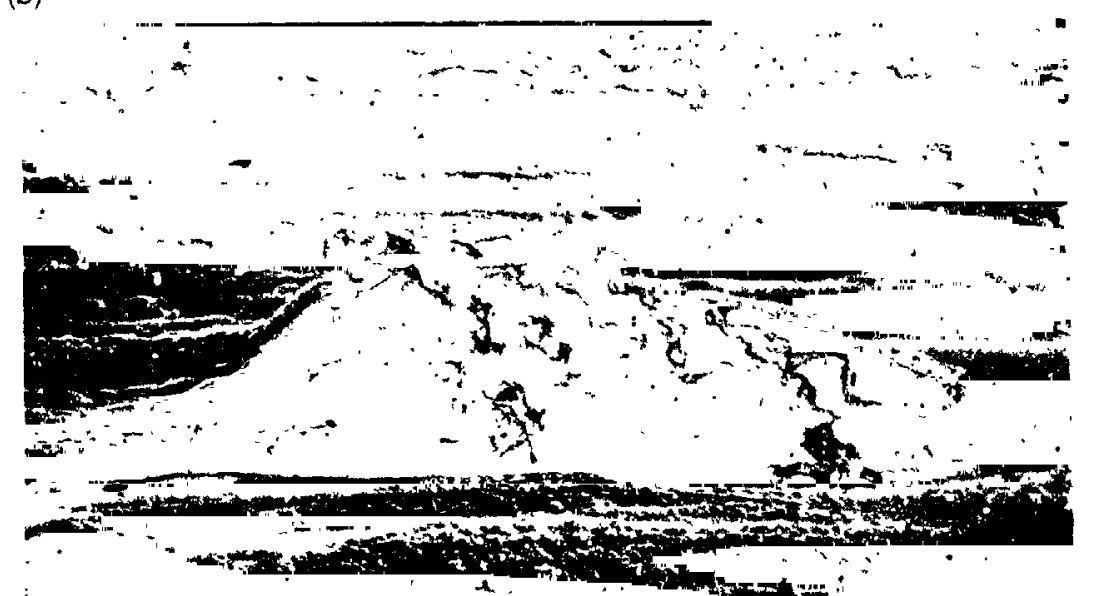

Flgure 32. Deposit Morphology for RP.1 Doped with Sulfur Compounds in a Copper Tube

$$
(-2
$$


ORIGINAL PACE 15

OF POOR QUALITY

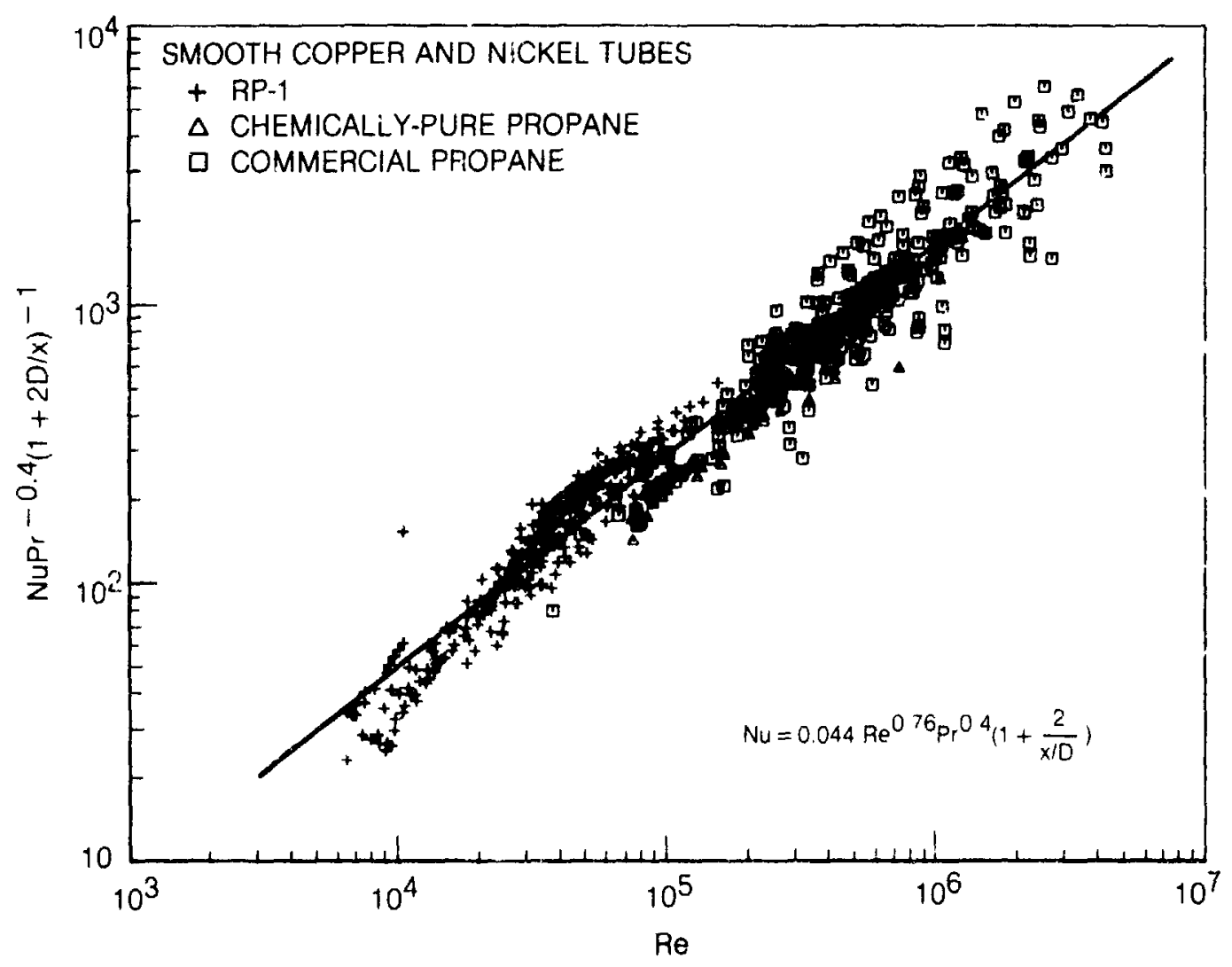

Figure 33. Forced-Convection Heat Transfer for Llquid Hydrocarbons in Clean Tubes 

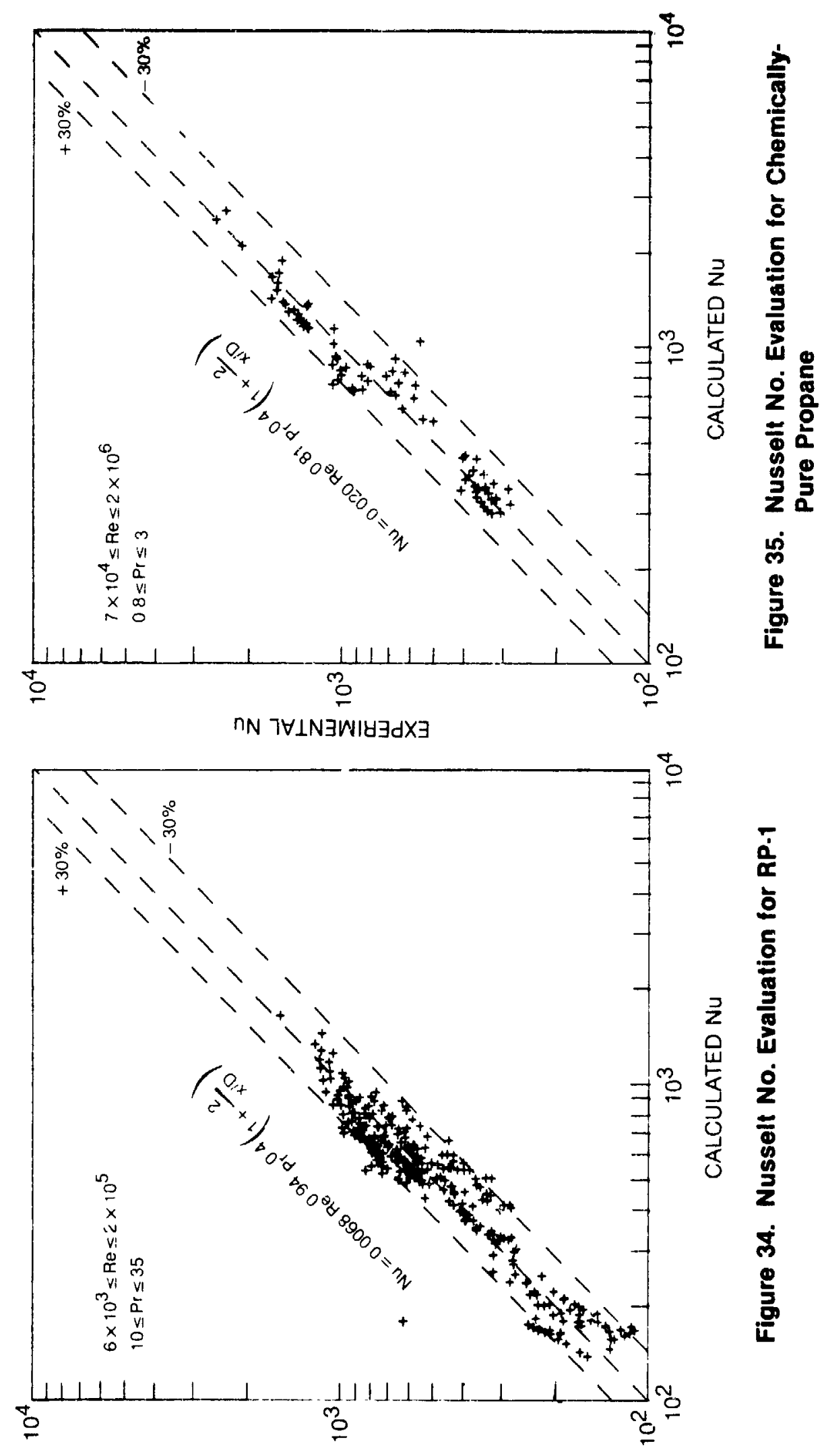

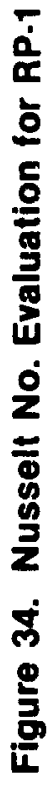

nN $7 \forall \perp N \exists W I Y \exists d \times \exists$ 

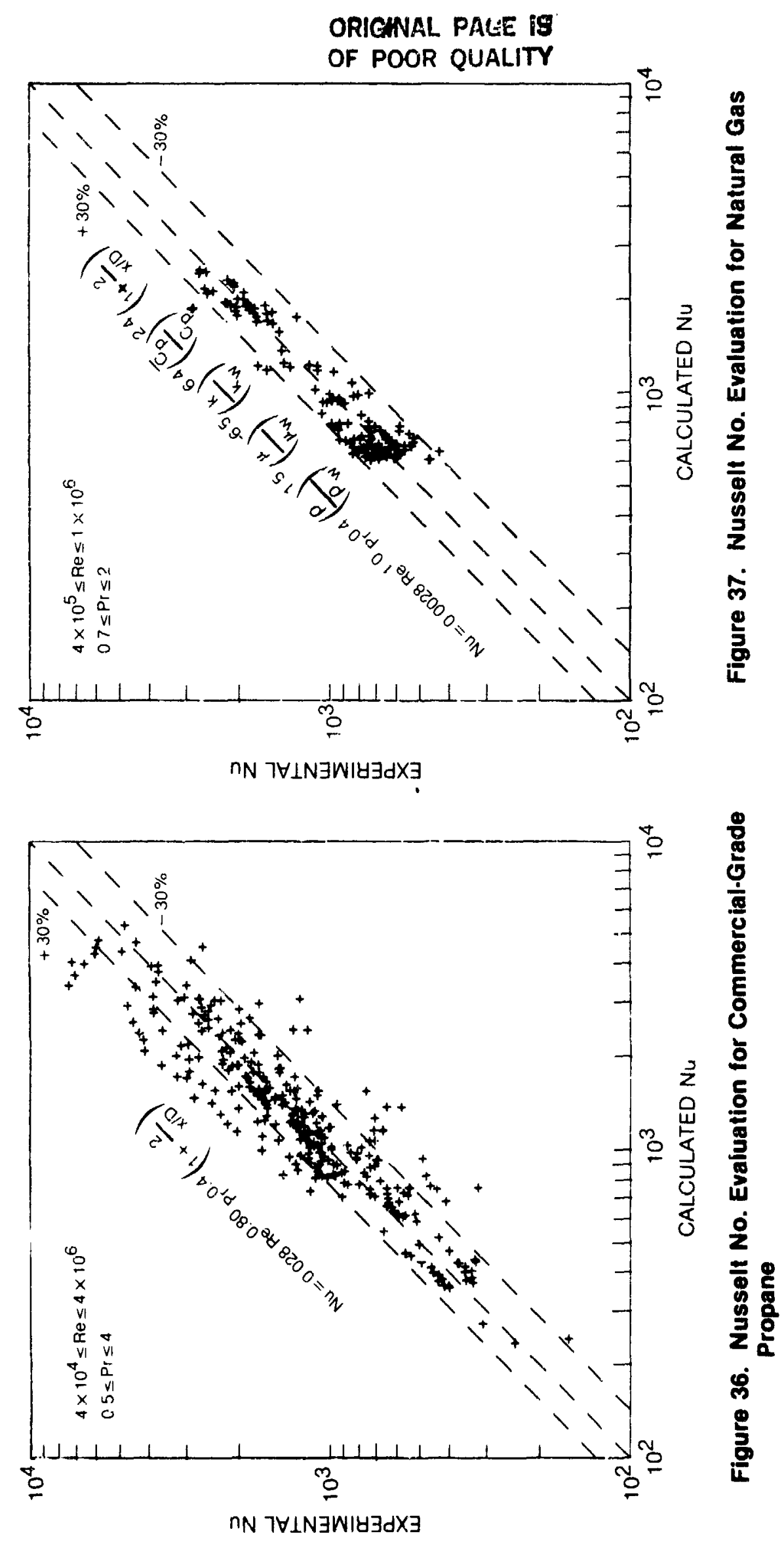
ORIGNAL PHEE IS

OF PC.OR QUALITY

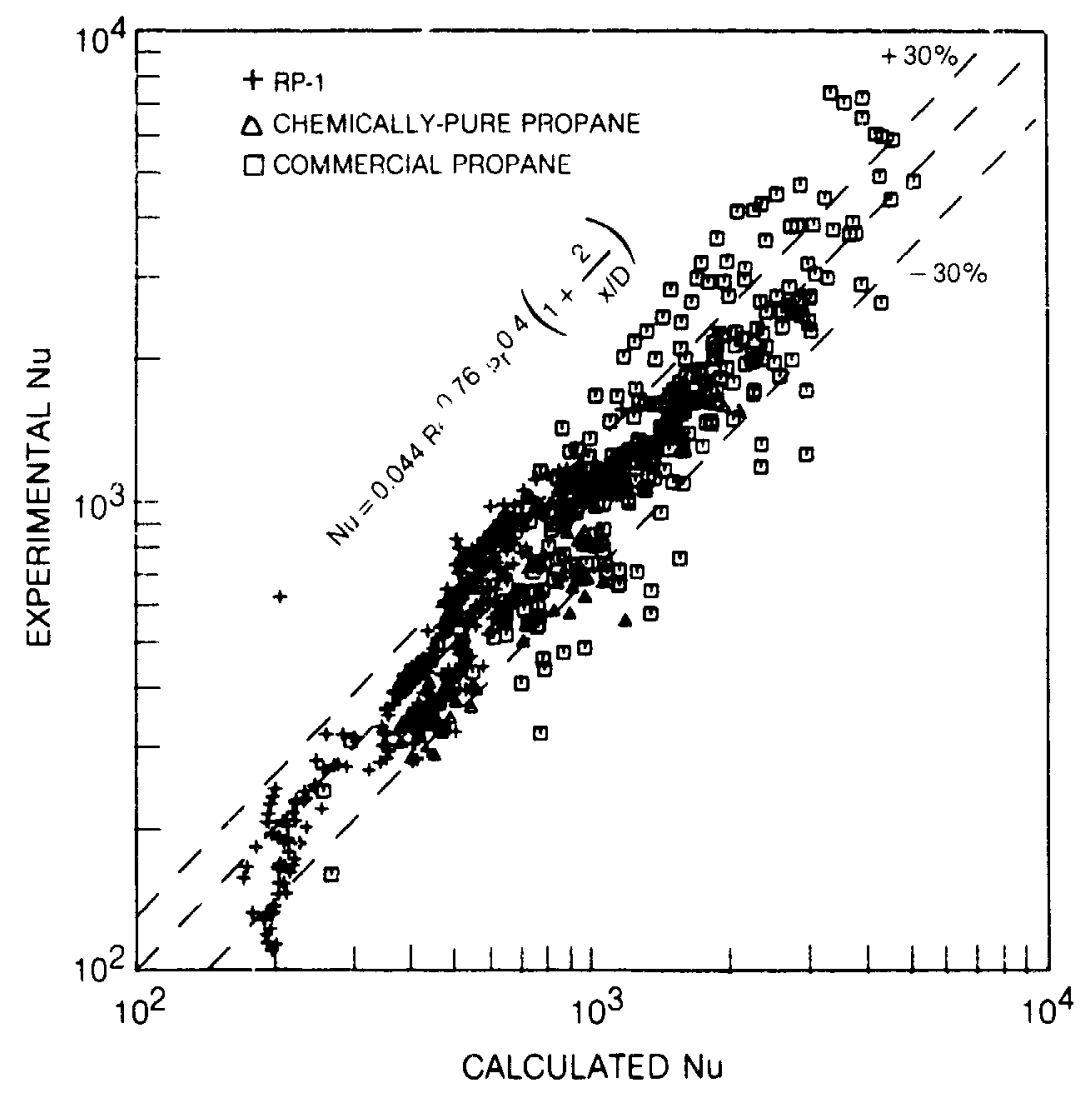

Figure 38. Nusselt No. Evaluation for Several Liquid Hydrocarbon Fuels 


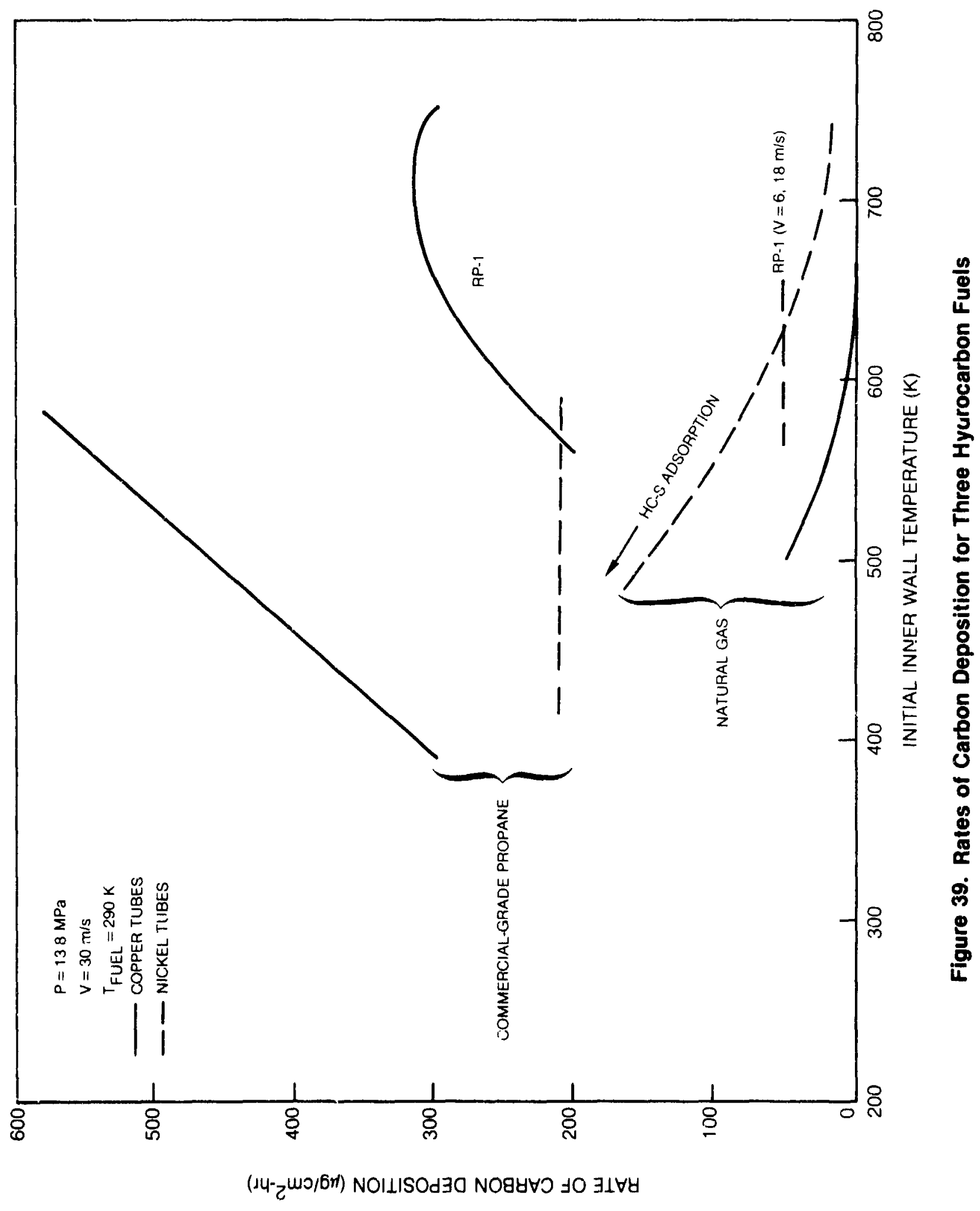


APPENIIX A

TABULATED TEST DATA

A-1 
TABLE A-1

SUMMARY OF DATA REDUCTION PARAMETERS

\begin{tabular}{|c|c|c|c|c|c|}
\hline I tem & Keyword & Definition and Symbol & Units & Measured & Calculated \\
\hline 1 & TW OUT & $\begin{array}{l}\text { Outer tube surface temp- } \\
\text { eralure, } T_{w_{0}}\end{array}$ & K & $\mathbf{x}$ & \\
\hline 2 & TW IN & $\begin{array}{l}\text { Inner tube surface temp- } \\
\text { erature, } T_{w_{i}}(1)\end{array}$ & K & & $\mathbf{x}$ \\
\hline 3 & F'TEL INLET P & Inlet fuel pressure, $P_{1}$ & $\mathrm{MPa}$ & $\mathbf{x}$ & \\
\hline 4 & FUEL EXIT P & Exit fuel pressure, $P_{2}$ & MPa & $\mathrm{x}$ & \\
\hline 5 & FUEL INLET TEMP & $\begin{array}{l}\text { Inlet fuel tempera- } \\
\text { ture, } \mathrm{T}_{\mathrm{f}_{l}}\end{array}$ & $\mathrm{~K}$ & $\mathbf{x}$ & \\
\hline 6 & FUEL EXIT TEMP & $\begin{array}{l}\text { Exit fuel temperature, } \\
T_{f_{2}}\end{array}$ & K & $\mathbf{x}$ & \\
\hline 7 & FLOW RATE & Fuel mass flow rate, $\dot{m}$ & $\mathrm{~kg} / \mathrm{s}$ & $\mathbf{x}$ & \\
\hline 8 & CURKENT & $\begin{array}{l}\text { Surrent through test } \\
\text { tube, I }\end{array}$ & Amps & $\mathbf{x}$ & \\
\hline 9 & VOLTAGE & $\begin{array}{l}\text { Voltage drop across test } \\
\text { tube, V }\end{array}$ & Volts & $\mathrm{x}$ & \\
\hline 10 & POWER & $\begin{array}{l}\text { Electrical power dis- } \\
\text { sipated in test tube, } \\
E=I \cdot V\end{array}$ & $\mathrm{~kW}$ & & $\mathbf{x}$ \\
\hline 11 & HEAT FLUX & $\begin{array}{l}\text { Electrical power E div- } \\
\text { ided by total inside lat- } \\
\text { eral surface area of test } \\
\text { tube, }(Q / A)\end{array}$ & $\mathrm{W} / \mathrm{cm}^{2}$ & & $\lambda$ \\
\hline 12 & INLET FUEL VEL & $\begin{array}{l}\text { Inlet fuel velocity as } \\
\text { calculated from steady } \\
\text { flow continuity, } v\end{array}$ & $\mathrm{~m} / \mathrm{s}$ & & $\mathbf{x}$ \\
\hline
\end{tabular}




\section{TABLE A-1 (Cont'd)}

\section{ORIGINAL PAGE IS}

SUMMARY OF DATA REDUCTION PARAMETERS

\begin{tabular}{|c|c|c|c|c|c|}
\hline Item & Keyword & Definition and Symbol & Units & Measured & Calculated \\
\hline 13 & ENERGY BALANCE & $\begin{array}{l}\text { Consistency check between } \\
\text { electrical power supplied } \\
\text { to test tube and thermal } \\
\text { power absorbed by fuel, } \\
\text { EB }(2)\end{array}$ & percent & & $\mathbf{x}$ \\
\hline 14 & $\begin{array}{l}\text { INLET REYNOLDS } \\
\text { NO }\end{array}$ & $\begin{array}{l}\text { Reynolds number at test } \\
\text { cube entrance based on } \\
\text { inside tube diameter, } \operatorname{Re}_{D}\end{array}$ & - & & $x$ \\
\hline 15 & $\begin{array}{l}\text { AVG IRICTION } \\
\text { FACTOR }\end{array}$ & $\begin{array}{l}\text { Tube overal } \\
\text { factor, } f(3) \text { friction }\end{array}$ & - & & $\mathrm{x}$ \\
\hline 16 & U & $\begin{array}{l}\text { Overall inside wall heat } \\
\text { transfer coefficient, } U\end{array}$ & $\mathrm{~W} / \mathrm{cm}^{2} \cdot \mathrm{K}$ & & $\mathrm{x}$ \\
\hline 17 & $\mathrm{~T} / \mathrm{K}$ & $\begin{array}{l}\text { Deposit thermal resistance } \\
\text { defined as ratio of deposit } \\
\text { thickness to deposit thermal } \\
\text { conductivity, t/k }\end{array}$ & $\mathrm{K} \cdot \mathrm{cm}^{2} / \mathrm{W}$ & & $\mathrm{x}$ \\
\hline 18 & $\mathbf{R C}$ & $\begin{array}{l}\text { Thermal resistance build- } \\
\text { rate, } k_{c}\end{array}$ & $\mathrm{~K} \cdot \mathrm{cm}^{2} / \mathrm{J}$ & & $\mathbf{x}$ \\
\hline
\end{tabular}

(1)

$$
T_{w_{i}}=T_{w_{0}}-1.27 \mathrm{E}
$$

(2)

$$
\begin{aligned}
E B=100 \frac{\dot{m{ }_{P_{b}}}\left(T_{f_{2}}-T_{f_{1}}\right)-E}{E} & E B=100 \frac{\dot{m}\left(h_{2}-h_{1}\right)-E}{E} \\
(R P-1) & \text { (Propane ana Natural Gas) }
\end{aligned}
$$

(3)

$$
f=\frac{\pi^{2}\left(p_{1}-P_{2}\right) \bar{\rho}_{b} D^{5}}{32 \dot{m}^{2} L}
$$

Note: $\vec{C}_{p_{b}}$ and $\vec{p}_{b}$ are evaluated at the bulk mean fuel temperature $\left(T_{f_{1}}+T_{f_{2}}\right) / 2$ 


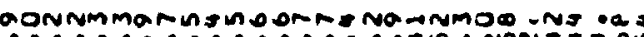

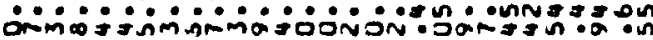

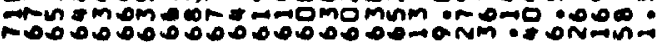

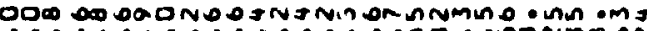

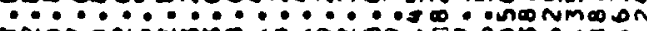

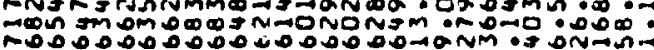

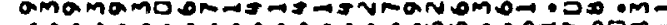

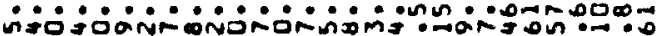 Nobisg}

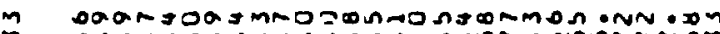

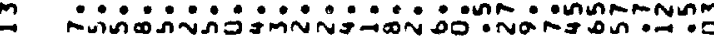

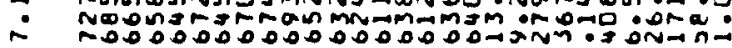

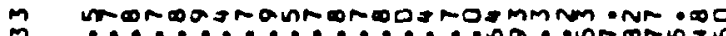

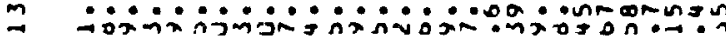

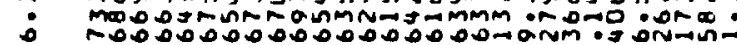
$m$ m $m$ socos

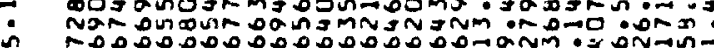

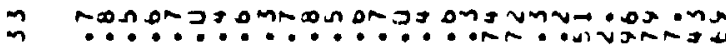

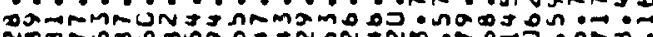

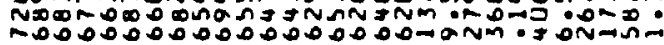

$\because \because \cdots 0 \cdots \cdots \cdots$

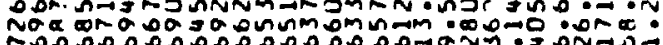

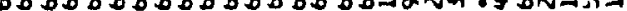

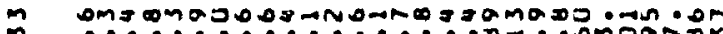

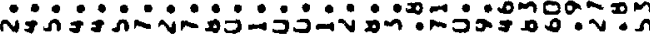

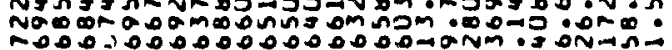

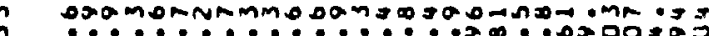

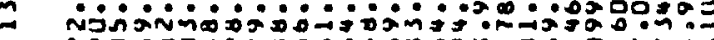

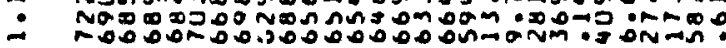

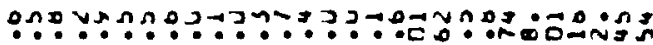

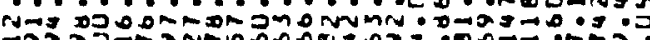

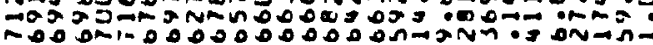

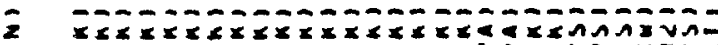

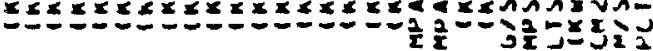

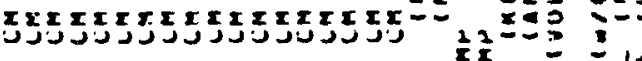

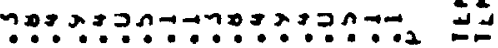

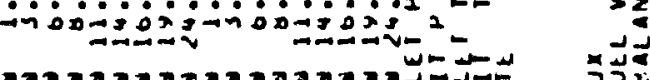

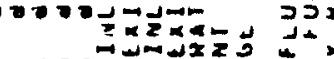

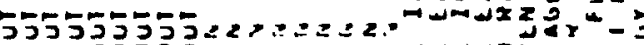

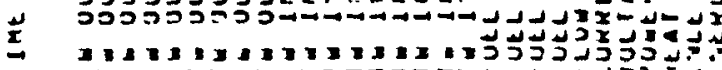

ORICNAL PAGE IS OF POOR QUALITY 


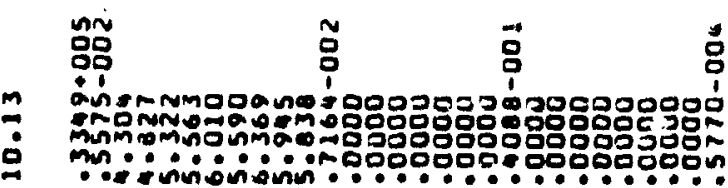

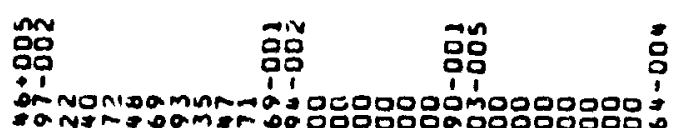

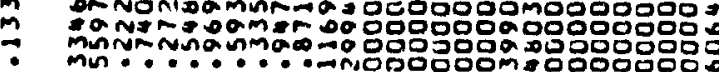

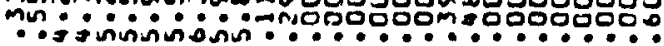

ำ

OO

路

ORIGNAL PAGE IS

$\dddot{m}$

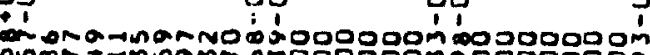

范

mu $\rightarrow$ nnannámmo

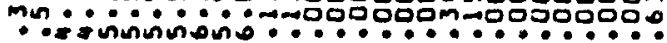

mo

뭄

O⿱一⿻口卄亅八

OF POOR QUALITY

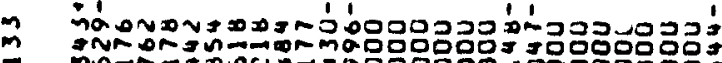

i mü

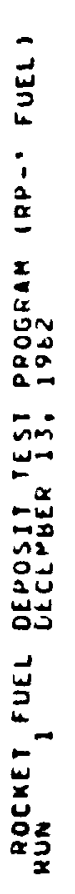

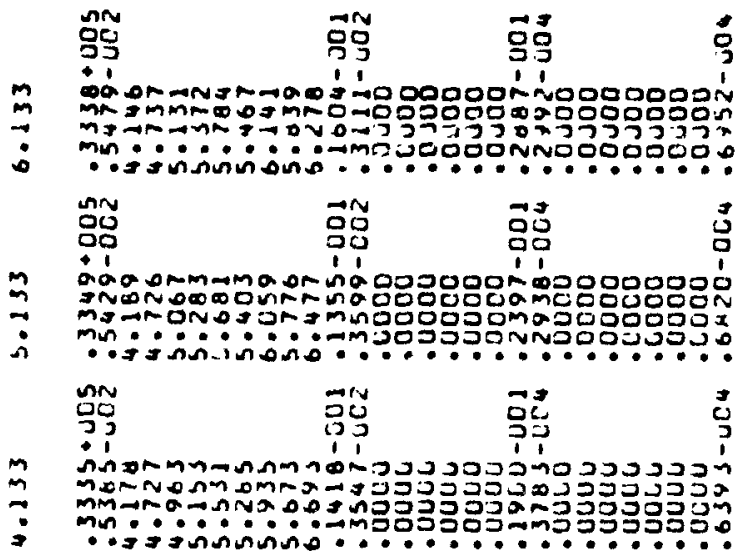




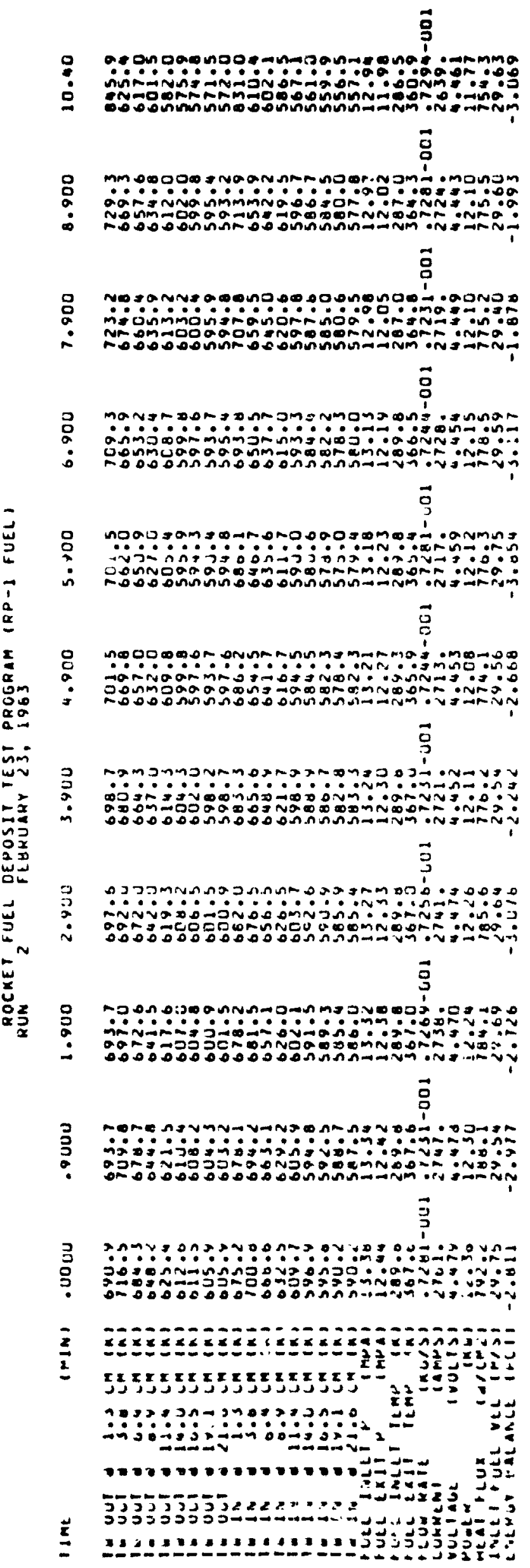

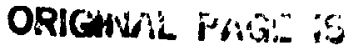
OF POOR QUALITY 


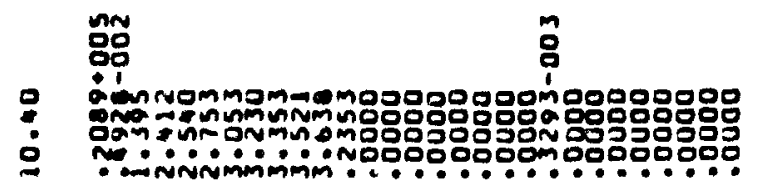

ORICANAL PASE IS

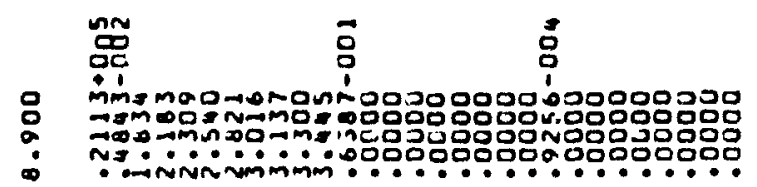
OF POOR QUALITY

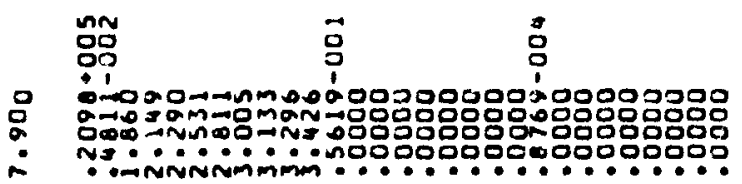

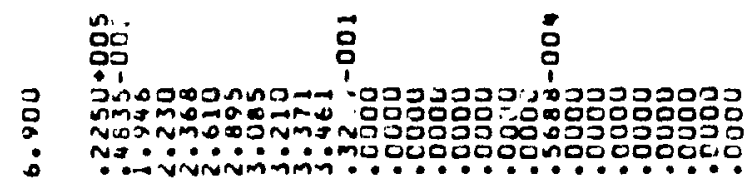

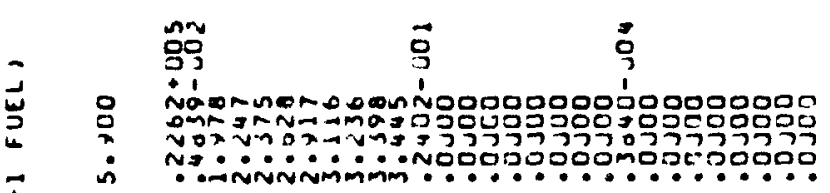

$\vec{i}$

$\underline{a}$

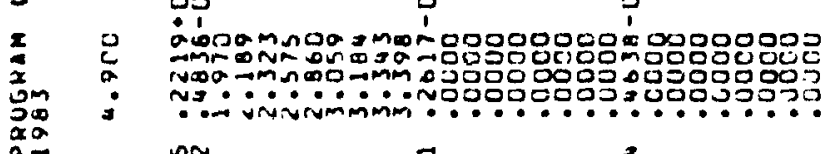

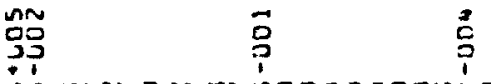

2 :

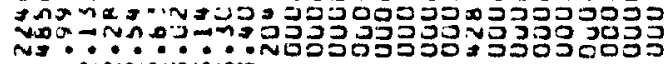

$\because$

คู้

$\overline{3}$

吕

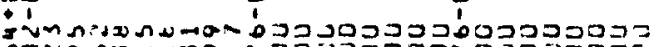

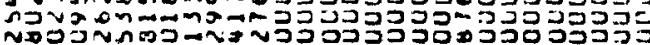

กับำกำ

กn

赵

萑

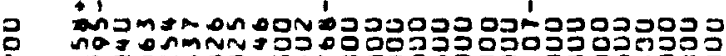

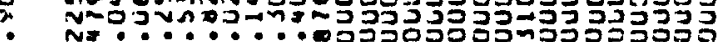

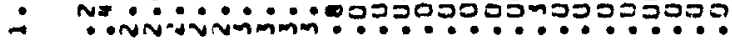

路 莲

ว

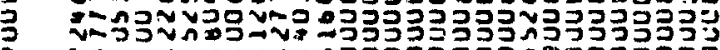

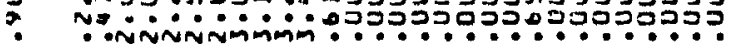

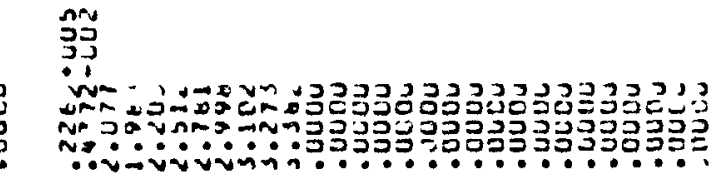

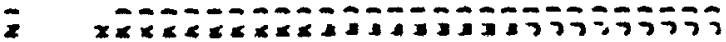

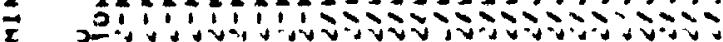

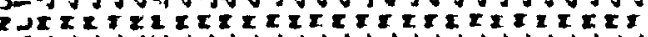

A

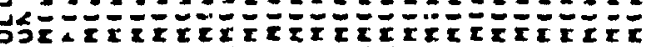
a

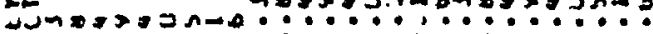

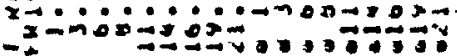

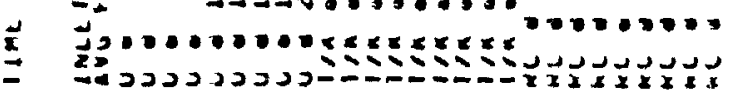


$\vec{\square}$

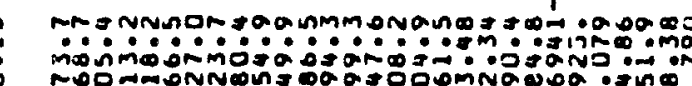

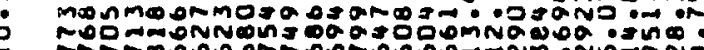

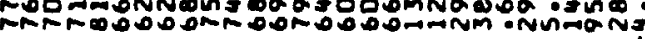

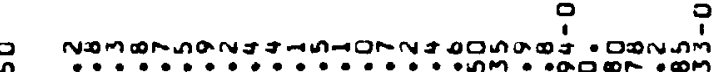
ï

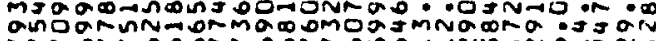

号

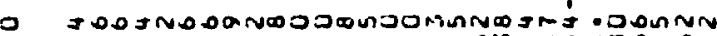

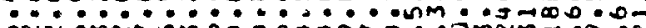

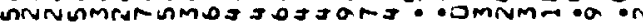
nno nmming

$\overrightarrow{0}$

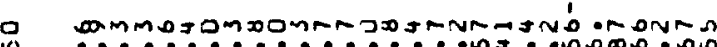
․

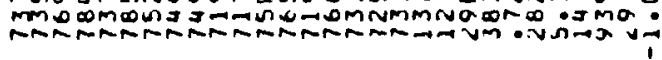

$\overrightarrow{\mathrm{O}}$

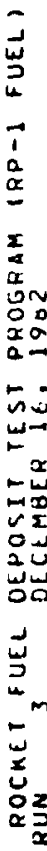

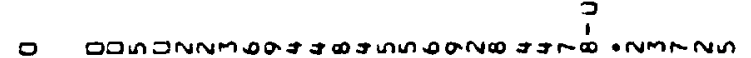
\&

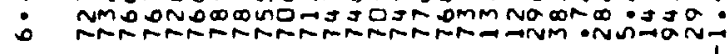

$\overrightarrow{8}$

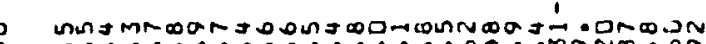

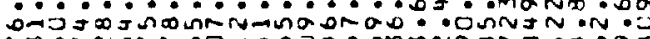

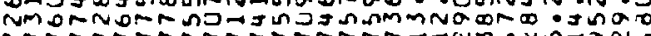

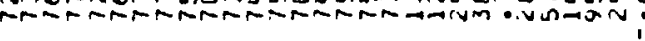<smiles>[SiH3]</smiles>

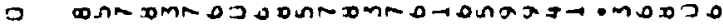
in $\because \cdots \cdots \cdots \cdots \cdots \cdots$ Foms

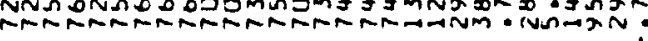

$\overrightarrow{\mathrm{g}}$

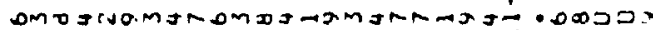

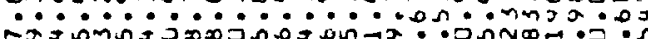

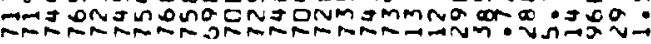

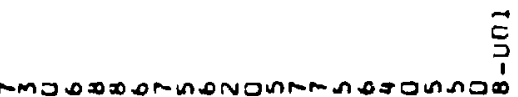

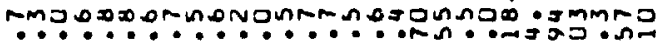

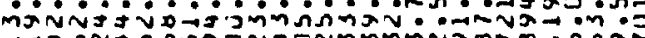

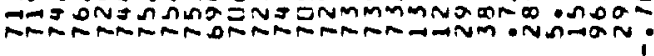

อ

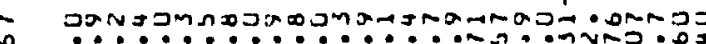

-

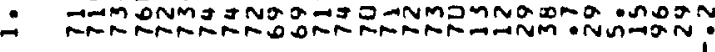

$\overrightarrow{3}$

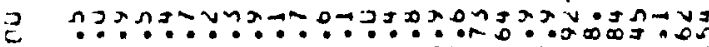

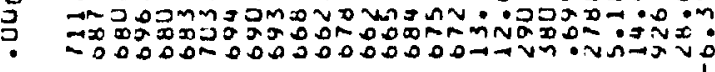

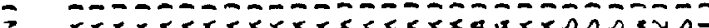

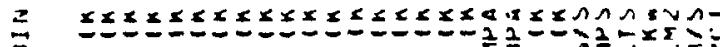

$\overrightarrow{5}$ -

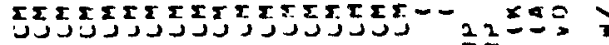

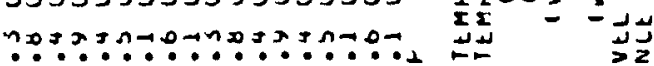

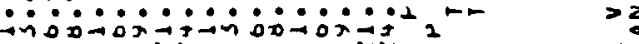

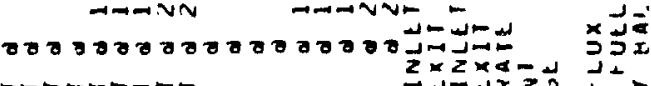

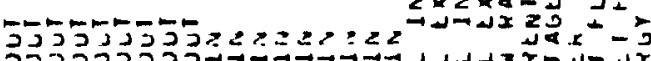
ل20د0ว
ORIENAL PAGE IS OF POOR QUALITY 


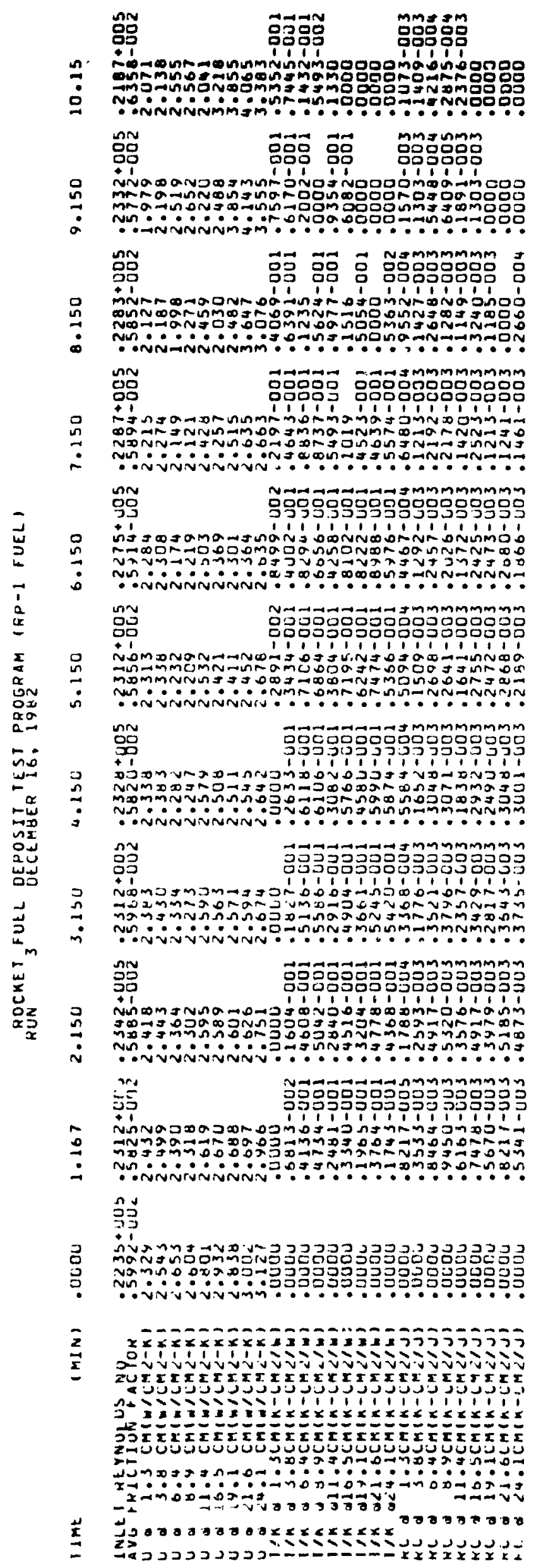

ORIENAL PAGE IS OF POOR QUALITY

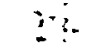




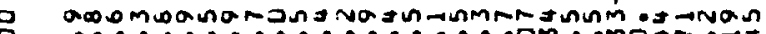

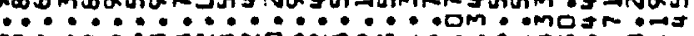

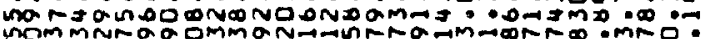

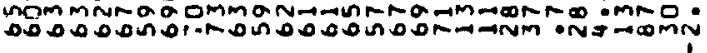

$\overrightarrow{8}$

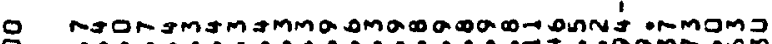

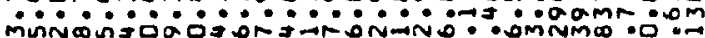

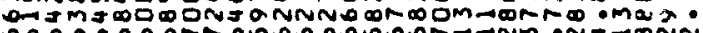

무

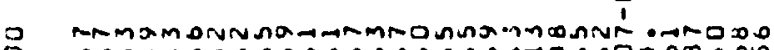
0.0000000Rnons000n00manim 00 作

.

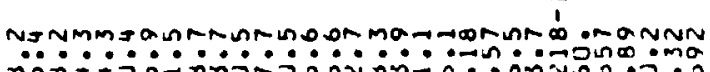

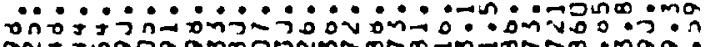

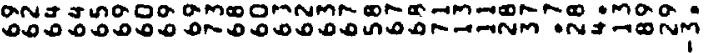

을

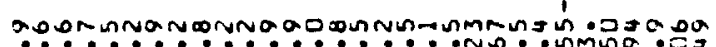

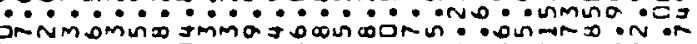

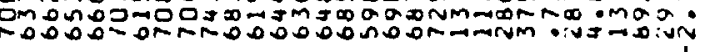

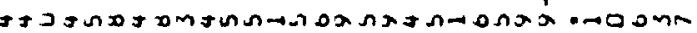
nin-

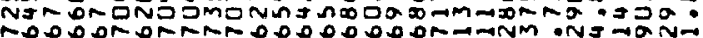

$\overline{8}$

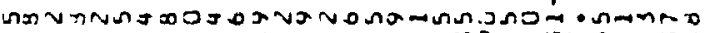

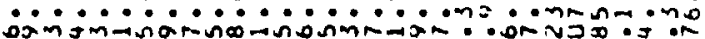

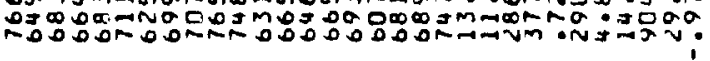

:

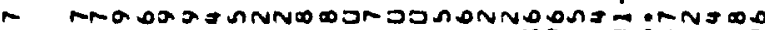
0ำำ morongonth

鸹

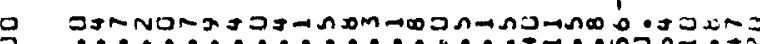

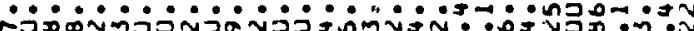

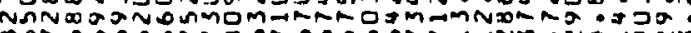<smiles>[SiH3]</smiles>

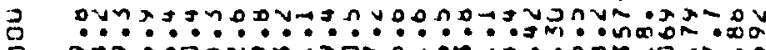
monñ

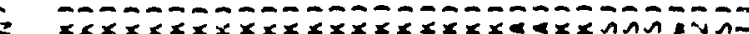

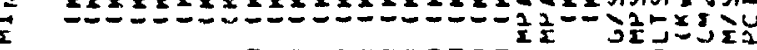

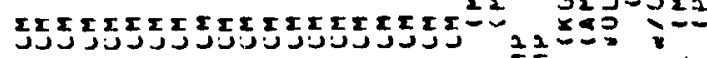

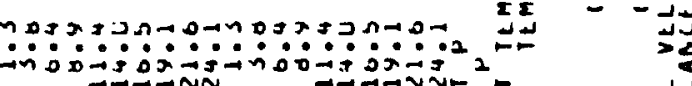

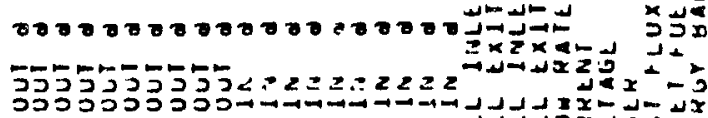

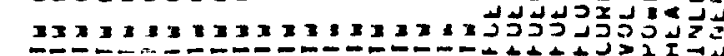




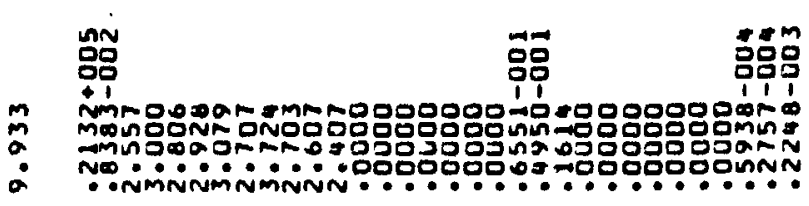

鮕

뭄모

菬苗

ORIGHYSL PARL IS

OF POOR QUALITY

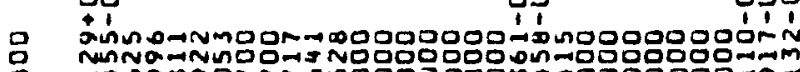

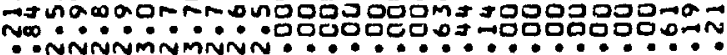

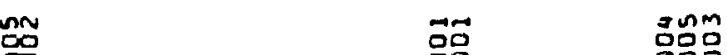

$\underset{\infty}{\infty}$

몽

음요

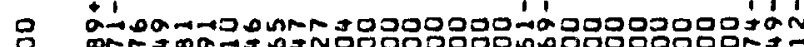

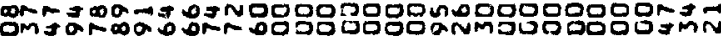
No - onnNinnNminnis.a.

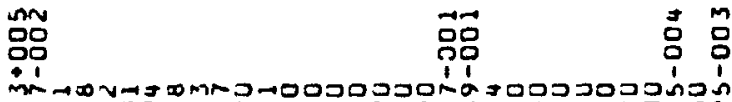

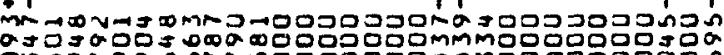

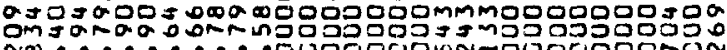

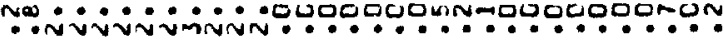

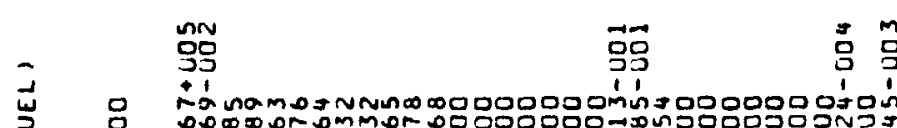

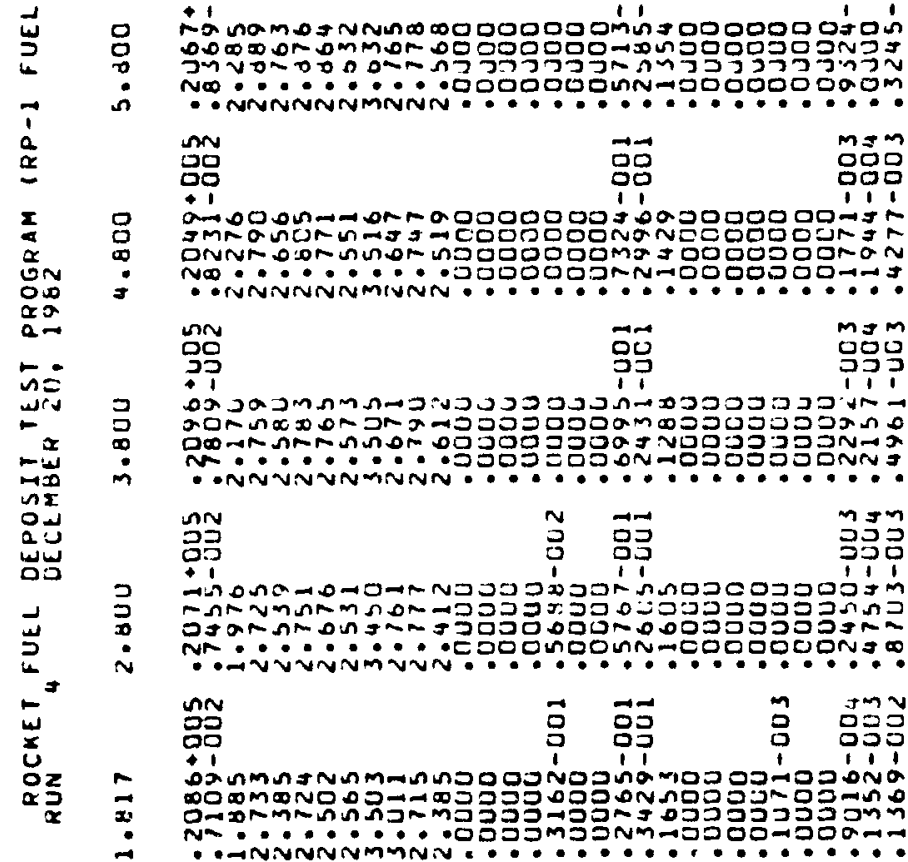

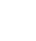




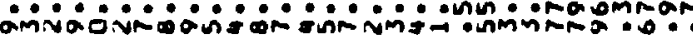

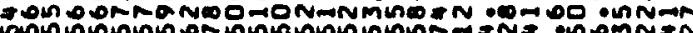

官

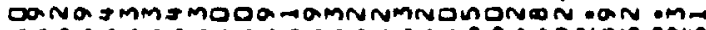

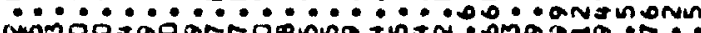
runmog a

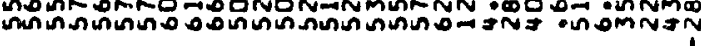

웅

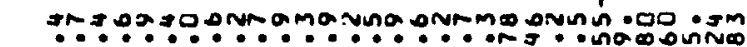

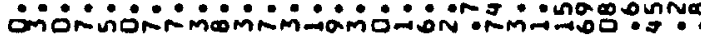
uninunue

$\vec{\circ}$

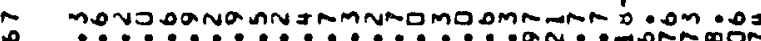

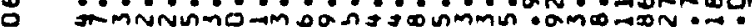

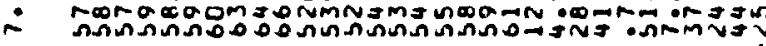

$\vec{g}$

moacomm

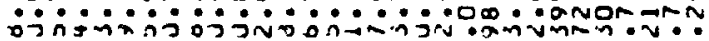

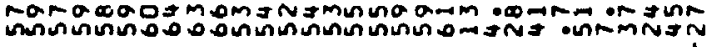

$\overrightarrow{\mathrm{g}}$

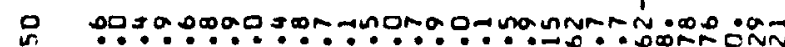
ripis

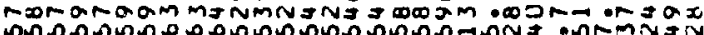

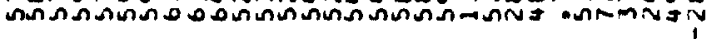

$\vec{\rho}$

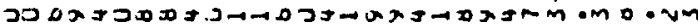

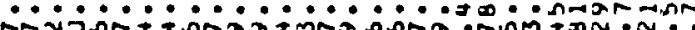

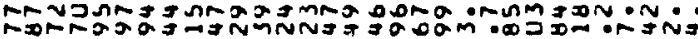

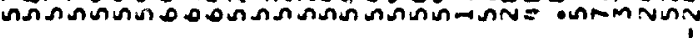

$\vec{z}$

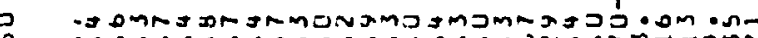
$\therefore$ a

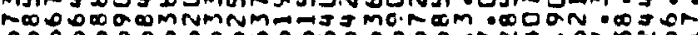

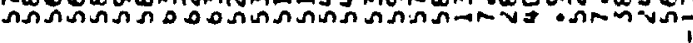

$\overrightarrow{\mathrm{C}}$

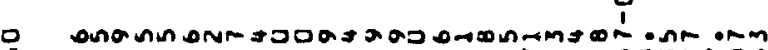

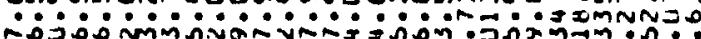

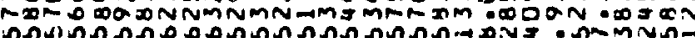

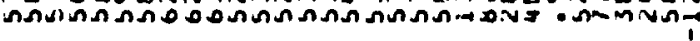

3 ด :

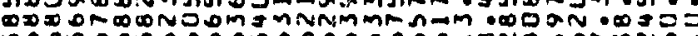

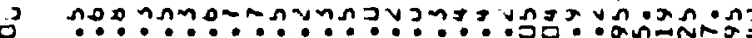

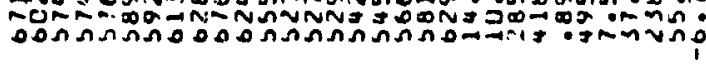

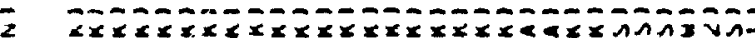

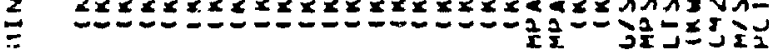

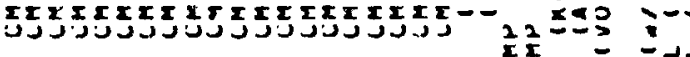

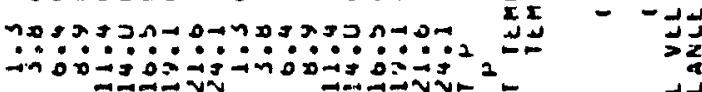

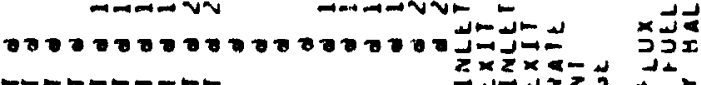

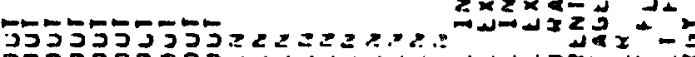




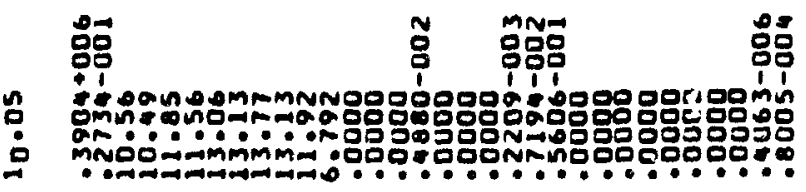

음음

0
0
0

品 80900

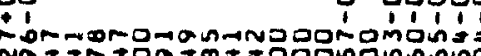

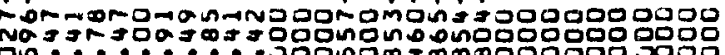

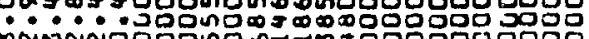

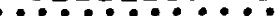

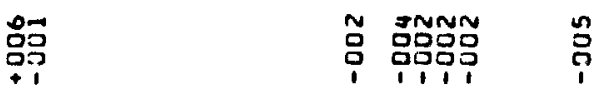

品

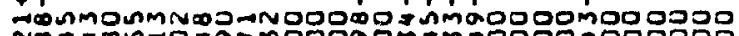

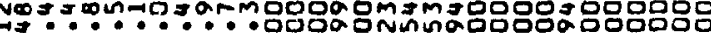

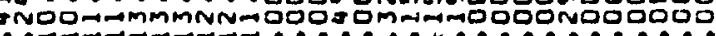

근

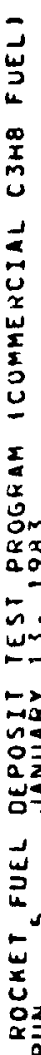

(1)

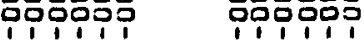

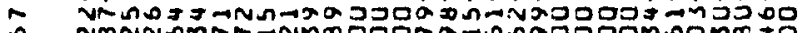

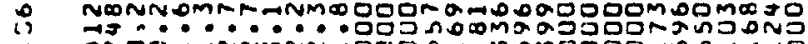

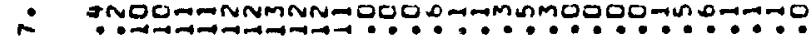

음

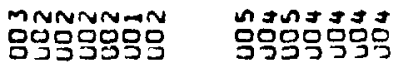

1

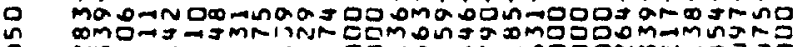

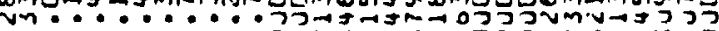

Fทด

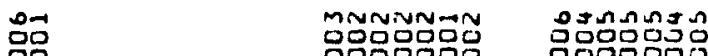

吅

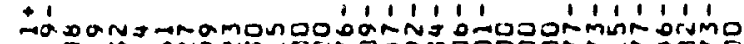

年

-

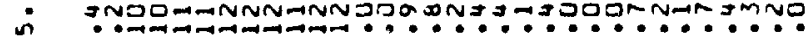

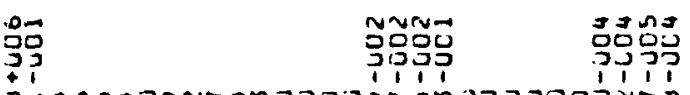

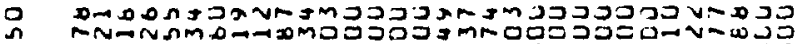

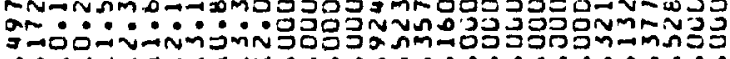

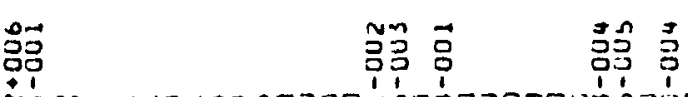

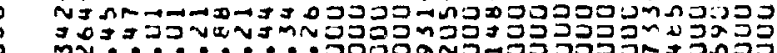
mข..........ำดั

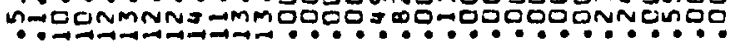
萿

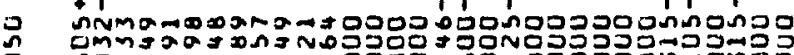

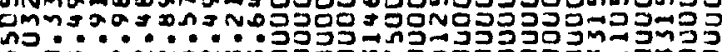

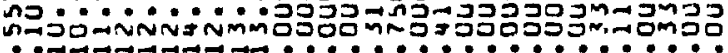

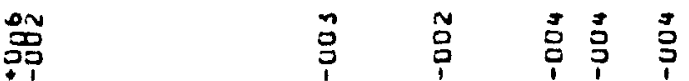

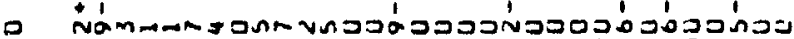

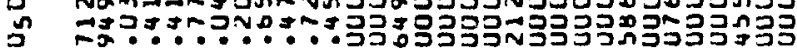

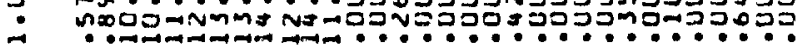

วิบับำ

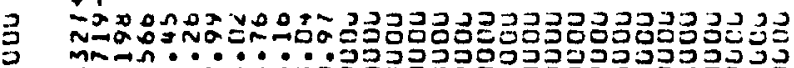

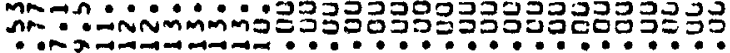

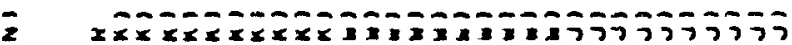

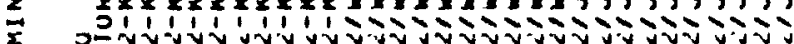

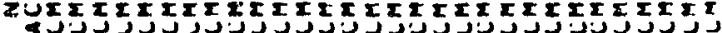
19

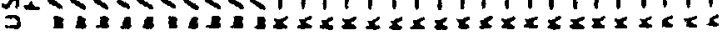

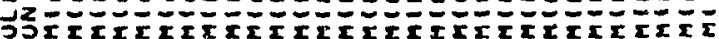

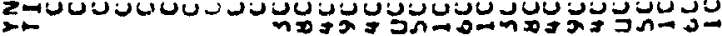
20

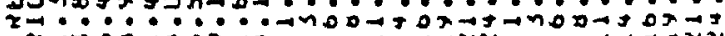
z

I Jّ

I
ORIGHAAL FAGE IS

OF POOR QUALITY 

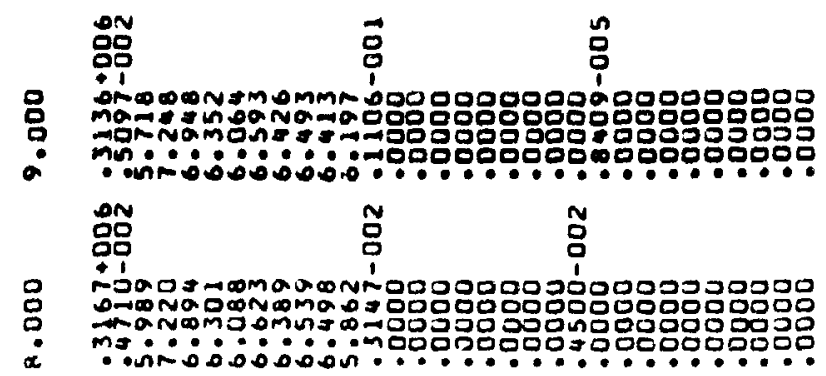

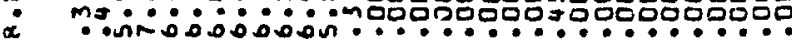
造

웅

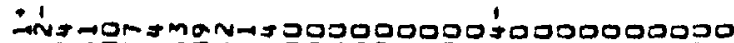
อnningn m. ..........00000000

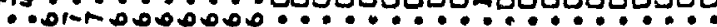

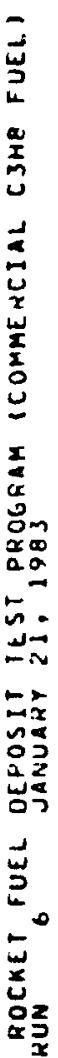

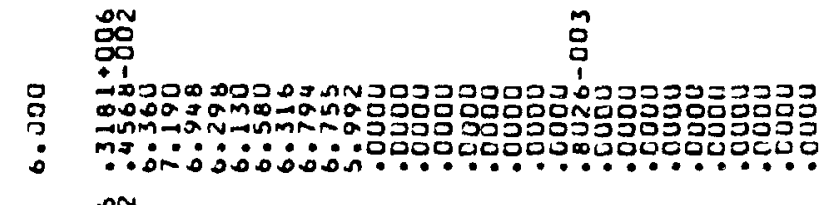

on

옥

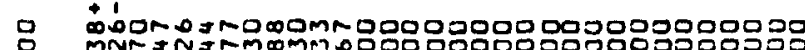
mnก 준 ที่ำ?

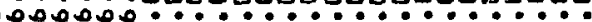
造 药ง m.

ำ

$\dddot{0}$

(1)

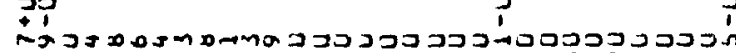

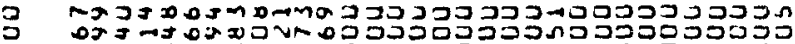

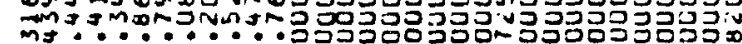

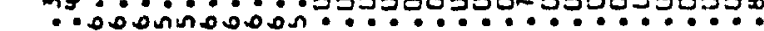

$\stackrel{0}{\circ}$

$+1$

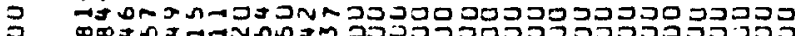

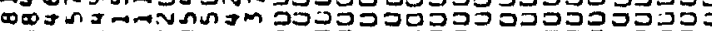

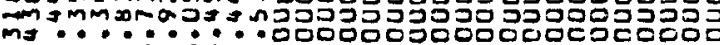

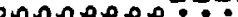

응

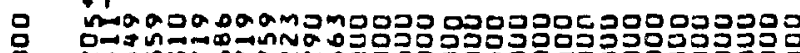

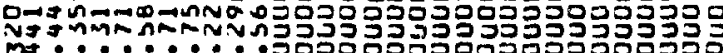

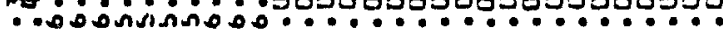
$\stackrel{0}{\infty}$

$\infty$ NNONA

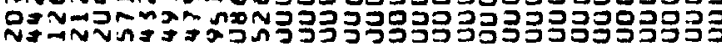

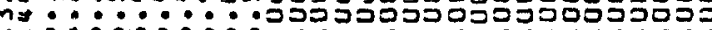

อู่อ

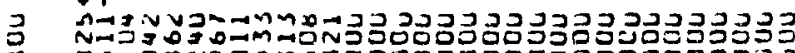

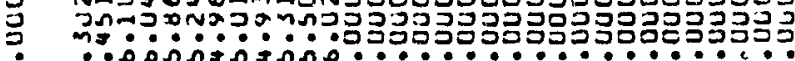

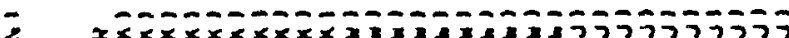

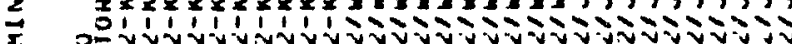

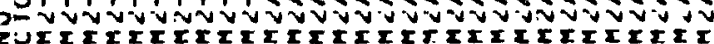

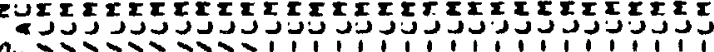

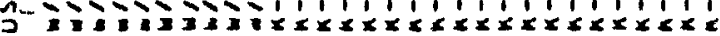

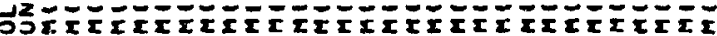
بون -

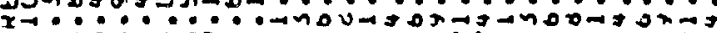

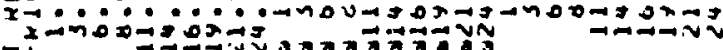
n.

\ل

=
ORIGNAL PAGE IS OF POOR QUALITY 


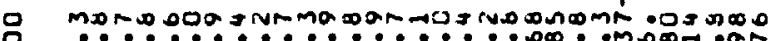

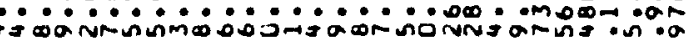
as grg⿻コ一𠃌 草

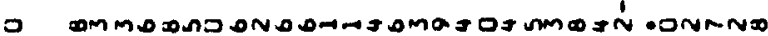

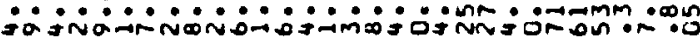
a

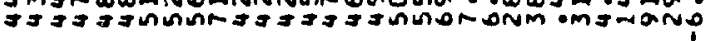

宫

aㅗ.

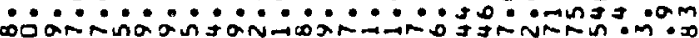

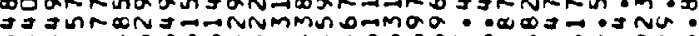

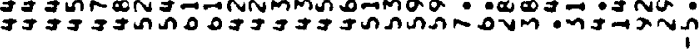

$\overline{5}$

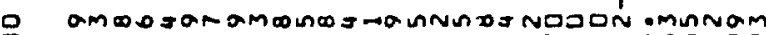
o $?$ ig ñ

$\vec{\circ}$

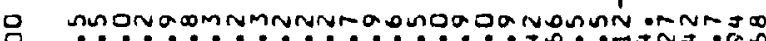

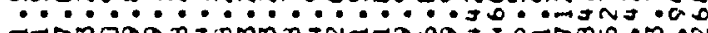

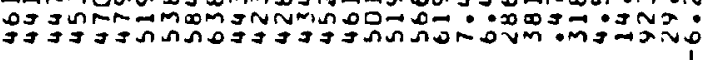

$\overrightarrow{0}$

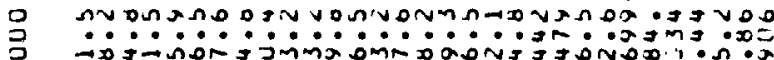
oma

$\vec{\Xi}$

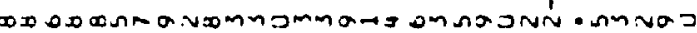

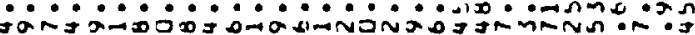

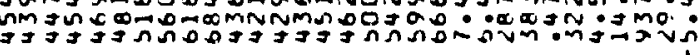

$\overrightarrow{0}$

8
$\dot{0}$

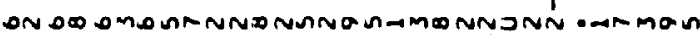

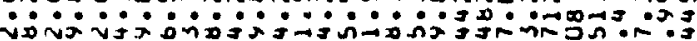

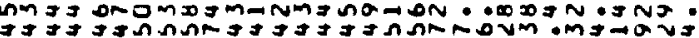

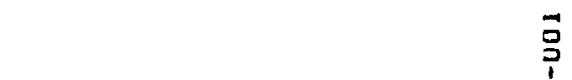

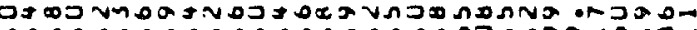

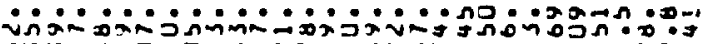

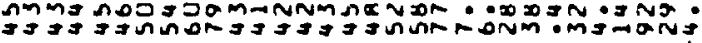

$\overrightarrow{3}$

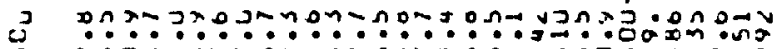

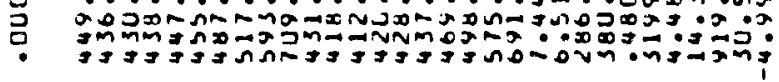

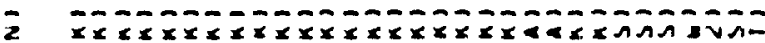

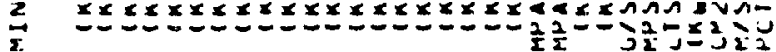

-

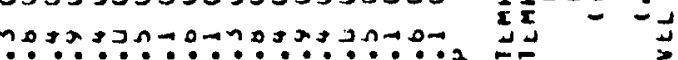

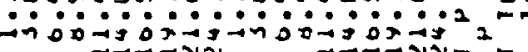

ORIGNAL PAEF IE OF POOR QUALITY 


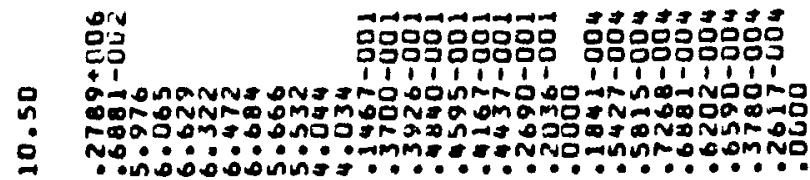

뭉

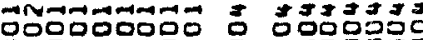

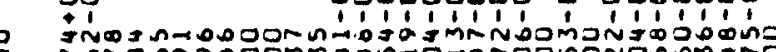

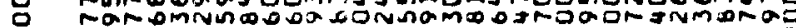

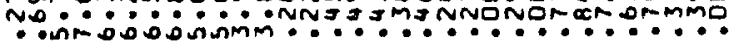

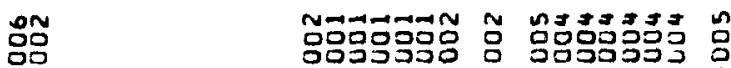

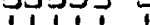

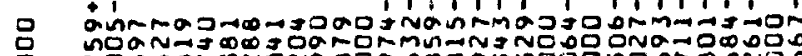

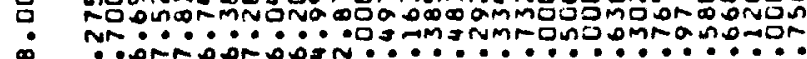

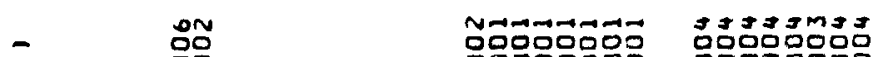

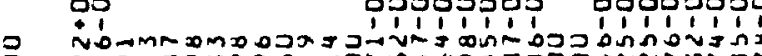

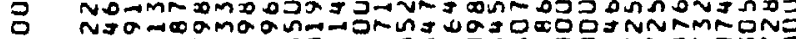

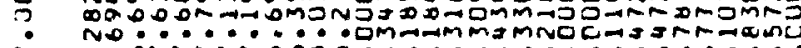

- ontantunga

on

$\underset{0}{0}$

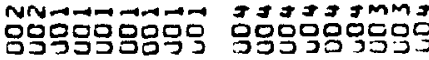

옹

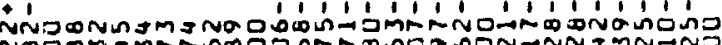

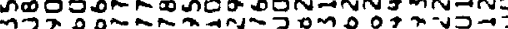

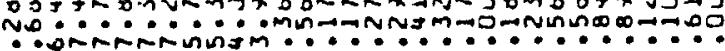

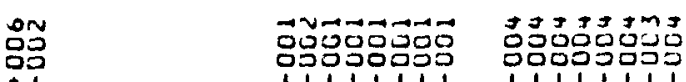

0

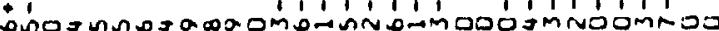

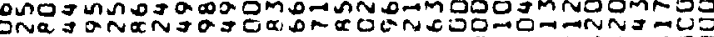
Douvinus

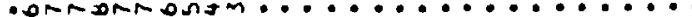

gूo

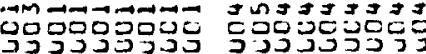

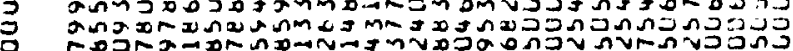

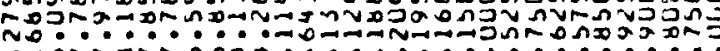

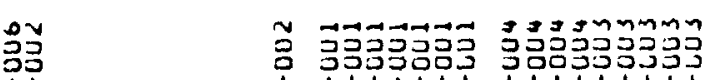

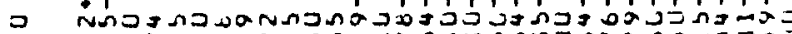

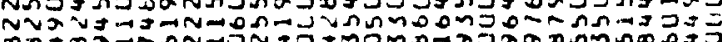

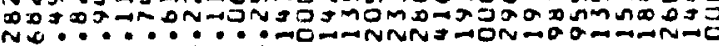

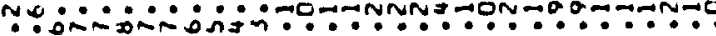
瓶

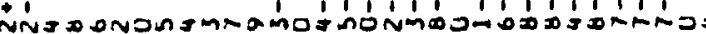

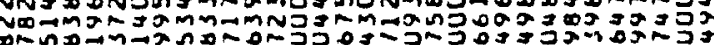

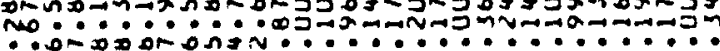
ㅇำ

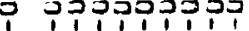

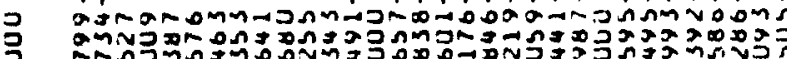

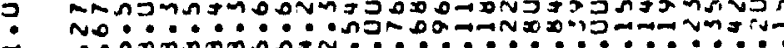

כुำ

व

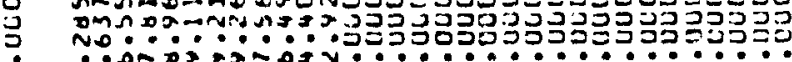

z

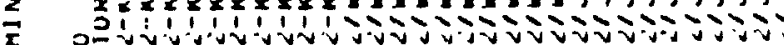

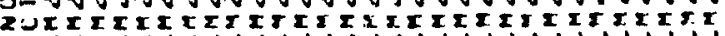
تصنs วิ

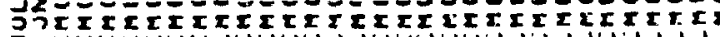

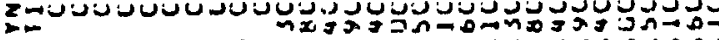
х $-$ 


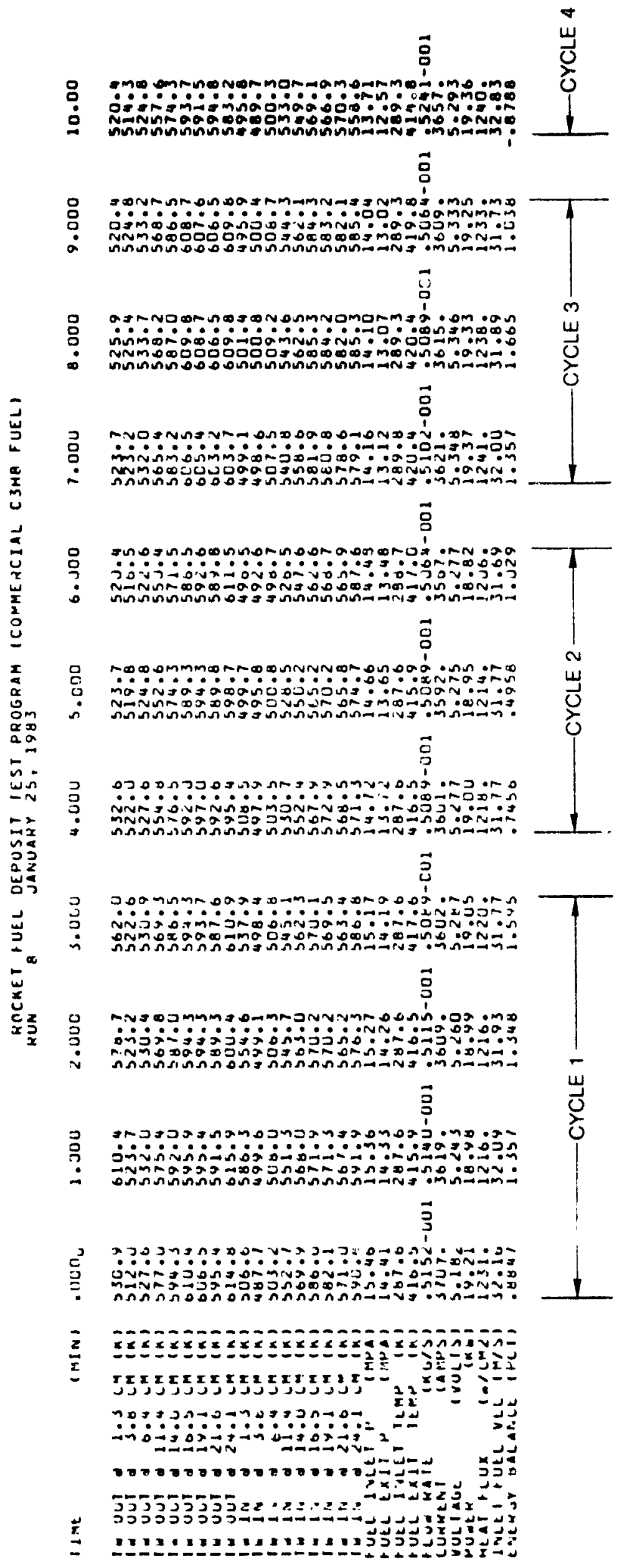

ORIGANAL PA:E Z: OF POOR QUALITY 


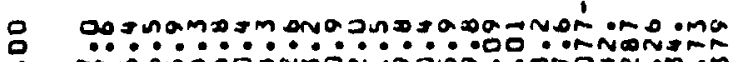
anmizaring

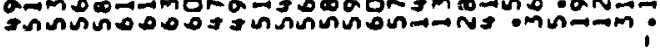

무

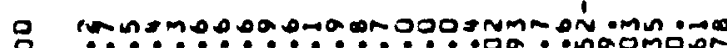

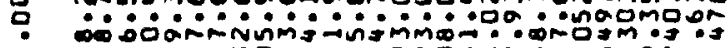
- Anñ⿻日禸

$\overrightarrow{\mathrm{g}}$

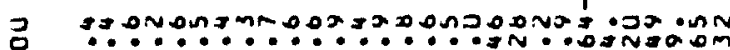
- nin vorinamón-

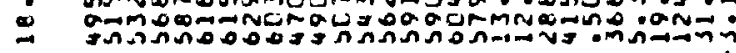

$\overrightarrow{0}$

- Dosnmnormnnoansnonsmnoń iogicam

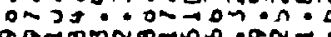

$=$ Fnnmiogosg

$\vec{g}$

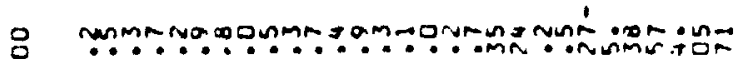
Domiga

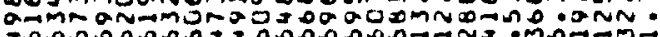

$\overrightarrow{0}$

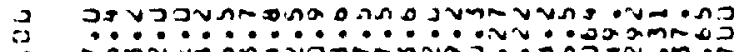
anma

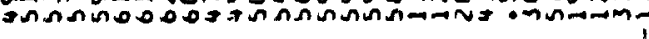

名

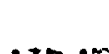

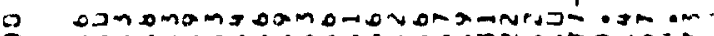

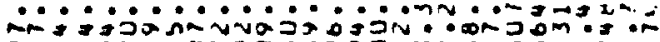

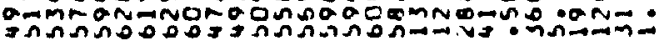

马े

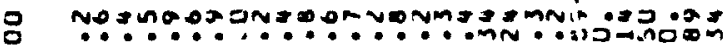
-

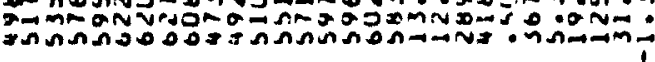

$\vec{g}$

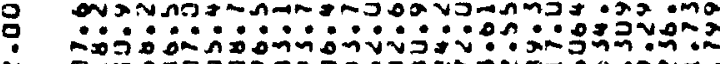

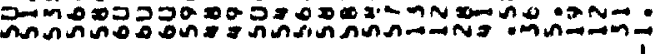

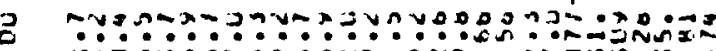
- Mogoniming

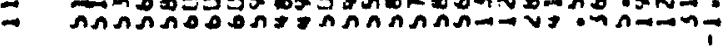

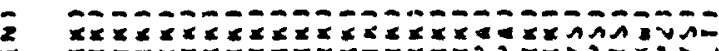

2

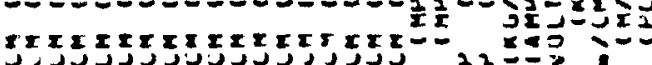
Tد

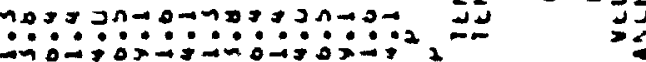

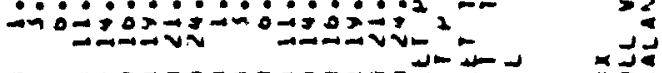

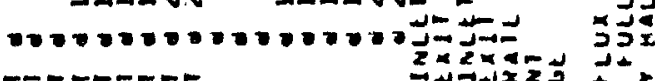

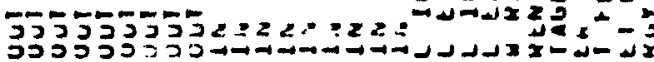


ORIGWAL FAT:

OF POOR QU:

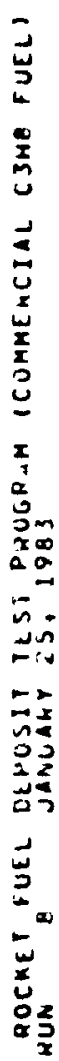

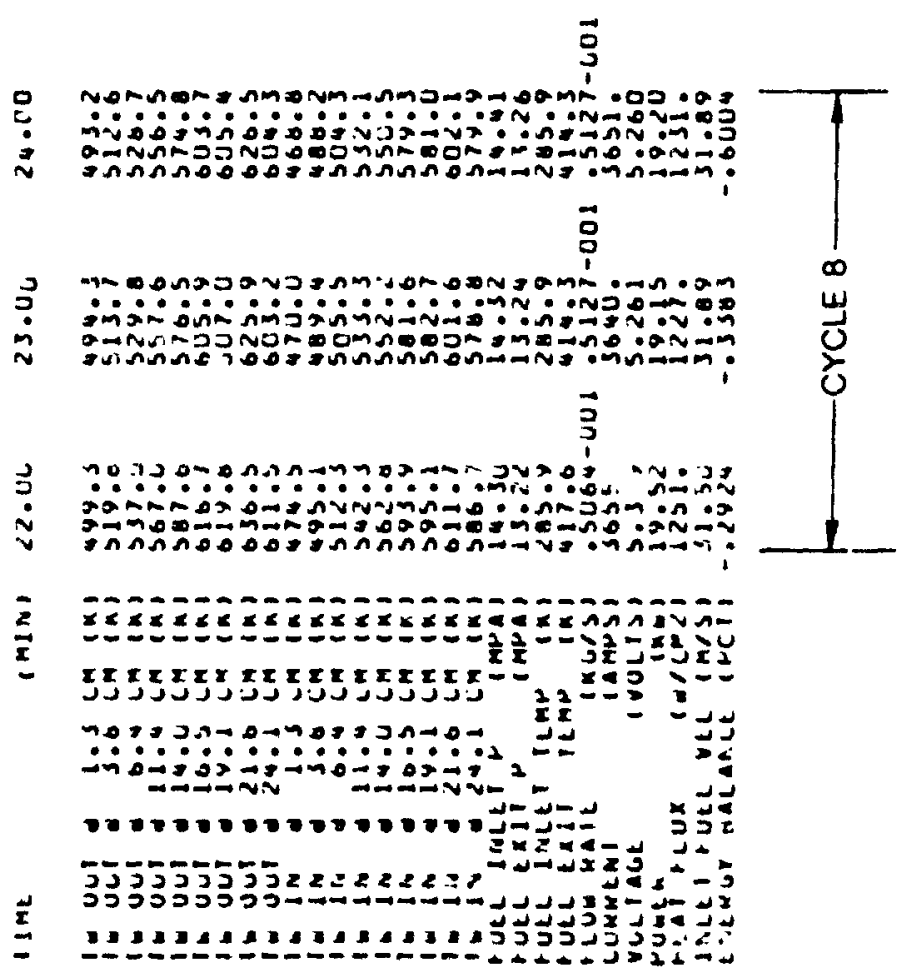




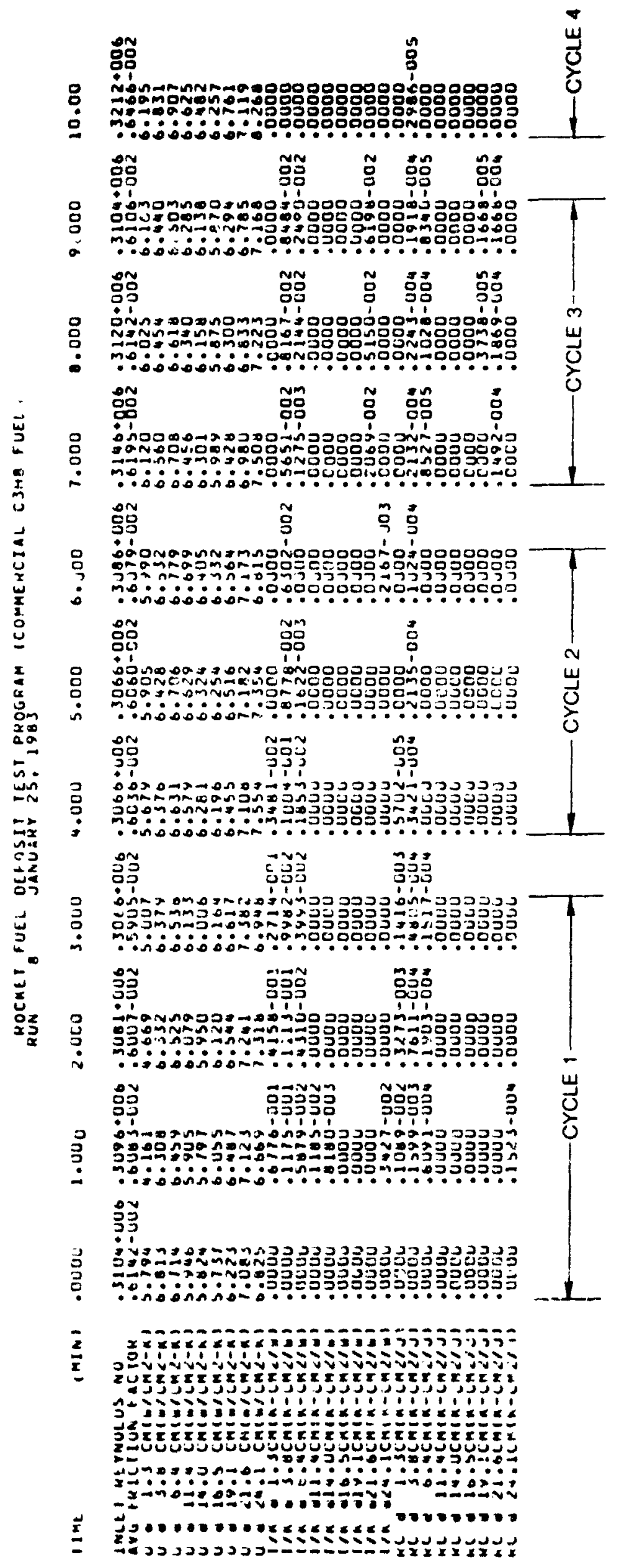

ORIGNAL PAGE IS OF POOR QUALITY 


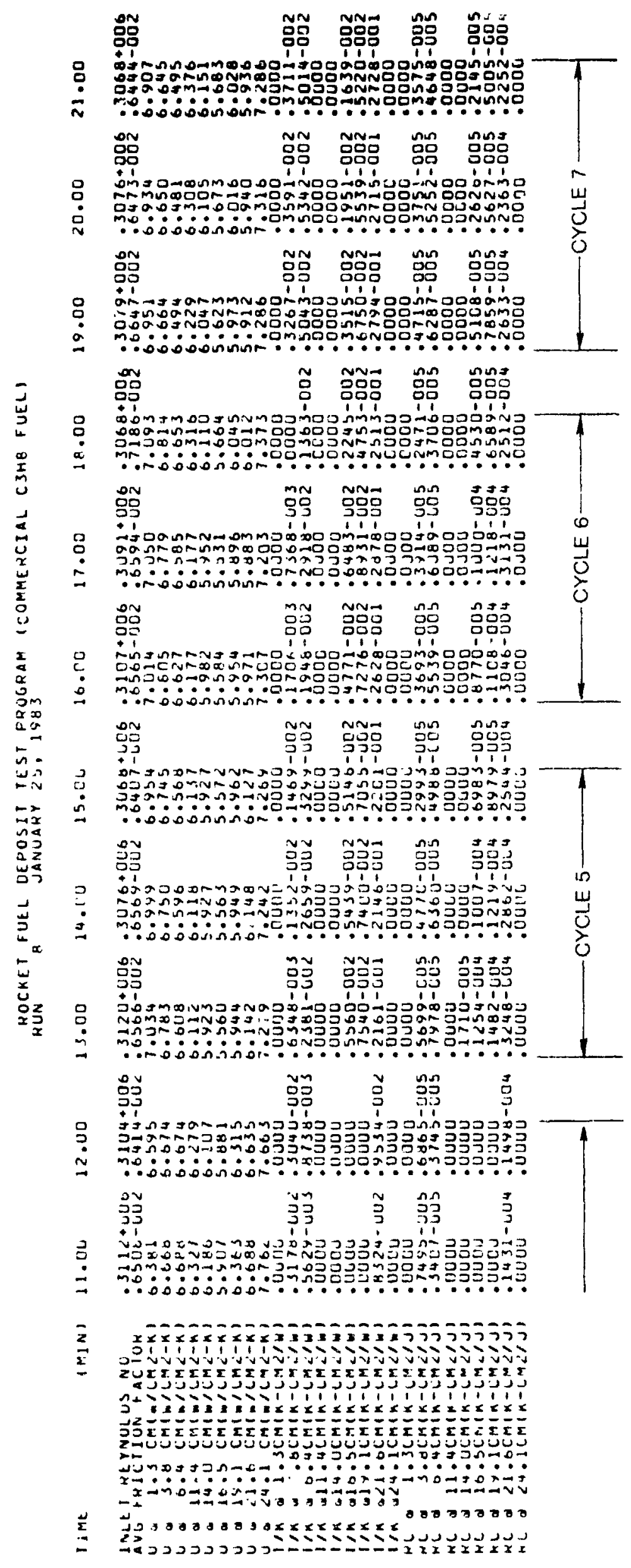

ORIGINAL PAGE IS
OF POOR QLIALITY

$\underset{4}{4}$ 
CRIGINAL PAGE IS

OF POJR QUALITY

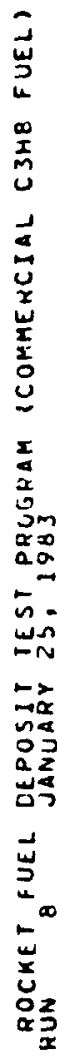

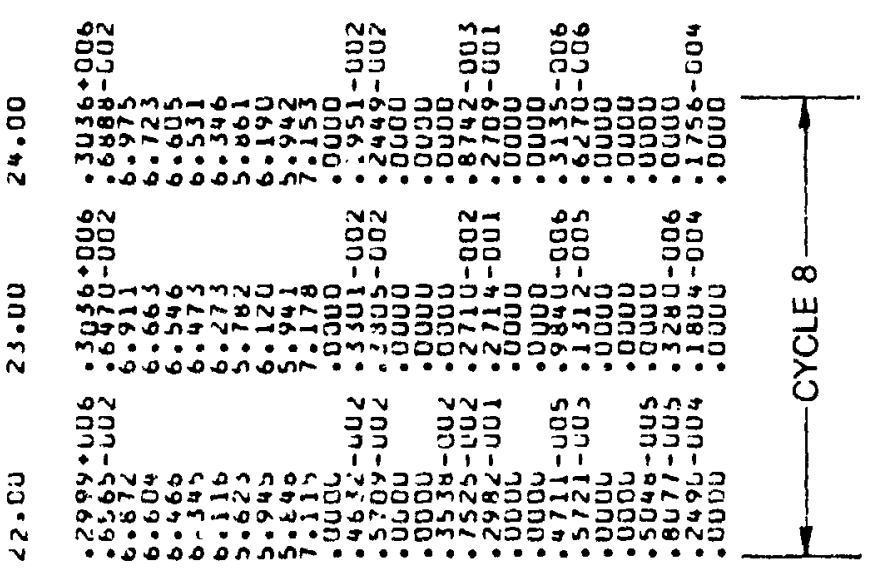

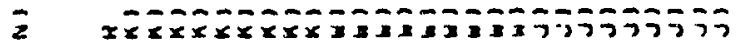

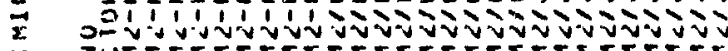

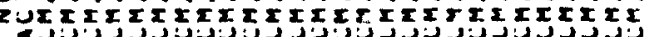

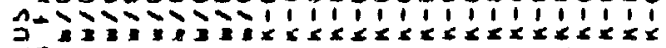

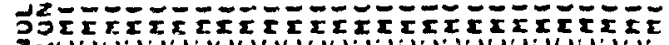
$x_{1}=0$

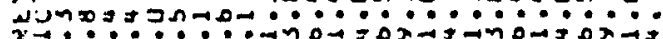

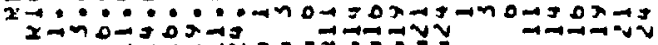
г

E 
$\overrightarrow{8}$

\section{8}

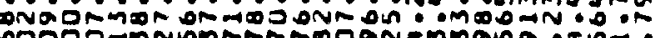

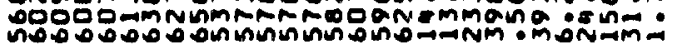

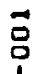

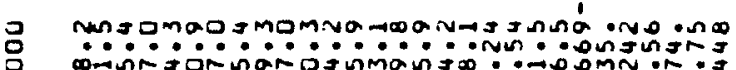
noging

号

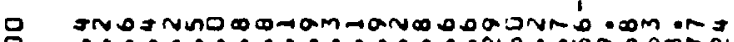

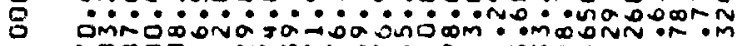

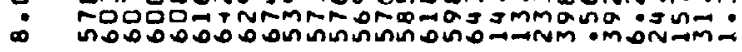
$\overrightarrow{0}$

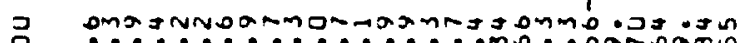

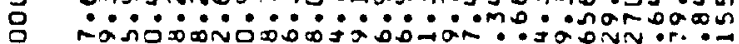

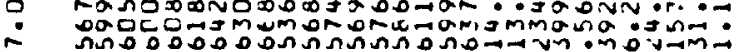

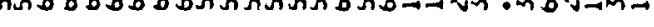

$\vec{g}$

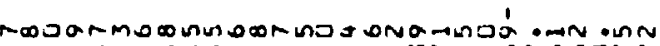

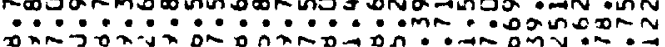
vino

$\overrightarrow{\mathrm{g}}$

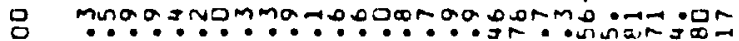

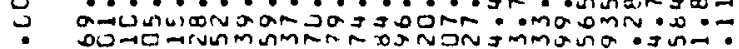
no:00000

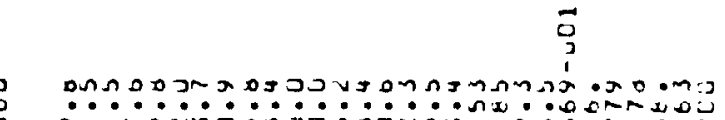

a

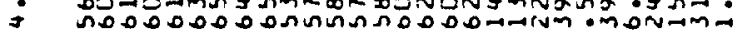

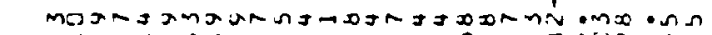

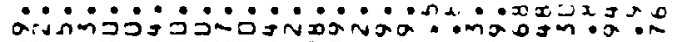
คำ-

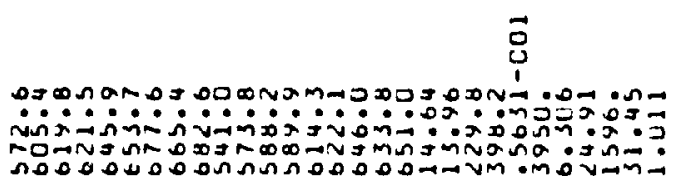

号

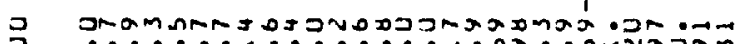

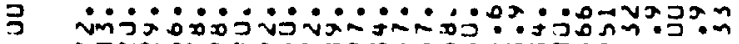
$\therefore$ กับ

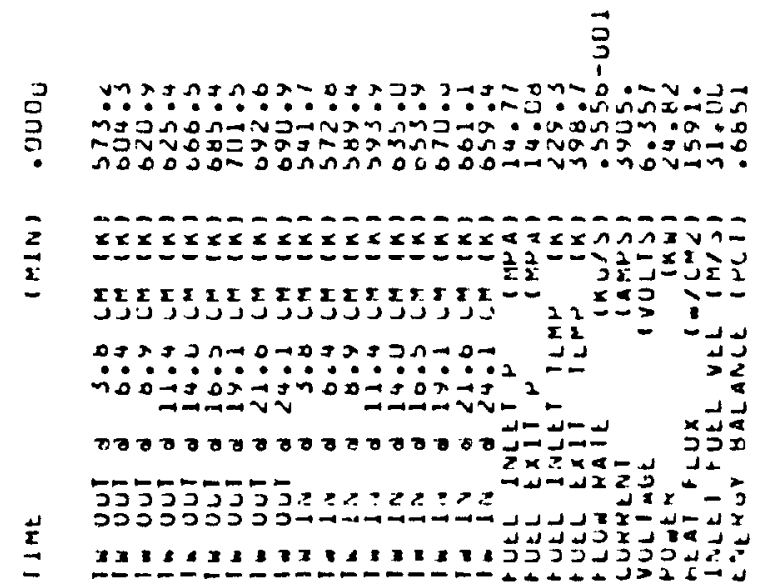




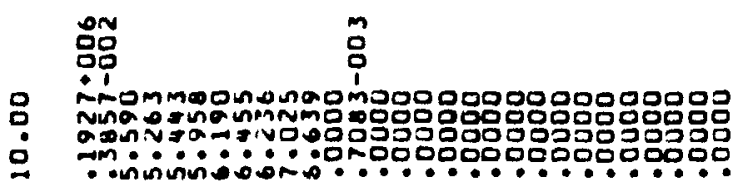

on

:

ín.

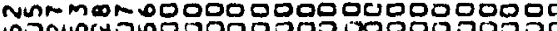

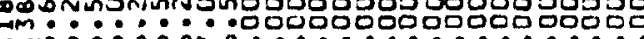

or

$+1$

00

웅

m.

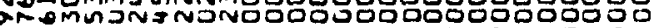

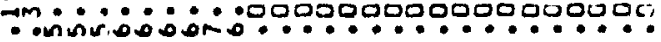

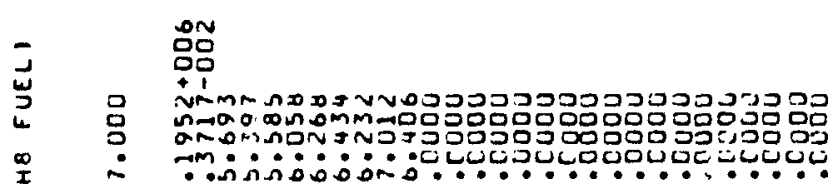

음음

은 inn

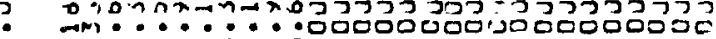

อับ

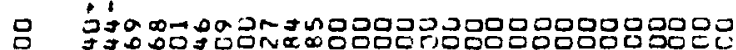

i

คก

03

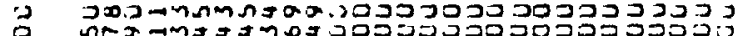

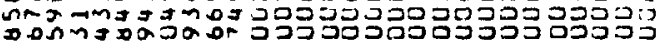

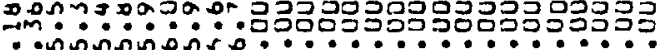

on

วอำ

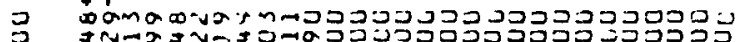

an. ñ.

-

잉

00

음

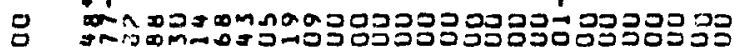
๓

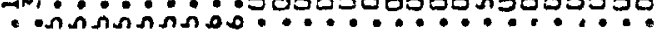

sis

总 $\quad \vec{g}$

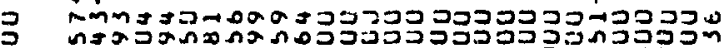

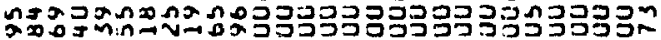

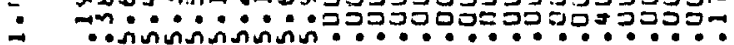

วิ่า

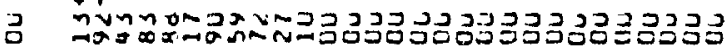

: "

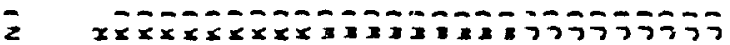

I 200

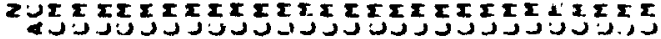

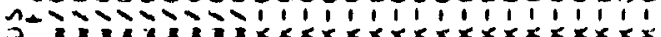

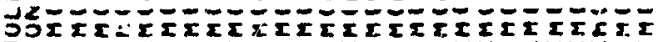

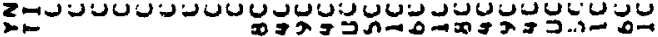

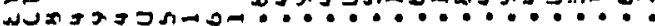

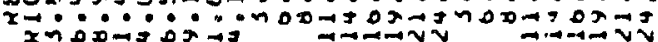

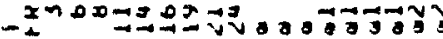

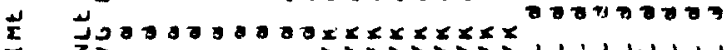

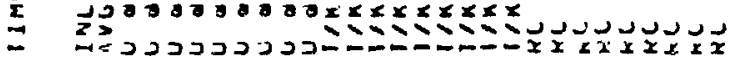

OFIGINAL PAGE IS OF: POOR QUALITY 
$\overrightarrow{8}$

$\because$

$\ddot{q}$

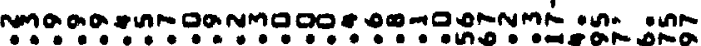

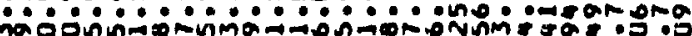

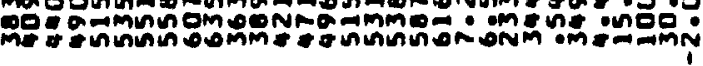

$\vec{\circ}$

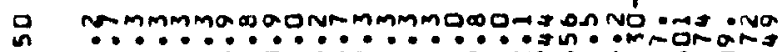

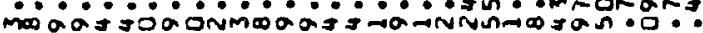
ma mo nunving o

$\overrightarrow{0}$

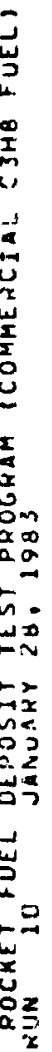

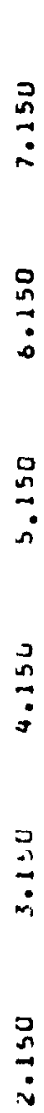

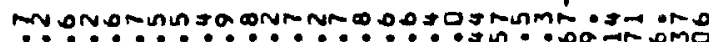

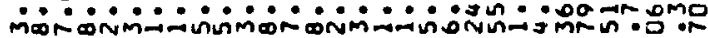
mmm-1mñons

号

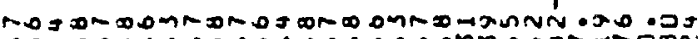

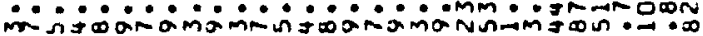
Domxons

$\overrightarrow{8}$

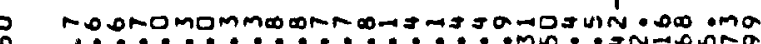
Q

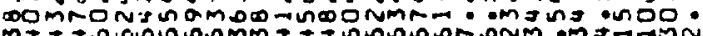

$\overrightarrow{0}$

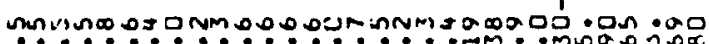

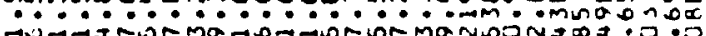

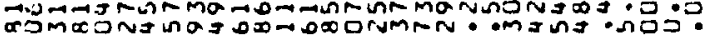

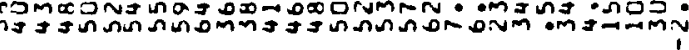

官

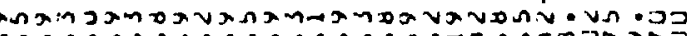
дора

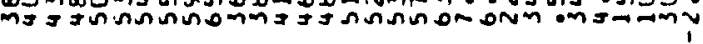

$\overrightarrow{0}$

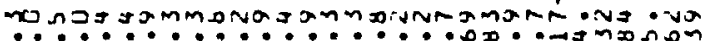

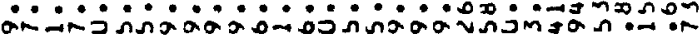
mona minoor

$\overrightarrow{8}$

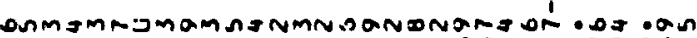

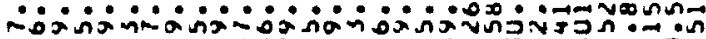

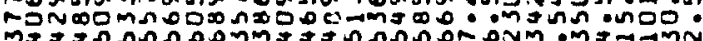

10

$\stackrel{\square}{a}$

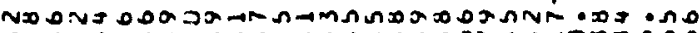

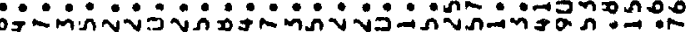

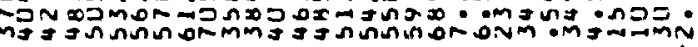

$\overrightarrow{3}$

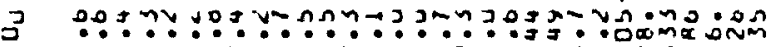

ng

$\frac{2}{2}$

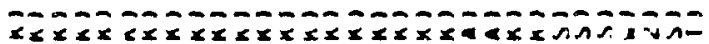

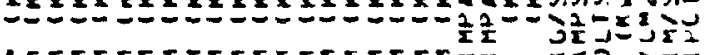

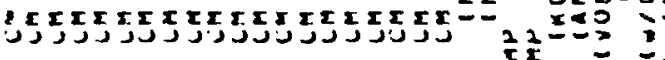

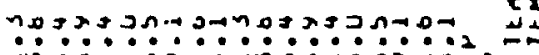

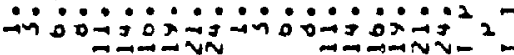

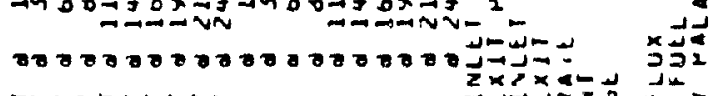

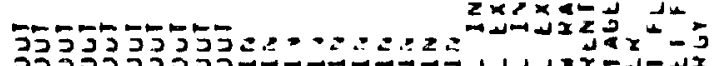

$\underline{\underline{z}}$

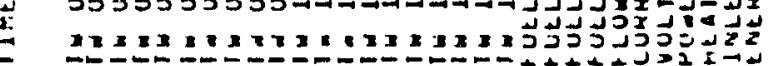




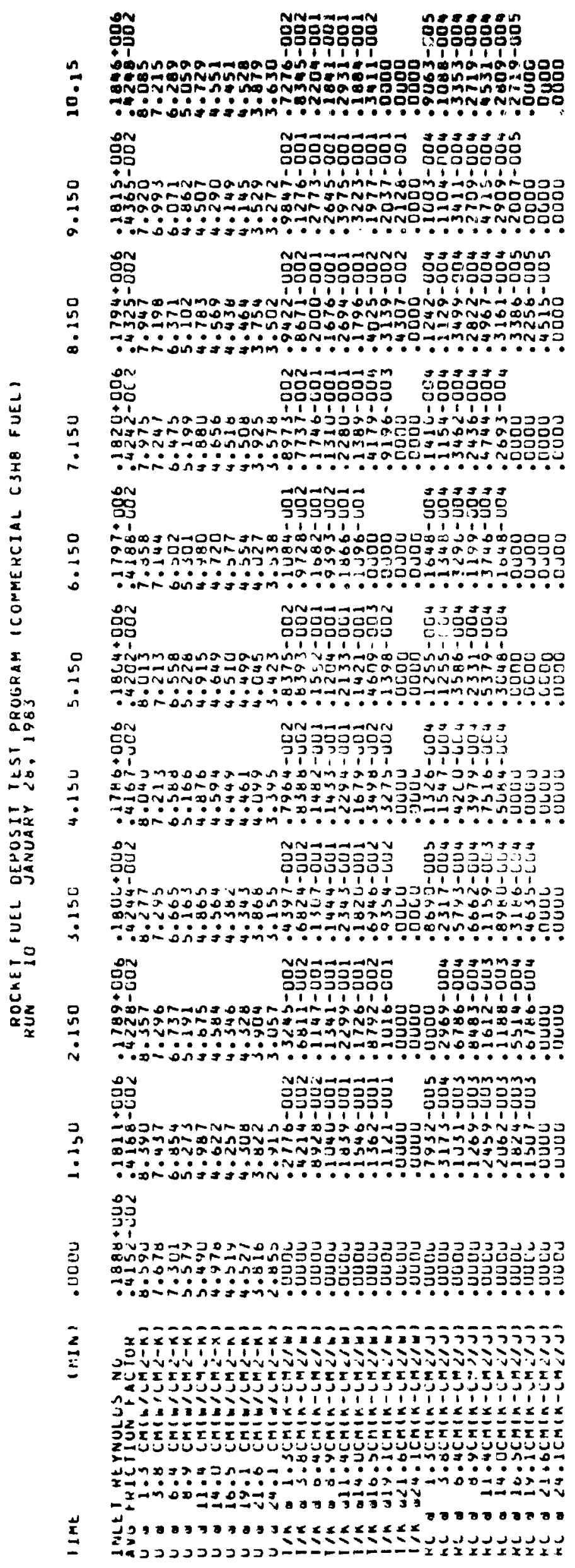




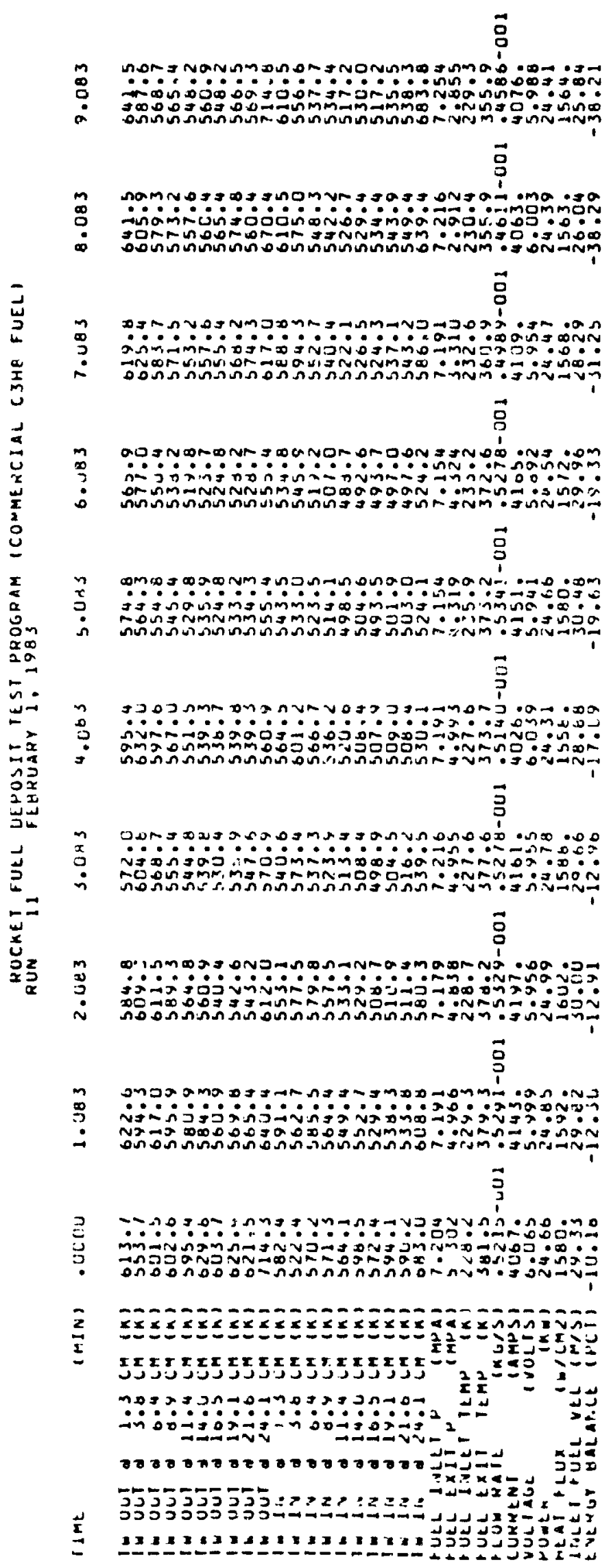




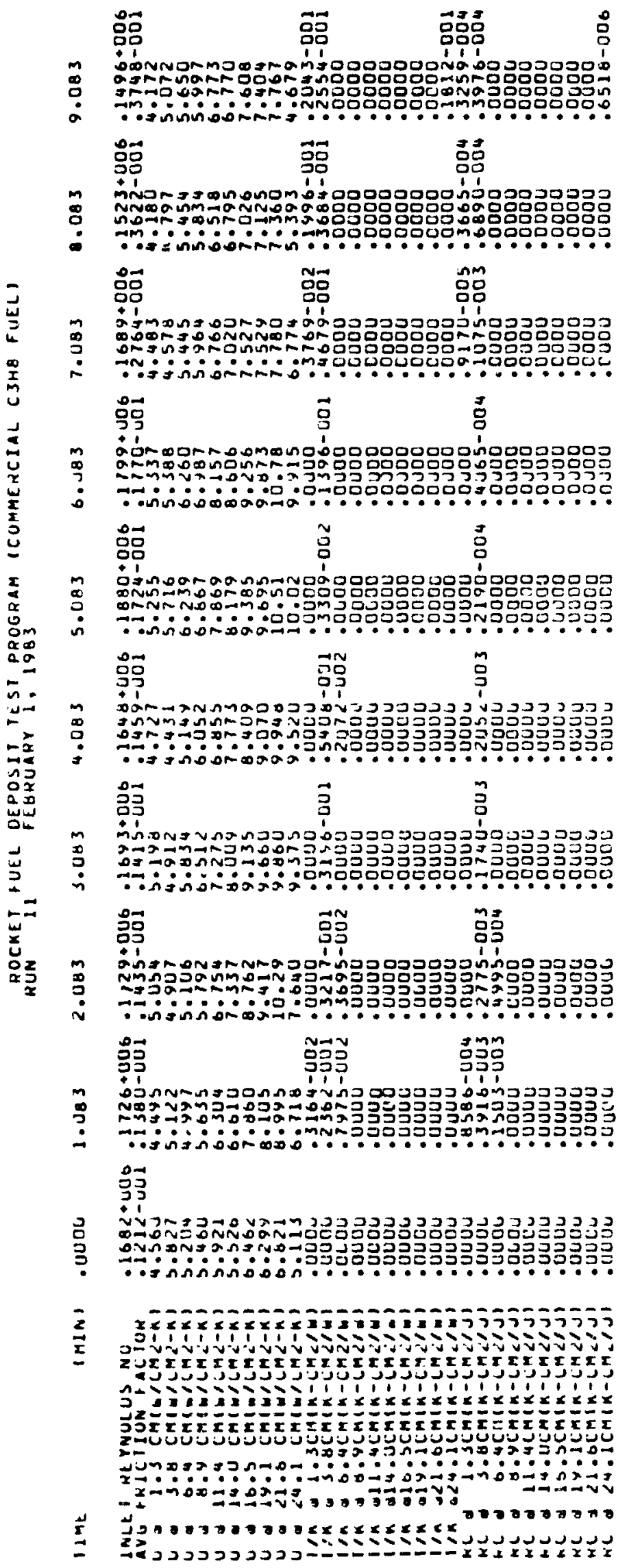


뭉

ORIGNAL PAC: : \&

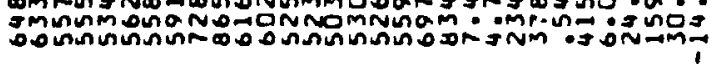

号

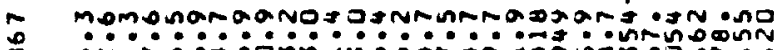
-

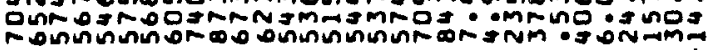

움

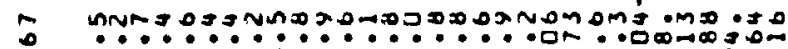

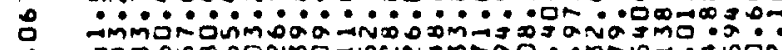

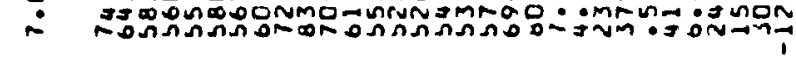

$\overrightarrow{\mathrm{O}}$

- Dagunmosmmatanammadmonusa mo anm

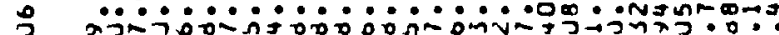
- mรRóñon

$\vec{b}$

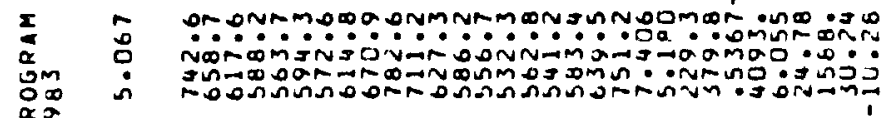
$\stackrel{\alpha}{a}=$ ค ons g nomangoññ

$\overrightarrow{3}$

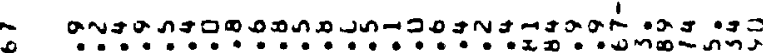

与

i Doำ $\simeq$

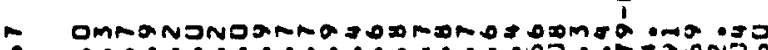

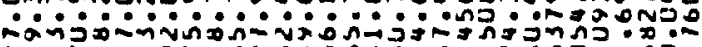
ond

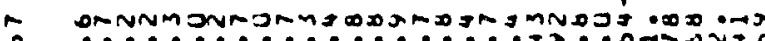

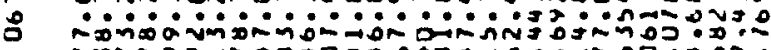

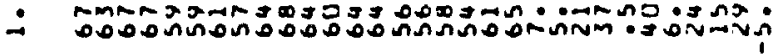

$\overrightarrow{3}$

马

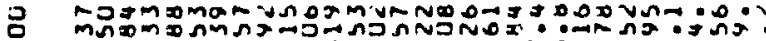

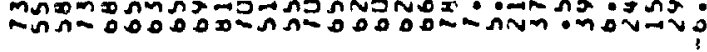

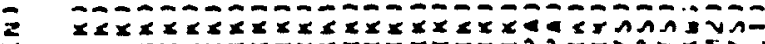

$\vec{x}$ :

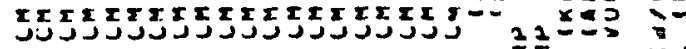

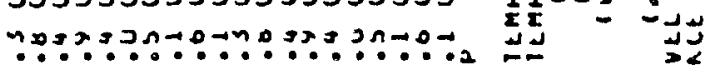

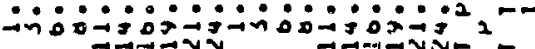
-

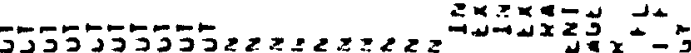
วงวว 


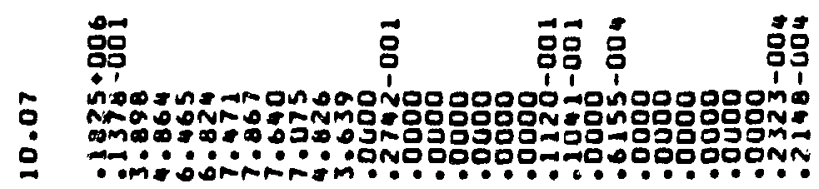

ORIGINAL FAG IT

OF POOR QUALITY

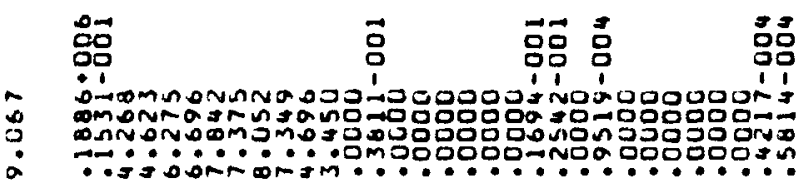

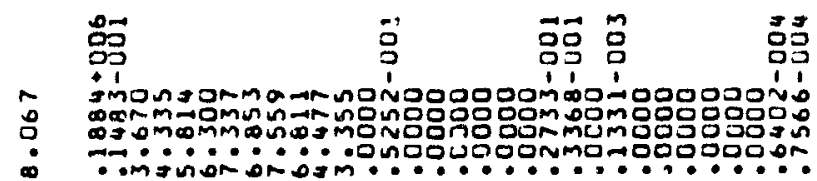

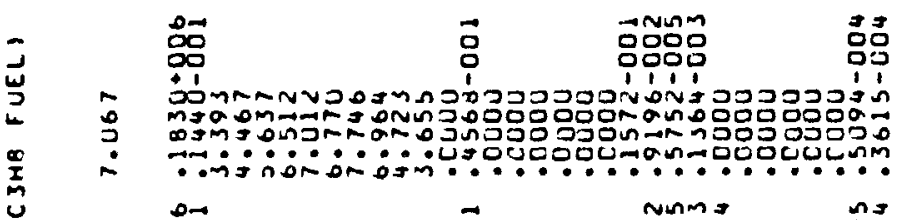

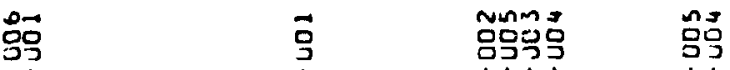

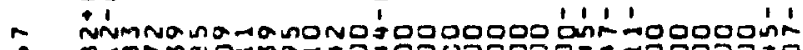

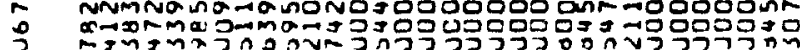

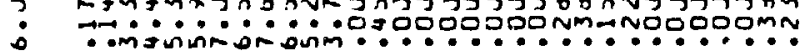

$\stackrel{2}{\mathrm{O}}$

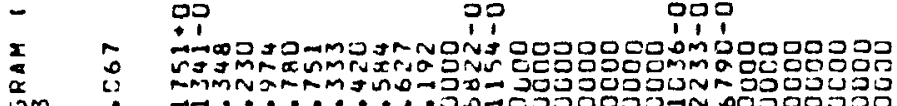

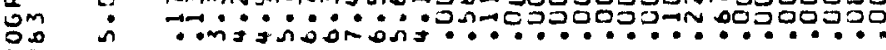

aㅡ

m:

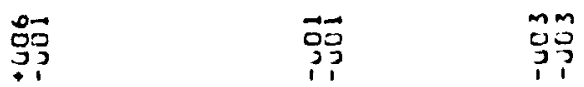

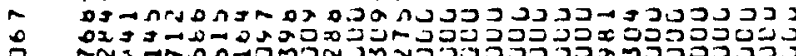

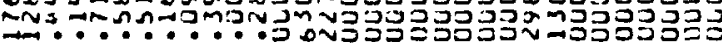

哂

$\overrightarrow{S \vec{J}}$

วิำ

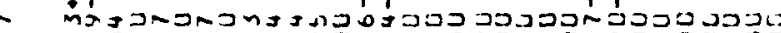

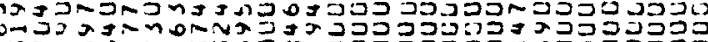

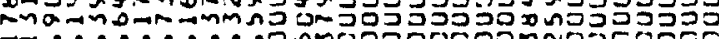

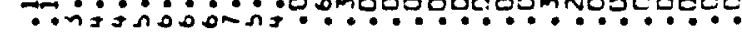

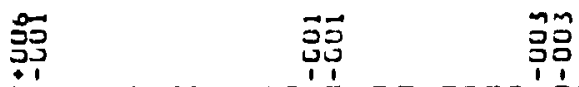

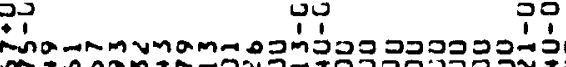

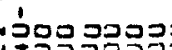

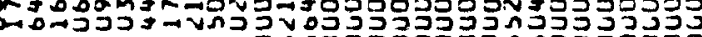

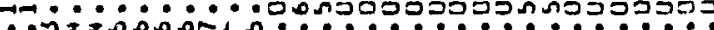

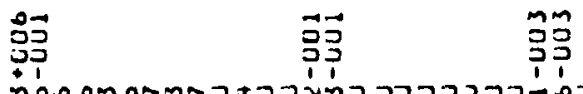

0

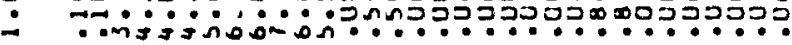

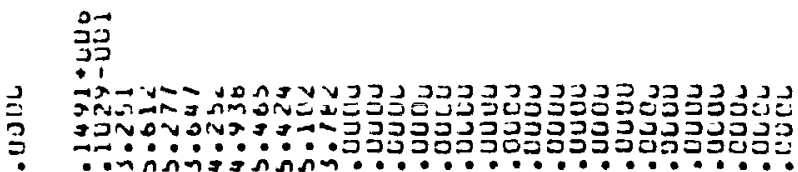

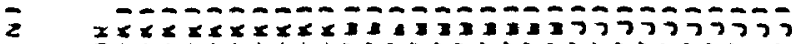

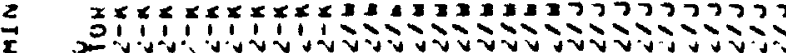

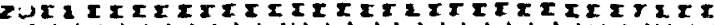

a

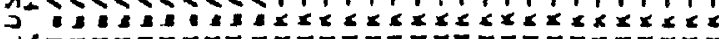

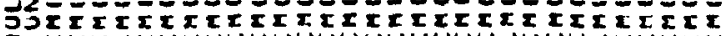

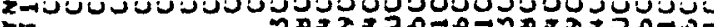

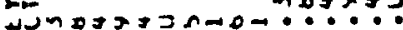
x-

E 


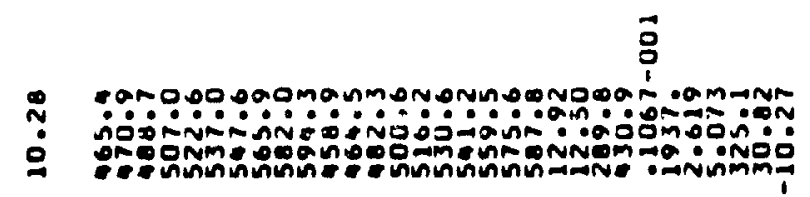

$\vec{\circ}$

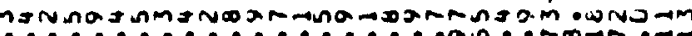

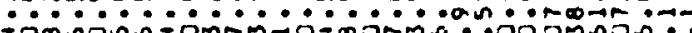

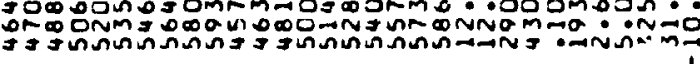

马

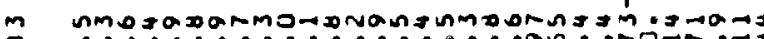

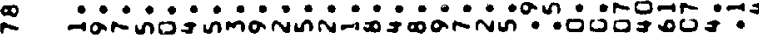
o owonm $\overrightarrow{0}$

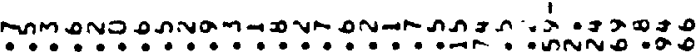

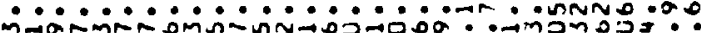

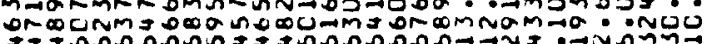

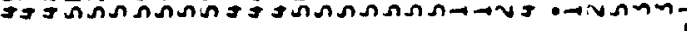

$\vec{g}$

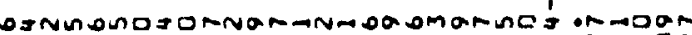

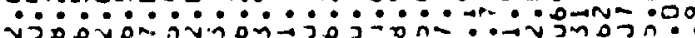

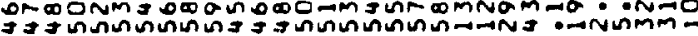

$\overrightarrow{0}$

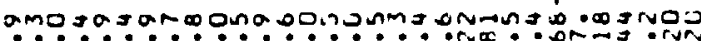
- ‥ Danncinimanjivajadinn ơ

$\overrightarrow{\mathrm{g}}$

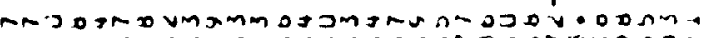

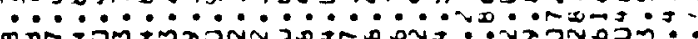
nox cum

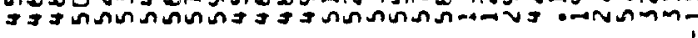

$\overrightarrow{\mathrm{g}}$

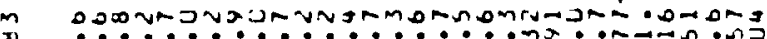

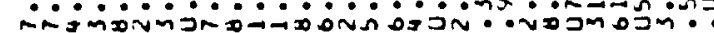

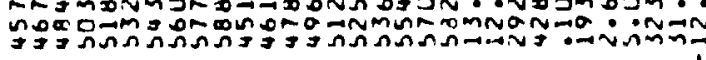

$\overrightarrow{0}$

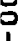

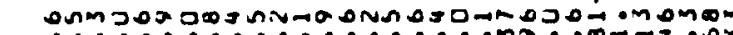

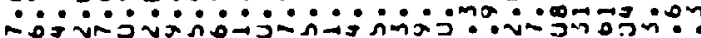

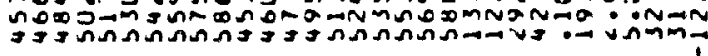

$\overrightarrow{3}$

$\stackrel{2}{2}$

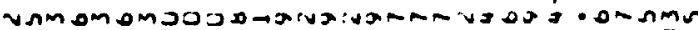

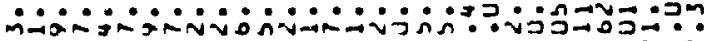
ơ

$\overrightarrow{3}$

2

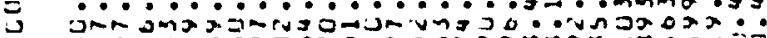
ố

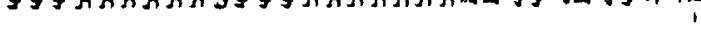
z

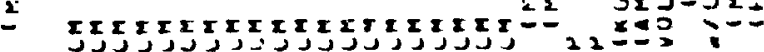

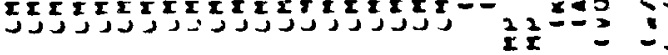

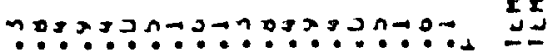

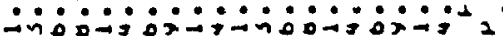

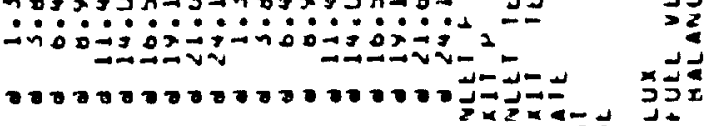

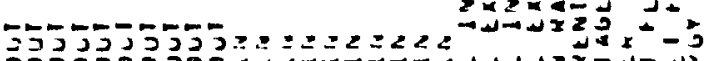




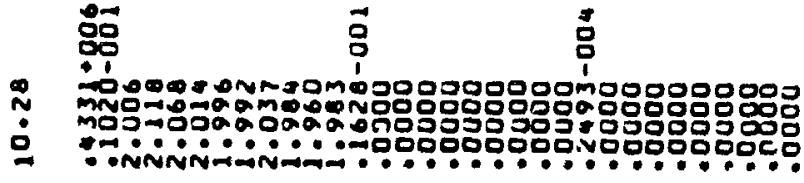

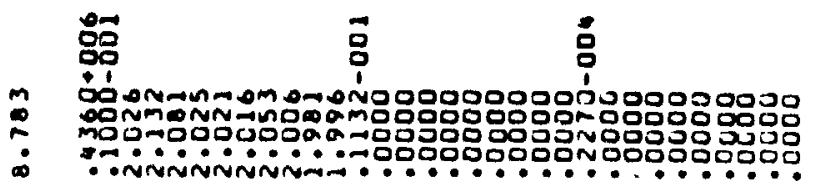

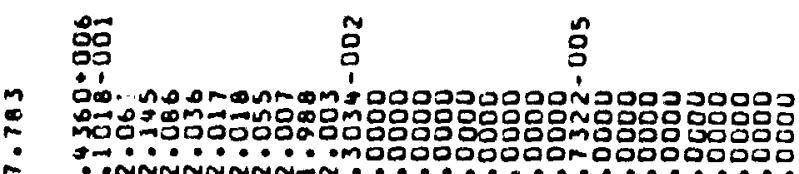

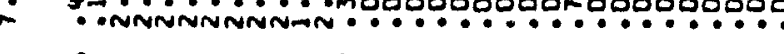

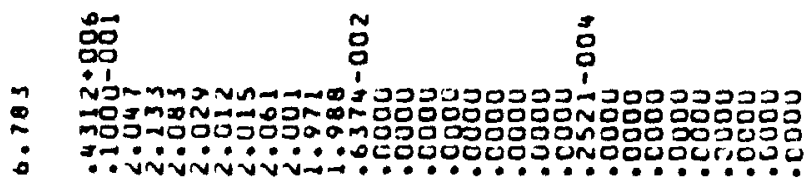

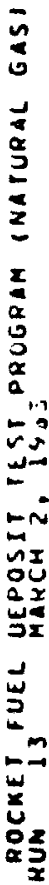

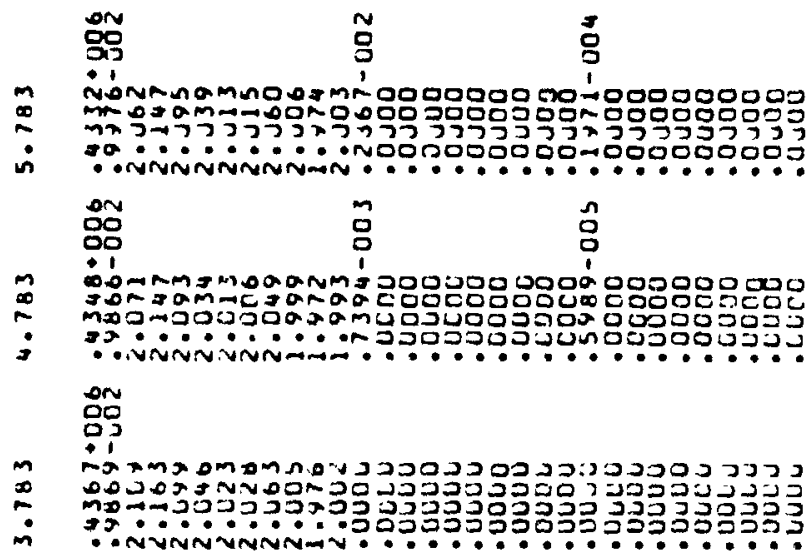

วิว

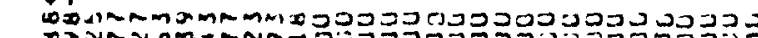

2 mกง

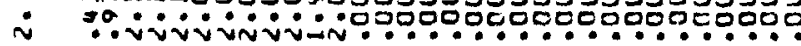
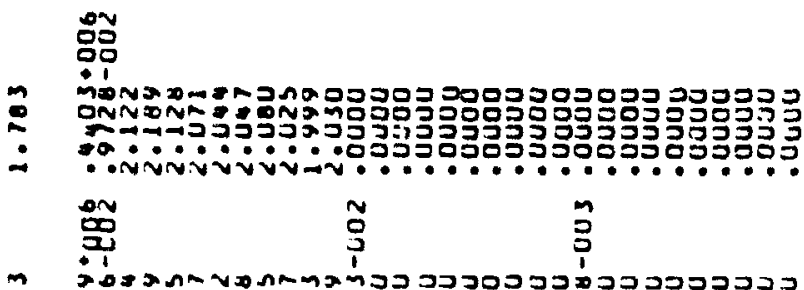

2.

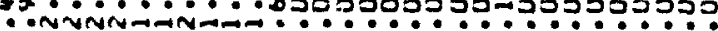

วิบ

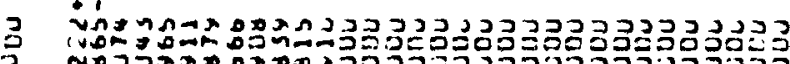

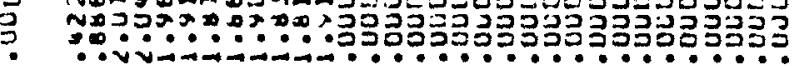

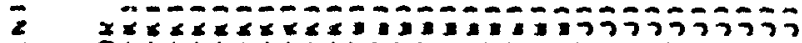

$\vec{x}$ o

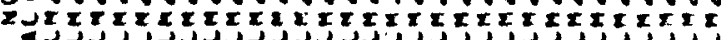

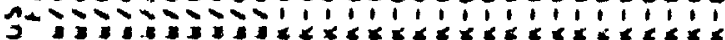

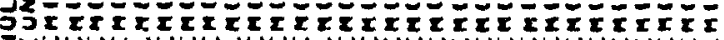

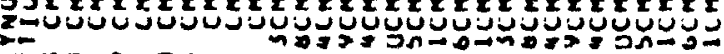

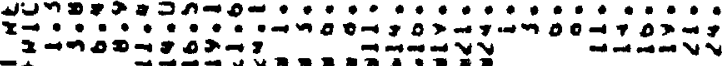

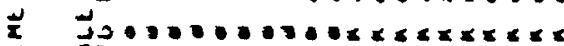
=
ORIGANAL P,:...

OF POOR QUALITY 


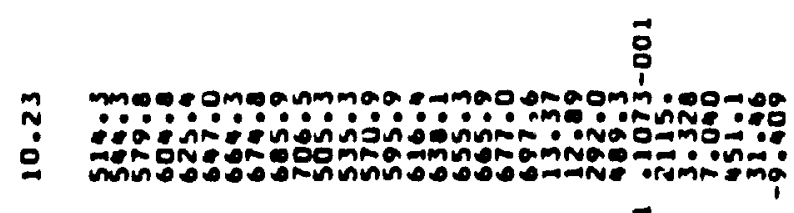

$\overrightarrow{8}$

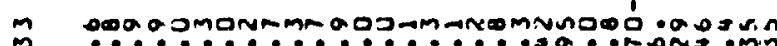
Gäñ

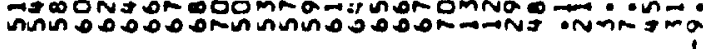

$\ddot{0}$

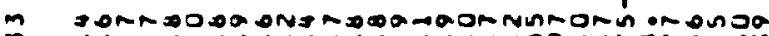

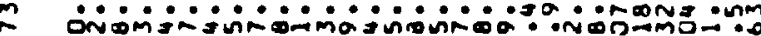

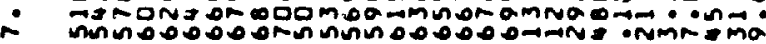

$\overrightarrow{0}$$$
\text { m }
$$

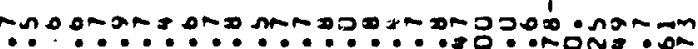

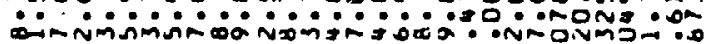

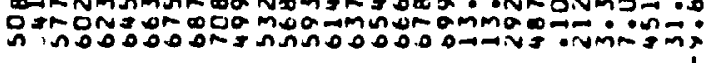

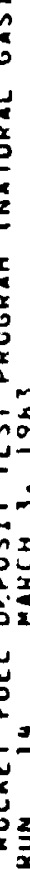

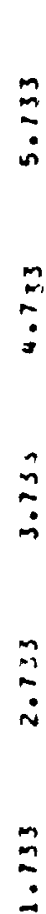

$\overrightarrow{0}$

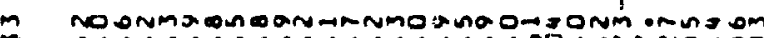

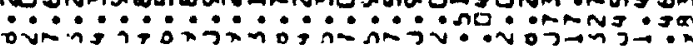

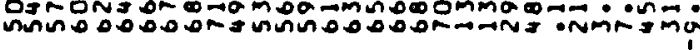

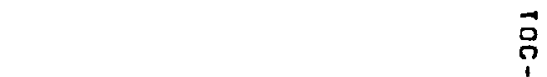

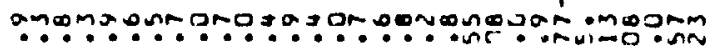

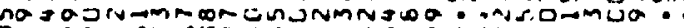

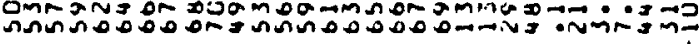

\section{$\overrightarrow{0}$}

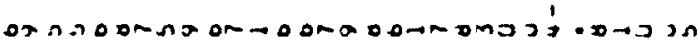

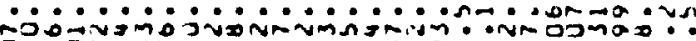

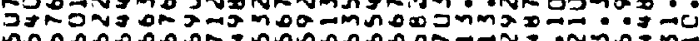

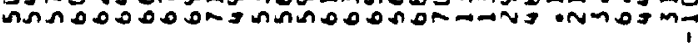

$\overrightarrow{8}$

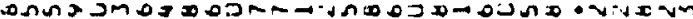

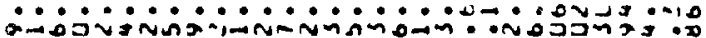
ospentos

$\overrightarrow{3}$

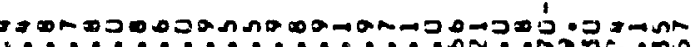

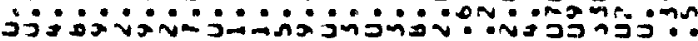

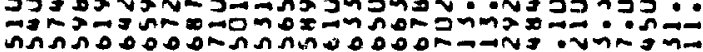<smiles>[SiH3]</smiles>

$\cong$

n กת:

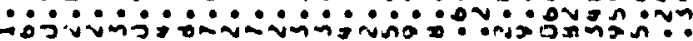

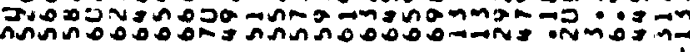

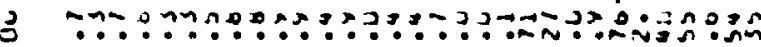

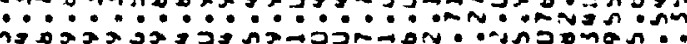

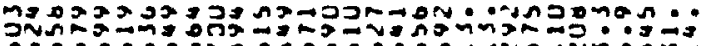

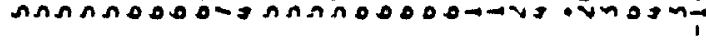

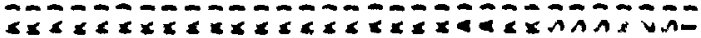

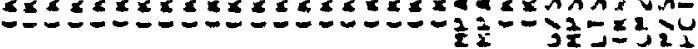

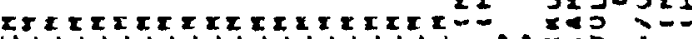

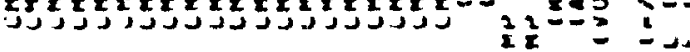

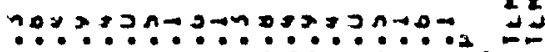

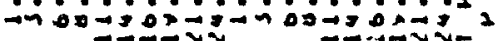

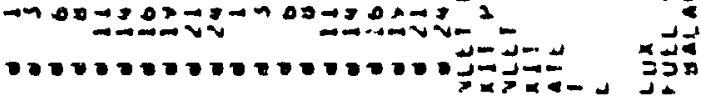

万弓冫 لإد
OKiGin $\because 2 \%$

OF POOR Quailit 


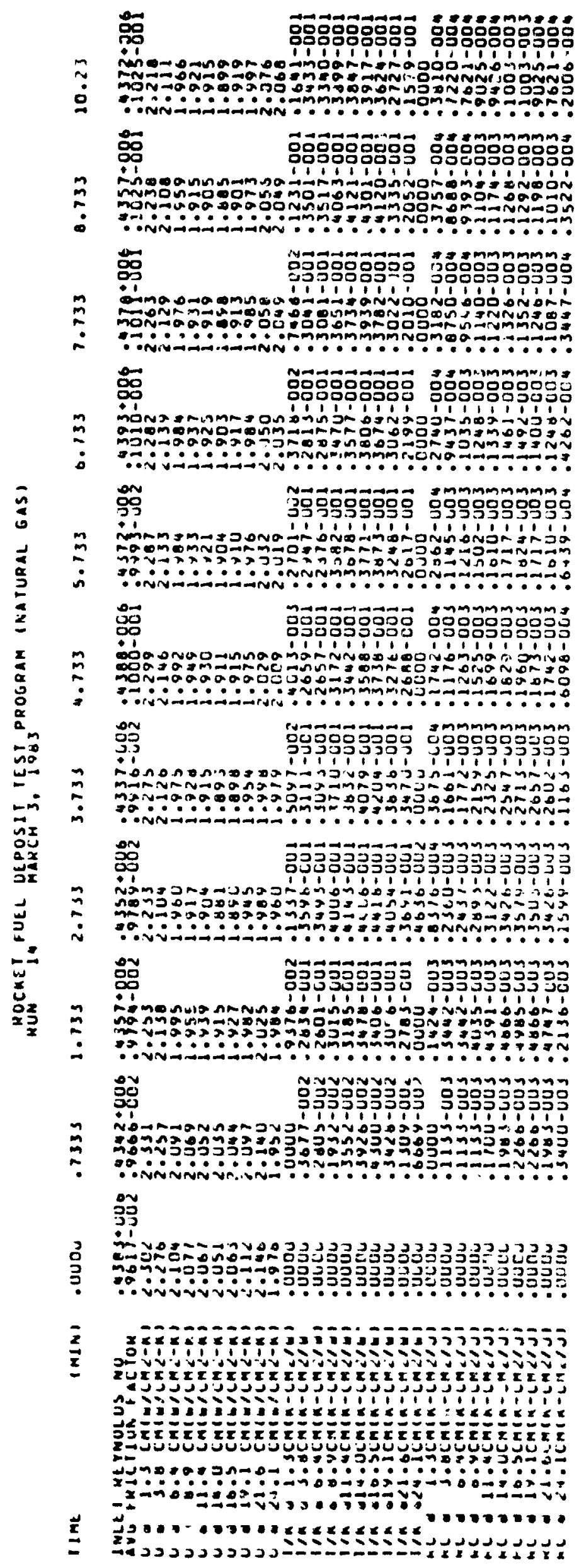

ORICANAL PACE IF
OF. POOF QUALITY 
宫

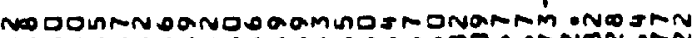

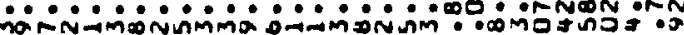
to

号

ORIGHTAL FHC:- Gï OF POOR QUALITY

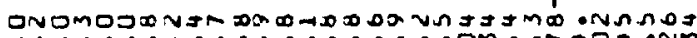

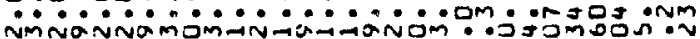

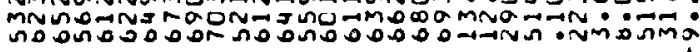
范

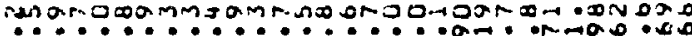

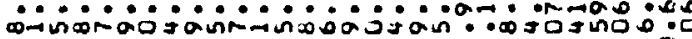

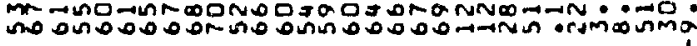

官

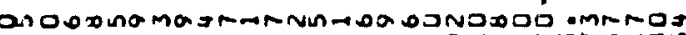

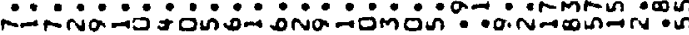

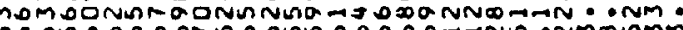

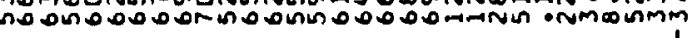

वี

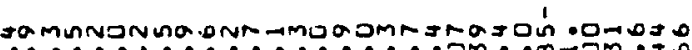
$\because \because \because \cdots \cdots$

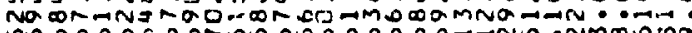

믐

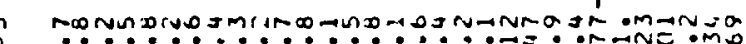
$\because \cdots \cdots \cdots \cdots \cdots \cdots$

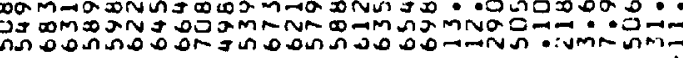

$\overrightarrow{0}$

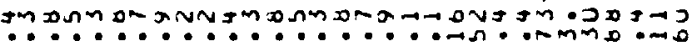
….............

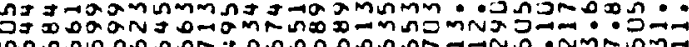

$\overrightarrow{0}$

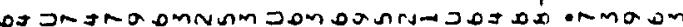
......................

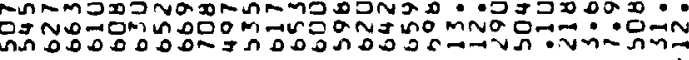
Oova

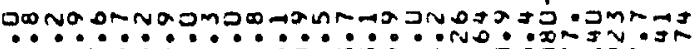

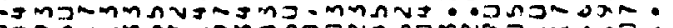

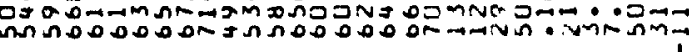<smiles>[SiH3]</smiles>

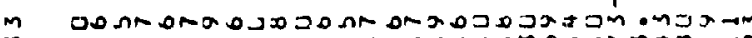

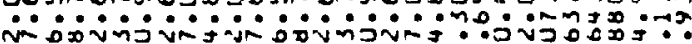
Jmamnam<smiles>[SiH3]</smiles>

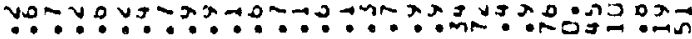

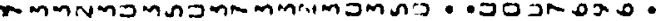

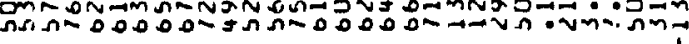

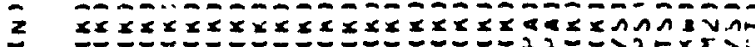

I

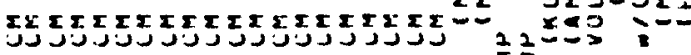

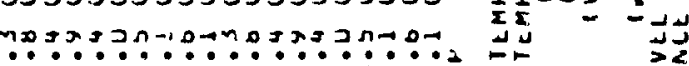

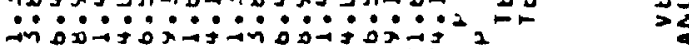
0000000000000000

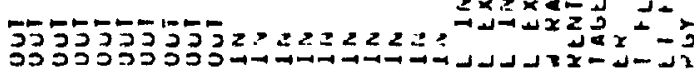




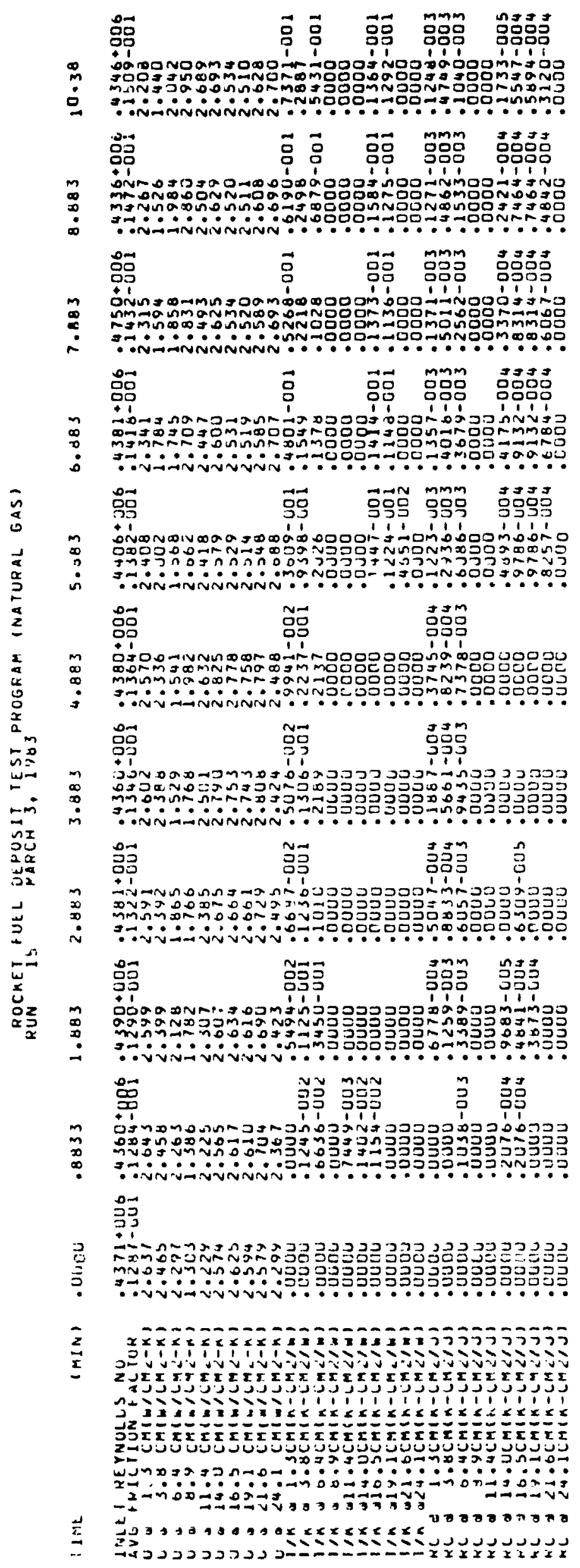

ORIGHASL
OF POOR QUALITY 


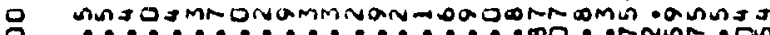

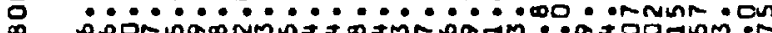

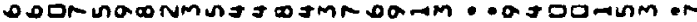

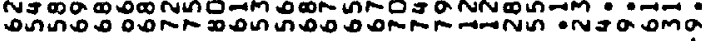

$\overrightarrow{0}$

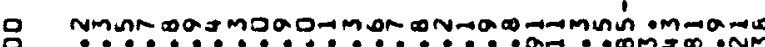
$\because \cdots 0 \cdots \cdots \cdots \cdots \cdots$

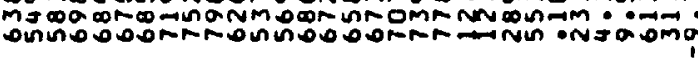

$\vec{\circ}$ 马 nกMe

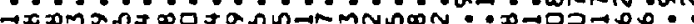

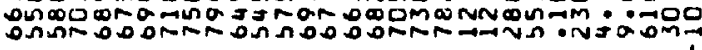

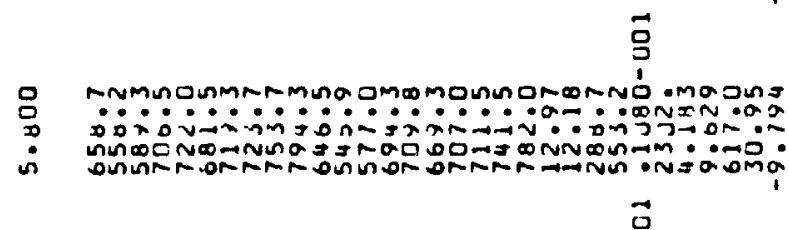

O

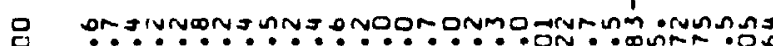

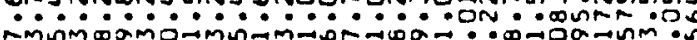
nungo:<smiles>[BH3-]</smiles>

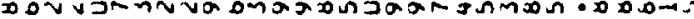
$\ldots \ldots \ldots \ldots \ldots \ldots$. anmondadminj OninR

官

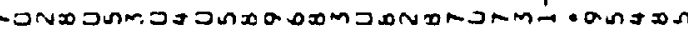

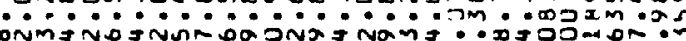

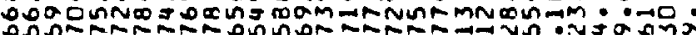<smiles>[CH-]</smiles>

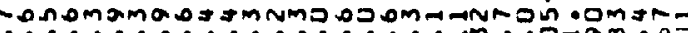

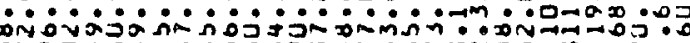

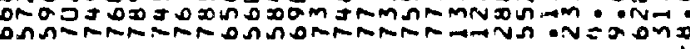

3

Dnongan ovת

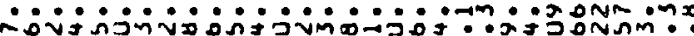

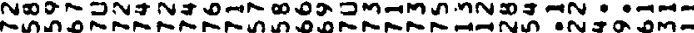<smiles>B</smiles>

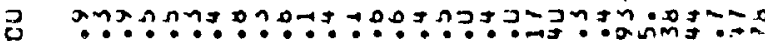

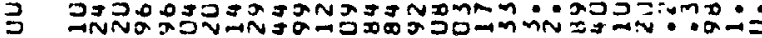

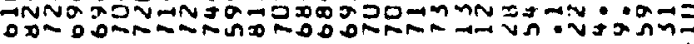

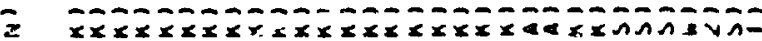

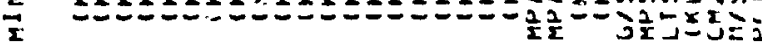

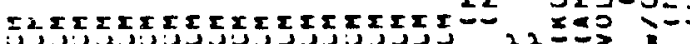
ג地

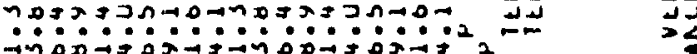

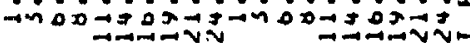

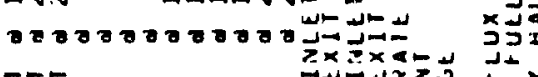

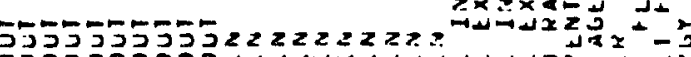

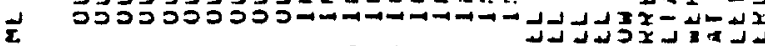




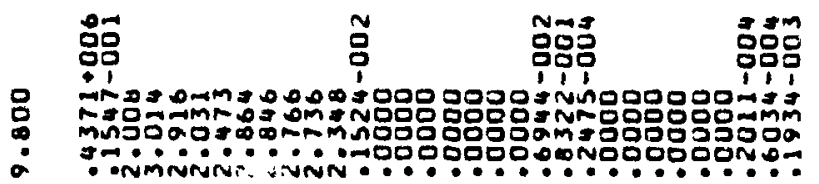

ORIGIFAL POS
OF POOR QUALITY

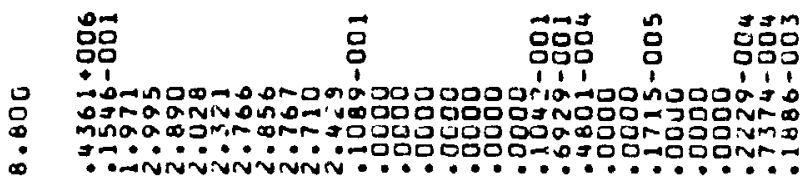

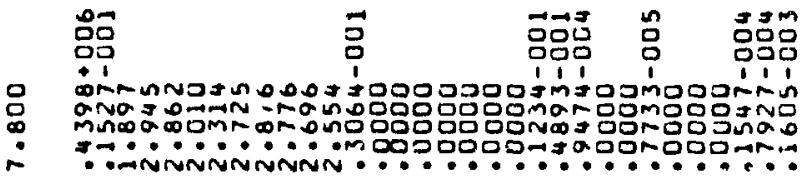

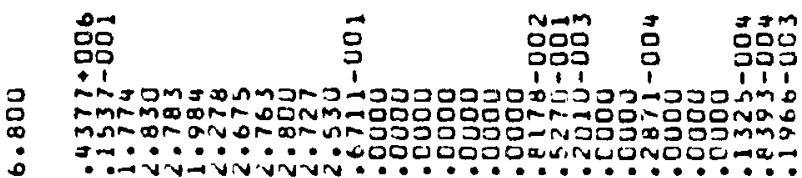

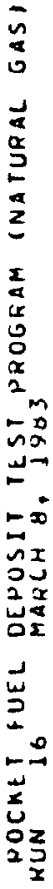

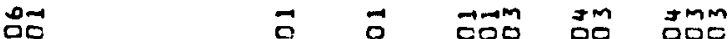

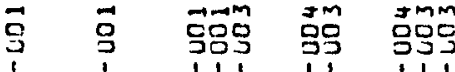

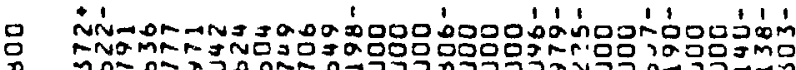
$\because-10$ -

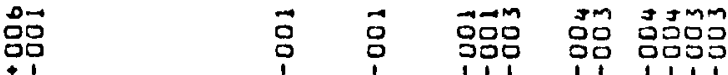

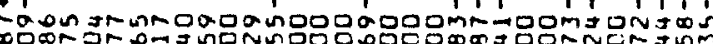
mo 7.-.0.

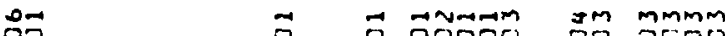

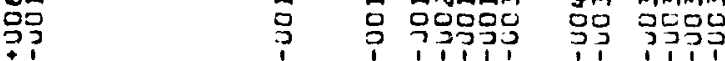

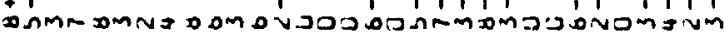

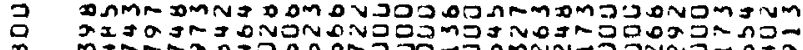
mำ

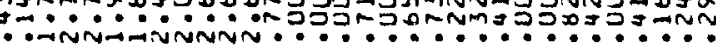
范

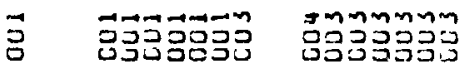

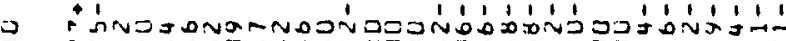

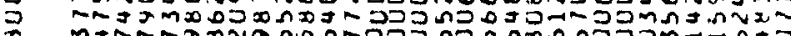

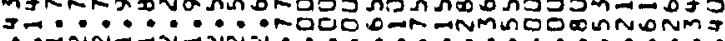

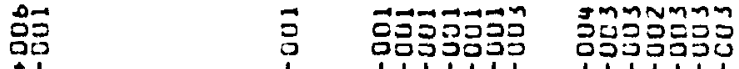

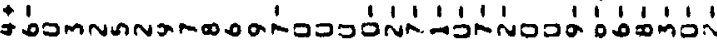

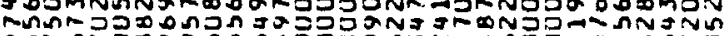

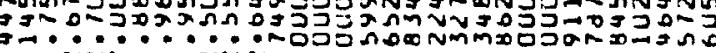

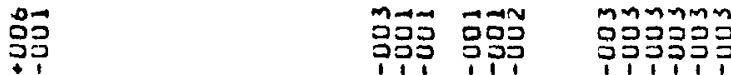

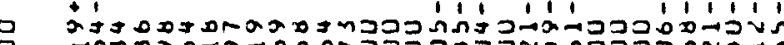

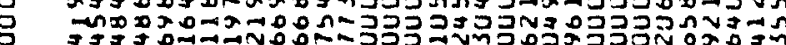

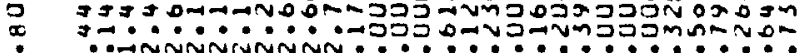

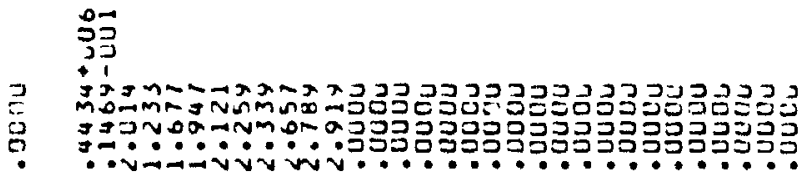

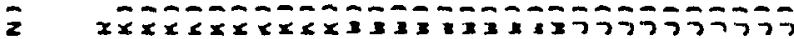

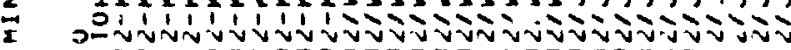

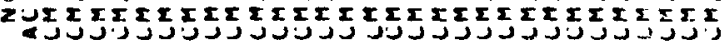

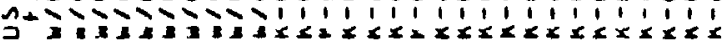

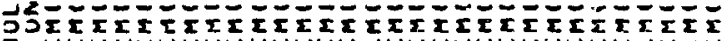
z-

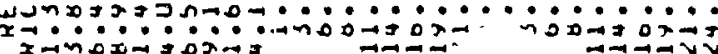
-

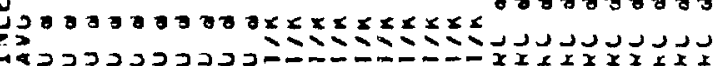




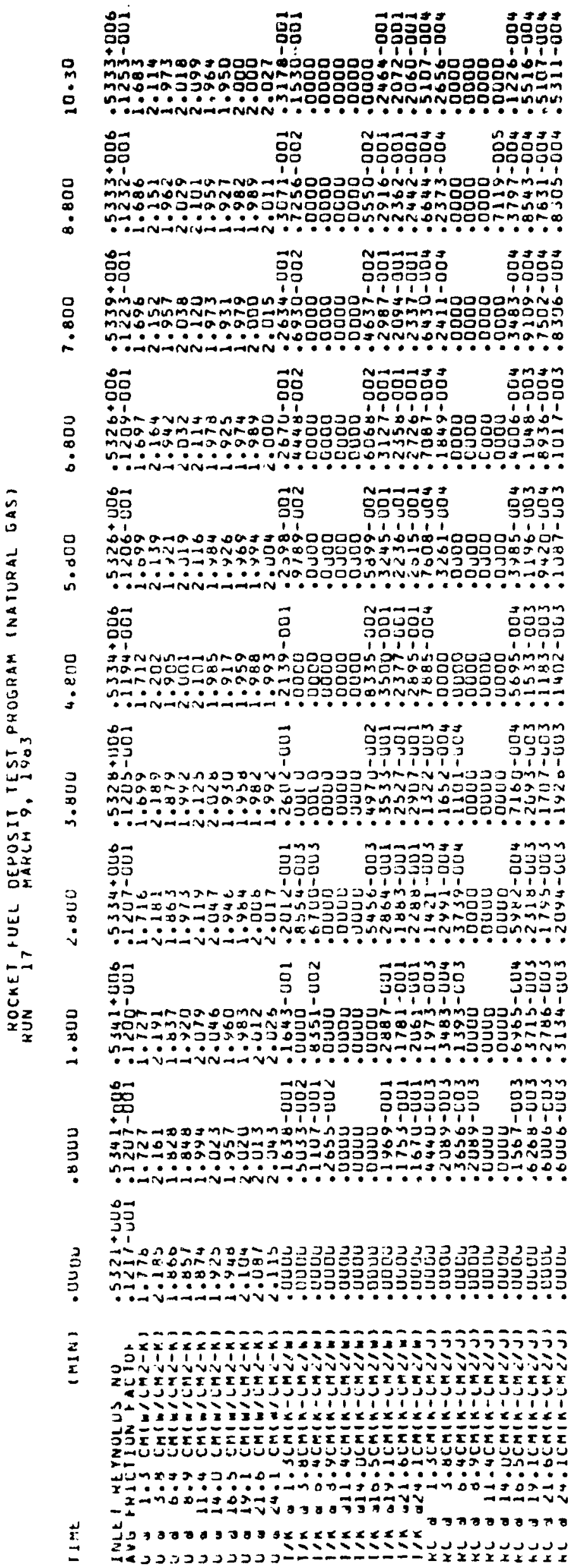

ORIGNAL PREL:" OF POOR GI:ALITY 


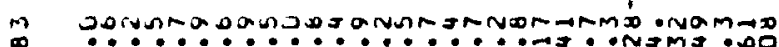

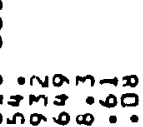

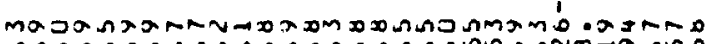

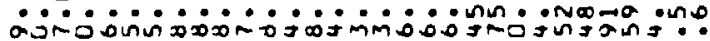

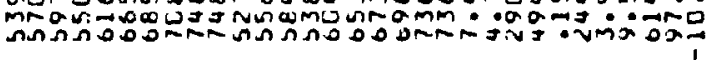

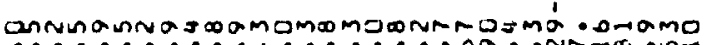

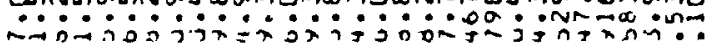
múñubour

응

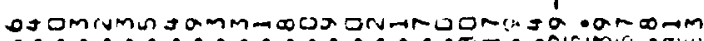

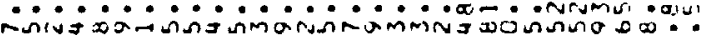
mnoñog D

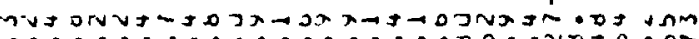

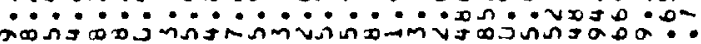

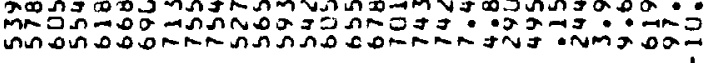<smiles>[BH2]</smiles>

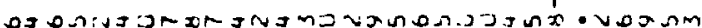

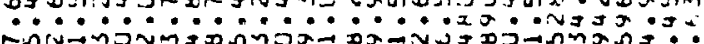

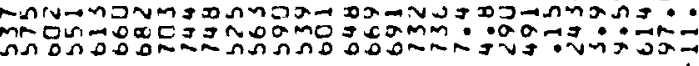

$\vec{\jmath}$

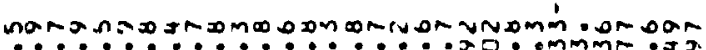

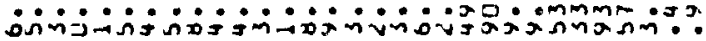
0ก0月

$\vec{\jmath}$

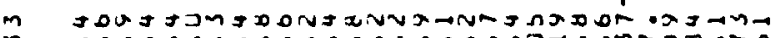
n

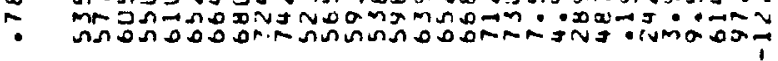

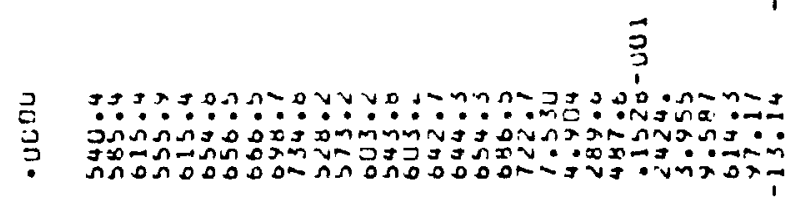

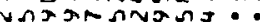

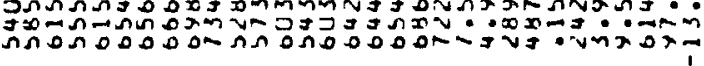

$\bar{z}$

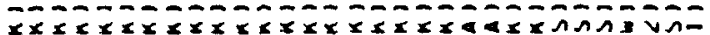

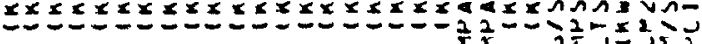

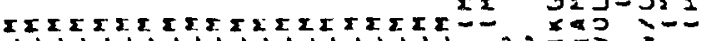

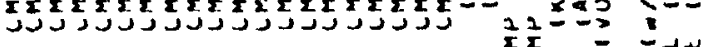

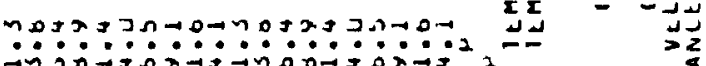

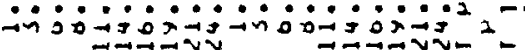




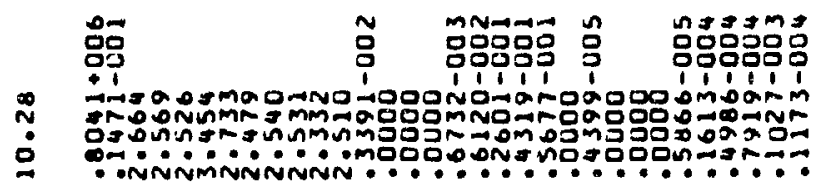

茄

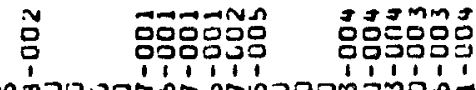

m nกno

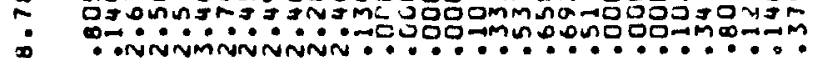

음

뭄듬ำ

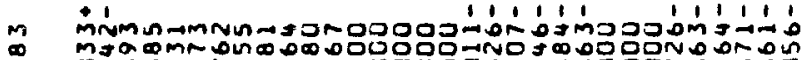

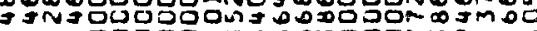

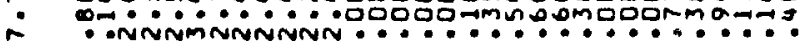

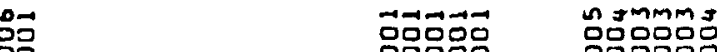

1

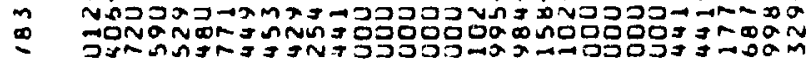

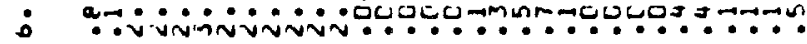

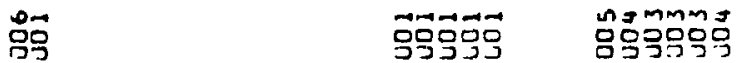

m ád a

m momn

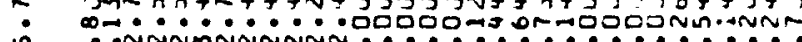

a

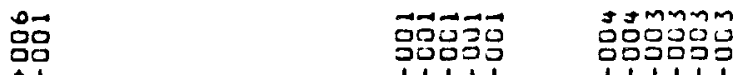

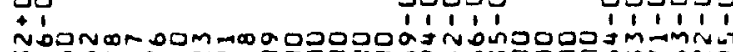

m mogñorogm

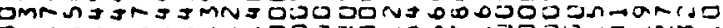

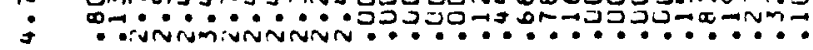

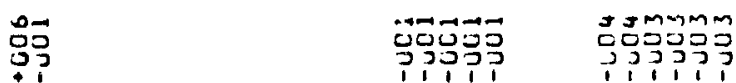

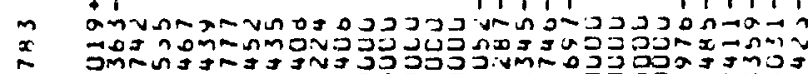

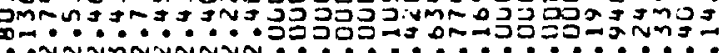

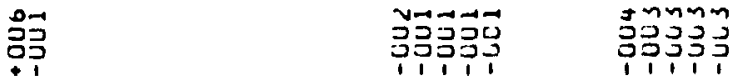

míns

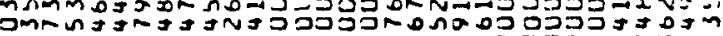

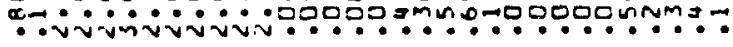

跑

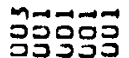

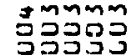

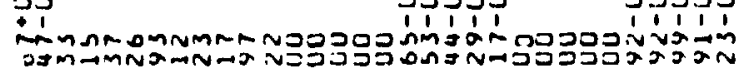

m-10.ำ.

므ำ

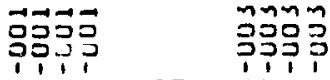

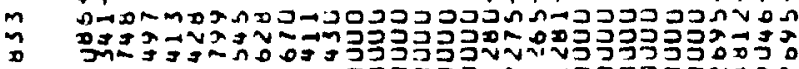

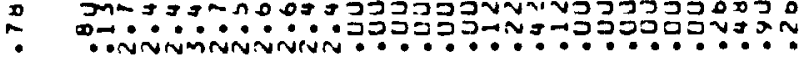

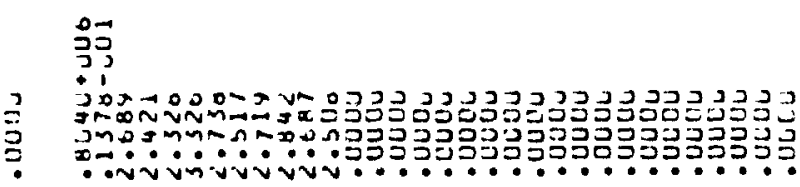

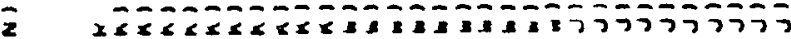

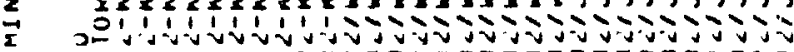

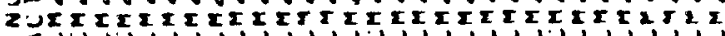

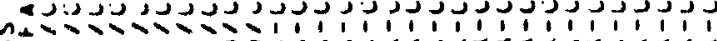

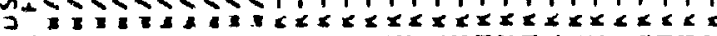

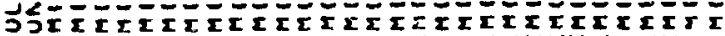

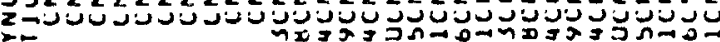

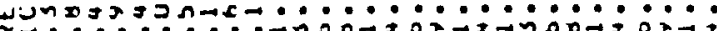

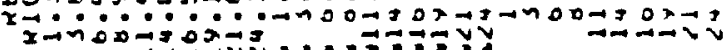

落 


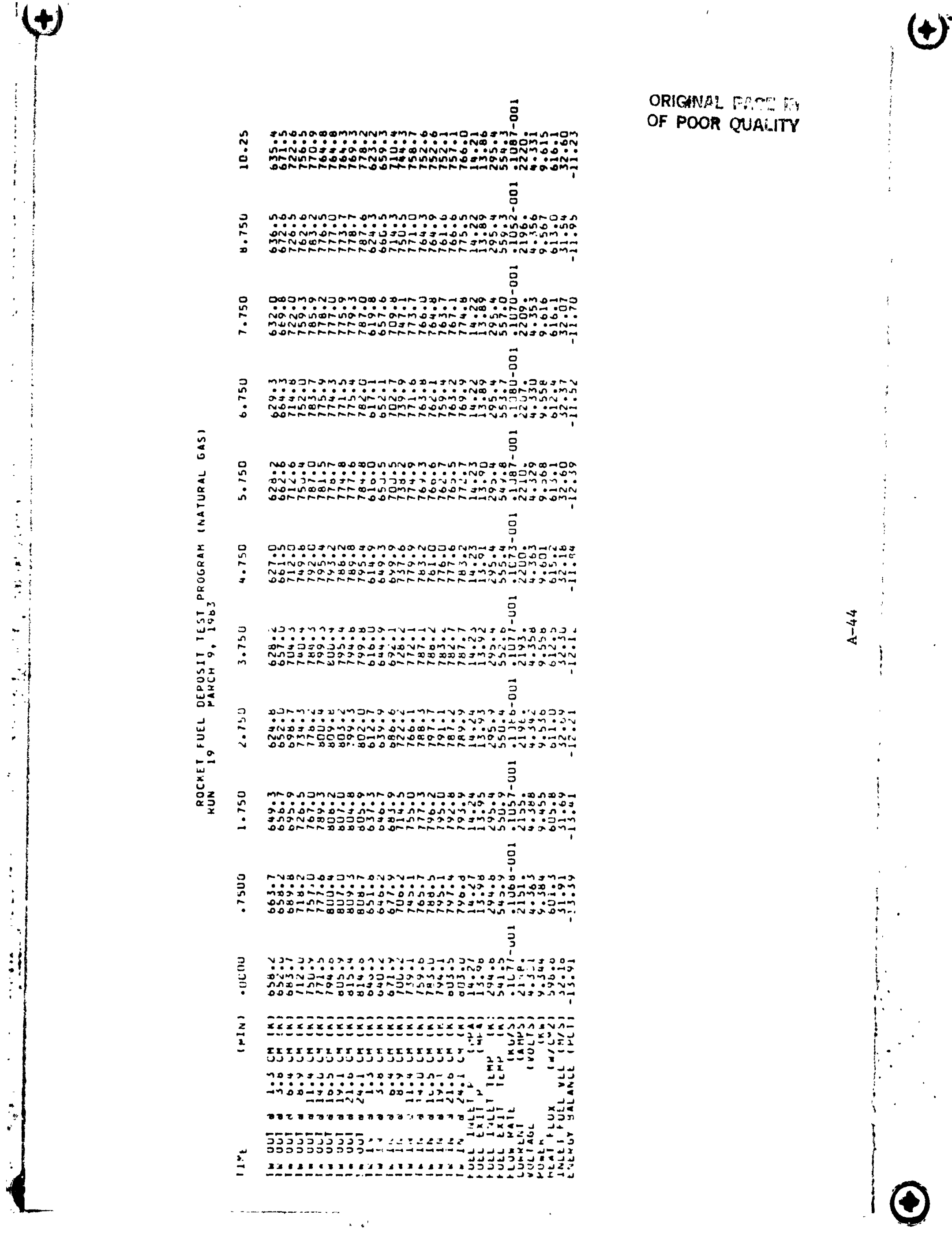




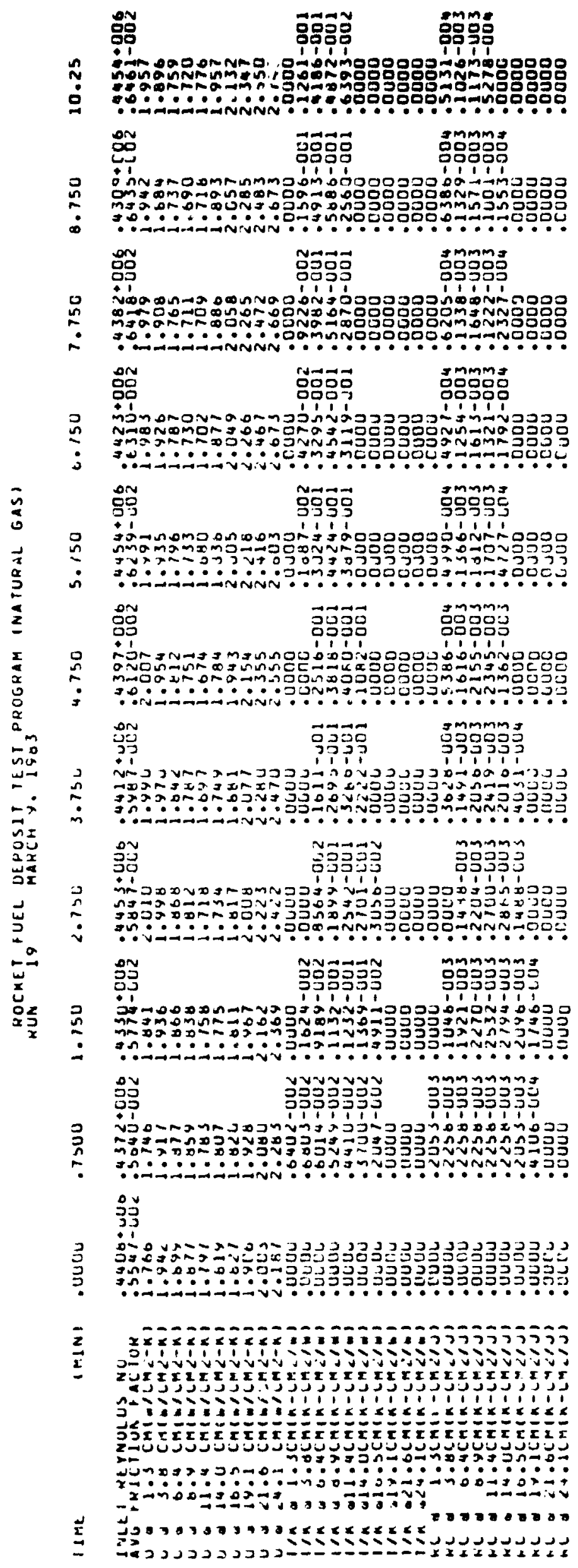

ORIGINAL PACE IS
OF POOR QUALITY 
:

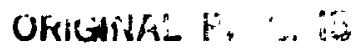

- monomagomagomomonmmanonom

OF POOR QUALITY

…

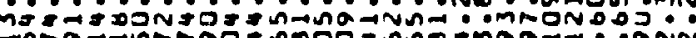

องกn์

$\overrightarrow{8}$

웅

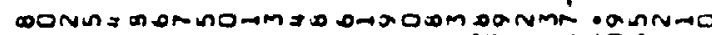
…....................

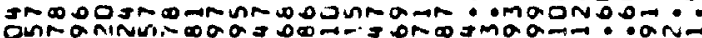

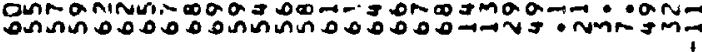

安

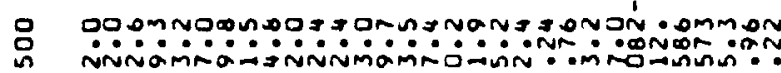

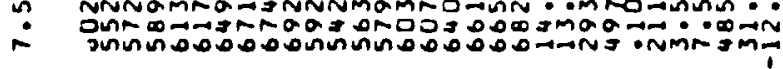

$\overrightarrow{\mathrm{C}}$

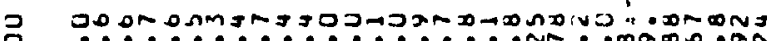

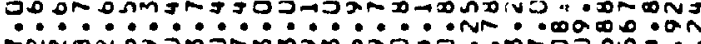

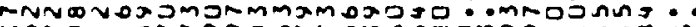
ดภรง

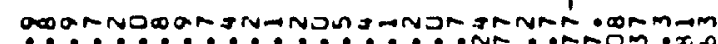

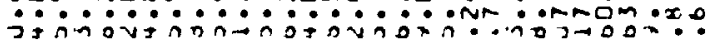

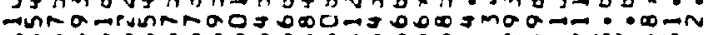
annusoososonnno

$\ddot{\mathrm{g}}$

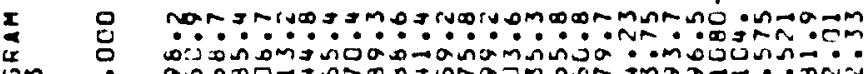

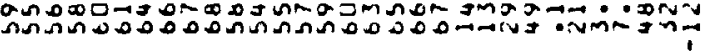<smiles>[BH3-]</smiles>

$\overrightarrow{0}$

O OUNonme

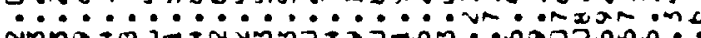

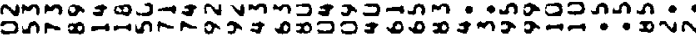

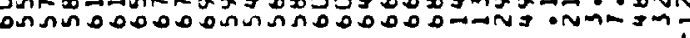

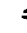

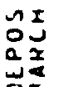

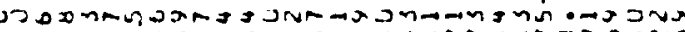

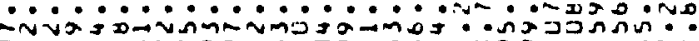
ontor.

$\overrightarrow{3}$

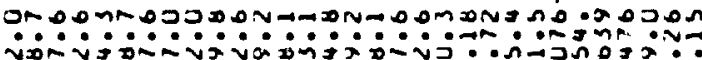

Von

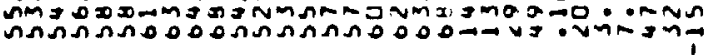

$\overrightarrow{0}$ 弓

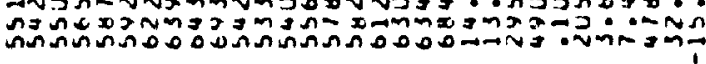

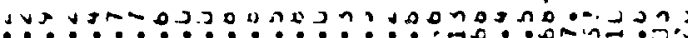

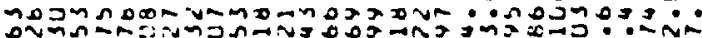

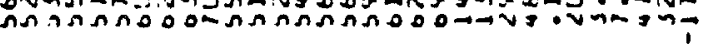
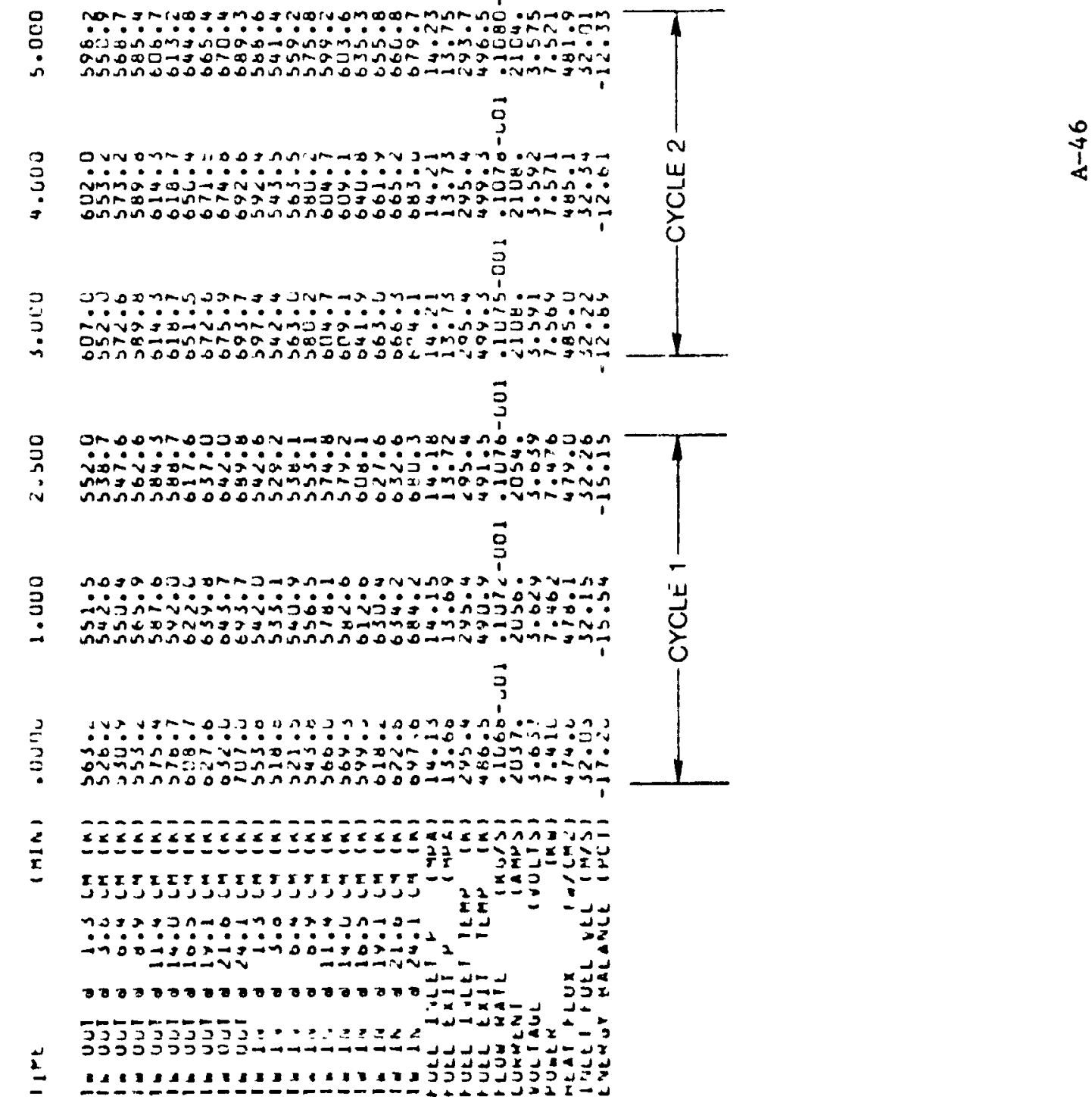


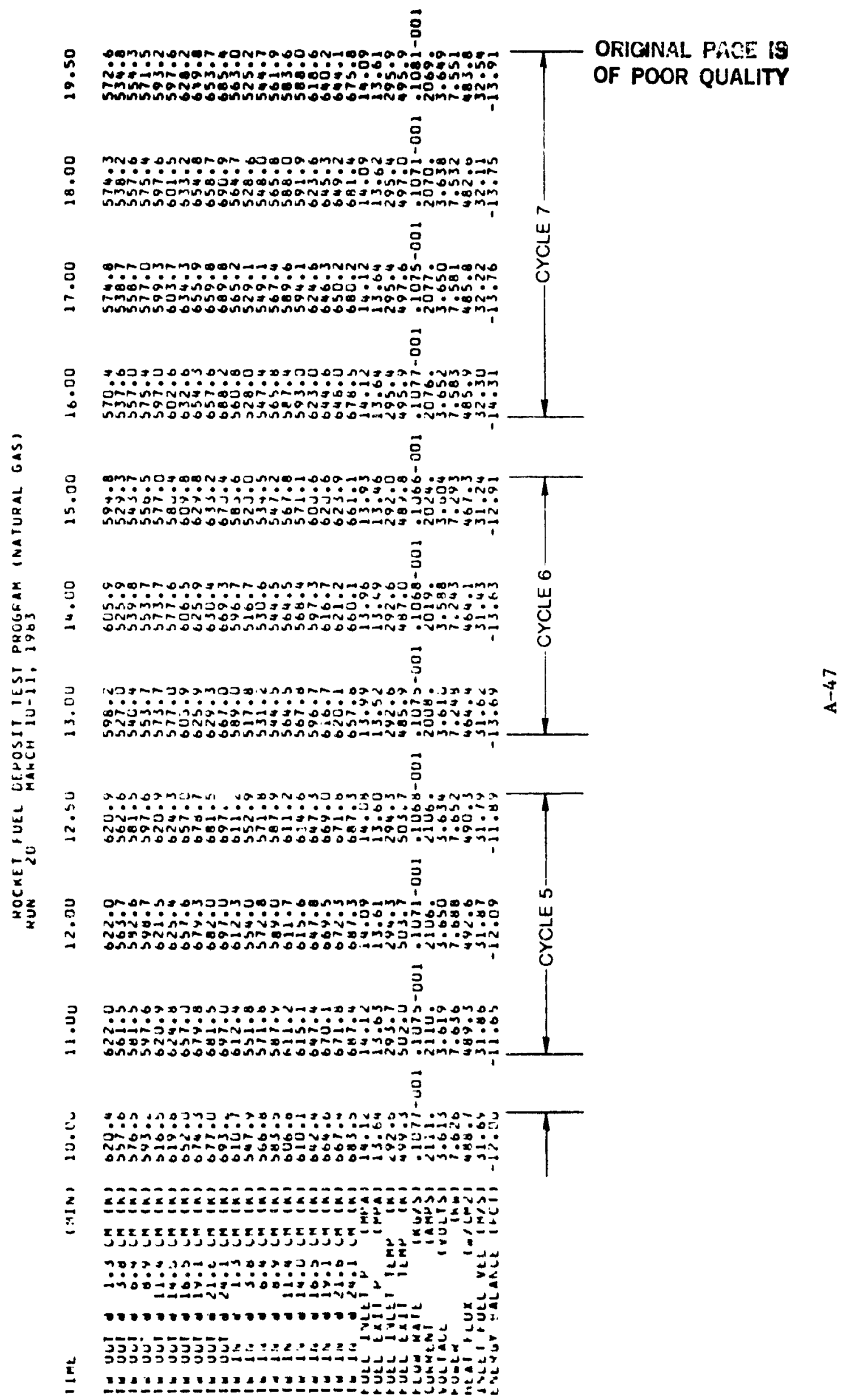


ORIGHAL FAGE HE OF POOR QUALITY

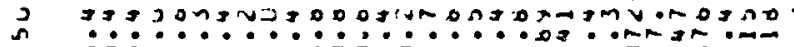
i ñoñ

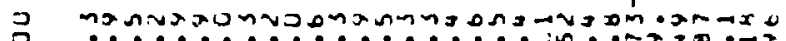
:00ำ ring

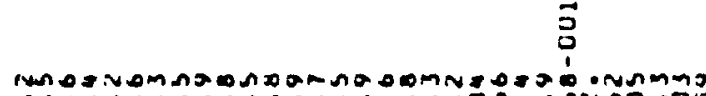
药 =0

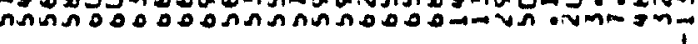

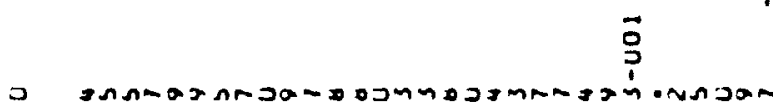

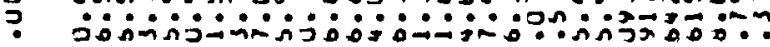

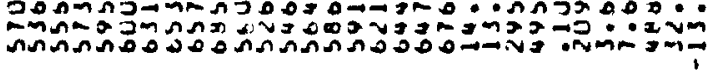<smiles>[SiH3]</smiles>

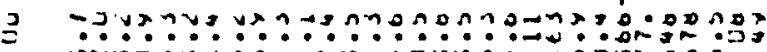
invjزjj-ing คnคำ

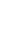

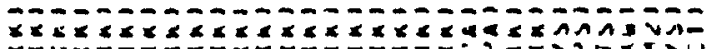

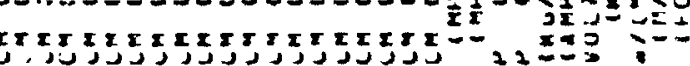

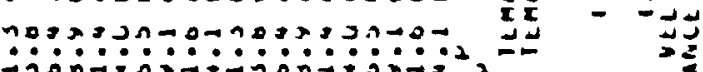

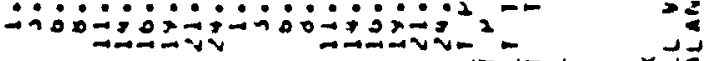

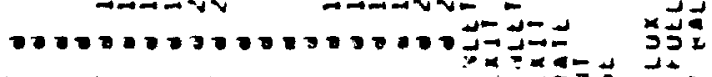

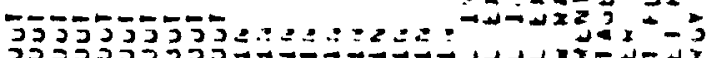




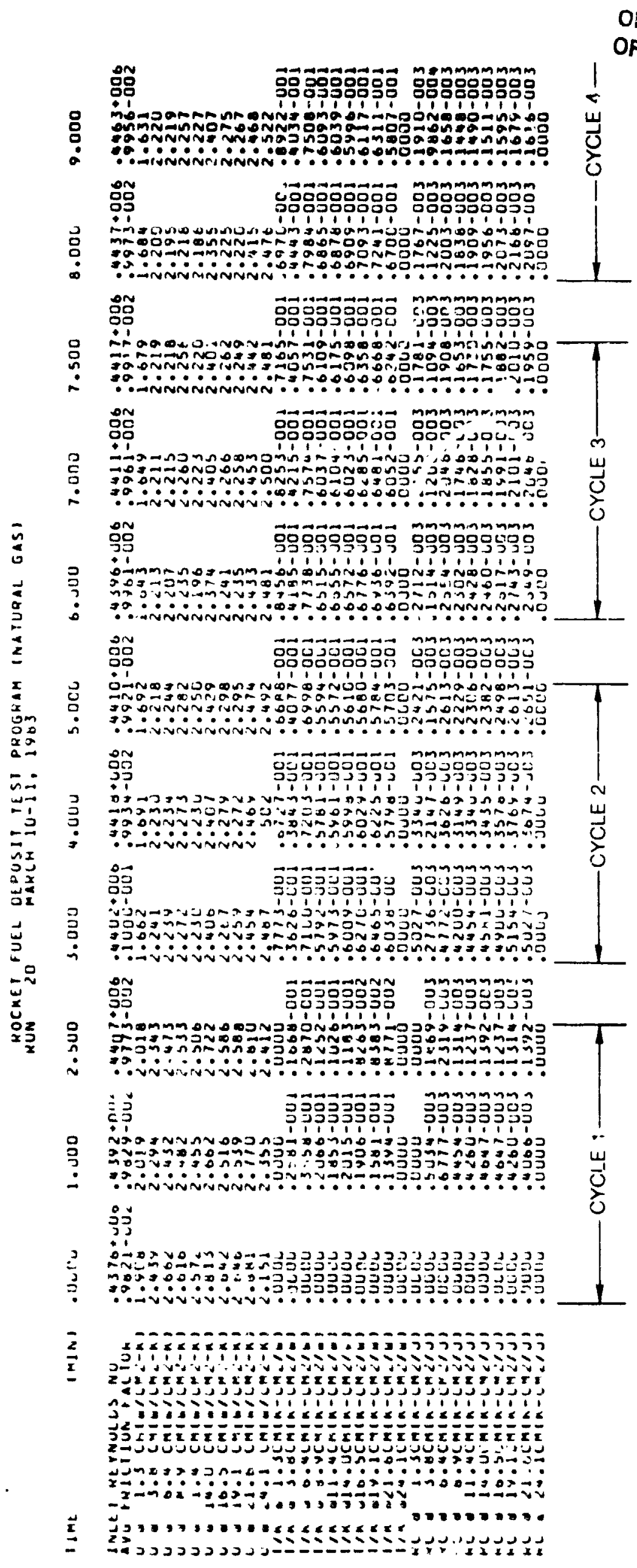

(4)

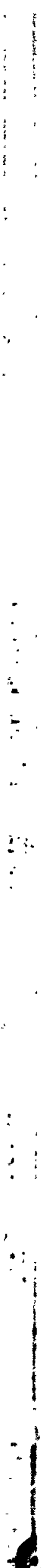

OF POOR Qufing 


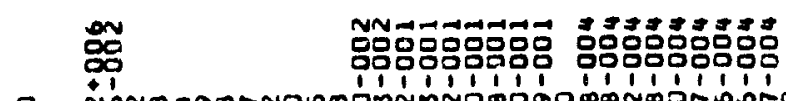

ORICNAL PAOE IS

OF POOR QUALITY

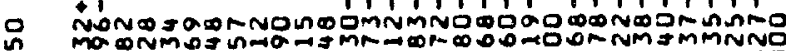
: to.0.…

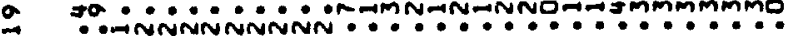

$\stackrel{\circ 0}{\circ 0}$

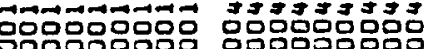

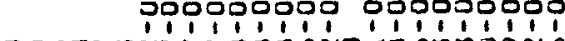

- Mndrnsodzrmñ

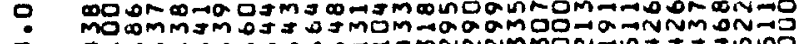

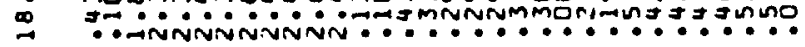

ㅁำ

$\infty$

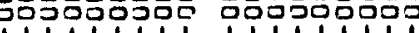

을

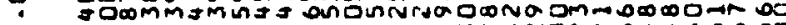

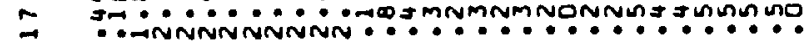

orv

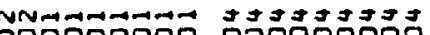

$\infty$

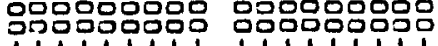

D Nom

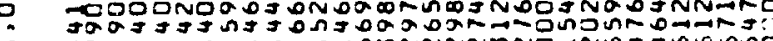

- Ja.

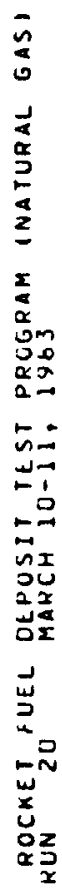

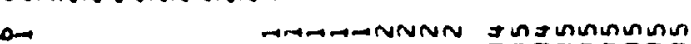

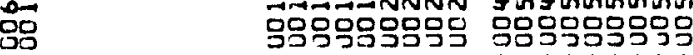

- \#́menmm

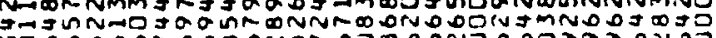

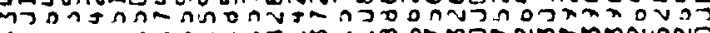

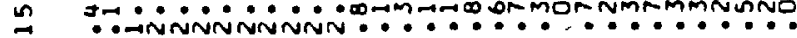
OA

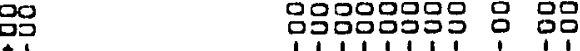

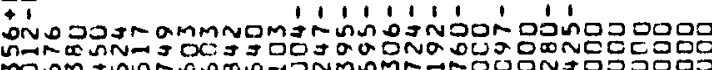

: monm

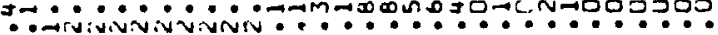

סु

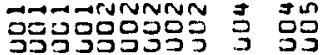

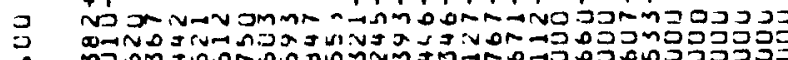

110

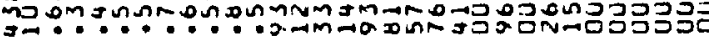

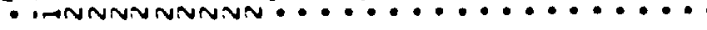

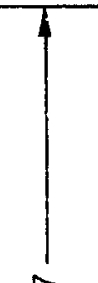

\section{.}

i
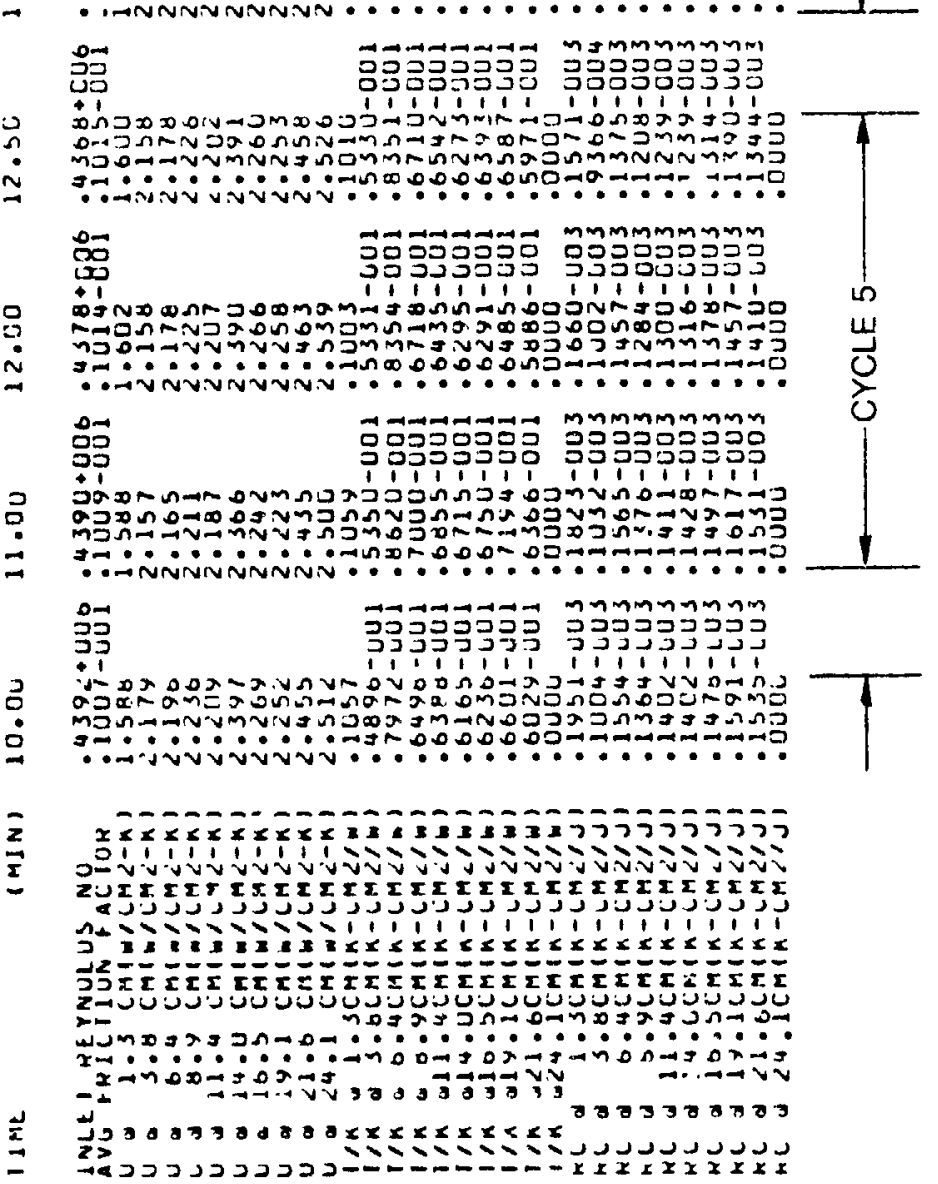
ORIGWAL FACE

OF POOR QUALITY

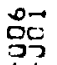

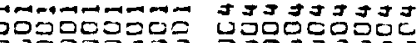

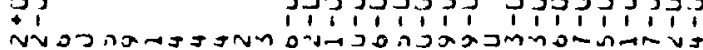

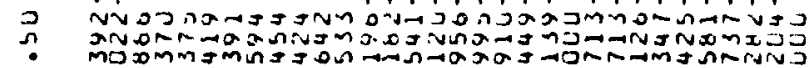

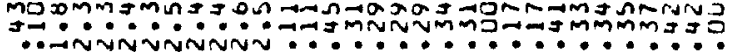

วิ

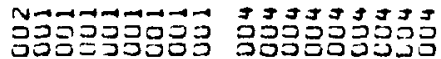

trurivarnagaz-

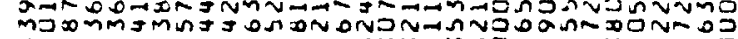

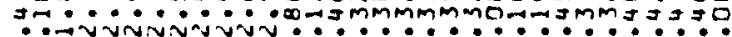

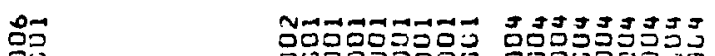
P.

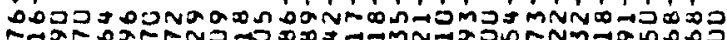

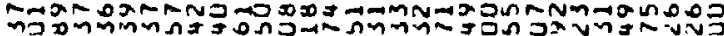
. 䟨

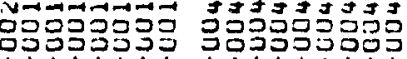
$+1$

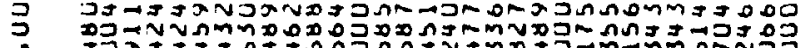
$\overrightarrow{0}$ : 早

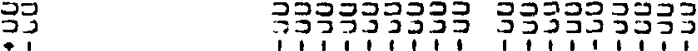

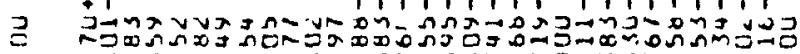

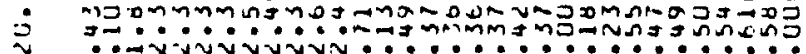

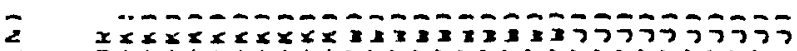

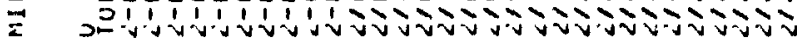

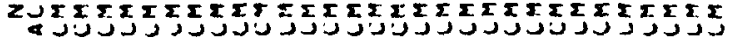
A+ JZ二- -

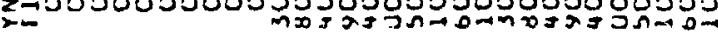

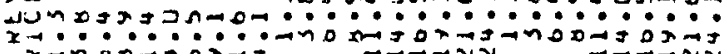
H,

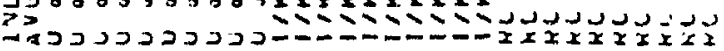




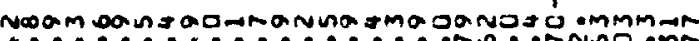

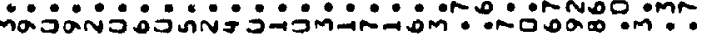
ñvm

$\overrightarrow{0}$

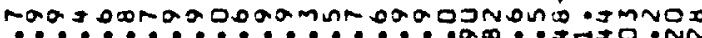

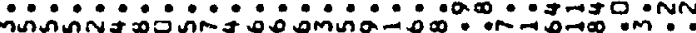

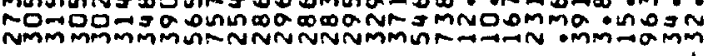

$\overrightarrow{3}$

$\ddot{0}$

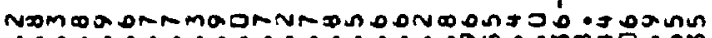

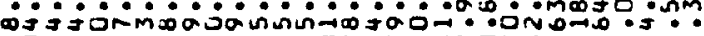
Nmminmmand

$\overrightarrow{0}$

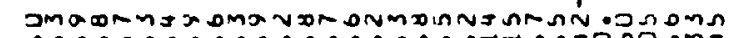

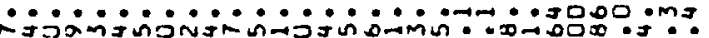

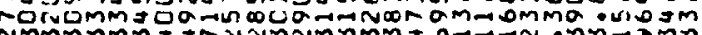

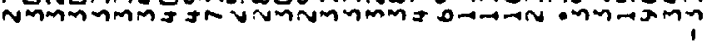

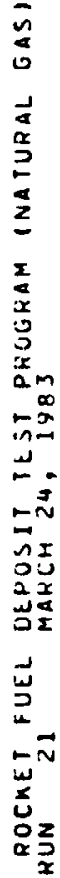

$\overrightarrow{0}$

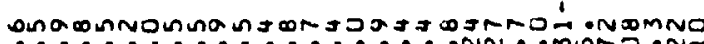
-Ojх

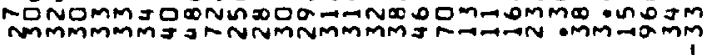

$\vec{U}$

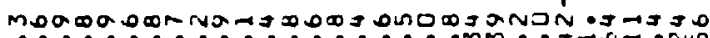
onjajijomjö-

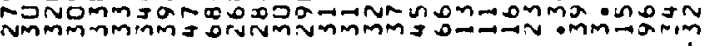

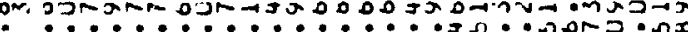

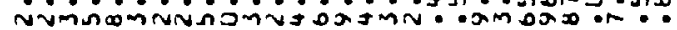

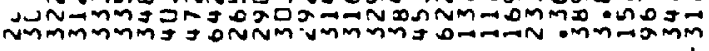

引

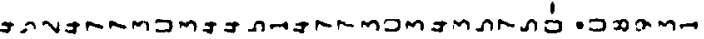
000000-

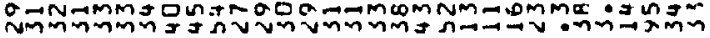<smiles>[CH-][CH-]</smiles>

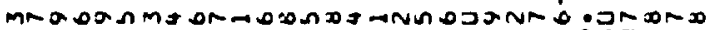

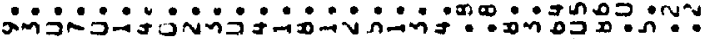

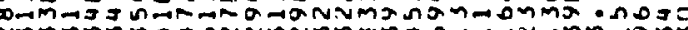
ขmmminnga

马े

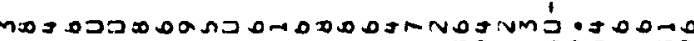

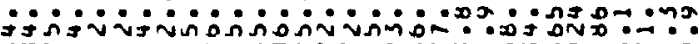

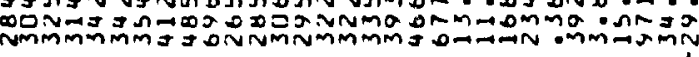

$\overrightarrow{3}$

อ Dovas

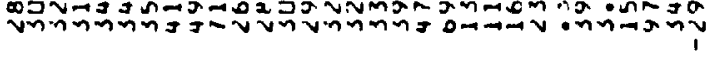

$\frac{2}{2}$

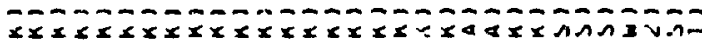

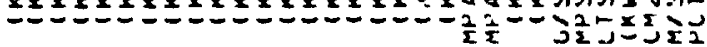

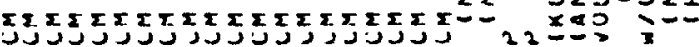

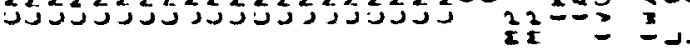

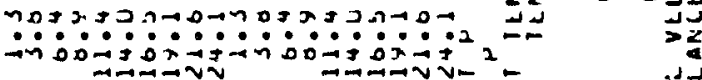

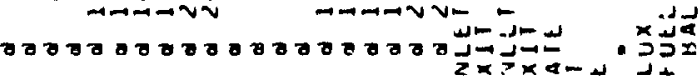

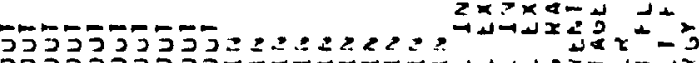




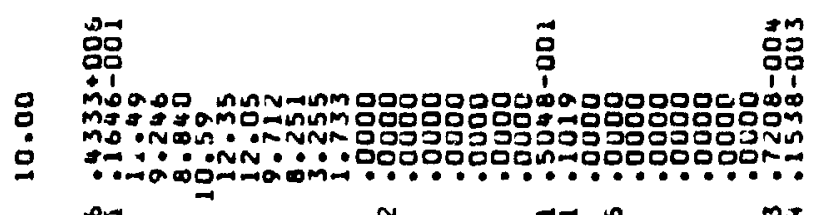

CRIGIAL PAGE IS OF POOR QUALITY

尖

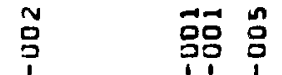

总

三 ấ

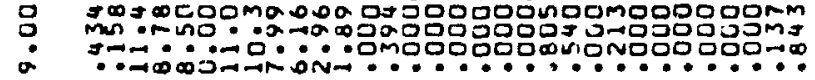

哭 落 拿 品

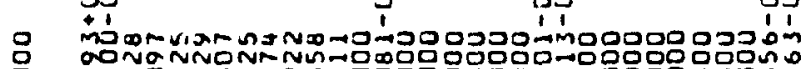

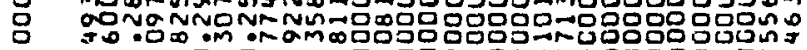

-

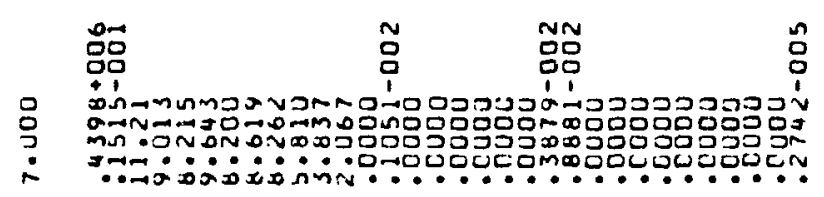

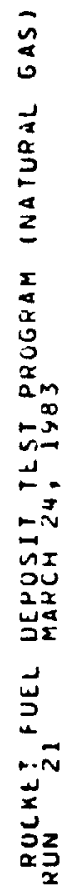

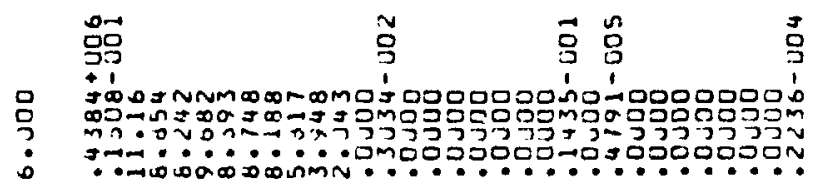

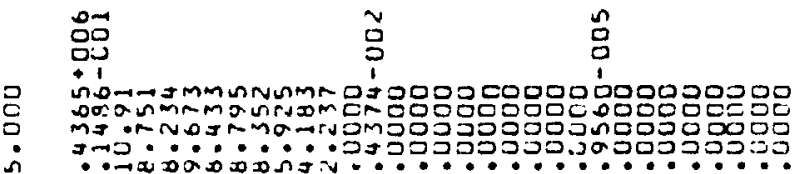

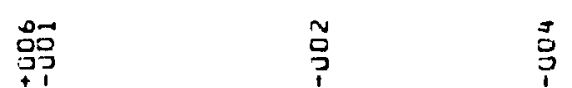

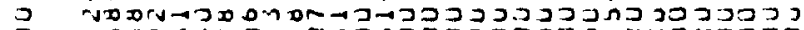

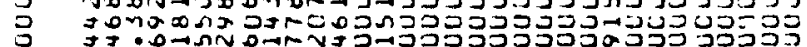

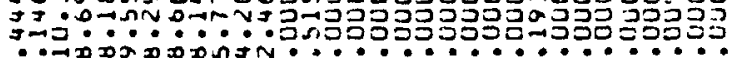

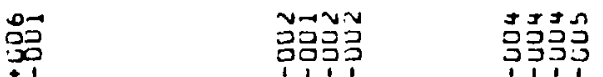

-

ว

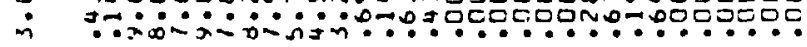

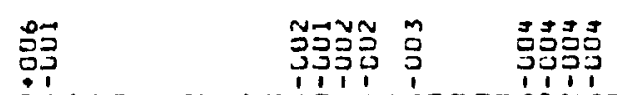

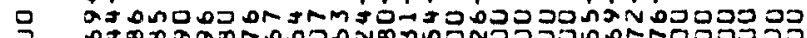

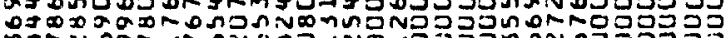

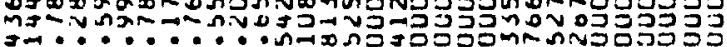

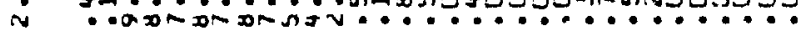

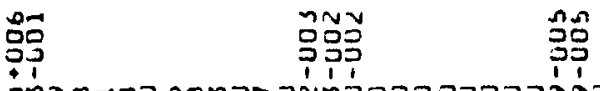

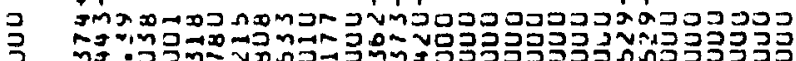

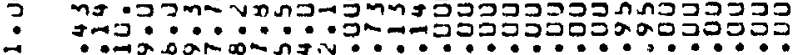

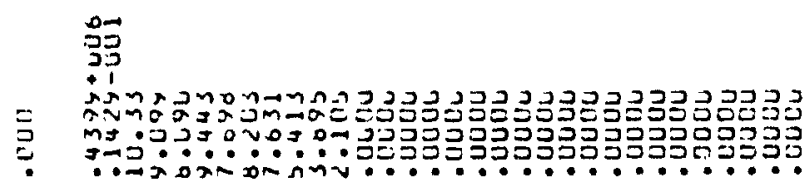

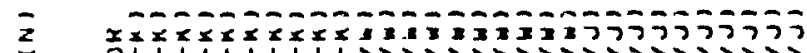

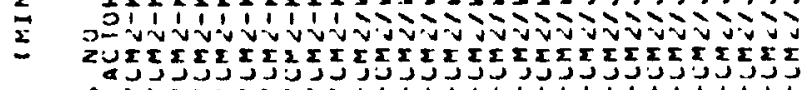

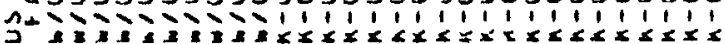

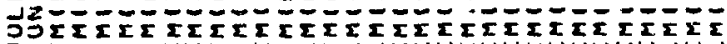

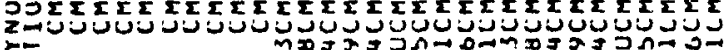
עี

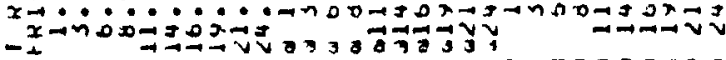

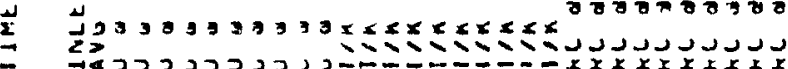




\section{ORICNAn TOM \\ OF POOR QUALIYY}

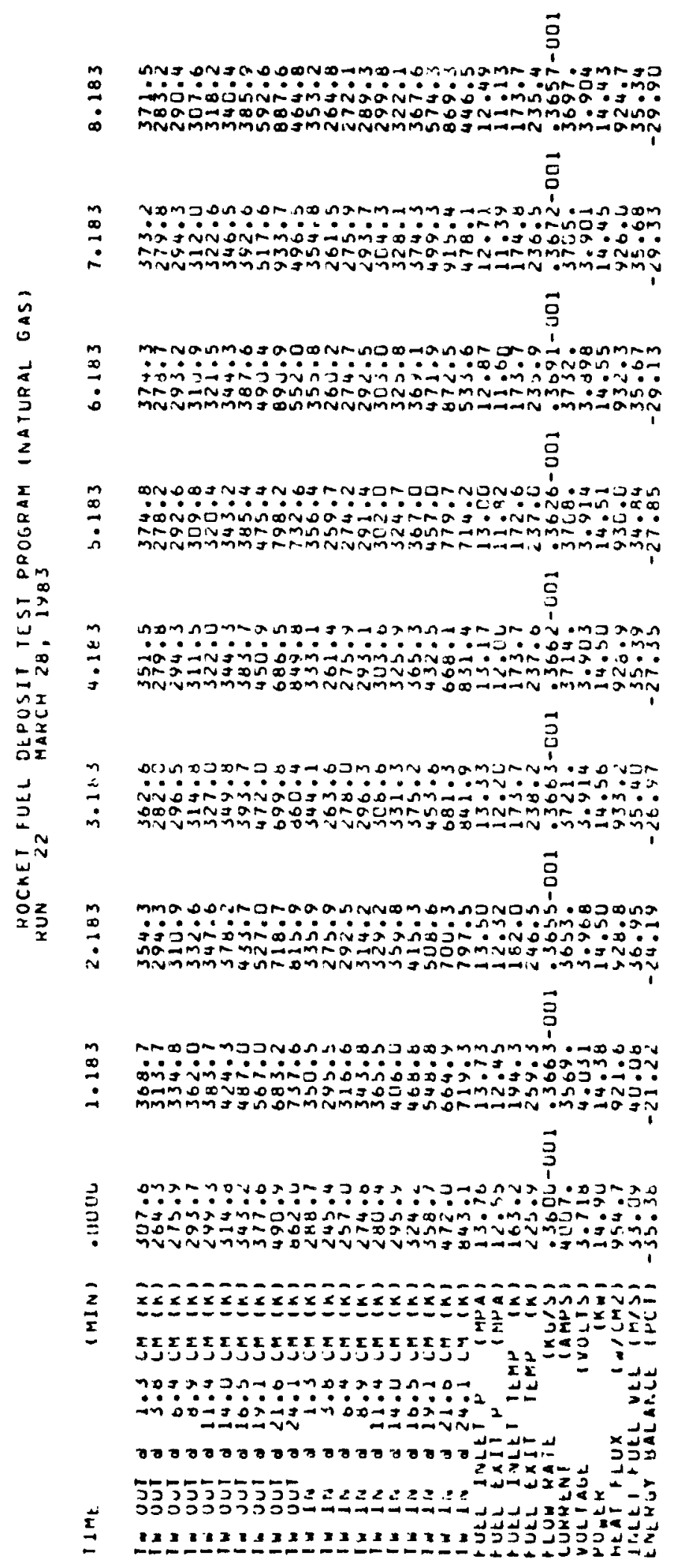


ORIGNAL PACE IS
OF POOR QUALITY

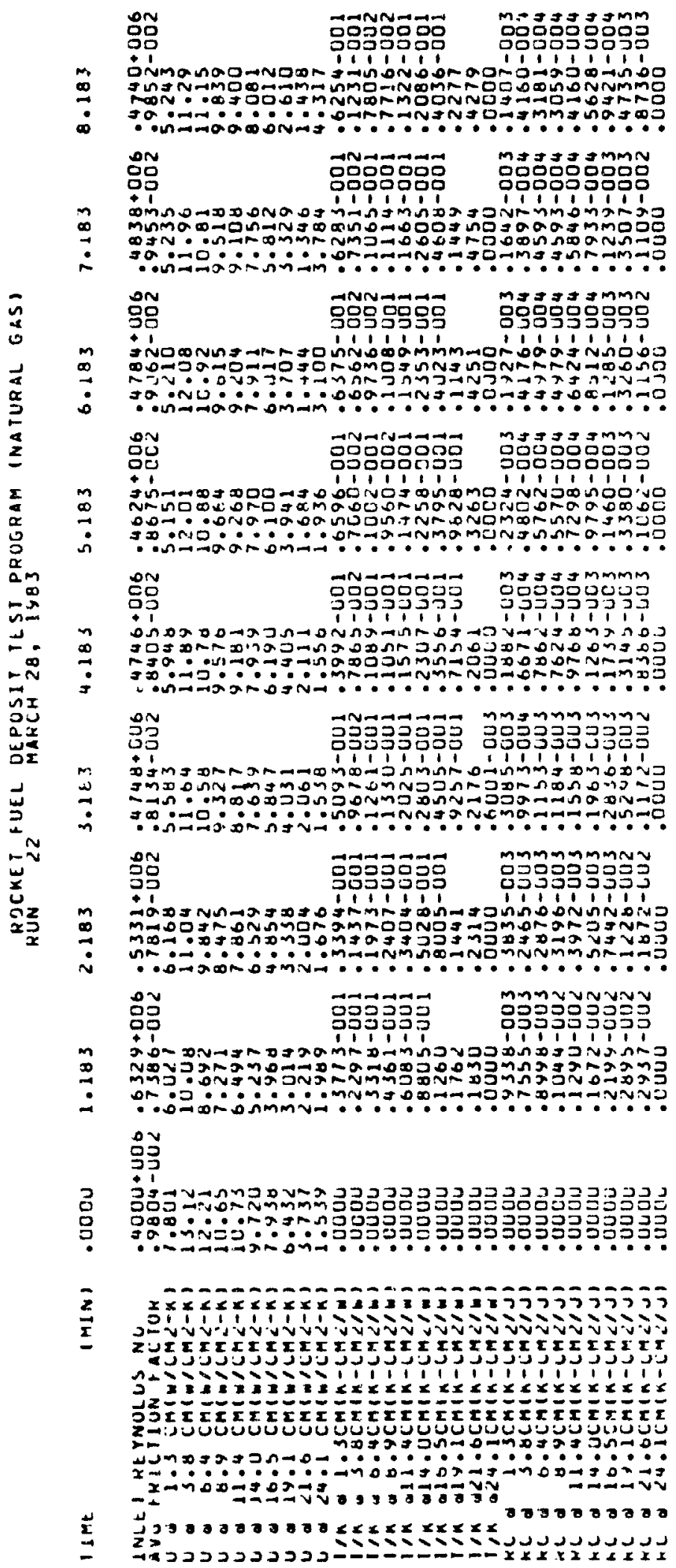




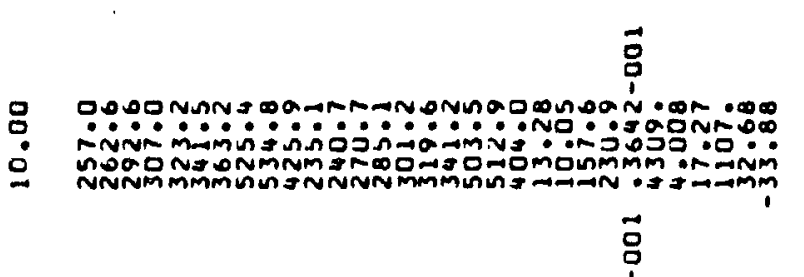

음

$\therefore$ (

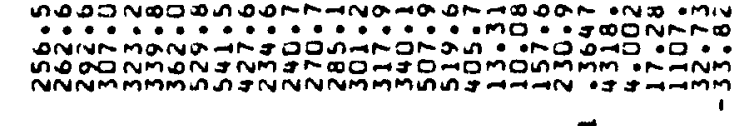

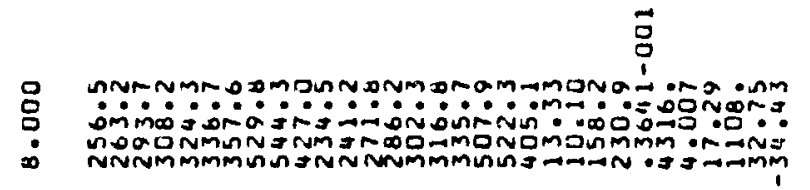

$\vec{g}$

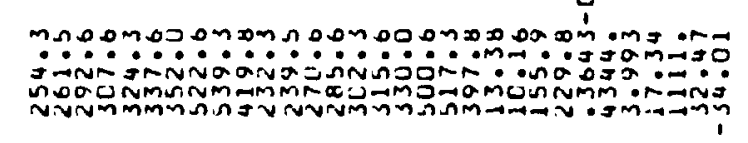

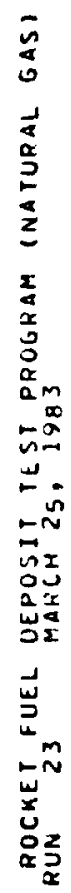$$
\text { naso }
$$

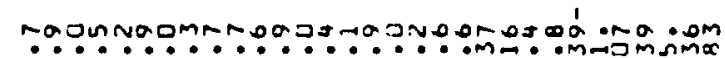

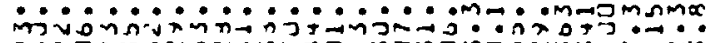

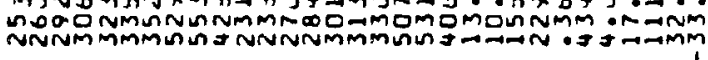

$\vec{g}$

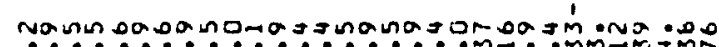
mo-

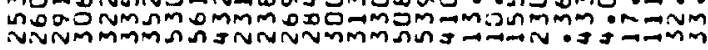

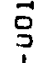

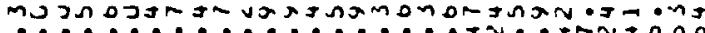

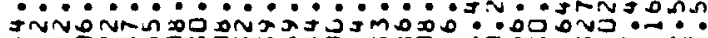
fivonm

$\overrightarrow{\vec{j}}$

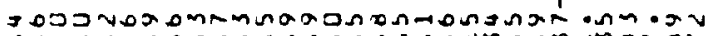
…………ำn Nำ

$\overrightarrow{5}$

nNon

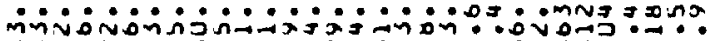
Nivinnming

$\overrightarrow{3}$

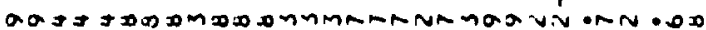

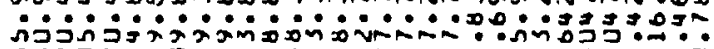

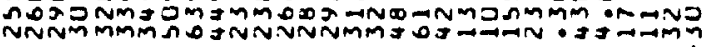

:

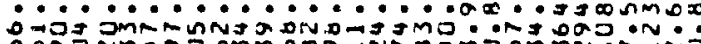

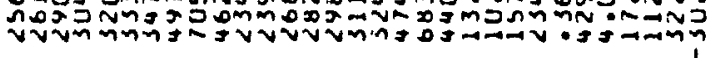

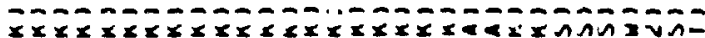

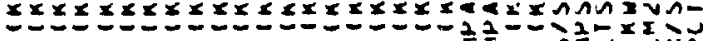

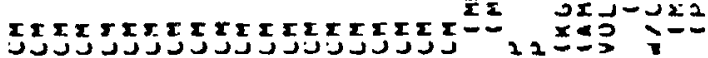

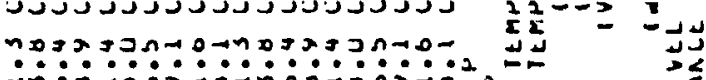

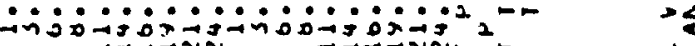

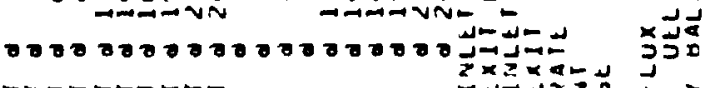

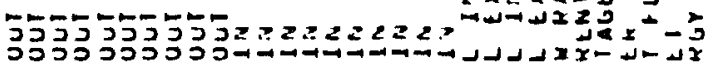
I
ORIGANAL Find OF POOR QUALITY 


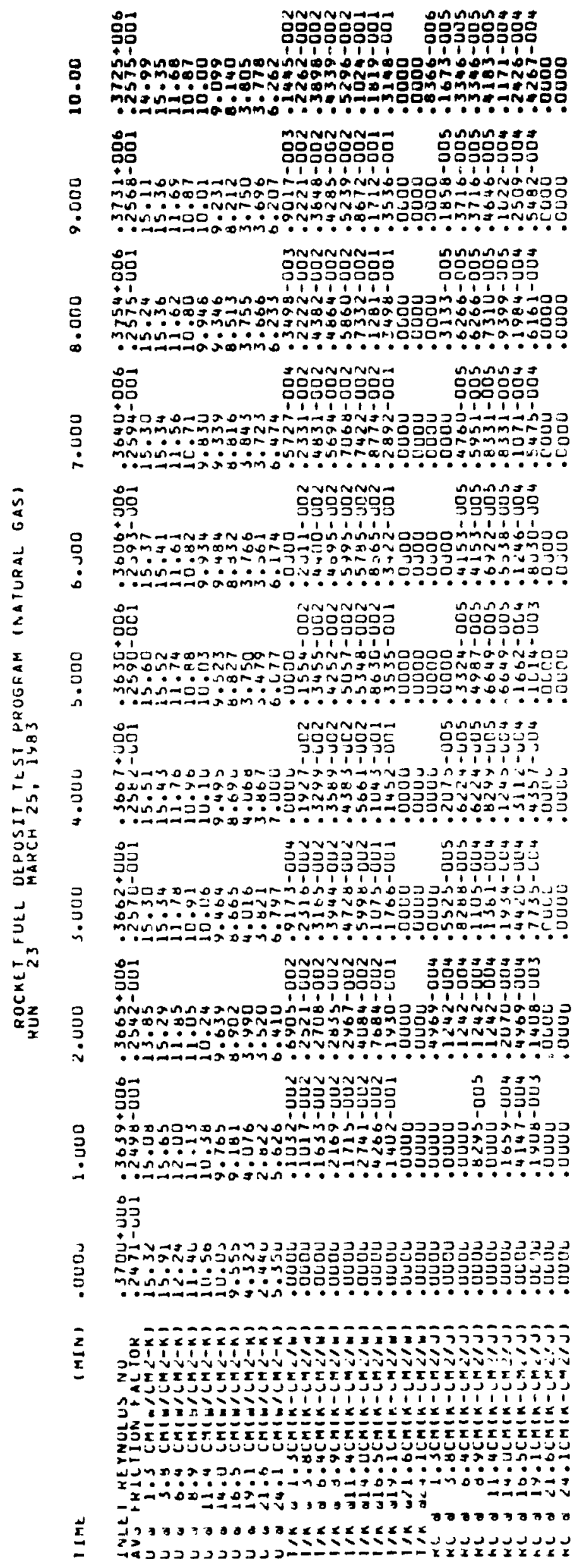
ORIGINAL FAS
OF POOR QUALITY 
है

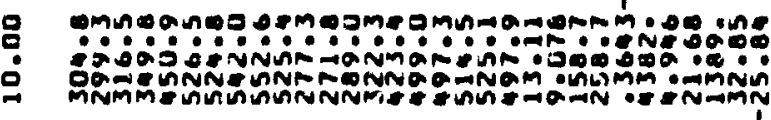

$\vec{\circ}$

옹

m

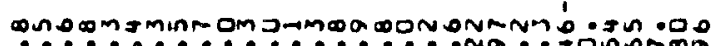
- Madió-

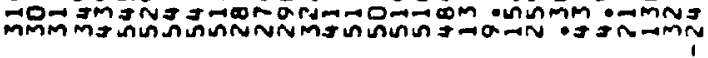

웅

욤

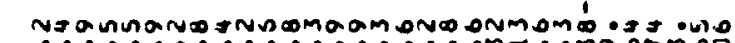

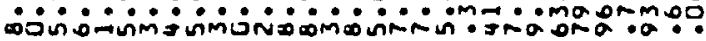

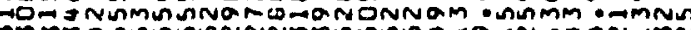

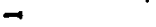

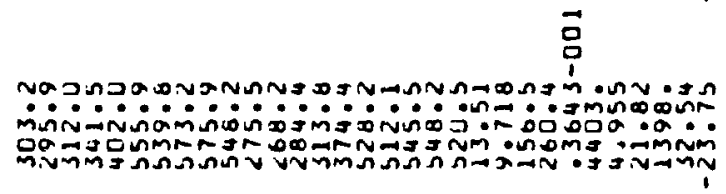

:

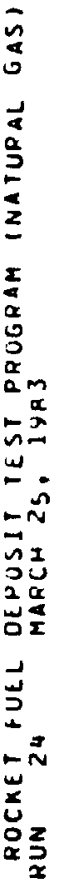

$\overrightarrow{8}$

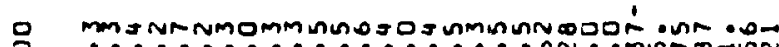

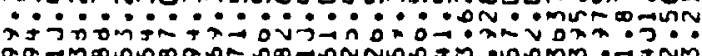

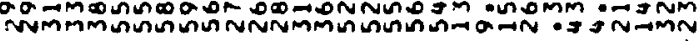

$\overrightarrow{0}$

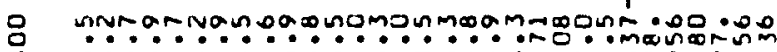

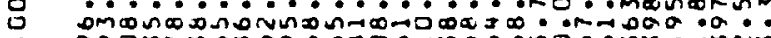

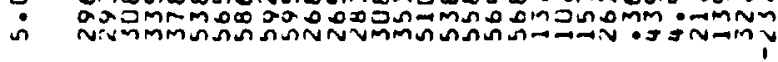

$\stackrel{i}{i}$

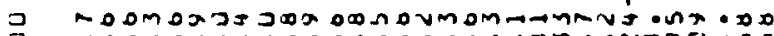

马

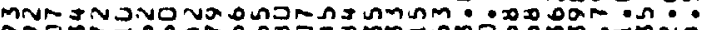

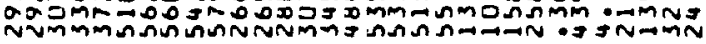

$\overrightarrow{\vec{b}}$

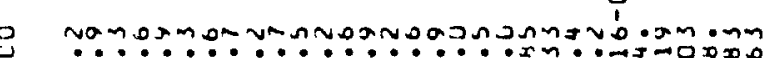
vamoramo nojis

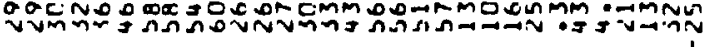

$\overrightarrow{3}$

$i$

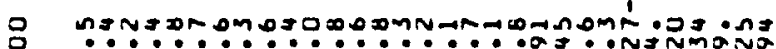

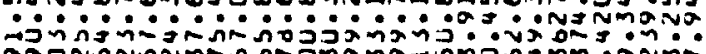

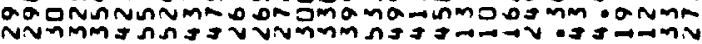

$\overrightarrow{5}$

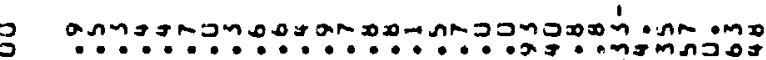

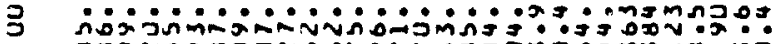

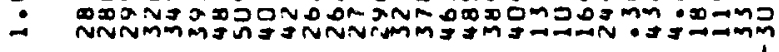

$\overrightarrow{3}$

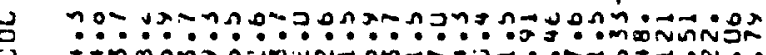

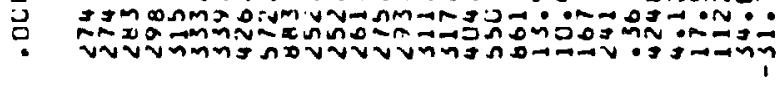

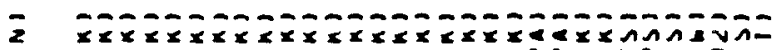

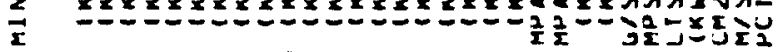

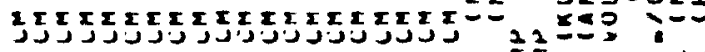
A0:

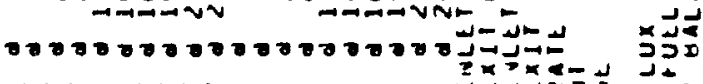




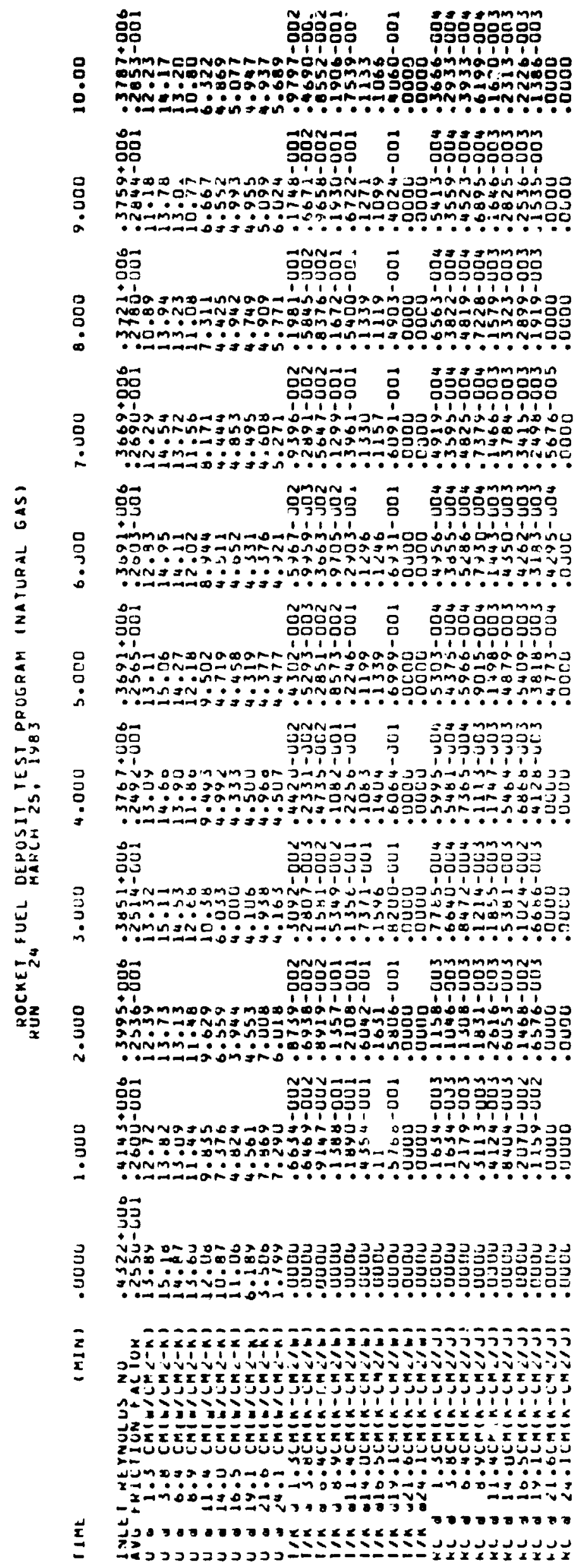

ORIGINAL F......

OF. POOR QUALITY 
$\tilde{8}$

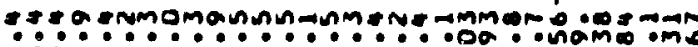

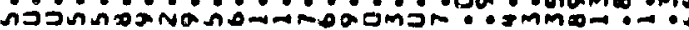
onoto:0000000000000

品

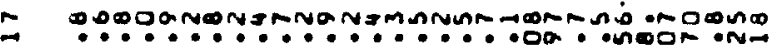
ino

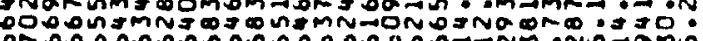

뭉

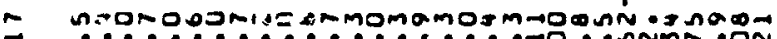

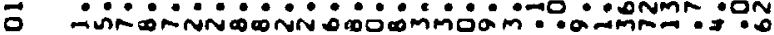
-

음

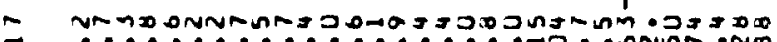

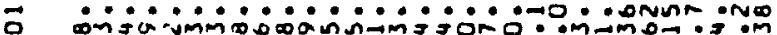

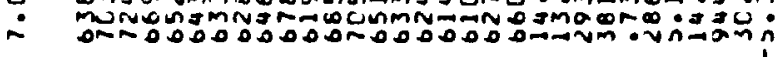

$\vec{g}$

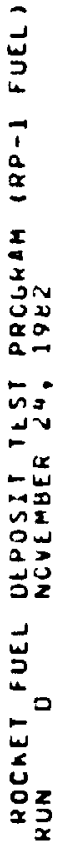

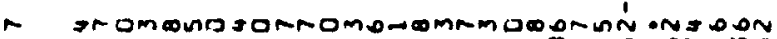

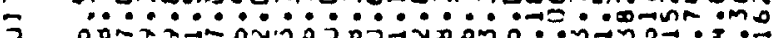

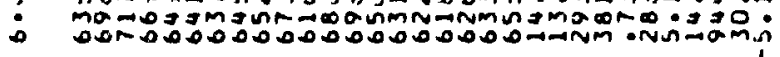

$\overrightarrow{\mathrm{O}}$

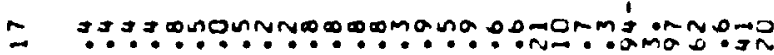

- Dosianinodiz- -

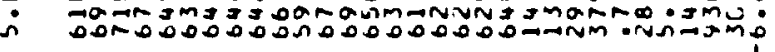

$\overrightarrow{\mathrm{g}}$

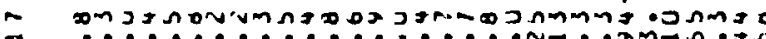

F

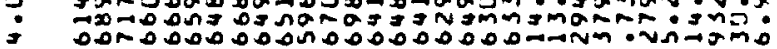

$\overrightarrow{3}$

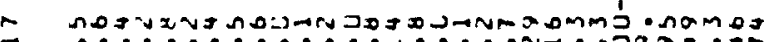

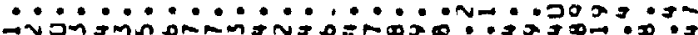
Corer

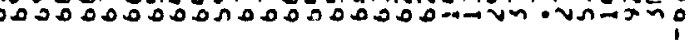

芩

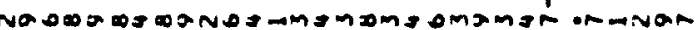

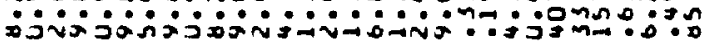

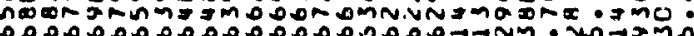

品

$m$ N

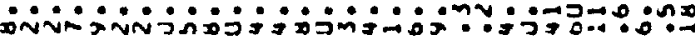
舟on $000000000000000000 \pi$ N

$\overrightarrow{3}$

с

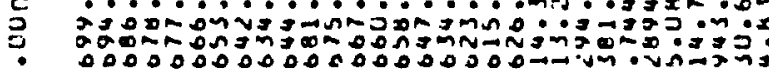

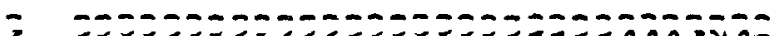

Z

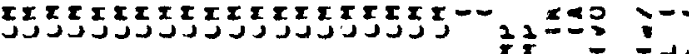

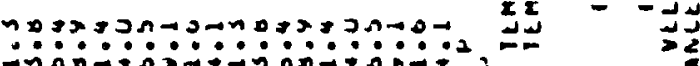

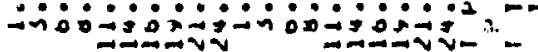

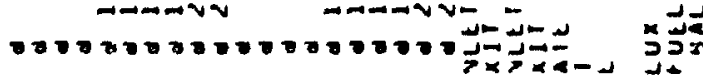

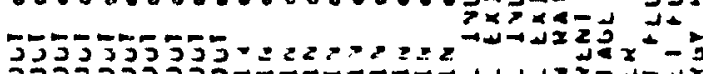

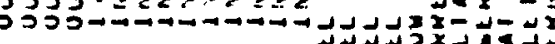

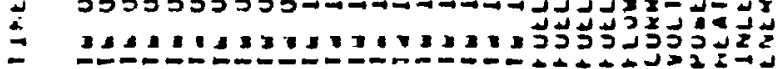

ORIGAIE: OF POOR QuAinit 


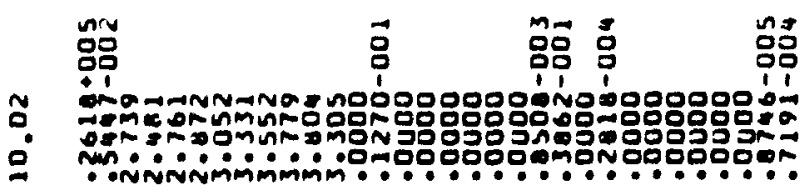

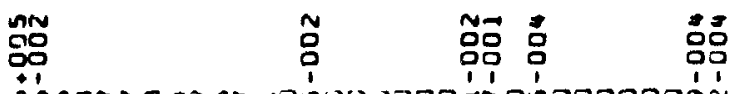

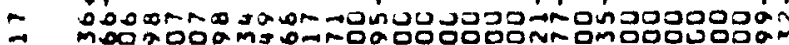

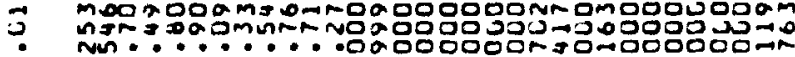

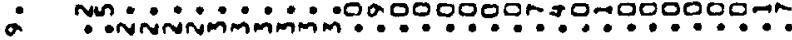

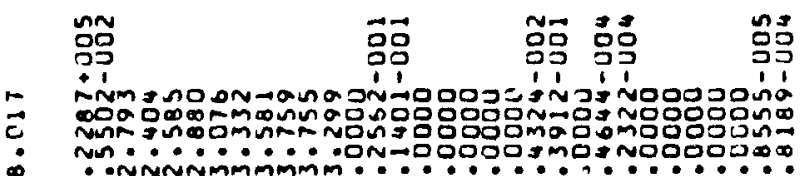

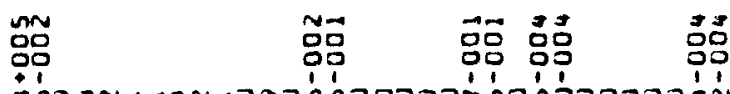
- max ona monanaszon:momagogogong

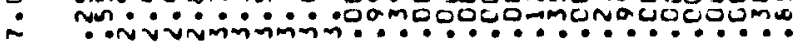

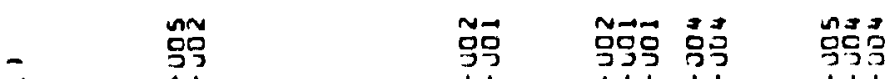

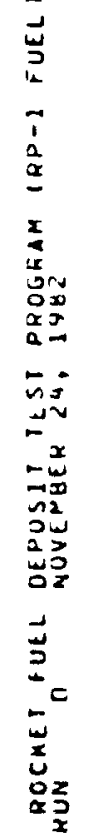

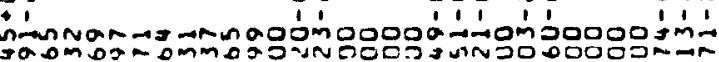

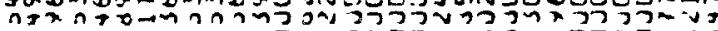

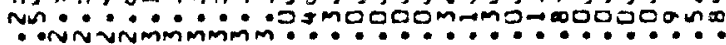
跑

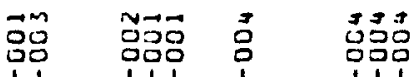
= åx $\vec{a}$ jackmama กี่

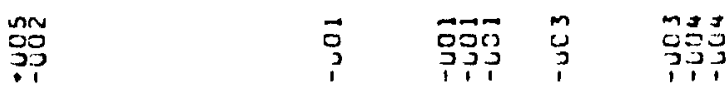

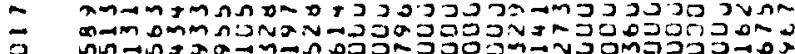

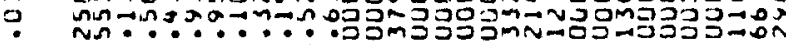

วิน

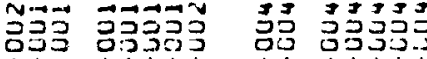

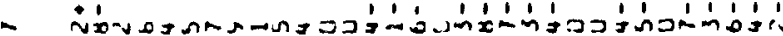

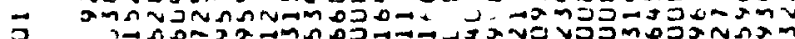

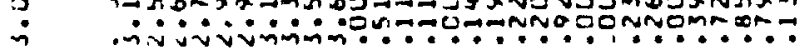
in

ำ

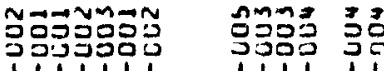

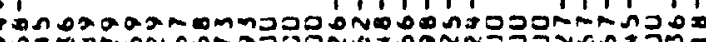
กภำ

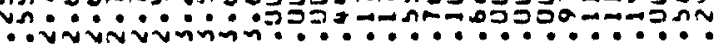
กิ๊

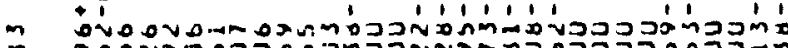
m N

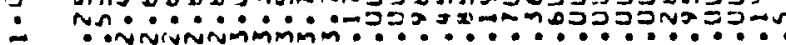

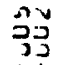

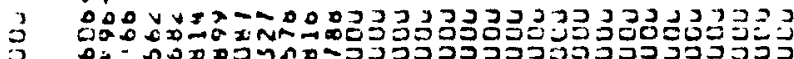
乌

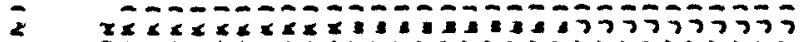

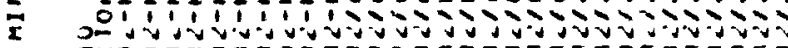

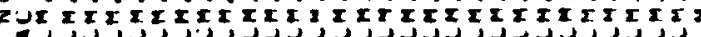

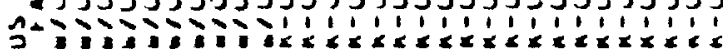

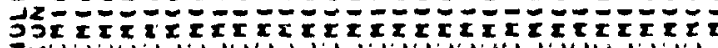
20 z

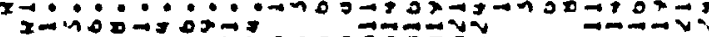
$\underline{\mathbf{x}}$
ORIGHAY PONA: 


\section{ORIGINAL PAGE IS OF POOF QUALITY}

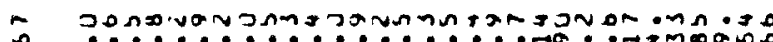

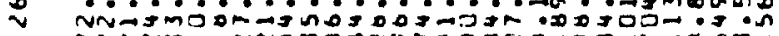

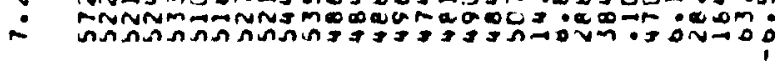

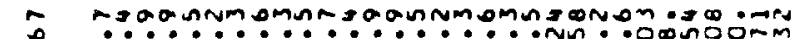

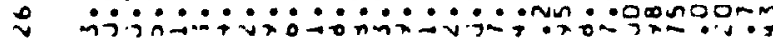

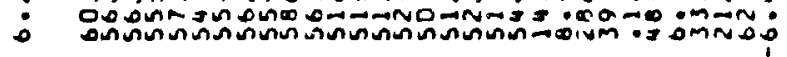

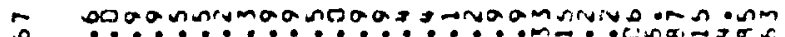

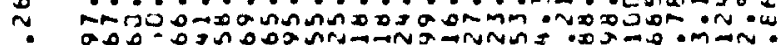

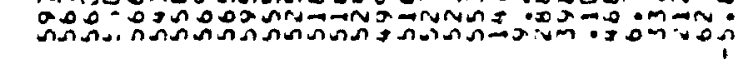

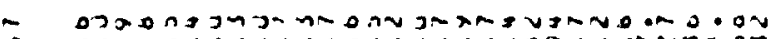

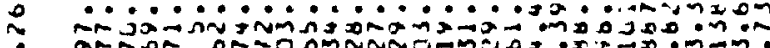
Añ

$\overrightarrow{3}$

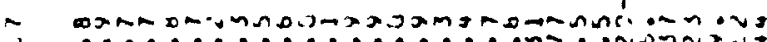

J

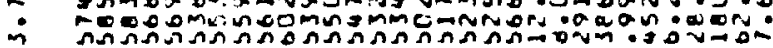

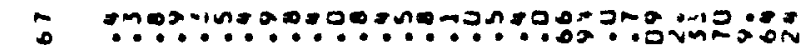

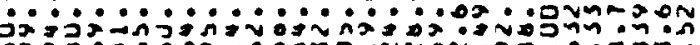

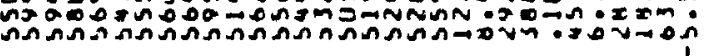

$\overrightarrow{0}$

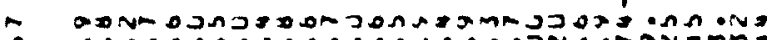

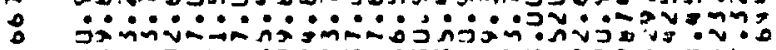

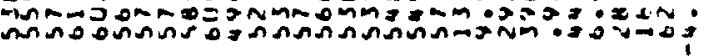

高

i:

马

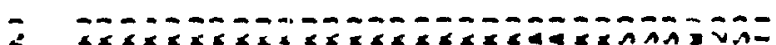

$\div$ :

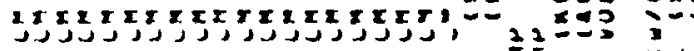

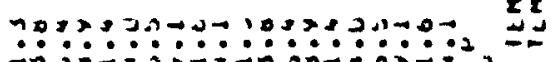

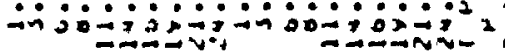

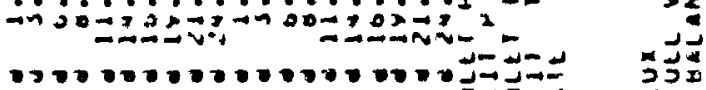

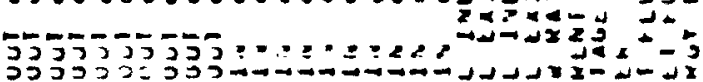
落 


\section{ORICNNAL PAGE IS
OF. POOR QUALTTY}
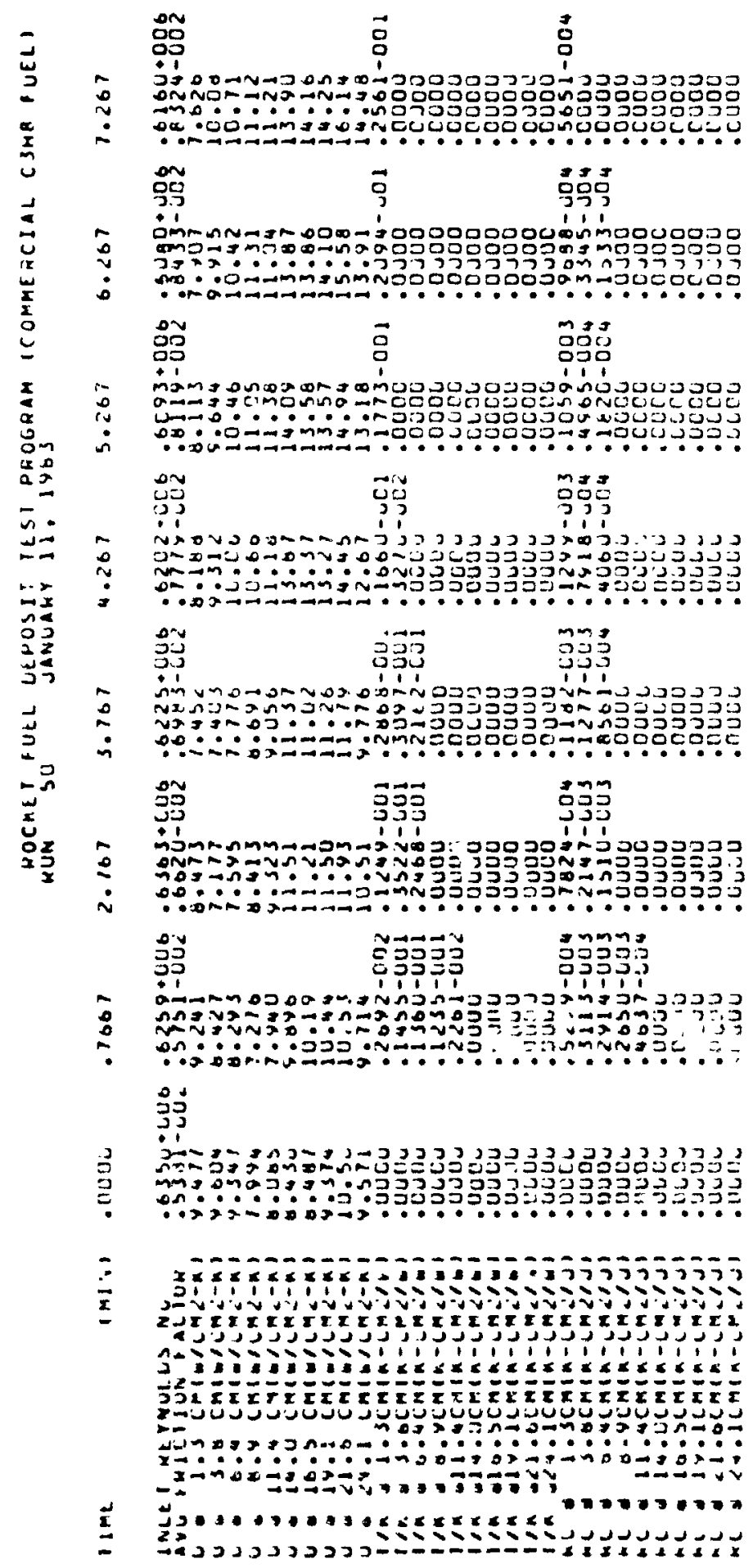

3 


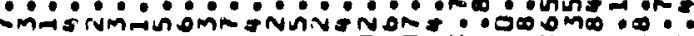

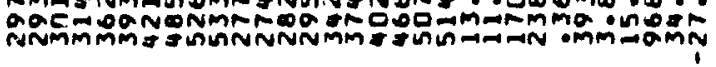

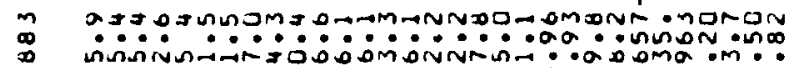

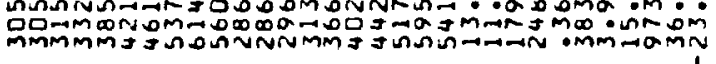

$\vec{\circ}$

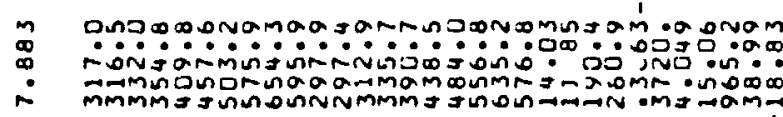

$\overrightarrow{\mathrm{g}}$

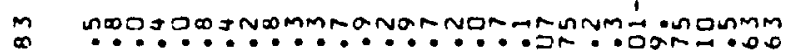

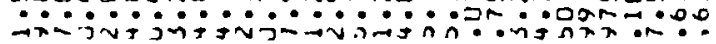
añomimmmm

$\vec{\square}$

modomsonm

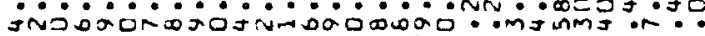

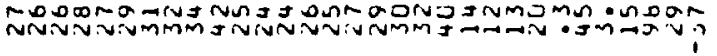

डิ

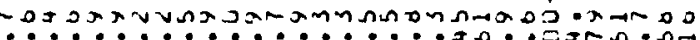
-

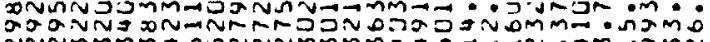

芆

(2)

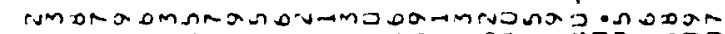
… mnnmñus

官

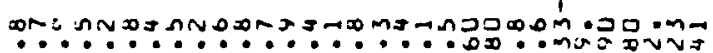

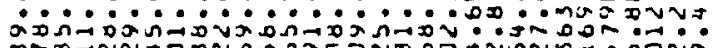

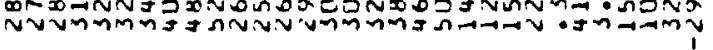

$\overrightarrow{3}$

$\stackrel{m}{m}$

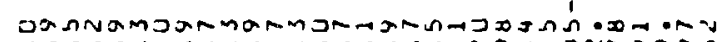

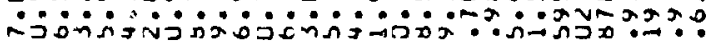

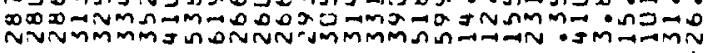

$\vec{\jmath}$

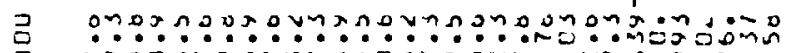

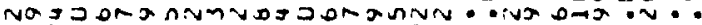

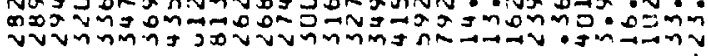

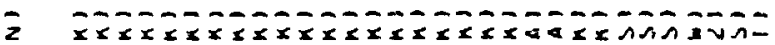

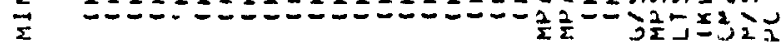

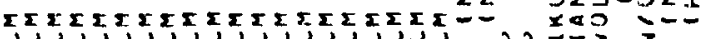

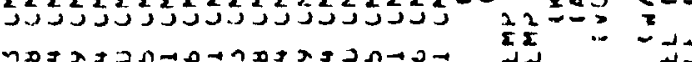
$\because \cdots \cdots \cdots \cdots 0^{2}=$

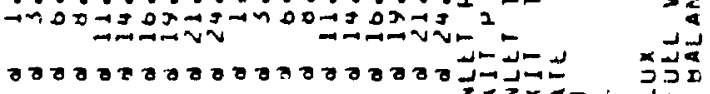

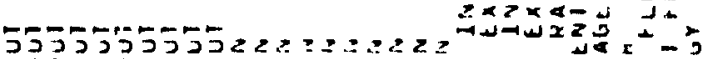

.




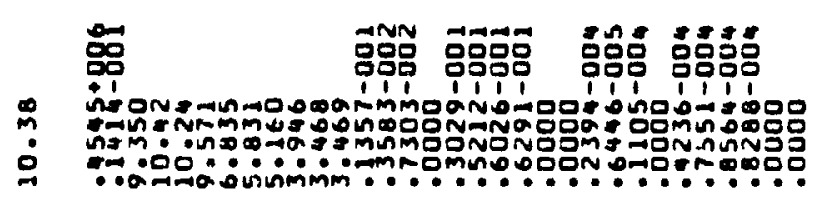

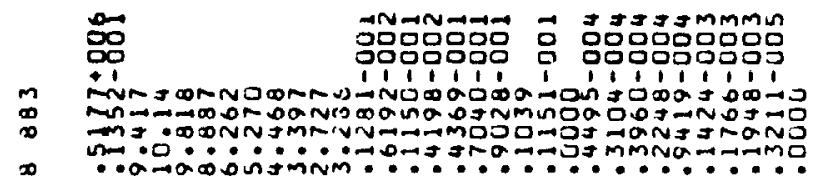

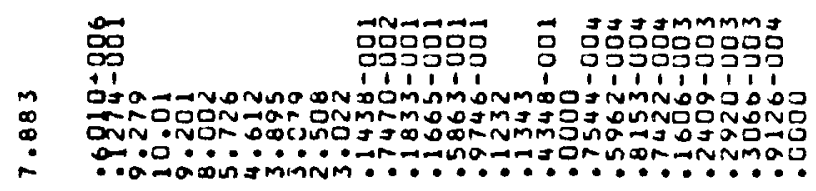

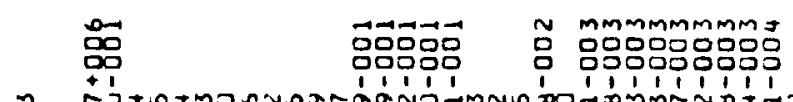

n mangmasvarána

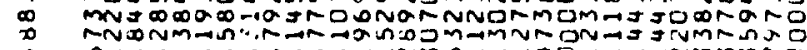

- $\because$ -

骂

落

m injscmor jrmanogogoocogóngogogogou

* mon-1.

i :

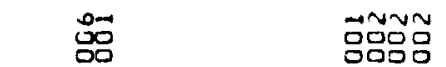

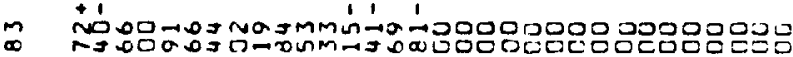

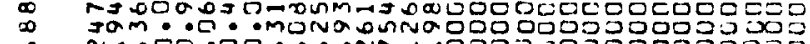

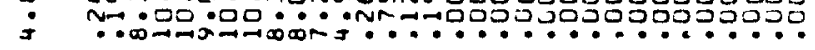

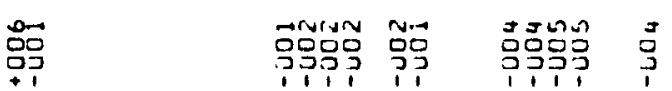

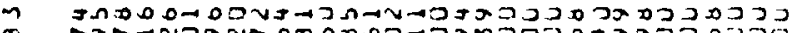

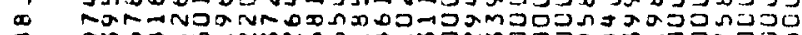

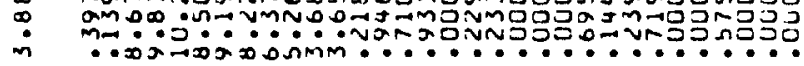
$\stackrel{0 \rightarrow 1}{30}$

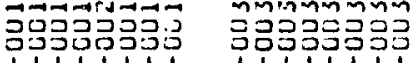

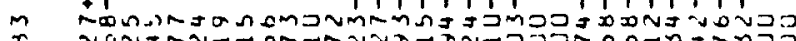

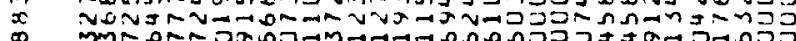

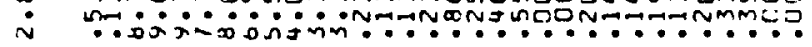

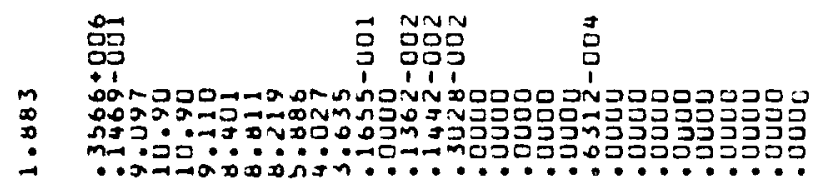

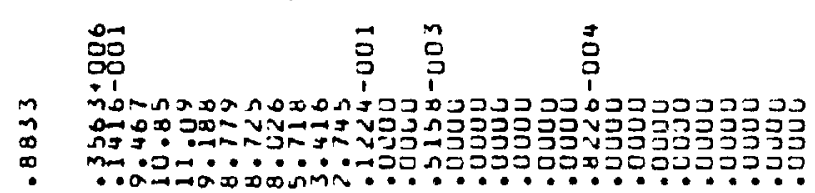
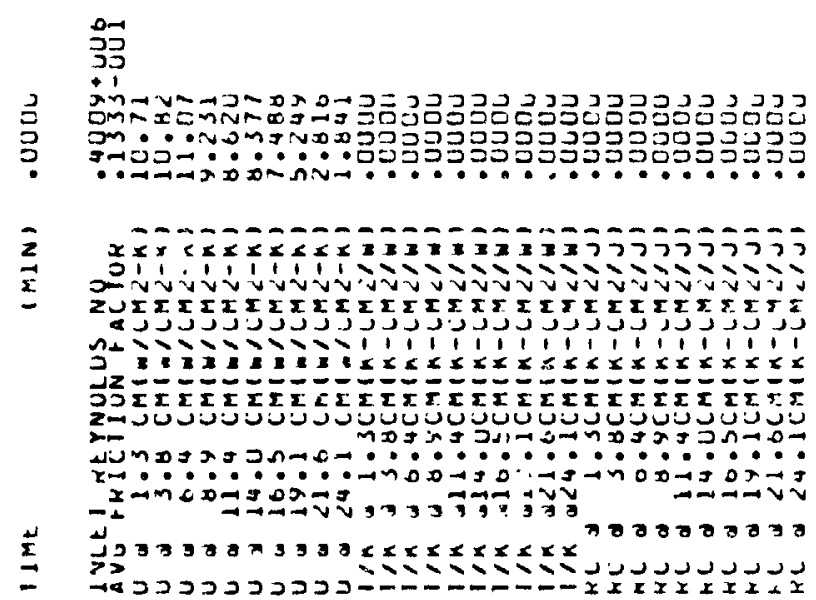